\title{
The role of rumination in the development of depressive symptoms in youth
}

Citation for published version (APA):

Rood, L. M. (2011). The role of rumination in the development of depressive symptoms in youth. [Doctoral Thesis, Maastricht University]. https://doi.org/10.26481/dis.20111103lr

Document status and date:

Published: 01/01/2011

DOI:

10.26481/dis.20111103Ir

Document Version:

Publisher's PDF, also known as Version of record

\section{Please check the document version of this publication:}

- A submitted manuscript is the version of the article upon submission and before peer-review. There can be important differences between the submitted version and the official published version of record.

People interested in the research are advised to contact the author for the final version of the publication, or visit the DOI to the publisher's website.

- The final author version and the galley proof are versions of the publication after peer review.

- The final published version features the final layout of the paper including the volume, issue and page numbers.

Link to publication

\footnotetext{
General rights rights.

- You may freely distribute the URL identifying the publication in the public portal. please follow below link for the End User Agreement:

www.umlib.nl/taverne-license

Take down policy

If you believe that this document breaches copyright please contact us at:

repository@maastrichtuniversity.nl

providing details and we will investigate your claim.
}

Copyright and moral rights for the publications made accessible in the public portal are retained by the authors and/or other copyright owners and it is a condition of accessing publications that users recognise and abide by the legal requirements associated with these

- Users may download and print one copy of any publication from the public portal for the purpose of private study or research.

- You may not further distribute the material or use it for any profit-making activity or commercial gain

If the publication is distributed under the terms of Article $25 \mathrm{fa}$ of the Dutch Copyright Act, indicated by the "Taverne" license above, 


\section{THE ROLE OF RUMINATION IN THE DEVELOPMENT OF DEPRESSIVE SYMPTOMS IN YOUTH}




\section{Acknowledgement}

The studies in the present dissertation were supported by an Innovational Research Incentive VENI grant (451-05-019) of the Foundation for Behavioural and Educational Sciences of the Netherlands Organisation for Scientific Research (NWO), awarded to Dr. Jeffrey Roelofs.

ISBN 978-90-75975-00-0

Production: Haveka BV De Grafische Partner, Alblasserdam

Cover: Edith Pijpers (www.edieart.com)

(c) Copyright Lea M. Rood, 2011

All rights reserved. Save exceptions stated by the law, no part of this publication may be reproduced, stored in a retrieval system of any nature, or transmitted in any form or by any means, electronic, mechanical, photocopying, recording or otherwise, included a complete or partial transcription, without the prior written permission of the author, application for which should be addressed to the author. 


\section{The role of rumination in the development of depressive symptoms in youth}

\section{PROEFSCHRIFT}

ter verkrijging van de graad van doctor aan

de Universiteit Maastricht, op gezag van de Rector Magnificus,

Prof. mr. G.P.M.F. Mols,

volgens het besluit van het College van Decanen,

in het openbaar te verdedigen op

donderdag 3 november 2011, om 16.00 uur

door

Lea Mikal Rood 


\section{Promotores:}

Prof. Dr. Susan M. Bögels (Universiteit van Amsterdam)

Prof. Dr. Arnoud Arntz

\section{Copromotor:}

Dr. Jeffrey Roelofs

\section{Beoordelingscommissie:}

Prof. Dr. Peter Muris (voorzitter)

Prof. Dr. Caroline Braet (Universiteit Gent)

Prof. Dr. Marcus Huibers

Dr. Marisol Voncken

Prof. Dr. Ed Watkins (University of Exeter) 


\section{Table of contents}

Chapter 1 General introduction 1

$\begin{array}{lll}\text { Chapter } 2 & \text { Dimensions of negative thinking and the relations with } & 17\end{array}$ symptoms of depression and anxiety in children and adolescents

Chapter 3 The influence of emotion-focused rumination and distraction on depressive symptoms in non-clinical youth: a meta-analytic review

Chapter 4 The influence of rumination and distraction on depressed and anxious mood: A prospective examination of the Response Styles Theory in children and adolescents

Chapter 5 Stress-reactive rumination, negative cognitive style, and stressors in relationship to depressive symptoms in nonclinical youth

Chapter 6 The interplay between cognitive vulnerability factors and stressors in relation to the development of depressive symptoms over time in youth

Chapter 7 Causal-analysis of stressful events, not focus on negative inferences, increases anxious affect compared to focus on contextual facts

Chapter 8 The effects of experimentally induced rumination, positive reappraisal, acceptance, and distancing when thinking about a stressful event on affect states in adolescents

Chapter 9 General discussion

Summary

Samenvatting 

Chapter 1

General introduction 
The stereotypical image of the troubled teenager experiencing hard times while going through puberty may suggest that feeling depressed is part of normal pubertal development. However, although occasionally feeling down might be a normal phenomenon during puberty, figures show that quite serious levels of depression occur among youth, with point-prevalence rates of major depressive disorder ranging from $0.4 \%$ to $2.5 \%$ in children and $0.4 \%$ to $8.3 \%$ in adolescents (e.g., Birmaher et al., 1996; Lewinsohn, Rohde, \& Seeley, 1998). Lewinsohn et al. (1998) reported lifetime prevalence rates of about $20 \%$ for major depression in adolescents aged 14 to 18 . A remarkable and consistent finding is that depression onset rates are considered equally distributed in young boys and girls but begin to rise in girls compared to boys during adolescence (e.g., Kessler, McConagle, Swartz, Blazer, \& Nelson, 1993; Lewinsohn et al., 1998). From around the age of 13 and on, girls start reporting higher levels of depression than boys (Angold \& Costello, 2006; Hankin \& Abramson, 2001; Hankin, Wetter, \& Cheeley, 2008; Nolen-Hoeksema, 1987). In adulthood, women are about twice as likely as men to experience a lifetime episode of major depression (see for a review Kuehner, 2003). Relapse and recurrence rates for depression are estimated at $30-70 \%$ for children and $20-54 \%$ in adolescents (e.g., Birmaher, Arbelaez, \& Brent, 2002). The recurrence rate of depression has been found twice as high in girls compared to boys in a late adolescent sample (Curry et al., 2010). This is interesting, as no gender differences in recurrence rates have been reported in adult samples (Kuehner, 2003). In sum, it can be concluded that the fairly high depression rates and recurrence rates that emerge during puberty and adolescence pose a significant societal problem that should be taken seriously. These numbers indicate that depression in youth is prevalent and warrant examination of factors that contribute to the onset and maintenance of depressive symptoms. Furthermore, they stress the relevance to increase the moderate effectiveness of current cognitive-behavioral treatments and preventive interventions for depression (see Weisz, McCarty \& Valeri, 2006). The examination of factors that may explain the notable gender differences in depression is of special interest.

Since the pioneering work of Beck (1967, 1979), cognitive approaches have become highly influential in the conceptualization and treatment of depression. In the past decade, there has been an increased interest in examining negative thinking that takes the form of rumination as a concomitant of depression (see special issue Cognitive Therapy and Research, 2004). In general, extensive research has demonstrated that types of repetitive thinking (i.e., rumination and worry) play a role in the development of symptoms of depression and anxiety (see for a review Watkins, 2008), but are also related to various other psychological problems (see Nolen-Hoeksema, Wisco, \& Lyubomirsky, 2008). As such, repetitive thought processes like rumination and worry might be considered transdiagnostic variables (see Harvey, Watkins, Mansell, \& Shafran, 2004; Matthews \& Wells, 2004). Several 
General INTRODUCtion

theoretical models of the emergence of gender differences in depression in adolescence have highlighted the role of rumination besides stress and biological factors (see Hankin \& Abramson, 2001; Hyde, Mezulis, \& Abramson, 2008; NolenHoeksema, 1994; Nolen-Hoeksema \& Girgus, 1994).

\section{Definitions of rumination}

Rumination appears in several forms and has been studied in relation to all kinds of psychopathology (Smith \& Alloy, 2009). As a result, a number of definitions and operationalizations of rumination have been proposed within different theoretical frameworks stemming from different origins (see Papageorgiou \& Wells, 2004). These include broad definitions and more specific definitions of rumination. According to Smith and Alloy (2009), generally taken, rumination may best be considered a stable trait to cope with experienced goal discrepancies, and as an experiential avoidance strategy. The most influential conceptualization of rumination in the field of depression is that of Nolen-Hoeksema (1987; 1991), who developed the concept of emotion-focused rumination. This type of rumination has been narrowly defined and will be described within the context of its elaborated theoretical framework in the section below.

\section{Emotion-focused rumination}

Emotion-focused rumination plays a key role in the Response Styles Theory (NolenHoeksema, 1987, 1991), an influential cognitive theory which was specifically developed to explain the gender difference in depression. Emotion-focused rumination is defined as "repetitively focusing on the fact that one is depressed, on one's symptoms of depression, and on the causes, meanings, and consequences of depressive symptoms" (Nolen-Hoeksema, 1991, p. 569). The Response Styles Theory proposes that women and men react differently to depressive moods. While women have a tendency to ruminate when confronted with negative feelings, men engage in distracting thoughts and behaviours. The theory predicts that a ruminative response style maintains and even exacerbates the depressive mood, while a distractive response style alleviates depressive symptoms (Nolen-Hoeksema, 1987). This difference in coping styles could thus provide an explanation for the fact that women are twice as likely as men to experience depressive episodes in their lives. In statistical terms, rumination is hypothesized to mediate the relationship between gender and depressive symptoms. Numerous studies in adults have shown that emotion-focused rumination plays a role in the onset, maintenance, and exacerbation of depressed mood (see for a review Nolen-Hoeksema et al., 2008). In addition, rumination is associated with negatively biased thinking, poor problem-solving, 
impaired motivation, and inhibition of instrumental behaviour (see Lyubomirsky \& Tkach, 2004). The hypothesized beneficial influence of distraction on depressive symptoms has not been clearly demonstrated, except for experimental studies demonstrating that distraction relieves depressed mood in the short-term (see NolenHoeksema et al., 2008).

With respect to the gender difference in the use of rumination and distraction, most studies did find that women have a greater tendency to ruminate than men (Butler \& Nolen-Hoeksema, 1994; Nolan, Roberts, \& Gotlib, 1998; Nolen-Hoeksema, Larson, \& Grayson, 1999; Nolen-Hoeksema, Morrow, \& Fredrickson, 1993). However, the assumption that men have a greater tendency to engage in distractive activities in response to sad mood is less frequently supported (e.g., Butler \& NolenHoeksema, 1994; Nolen-Hoeksema et al., 1993). Rumination has been shown to fully mediate the gender differences in depression in adults (Nolen-Hoeksema et al., 1999), suggesting that women are more at risk for depression because they ruminate more than men.

Nolen-Hoeksema has re-conceptualized the Response Styles Theory into a diathesis stress-model (see Nolen-Hoeksema, 1994, Nolen-Hoeksema \& Girgus, 1994), suggesting that emotion-focused rumination may be a vulnerability factor to depression in combination with other factors (e.g., stress) rather than an independent risk factor. This re-conceptualization proposes that during early adolescence, girls start to ruminate more and experience more stressful events than boys. The increased experience of stress combined with the stronger tendency for girls to ruminate leads to a stronger increase of depressive symptoms in girls than in boys. However, emotion-focused rumination and stressors have not been found to significantly interact in the prediction of depressive symptoms over time in youth (Abela, Parkinson, Stolow, \& Starrs, 2009; Schwartz \& Koenig, 1996). As Skitch and Abela (2008) have pointed out, this might be due to the fact that emotion-focused rumination occurs in the response to an already depressed mood and may worsen the effects of a depressed mood rather than the effects of stressors. A specific form of rumination that occurs in response to stress might be more likely to worsen the effects of stressors.

On the basis of the negative consequences of emotion-focused rumination, an intriguing question is why individuals, in particular women, are inclined to ruminate when having to deal with depressed feelings or stressful events. Positive metacognitive beliefs about the functions and consequences of rumination seem to play an important role in the instigation of the ruminative process (see Papageorgiou \& Wells, 2004). People may believe that by focusing on their negative emotional states, they are going to understand themselves, gain insight into their problems and therefore become more able to solve them (Lyubomirsky \& Nolen-Hoeksema, 1993; Nolen-Hoeksema, 1991). According to Nolen-Hoeksema (1991; 1996) individuals 
engage in emotion-focused rumination mostly purposefully, but the ruminative process can also occur automatically.

\section{The adaptive/maladaptive features of rumination}

A recent line of research instigated by Treynor, Gonzalez, and Nolen-Hoeksema (2003) has focused on a potentially less maladaptive component of emotion-focused rumination, which has been labelled reflective pondering (defined as an intentional attempt at cognitive problem-solving in order to restore mood), as opposed to the maladaptive form of rumination focused on depressive symptoms, brooding (defined as passively dwelling on depressive symptoms). There is evidence that brooding more than reflective pondering negatively affects mood state (e.g., Burwell \& Shirk, 2007; Joormann, Dkane, \& Gotlib, 2006; Miranda \& Nolen-Hoeksema, 2007; Moberly \& Watkins, 2008; Raes \& Hermans, 2008; Roelofs, Huibers, Peeters, \& Arntz, 2008; Treynor et al., 2003). The existence of a constructive reflective quality in depressive analytical rumination is consistent with philosophically-fed ideas on an evolutionarybased adaptive function of depression, namely offering the opportunity to work through crucial life issues (see Andrews \& Thomson, 2009). The differential effects of brooding and reflective pondering on negative mood can be explained on the basis of the elaborated control theory of Watkins $(2008)^{1}$.

According to the elaborated control theory, there are three underlying dimensions that determine whether the outcome of repetitive thinking might be constructive or unconstructive: valence of thought content, intrapersonal and situational context, and level of processing. More specifically, the outcome of repetitive thinking is most likely to have unconstructive consequences: (1) when valence of thought content is negative; (2) when repetitive thinking occurs in a negative context (e.g., a negative mood state or stressful experience) or in combination with a depressogenic personality trait; and (3) when an abstract level of processing is adopted. This means that emotion-focused rumination is likely to have unconstructive consequences due to the focus on negatively valenced content (i.e., depressive symptoms), the negative intrapersonal context in which it occurs (i.e., depressed mood), and the abstract nature of the thought process (e.g., search for causes, meanings, and implications; tendency to generalize). Although brooding and reflective pondering are characterized by a negative intrapersonal context and an abstract level of processing, they differ with regard to the degree of negatively valenced thought content and the level of abstractness, which are higher in brooding than in reflective pondering. More general conceptualisations of rumination define the

\footnotetext{
${ }^{1}$ Watkins (2008) takes a transdiagnostic approach to rumination. That is, he views the process of repetitive thinking and its qualities to be similar across different disorders, whereas content may differ depending on the nature of the disorder.
} 
process as not necessarily unconstructive. If the focus of processing is on concrete, specific aspects of the stressful event when searching for insight, rumination might be constructive (Watkins, 2008). An example of repetitive thinking in an abstract processing mode focused on positive content within a negative context is finding benefit (Watkins, 2008), which has constructive consequences (see Helgeson, Reynolds, \& Tomich, 2006).

The next section focuses on another specific form of rumination, stressreactive rumination. There is evidence that stress-reactive rumination is a better predictor of onset and maintenance of depression than emotion-focused rumination in adults (Robinson \& Alloy, 2003). The examination of stress-reactive rumination in youth is novel and may contribute to knowledge on the onset and development of depressive symptoms in youth. Therefore, the present dissertation focused on the examination of emotion-focused rumination as well as stress-reactive rumination.

\section{Stress-reactive rumination}

Theoretically extending the Response Styles Theory, Alloy and colleagues developed the concept of stress-reactive rumination to refer to the tendency to ruminate about negative inferences following stressful life events (Alloy et al., 2000; Robinson \& Alloy, 2003). These negative inferences, which are described in the Hopelessness Theory of depression (Abramson, Metalsky, \& Alloy, 1989), together determine a 'negative cognitive style' and include the tendencies (1) to view the causes of negative events as global and stable; (2) to view negative events as having many disastrous consequences; and (3) to view the self as flawed and deficient after the occurrence of negative events. The Hopelessness Theory hypothesizes that a negative cognitive style leads to hopelessness depression only in the presence of stressful events. In other words, stress is necessary for negative inferences to be activated and subsequently lead to symptoms of hopelessness and depression.

Alloy and colleagues $(2000 ; 2003)$ hypothesized that the influence of negative inferences on the development of depressive symptoms also can be activated by rumination: when negative inferences are constantly rehearsed by ruminative thinking, negative inferences are more likely to cause increases in depressive symptoms. This specific kind of rumination might be a key vulnerability trait factor involved in the onset of depressive symptoms, especially in combination with a negative cognitive style (Alloy et al., 2000; Robinson \& Alloy, 2003). Indeed, the findings of Alloy and colleagues suggest that individuals who have a negative cognitive style combined with a tendency to ruminate about the negative inferences are more likely to develop depressive episodes and to experience more severe and longer episodes. Results showed that stress-reactive rumination was a more 
GENERAL INTRODUCTION

powerful predictor of depression than emotion-focused rumination (Alloy et al., 2000; Robinson \& Alloy, 2003).

\section{Rumination in relation to other constructs}

Stress-reactive rumination and emotion-focused rumination differ from each other with regard to focus on thought content (i.e., negative attributions and inferences versus negative feelings, respectively), and hypothesized role in the development of depression (i.e., onset versus maintenance, respectively). Emotion-focused rumination should be distinguished from related constructs, for example negative automatic thoughts, self-focused attention, private self-consciousness, obsessions, and worry, although these constructs seem to overlap to a certain extent (see reviews Papageorgiou \& Wells, 2004; Smith \& Alloy, 2009). For example, although conceptualized as a habitual style of responding to a depressed mood, emotionfocused rumination also involves a particular type of self-focused attention (NolenHoeksema \& Morrow, 1993; Mor \& Winquist, 2002). At first sight, stress-reactive rumination seems to share some overlap with self-blame (i.e., repetitive focus on negative internal attribution) and catastrophizing thoughts (i.e., repetitive focus on the negative consequences of a stressful event).

What distinguishes both types of rumination from these other constructs is the repetitive nature of the thought process, its focus on coping activated by displeasure, and the relatively realistic content of thoughts (Papageorgiou \& Wells, 2004; Smith \& Alloy, 2009). Of particular interest is the overlap between rumination and worry (Borkovec, 1994). Although worry and rumination may seem similar with respect to thought process (repetitive, negative, unproductive thoughts) and problem-solving qualities (e.g., Carver, 1996; Davey, 1994), they differ with respect to content and goal orientation (e.g., Segerstrom, Tsao, Alden, \& Craske, 2000). That is, rumination is thought to be past-oriented, while worrying is more future-oriented (Watkins, Moulds, \& Mackintosh, 2005).

\section{Relevance of examining the role of rumination in youth}

In the Response Styles Theory and its conceptual extension by Alloy and colleagues, distinct types of rumination have been described that have potentially different roles at different stages in the development of depression. Theoretically, emotion-focused rumination is related to the maintenance of depression, while stress-reactive rumination may play an important role especially in the onset of depressive symptoms. Therefore, stress-reactive rumination may be more strongly related to depressive symptoms in non-clinical adolescents than emotion-focused rumination. 
Furthermore, stress-reactive rumination may be more likely to interact with stressful events than emotion-focused rumination because of the different focus of this rumination type. With the introduction of stress-reactive rumination, Alloy and colleagues (2000) suggested integrating the Response Styles Theory and the Hopelessness Theory. This integrative theory proposes that negative cognitive style is more likely to lead to depression in the presence of stressors, in individuals that have a strong tendency to ruminate on negative attributions and inferences.

Examining stress-reactive rumination in interaction with stressful events and negative cognitive style may contribute to a more accurate test of components of the integrated models on the emergence of gender differences in depression in adolescence. A more accurate identification of vulnerability factors that play a role in the development of depression can help ameliorate interventions for prevention and treatment. When examining cognitive vulnerability models in youth, it is important to take into account developmental factors, such as gender and age.

\section{Examining the role of rumination from a developmental perspective: models of gender differences in depression}

Since the formulation of the Response Styles Theory, a number of integrative models have been proposed that offer an explanation of the emergence of gender differences in depression in adolescence. These models depart from a diathesisstress account and are based on the Hopelessness Theory and the Response Styles Theory. In these models, researchers have proposed that gender may moderate the influence of cognitive factors (i.e., negative cognitive style and rumination) combined with stressors on depressive symptoms, with the interaction effect between cognitive factors and stressors being more pronounced in girls than in boys (Hankin \& Abramson, 2001; Hyde et al., 2008). These elaborated models also include the roles of temperament and biological factors (e.g., genetic vulnerability, hormonal changes, pubertal development, and pubertal timing) which can contribute to depression directly, but also indirectly via their contributions to the development of cognitive vulnerability and to the likelihood to experience certain stressful events (see Hyde et al., 2008). The cognitive vulnerability-transactional stress theory describes reciprocal pathways between variables to depression. For example, negative events cause elevated levels of negative affect that in turn may lead to more negative events ("dependent negative events"; see Hankin \& Abramson, 2001). These recently developed integrative models are quite difficult to examine; however, components of the models have been tested. There is abundant evidence from cross-sectional studies that a negative attributional style is associated with depressive symptoms in youth (see for reviews Gladstone \& Kaslow, 1995; Joiner \& Wagner, 1995). 
GENERAL INTRODUCTION

Furthermore, studies have shown that major life events are related to depression and the onset of depression in particular (see for reviews Kessler, 1997; Tennant, 2002), and also daily hassles have been shown to play a role in depression (Kanner, Coyne, Schaefer, \& Lazarus, 1981). Longitudinal studies have yielded mixed results regarding the interaction between cognitive vulnerability factors and stressors in youth samples, which may be partially explained by the moderating role of age (for an overview see Cole et al., 2008). Empirical support for the interaction between negative cognitive style and stress has been found stronger in adolescent samples than in child samples (see for reviews Abela \& Hankin, 2008; Cole et al., 2008; Hyde et al., 2008; Joiner \& Wagner, 1995; Lakdawalla, Hankin, \& Mermelstein, 2007).

There is mixed evidence for gender as a moderator of the interaction effect between negative cognitive style and stress, with some studies supporting the interaction only in early adolescent girls (Abela \& McGirr, 2007; partial support in Abela, 2001), and other studies only in middle to late adolescent boys (Hankin, Abramson, \& Siler, 2001; Stone, Gibb, \& Coles, 2010). There is consistent evidence that the relation between rumination and depressive symptoms is stronger in adolescent girls than in boys (Grant et al., 2004; Jose \& Brown, 2008).

In sum, models explaining gender differences in depression have proposed that cognitive vulnerability factors combined with high levels of stress may lead to more depressive symptoms especially in girls, and that cognitive vulnerability and stress start to worsen each other's effects from the beginning of adolescence. Findings indicate that the moderating roles of both age and gender, as well as their potential interplay, should be included in the examination of cognitive models of depression in youth.

Preventive interventions targeting rumination may help reducing the rise in depression levels in girls during adolescence. Based on their meta-analysis, Weisz et al. (2006) suggest that cognitive-behavioural therapy, with its emphasis on altering the content of thinking (e.g., dysfunctional cognitions), may not be the most effective treatment of depression in youth under the age of 19. As evidence suggests that rumination is a vulnerability factor to depression (see Nolen-Hoeksema et al., 2008; Watkins, 2008), cognitive-behavioural approaches may benefit from putting more emphasis on altering the process of thinking. Behavioural activation and ruminationfocused cognitive behaviour therapy aim at reducing ruminative processes (Dimidjian et al., 2006; Watkins et al., 2007; Wilkinson \& Goodyer, 2008).

\section{Main aims of the dissertation}

Quite some studies have examined emotion-focused rumination in the development of depressive symptoms in adults as well as in youth. Stress-reactive rumination has never been assessed in youth. The main focus of the present dissertation was to 
examine the roles of emotion-focused rumination and stress-reactive rumination in the development and maintenance of depressive symptoms in non-clinical youth. The main research questions concerned the extent to which types of rumination are related to depressive symptoms, taking into account the possible moderating roles of age and gender; and whether rumination exerts its influence on depressive symptoms by moderating the effects of stressors or a negative cognitive style.

Furthermore, the current dissertation focused on the causal nature of the rumination-depression relationship. In this dissertation, findings will be presented from cross-sectional, longitudinal, and experimental studies.

\section{Outline of the dissertation}

As this was the first study to assess stress-reactive rumination in youth, Chapter 2 covers a psychometric evaluation of the child version of the Dutch Stress-Reactive Rumination Scale. In addition, Chapter 2 aimed to examine the extent to which stress-reactive rumination, emotion-focused rumination, and worry are independent and distinct types of repetitive thinking. Furthermore, the relative contributions of types of repetitive thinking in relation to symptoms of depression and anxiety were assessed.

In order to examine the strength of the evidence for the key predictions of the Response Styles Theory, findings from all studies in non-clinical youth so far were summarized in Chapter 3. The extent to which emotion-focused rumination and distraction are related to concurrent and future levels of depressive symptoms was examined by computing overall effect sizes for these relationships. Furthermore, overall effect sizes were computed to investigate the extent to which studies show that girls ruminate more than boys, and whether boys have higher distraction scores than girls.

Chapter 4 comprises a short-term prospective study on the roles of emotionfocused rumination and distraction in the prediction of depressive symptoms over time, taking on a new approach. The ratio approach was investigated as a potentially more insightful and fine-tuned test of the Response Styles Theory. More specifically, it was expected that a high ratio score of emotion-focused rumination divided by distraction would be positively associated with residual change in depressive symptoms, whereas low ratio scores would be negatively associated with residual change in depressive symptoms.

Chapter 5 describes a cross-sectional study that examines three theoretical models on cognitive vulnerability for depression in youth. The concept of stressreactive rumination is introduced and tested within the context of two of the three theoretical models. First, it was hypothesized that stress-reactive rumination would exacerbate the relationship between negative cognitive style and depressive 
symptoms (Robinson \& Alloy, 2003). Second, stress-reactive rumination was hypothesized to exacerbate the relationship between stressors and depressive symptoms (diathesis-stress model). Third, it was hypothesized that negative cognitive style would exacerbate the relationship between stressors and depressive symptoms (Hopelessness Theory). A developmental perspective was taken by including the possibly moderating roles of age and gender. Domain specificity of negative cognitive style was explored as well. Furthermore, this study assessed whether pubertal development was a more sensitive moderator of the models than age.

Chapter 6 presents the results of a two-year multi-wave study in 800 children and adolescents, which examined the integration of the Response Styles Theory and Hopelessness Theory. Specificity of type of rumination was assessed by examining stress-reactive rumination as well as emotion-focused rumination. It was expected that rumination, negative cognitive style, and stressors would co-vary with depressive symptoms, and that the combination of high rumination, high negative cognitive style, and high levels of stressors would be related to the highest level of depressive symptoms. Furthermore, the combination of high rumination, high negative cognitive style, and high levels of stressors was expected to predict the highest levels of depressive symptoms one year later. The moderating roles of age and gender were explored in combination with each other.

Although cross-sectional and longitudinal studies are suitable for examining intricate theoretical models and relative contributions of variables, they do not allow drawing conclusions on whether the nature of these relationships is causal. Therefore, two experimental studies were carried out in non-clinical youth, in the context of explaining the role of stress-reactive rumination in the onset of depression. Chapter 7 consists of an explorative experimental study comparing the causal effects of three types of processing of negative personal events, (1) focus on negative inferences, (2) causal-analytical reasoning, and (3) perceptual details processing, on negative affect in university students. A focus on negative inferences and a more reflective form of rumination labelled causal-analytical reasoning were manipulated in the context of the current debate on adaptive and maladaptive components of rumination. It was expected that focus on negative inferences and causal-analytical reasoning would cause significantly stronger increases in negative affect than perceptual details processing, with the strongest increases after focus on negative inferences.

Chapter 8 describes an experimental study in non-clinical adolescents, which compared the causal effects of rumination, positive reappraisal, mindfulness-based acceptance, and distancing, in response to stressful events on positive and negative affect. We expected that (1) participants would show a greater increase in negative affect after the rumination induction compared to the acceptance, positive reappraisal, and distancing inductions; and that (2) participants would show a 
stronger increase in positive affect, and a stronger decrease in negative affect, after the positive reappraisal induction compared to the other inductions.

Chapter 9 comprises a general conclusion and critical discussion of the studies described in this dissertation, as well as recommendations for future research.

\section{References}

Abela, J.R.Z. (2001). The hopelessness theory of depression: a test of the diathesis-stress and causal mediation components in third and seventh grade children. Journal of Abnormal Child Psychology, 29, 241-254.

Abela, J.R.Z., \& Hankin, B.L. (2008). Cognitive vulnerability to depression in children and adolescents: a developmental psychopathology perspective. In J.R.Z. Abela \& B.L. Hankin (Eds.), Handbook of depression in children and adolescents (pp. 35-78). New York: The Guilford Press.

Abela, J.R.Z., \& McGirr, A. (2007). Operationalizing cognitive vulnerability and stress from the perspective of the hopelessness theory: A multi-wave longitudinal study of children of affectively ill parents. British Journal of Clinical Psychology, 46, 377-395.

Abela, J.R.Z., Parkinson, C., Stolow, D., \& Starrs, C. (2009). A test of the integration of the hopelessness and response styles theories of depression in middle adolescence. Journal of Clinical Child and Adolescent Psychology, 38, 354-364.

Abramson, L., Metalsky, G., \& Alloy, L. (1989). Hopelessness depression: A theory-based subtype of depression. Psychological Review, 96(2), 358-372.

Alloy, L., Abramson, L., Hogan, M., Whitehouse, W., Rose, D., Robinson, M., et al. (2000). The Temple-Wisconsin cognitive vulnerability to depression project: lifetime history of axis I psychopathology in individuals at high and low cognitive risk for depression. Journal of Abnormal Psychology, 109, 403-418.

Andrews, P. W., \& Thomson, J. A. Jr. (2009). The bright side of being blue: depression as an adaptation for analyzing complex problems. Psychological Review, 116, 620-654.

Angold, A., \& Costello, E. J. (2006). Puberty and depression. Child and Adolescent Psychiatric Clinics of North America, 15, 919-937.

Beck, A. (1967). Depression: Clinical, experimental and theoretical aspects. New York: Harper \& Row.

Beck, A., Rush, A., Shaw, B., \& Emery, G. (1979). Cognitive therapy of depression. New York: Guilford.

Birmaher, B., Ryan, N. D., Williamson, D. E., Brent, D. A., Kaufman, J., Dahl, R. E., et al. (1996). Childhood and adolescent depression: a review of the past 10 years. Part I. Journal of American Academy of Child and Adolescent Psychiatry, 35(11), 1427-1439.

Birmaher, B., Arbelaez, C., \& Brent, D. (2002). Course and outcome of child and adolescent major depressive disorder. Child and Adolescent Psychiatric Clinics North America, 11, 619-637.

Borkovec, T. (1994). The nature, functions, and origins of worry. In G. Davey \& F. Tallis (Eds.), Worrying: perspectives on theory, assessment and treatment (pp. 5-33). Chichester: John Wiley \& Sons.

Burwell, R., \& Shirk, S. (2007). Subtypes of rumination in adolescence: associations between brooding, reflection, depressive symptoms, and coping. Journal of Clinical Child and Adolescent Psychology, 36(1), 56-65.

Butler, L., \& Nolen-Hoeksema, S. (1994). Gender differences in responses to depressed mood in a college sample. Sex Roles, 30(5/6), 331-346. 
Carver, C. (1996). Goal engagement and the human experience. In R. J. Wyer (Ed.), Ruminative thoughts (Vol. IX, pp. 49-61). Mahwah, New Jersey: Lawrence Erlbaum Associates, Inc.

Cole, D. A., Ciesla, J. A., Dallaire, D. H., Jacquez, F. M., Pineda, A. Q., LaGrange, B., et al. (2008). Emergence of attributional style and its relation to depressive symptoms. Journal of Abnormal Psychology, 117, 16-31.

Curry, J., Silva, S., Rohde, P., Ginsburg, G., Kratochvil, C., Simons, A., Kirchner, J., May, D., Kennard, B., Mayes, T., Feeny, N., Albano, A. M., Lavanier, S., Reinecke, M., Jacobs, R., BeckerWeidman, E., Weller, E., Emslie, G., Walkup, J., Kastelic, E., Burns, B., Wells, K., \& March, J. (2010). Recovery and recurrence following treatment for adolescent major depression. Archives of General Psychiatry. doi:10.1001/archgenpsychiatry.2010.150.

Davey, G. (1994). Pathological worrying as exacerbated problem-solving. In G. Davey \& F. Tallis (Eds.), Worrying: Perspectives on Theory, Assessment, and Treatment. Chichester: Wiley \& Sons.

Dimidjian, S., Hollon, S., Dobson, K., Schmaling, K., Kohlenberg, R., Addis, M., et al. (2006). Randomized trial of behavioral activation, cognitive therapy, and antidepressant medication in the acute treatment of adults with major depression. Journal of Consulting and Clinical Psychology, 74(4), 658-670.

Gladstone, T. R. G., Kaslow, N. J. (1995). Depression and attributions in children and adolescents: a meta-analytic review. Journal of Abnormal Child Psychology, 23, 597-606.

Grant, K., Lyons, A., Finkelstein, J.-A., Conway, K., Reynolds, L., O'Koon, J., et al. (2004). Gender differences in rates of depressive symptoms among low-income, urban, African American youth: a test of two mediational hypotheses. Journal of Youth and Adolescence, 33(6), 523-533.

Hankin, B.L., \& Abramson, L.Y. (2001). Development of gender differences in depression: an elaborated cognitive vulnerability-transactional stress theory. Psychological Bulletin, 127, 773796.

Hankin, B.L., Abramson, L.Y., \& Siler, M. (2001). A prospective test of the hopelessness theory of depression in adolescence. Cognitive Therapy and Research, 25, 607-632.

Hankin, B. L., Wetter, E., \& Cheeley, C. (2008). Sex differences in child and adolescent depression: a developmental psychopathological approach. In J. R. Z. Abela \& B. L. Hankin (Eds.), Handbook of depression in children and adolescents (pp. 377-414). New York: The Guilford Press.

Harvey, A., Watkins, E., Mansell, W., \& Shafran, R. (2004). Cognitive behavioral processes across psychological disorders: A transdiagnostic approach to research and treatment. Oxford: Oxford University Press.

Helgeson, V. S., Reynolds, K. A., \& Tomich, P. L. (2006). A meta-analytic review of benefit finding and growth. Journal of Consulting and Clinical Psychology, 74(5), 797-816.

Hyde, J.S., Mezulis, A.H., \& Abramson, L.Y. (2008). The ABCs of depression: Integrating affective, biological, and cognitive models to explain the emergence of the gender difference in depression. Psychological Review, 115, 291-313.

Joiner, T. E., Wagner, K. D. (1995). Attributional style and depression in children and adolescents: a meta-analytic review. Clinical Psychology Review, 15, 777-798.

Joormann, J., Dkane, M., \& Gotlib, I. (2006). Adaptive and maladaptive components of rumination? Diagnostic specificity and relation to depressive biases. Behavior Therapy, 37, 269-280.

Jose, P., \& Brown, I. (2008). When does the gender difference in rumination begin? Gender and age differences in the use of rumination by adolescents. Journal of Youth and Adolescence, 37, 180-192.

Kanner, A.D., Coyne, J.C., Schaefer, C., \& Lazarus, R.S. (1981). Comparison of two modes of stress measurement: daily hassles and uplifts versus major life events. Journal of Behavioral Medicine, 4, 1-39. 
Kessler, R. C. (1997). The effects of stressful life events on depression. Annual Review of Psychology, 48, 191-214.

Kessler, R. C., McGonagle, K. A., Swartz, M., Blazer, D. G., \& Nelson, C. B. (1993). Sex and depression in the National Comorbidity Survey. I: Lifetime prevalence, chronicity and recurrence. Journal of Affective Disorders, 29(2-3), 85-96.

Kuehner, C. (2003). Gender differences in unipolar depression: an update of epidemiological findings and possible explanations. Acta Psychiatrica Scandinavica, 108, 163-174.

Lakdawalla, Z., Hankin, B. L., \& Mermelstein, R. (2007). Cognitive theories of depression in children and adolescents: a conceptual and quantitative review. Clinical Child and Family Psychological Review, 10, 1-24.

Lewinsohn, P., Rohde, P., \& Seeley, J. (1998). Major depressive disorder in older adolescents: prevalence, risk factors, and clinical implications. Clinical Psychology Review, 18(7), 765-794.

Lyubomirsky, S., \& Nolen-Hoeksema, S. (1993). Self-perpetuating properties of dysphoric rumination. Journal of Personality and Social Psychology, 65, 339-349.

Lyubomirsky, S., \& Tkach, C. (2004). The consequences of dysphoric rumination. In C. Papageorgiou \& A. Wells (Eds.), Depressive rumination: nature, theory, and treatment (pp. 21-41). Chichester: John Wiley \& Sons.

Matthews, G. \& Wells, A. (2004). Rumination, depression and metacognition: The S-REF model. In: C. Papageorgiou \& A. Wells (Eds.). Depressive Rumination: Nature, Theory and Treatment. Chichester, UK: Wiley.

Miranda, R., \& Nolen-Hoeksema, S. (2007). Brooding and reflection: Rumination predicts suicidal ideation at one-year follow up in a community sample. Behaviour Research and Therapy, 45, 3088-3095.

Moberly, N., \& Watkins, E. (2008). Ruminative self-focus and negative affect: an experience sampling study. Journal of Abnormal Psychology, 117(2), 314-323.

Mor, N., \& Winquist, J. (2002). Self-focused attention and negative affect: A meta-analysis. Psychological Bulletin, 128, 638-662.

Nolan, S., Roberts, J., \& Gotlib, I. (1998). Neuroticism and ruminative response style as predictors of change in depressive symptomatology. Cognitive Therapy and Research, 22(5), 445-455.

Nolen-Hoeksema, S. (1987). Sex differences in unipolar depression: evidence and theory. Psychological Bulletin, 101(2), 259-282.

Nolen-Hoeksema, S. (1991). Responses to depression and their effects on the duration of depressive episodes. Journal of Abnormal Psychology, 100(4), 569-582.

Nolen-Hoeksema, S. (1994). An interactive model for the emergence of gender differences in depression in adolescence. Journal of Research on Adolescence, 4, 519-534.

Nolen-Hoeksema, S. (1996). Chewing the cud and other ruminations. In R. S. Wyer, Jr. (Ed.), Ruminative thoughts (pp. 135-144). Mahwah, NJ: Lawrence Erlbaum.

Nolen-Hoeksema, S., \& Girgus, J. (1994). The emergence of gender differences in depression during adolescence. Psychological Bulletin, 115(3), 424-443.

Nolen-Hoeksema, S., Larson, J., \& Grayson, C. (1999). Explaining the gender difference in depressive symptoms. Journal of Personality and Social Psychology, 77(5), 1061-1072.

Nolen-Hoeksema, S., \& Morrow, J. (1993). Effects of rumination and distraction on naturally occurring depressed mood. Cognition and Emotion, 7, 561-570.

Nolen-Hoeksema, S., Morrow, J., \& Fredrickson, B. (1993). Response styles and the duration of episodes of depressed mood. Journal of Abnormal Psychology, 102(1), 20-28.

Nolen-Hoeksema, S., Wisco, B. E., \& Lyubomirsky, S. (2008). Rethinking rumination. Perspectives on Psychological Science, 3, 400-424. 
Papageorgiou, C., \& Wells, A. (2004). Depressive rumination: Nature, Theory and Treatment. Chichester: John Wiley \& Sons.

Raes, F., \& Hermans, D. (2008). On the mediating role of subtypes of rumination in the relationship between childhood emotional abuse and depressed mood: brooding versus reflection. Depression and Anxiety, 25, 1067-1070.

Robinson, M., \& Alloy, L. (2003). Negative cognitive styles and stress-reactive rumination interact to predict depression: a prospective study. Cognitive Therapy and Research, 27(3), 275-292.

Roelofs, J., Huibers, M., Peeters, F., \& Arntz, A. (2008). Effects of neuroticism on depression and anxiety: Rumination as a possible mediator. Personality and Individual Differences, 44, 576-586.

Schwartz, J., \& Koenig, L. (1996). Response styles and negative affect among adolescents. Cognitive Therapy and Research, 20(1), 13-36.

Segerstrom, S., Tsao, J., Alden, L., \& Craske, M. (2000). Worry and rumination: repetitive thought as a concomitant and predictor of negative mood. Cognitive Therapy and Research, 24(6), 671-688.

Skitch, S., \& Abela, J. R. Z. (2008). Rumination in response to stress as a common vulnerability factor to depression and substance misuse in adolescence. Journal of Abnormal Child Psychology, 36, 1029-1045.

Smith, J.M., \& Alloy, L.B. (2009). A roadmap to rumination: A review of the definition, assessment, and conceptualization of this multifaceted construct. Clinical Psychology Review, 29, 116-128.

Stone, L. B., Gibb, B. E., \& Coles, M. E. (2010). Does the hopelessness theory account for sex differences in depressive symptoms among young adults? Cognitive Therapy and Research, $34,177-187$.

Tennant, C. (2002). Life events, stress and depression: a review of recent findings. Australian and New Zealand Journal of Psychiatry, 36, 173-182.

Treynor, W., Gonzalez, R., \& Nolen-Hoeksema, S. (2003). Rumination reconsidered: a psychometric analysis. Cognitive Therapy and Research, 27(3), 247-259.

Watkins, E. (2008). Constructive and unconstructive repetitive thoughts. Psychological Bulletin, 134, 163-206.

Watkins, E., Moulds, M., \& Mackintosh, B. (2005). Comparisons between rumination and worry in a non-clinical population. Behaviour Research and Therapy, 43, 1577-1585.

Watkins, E., Scott, J., Wingrove, J., Rimes, K., Bathurst, N., Steiner, et al. (2007). Ruminationfocused cognitive behaviour therapy for residual depression: A case series. Behaviour Research and Therapy, 45, 2144-2154.

Weisz, J., McCarty, C., \& Valeri, S. (2006). Effects of psychotherapy for depression in children and adolescents: a meta-analysis. Psychological Bulletin, 132(1), 132-149.

Wilkinson, P., \& Goodyer, I. (2008). The effects of cognitive-behavioural therapy on mood-related ruminative response style in depressed adolescents. Child and Adolescent Psychiatry and Mental Health, 2(3). doi: 10.1186/1753-2000-2-3 



\title{
Chapter 2
}

\section{Dimensions of negative thinking and the relations with symptoms of depression and anxiety in children and adolescents ${ }^{1}$}

\author{
Lea Rood, Jeffrey Roelofs, Susan M. Bögels, Lauren B. Alloy
}

\begin{abstract}
The current study sought to examine three forms of negative, repetitive thinking in non-clinical children and adolescents aged between 10 and 18. More specifically, this study addressed the degree to which stress-reactive rumination can be differentiated from other forms of repetitive thinking, such as emotion-focused rumination and worry, and the associations between the various indices of repetitive thinking and symptoms of anxiety and depression. Participants completed a battery of self-report questionnaires including measures of stress-reactive rumination, emotion-focused rumination, worry, and symptoms of anxiety and depression. Results showed that stress-reactive rumination, emotion-focused rumination and worry are related but distinct forms of repetitive negative thinking. Positive associations were found between all indices of repetitive thinking and symptoms of depression and anxiety, but the effects of emotion-focused rumination disappeared when controlling for the other forms of repetitive thinking. The findings are discussed in the light of current theories and previous research, and directions for future research are provided.
\end{abstract}

\footnotetext{
${ }^{1}$ Published in: Cognitive Therapy and Research, 34(4), 333-342.
} 


\section{Introduction}

Unconstructive forms of repetitive thinking may represent a cognitive vulnerability factor implicated in the development and maintenance of various emotional disorders such as anxiety disorders and depression (e.g., Watkins, 2008). More specifically, repetitive thinking characterized by negatively valenced thought content (e.g., thoughts about depressive or anxious mood), a negative intrapersonal context (e.g., negative mood or negative self-beliefs), and an abstract level of construal (i.e., thinking about meanings and implications) is thought to contribute to negative mood states. In the literature, different types of repetitive thinking are distinguished, with their own conceptualizations and qualities. Emotion-focused rumination is considered a predominantly unconstructive form of repetitive thinking (see Watkins, 2008), which involves repetitive thoughts about depressive symptoms and the causes and consequences of these symptoms (e.g., Nolen-Hoeksema, 1987). According to the response styles theory (e.g., Nolen-Hoeksema, 1987; 1991; 1998), engaging in emotion-focused rumination is related to amplified and prolonged periods of depression in adults (see for comprehensive reviews Lyubomirsky \& Tkach, 2004; Nolen-Hoeksema, 1998). In youth, emotion-focused rumination is positively associated with concurrent levels of depressive symptoms (e.g., Abela, Vanderbilt, \& Rochon, 2004; Muris, Roelofs, Meesters, \& Boomsma, 2004; Papadakis, Prince, Jones, \& Strauman, 2006) and may predict increases in depressive symptoms over time (e.g., Abela, Aydin, \& Auerbach, 2007; Abela, Brozina, \& Haigh, 2002; Burwell \& Shirk, 2007; Schwartz \& Koenig, 1996).

Stress-reactive rumination is another form of repetitive thinking that has been introduced by Alloy and colleagues (Alloy et al., 2000; Robinson \& Alloy, 2003), as an extension of the response styles theory. More specifically, stress-reactive rumination involves the tendency to ruminate on negative inferences following stressful events (Robinson \& Alloy, 2003). The content of stress-reactive thoughts is consistent with hopelessness theory (Abramson, Metalsky, \& Alloy, 1989), but is somewhat different from dysfunctional attitudes (Beck, 1967) that may be focused on beliefs that their happiness depends on being perfect or others' approval (see Robinson \& Alloy, 2003). That is, stress-reactive rumination involves the process of repetitively thinking about negative inferences in response to the occurrence of stressful events. As emotion-focused rumination was theoretically linked to the maintenance of depressive symptoms, stress-reactive rumination has been developed to explain the onset of depressive symptoms. There is indeed some evidence to suggest that stress-reactive rumination, in combination with negative cognitive style, contributes to the onset of depression in adults, and that stress-reactive rumination may be an even more consistent predictor of the onset and duration of depressive symptoms than emotion-focused rumination in adults (Alloy et al., 2000; Robinson \& Alloy, 2003). 
However, to the authors' best knowledge, there have been no systematic attempts to examine stress-reactive rumination in relation to symptoms of psychopathology in youth.

Worry is yet another form of repetitive negative thinking and can be defined as a chain of thoughts and images that are negatively affect-laden and relatively uncontrollable (Borkovec, Robinson, Pruzinsky, \& DePree, 1983; Roemer \& Borkovec, 1993). Although worry has problem-solving qualities (e.g., Borkovec et al., 1983), excessive worrying has been considered a key element of generalized anxiety disorder (American Psychiatric Association, 2000), but has also been found to play a role in other anxiety problems such as obsessive-compulsive disorder, social phobia, and panic disorder (e.g., Borkovec, 1994; Dugas et al., 1998; Muris, 2007). In youth, high levels of worry seem to be associated with more anxiety symptoms (e.g., Weems, Silverman, \& LaGreca, 2000) and the level of induced panic symptoms (e.g., Leen-Feldner, Feldner, Tull, Roemer, \& Zvolensky, 2006). Research with clinically anxious youth has demonstrated that worry is not only present in generalized anxiety disorder, but also in separation anxiety disorder and social phobia (e.g., Perrin \& Last, 1997; Weems et al., 2000).

Another important issue is the relationship between the different forms of repetitive thought and symptoms of depression and anxiety. So far, most research has focused on the relationships between emotion-focused rumination and worrying on the one hand, and symptoms of depression and anxiety on the other hand. In keeping with the notion that emotion-focused rumination and worry can be considered transdiagnostic variables (e.g., Harvey, Watkins, Mansell, \& Shafran, 2004), there is evidence to suggest that both forms of negative repetitive thinking are related to both anxiety and depression symptoms in adults (e.g., Blagden \& Craske, 1996; Fresco, Frankel, Mennin, Turk, \& Heimberg, 2002; Molina, Borkovec, Peasley, \& Person, 1998; Muris, Roelofs, Rassin, Franken, \& Mayer, 2005; Nolen-Hoeksema, 2000; Roberts, Gilboa, \& Gotlib, 1998; Sarin, Abela, \& Auerbach, 2005; Starcevic, 1995; Watkins, 2004) and youth (e.g., Calmes \& Roberts, 2007; Fresco et al., 2002; Hong, 2007; Muris et al., 2004; Segerstrom, Tsao, Alden, \& Craske, 2000). To date, there is no research that has examined whether stress-reactive rumination is a transdiagnostic variable in terms of relations with both symptoms of anxiety and depression.

Taken together, from a theoretical and conceptual point of view, emotionfocused rumination, stress-reactive rumination, and worry represent three dimensions of negative thinking that have a certain degree of overlap, particularly with respect to being unconstructive repetitive thoughts. Despite the overlap, a number of studies have addressed the extent to which emotion-focused rumination and worry can be distinguished (Fresco et al., 2002; Muris et al., 2004; Watkins, Moulds, \& Mackintosh, 2005). Factor analytic studies have revealed that emotion-focused rumination and 
worry are related, but distinct, as they load on different intercorrelated factors (see Fresco et al., 2002; Muris et al., 2004). Several other researchers have failed to find as much difference between emotion-focused rumination and worry (e.g., Segerstrom et al., 2000; Watkins et al., 2005), where the only difference found was temporal orientation, with emotion-focused rumination focused on the past and worry focused on the future. To date, there are no factor analytic studies that have investigated the degree of distinctiveness between stress-reactive rumination and other forms of repetitive thinking. The aim of the present study was to examine whether stressreactive rumination is an independent form of negative repetitive thinking by means of a joint exploratory factor analysis comprising the items from three self-report scales of emotion-focused rumination, stress-reactive rumination, and worrying, respectively, in children and adolescents. Given important developmental differences such as the emergence, stabilization, and crystallization of cognitive vulnerability factors for depression between younger and older participants (see Abela \& Hankin 2008), we conducted two separate factor analyses in the younger sample (ages 1013) and the older sample (ages 14-18). The second aim of this study was to examine cross-sectional relations between stress-reactive rumination, and symptoms of depression and anxiety. The extent to which the three forms of repetitive thinking were related to symptoms of depression and anxiety was investigated by assessing the association with and without controlling for the effects of the other forms of repetitive thinking, age, gender, and for concurrent anxiety/depression symptoms. From a transdiagnostic perspective, we hypothesized that all three dimensions (i.e., emotion-focused rumination, stress-reactive rumination and worrying) would account for a significant portion of the variance in symptoms of depression and anxiety.

\section{Method}

\section{Participants and procedure}

Two samples were used in the current study. Participants of sample one were recruited at primary and secondary schools in the southern regions of The Netherlands. First, principals of schools were approached and informed about the purpose of the study. When given permission to recruit at their school, the researchers came into the classrooms during regular class and held a 10-minute talk in front of all pupils. The purpose of the study was explained as 'examining the influence of the way teenagers think on what they feel'. Subsequently, informed consent forms were handed out and returned two weeks later. Response rates varied somewhat per school. On average, $25 \%$ of the youngsters who were approached agreed to participate in a three-year longitudinal study. There was no compensation in turn for participation. Written informed consent was obtained from all parents and from the children where appropriate. A total number of 805 participants (323 boys 
and 482 girls) completed the baseline measurement of the longitudinal study. Of these individuals, some had more than $10 \%$ missing values on one of the measures included in the current study and were therefore excluded for that specific measure. As a consequence, sample size ranged between 779 and 805 across the various analyses. The mean age of the sample was $12.4(\mathrm{SD}=1.9)$, ranging from 10 to 18 . Ethnicity was not reported but it is estimated that about $95 \%$ of the sample were Caucasian. Participants completed a battery of questionnaires at home, as part of a three-year follow-up study. Participants could indicate whether they preferred completing the questionnaires on the internet or on paper. The majority $(78.3 \%)$ filled in the questionnaires on the internet and the remaining $21.7 \%$ preferred the paperand-pencil version. The proportion of the sample that exhibited clinically significant levels of depressive symptoms was $12.9 \%$ (CDI cut off score $\geq 16$; see Timbremont, Braet, \& Dreessen, 2004). As for clinical levels of trait anxiety symptoms, $7.5 \%$ of the girls and $8.4 \%$ of the boys scored above the cut off scores of two standard deviations above the mean (STAIC cut off score for girls $\geq 46$; for boys $\geq 42$; see Bakker, van Wieringen, van der Ploeg, \& Spielberger, 1989).

For the purpose of the factor analysis, data from a second sample which also completed the three questionnaires assessing negative repetitive thinking (see measures), was used and combined with sample one. In the second sample, a total of 801 children and adolescents (367 boys and 434 girls) with a mean age of 12.9 years $(S D=2.1$, age range $10-18$ years) participated. The vast majority of the youth (>95\%) were Caucasian. The self-report measures were completed during regular class time. The teacher and a research assistant were available to answer questions and to ensure confidential responding. Response rates were higher $(40 \%)$, which is probably due to the difference in commitment to a study with a single measurement and with three waves. The combined dataset resulted in two groups of 1078 children aged 10 to 13, and 528 adolescents aged 14 to 18 .

\section{Measures}

Repetitive negative thinking

The Children's Response Styles Scale (CRSS; Ziegert \& Kistner, 2002; Dutch version: Muris et al., 2004) is a self-report questionnaire that measures the tendency to ruminate and the tendency to seek distraction in response to feelings of sadness in children. The CRSS consists of 20 items and is based on the Response Styles Questionnaire for adults (RSQ; Nolen-Hoeksema \& Morrow, 1991). The rumination subscale (10 items) represents thoughts and behaviours that maintain the focus on emotions (e.g., "When I'm feeling sad, I think about the other times I felt that way"). Items are rated on a five-point Likert type scale (i.e., 1=never, 2=almost never, $3=$ sometimes, $4=$ often, and 5=always). Reliability of the CRSS in terms of internal 
consistency is good $(\alpha=.81)$ and validity is adequate to good (Muris et al., 2004; Ziegert \& Kistner, 2002).

The Stress-Reactive Rumination Scale for children (SRRS-C) is a downward extension of the same scale developed for adults (SRRS; Robinson, 1997; Robinson \& Alloy, 2003). The SRRS-C aims to measure the frequency of negative thoughts about the negative inferences following stressful events (e.g., "I think about how the stressful event was totally my fault"). The SRRS-C consists of nine items and participants are instructed to score the frequency of each item on a four-point Likert type scale (i.e., 1=almost never, 2=sometimes, 3=often, 4=almost all the time). Reliability and discriminant validity of the adult version of the SRRS are acceptable (Robinson \& Alloy, 2003). The child version of the SRRS was translated into Dutch, and subsequently back translated by a native English speaker and was then approved by the original authors.

The Penn State Worry Questionnaire for children and adolescents (PSWQ-C; Chorpita Tracey, Brown, Collica, \& Barlow, 1997; Dutch version: Muris et al., 2004) is a self-report questionnaire which aims to measure the tendency to worry in an excessive and uncontrollable way (e.g., "I am really bothered by the worrying I do" and "I really worry about things"). Items are scored on a four-point Likert type rating scale (i.e., $0=$ never, $1=$ seldom, $2=$ often, $3=$ =always). The PSWQ-C is reliable in terms of internal consistency and possesses high convergent and discriminant validity (Muris et al., 2004). Test-retest stability is good (Chorpita et al., 1997).

\section{Depressive symptoms}

The Children's Depression Inventory (CDI; Kovacs, 1981; Dutch version: Timbremont \& Braet, 2001; 2002) is based on the Beck Depression Inventory for adults. The CDI is a widely used self-report questionnaire which aims to measure the level of depressive symptoms in children from 7 to 17 years old. It consists of 27 items, covering feelings of sadness, self-guilt, loss of appetite, insomnia, and adjustment to school. For each item, three statements are given. The subject has to choose one of three statements (e.g., "I am sad sometimes / I am often sad / I am always sad") that represents best how he or she has been feeling the last two weeks. Reliability in terms of internal consistency is good and the convergent validity of the CDI is supported. The CDI has some overlap with anxiety symptoms which reduces the discriminant validity of the CDI (Timbremont \& Braet, 2001).

\section{Anxiety symptoms}

The trait version of the Spielberger State-Trait Anxiety Inventory for children (STAITC; Spielberger, Edwards, Lushene, Montuori, \& Platzek, 1973; Dutch version: Bakker et al., 1989) is based on the STAI for adults (Spielberger, Gorsuch, \& Lushene, 1970). The STAI-TC consists of 20 items that aim to measure trait anxiety 
(e.g., "I am afraid to do things wrong"). Items are rated on a three-point Likert type scale (i.e., 1=almost never, 2=sometimes, 3=often). Reliability and convergent validity of the STAI-TC are good, but the discriminant validity remains questionable due to overlap with depressive symptoms (Muris, Merckelbach, Ollendick, King, \& Bogie, 2002).

\section{Statistical analysis}

The data were analysed using SPSS version 13.0. For individuals with less than $10 \%$ missing on values of a single self-report measure, a regression technique was used to impute the missing values by estimating the value on the basis of the scores of that individual on the remaining items, as well as on the scores of others on the item for which a score was missing. For the factor analyses, data from two samples were combined to obtain a sufficient number of participants to do factor analysis in children and adolescents separately. A principal factor analysis with oblimin rotation (which allows the obtained factors to be intercorrelated) was carried out on the items of the SRRS-C, the rumination scale of the CRSS and the PSWQ-C, separately for the two age categories of 10-13 and 14-18. In order to determine the number of factors to retain, we relied on parallel analysis (O'Connor, 2000), which is considered a sophisticated procedure for selecting the number of factors in a factor analysis (e.g., Hayton, Allen, \& Scarpello, 2004). The advantage of parallel analysis over other factor retention methods is that it corrects for the effects of sampling error. By means of parallel analysis, random eigenvalues are generated from random data, based on the number of variables and sample size of the data one wishes to analyse. Subsequently, the random eigenvalues have to be compared to the eigenvalues produced by the factor analysis. The number of factors to retain is determined by the number of eigenvalues, for which the real eigenvalue obtained by factor analysis is greater than the random eigenvalue. When an eigenvalue generated from the exploratory factor analysis is higher than the random eigenvalue generated from the parallel analysis, it can be assumed that the eigenvalue represents a real factor, that accounts for more variance than a parallel component based on random data (see Hayton et al., 2004). Further, the scree-plots were inspected visually. Subsequently, the internal consistency of the obtained dimensions of repetitive thinking was determined by computing reliability coefficients (Cronbach's alpha).

For the second aim of this study, analyses were carried out on data from sample one, for which measures of depressive and anxiety symptoms were available. First, to examine the concurrent criterion validity, zero-order correlations between the forms of repetitive thought, and symptoms of depression and anxiety were computed. Second, to examine the relative predictive validity of the dimensions of negative thinking, we computed partial correlation coefficients between each type of negative thinking and symptoms of depression, controlling for the other two types of negative 
thinking, age, gender, and anxiety symptoms. For example, in the computation of the partial correlation between depressive symptoms and stress-reactive rumination, we controlled for worry, emotion-focused rumination, age, gender, and symptoms of anxiety. In a similar vein, we computed partial correlations between each type of negative thinking and anxiety symptoms, controlling for the other two types of negative thinking, age, gender, and depressive symptoms. As an aside, gender differences on the self-report measures and differences on the total scores of the measures for those who completed the questionnaires by computer or paper were tested by means of t-tests over the whole sample.

\section{Results}

Joint factor analysis on SRRS-C, CRSS, and PSWQ-C items

An exploratory joint principal factor analysis (PFA) was carried out on all 33 items of the SRRS-C, CRSS, and PSWQ-C, in a sample of children aged 10 to $13(N=1078)$, and in a sample of adolescents aged 14 to $18(N=528)$. Parallel analysis was used as a method to determine the number of factors to retain. For the sample aged 10 to 13 , the first five eigenvalues obtained with PFA were 11.41, 2.61, 1.60, 1.06, and 1.02, while the random eigenvalues obtained by means of parallel analysis were 1.38, $1.33,1.29,1.26$, and 1.24. Thus, three factors should be retained according to the parallel test. In addition, the scree test supported a three-factor model as a clear break was found after the third factor. Bartlett's tests for sphericity were significant and all MSA values were higher than .80 , indicating that the variables involved correlate with each other and with more than one variable, which means that factor analysis can be applied to these data in a meaningful way. The communalities ranged from .24 to .53 , indicating that all items explained a unique part of the variance across all factors. The three-factor model explained $42.1 \%$ of the variance. The first factor consisted of all PSWQ-C items and was therefore labelled the 'worryscale'; the second factor consisted of CRSS items representing the 'emotion-focused

Table 1: Factor loadings (pattern coefficients) as obtained by principal factor analysis with Oblimin rotation of the PSWQ-C, SRRS-C and CRSS

\begin{tabular}{|c|c|c|c|c|c|c|c|}
\hline Item & Item description & \multicolumn{2}{|l|}{ Factor 1} & \multicolumn{2}{|c|}{ Factor 2} & \multicolumn{2}{|c|}{ Factor 3} \\
\hline & & $\leq 13$ & $\geq 14$ & $\leq 13$ & $\geq 14$ & $\leq 13$ & $\geq 14$ \\
\hline PSWQ-C 10 & I have been a worrier all my life. & .77 & .77 & -.10 & -.01 & .01 & -.04 \\
\hline PSWQ-C 13 & I worry all the time. & .75 & .86 & -.05 & -.08 & .00 & -.07 \\
\hline PSWQ-C 6 & I'm always worrying about something. & .74 & .83 & -.04 & -.07 & -.03 & .00 \\
\hline PSWQ-C 2 & I really worry about things. & .72 & .73 & .06 & .06 & -.07 & -.00 \\
\hline PSWQ-C 12 & Once I start worrying, I can't stop. & .69 & .65 & .00 & .07 & .01 & .06 \\
\hline PSWQ-C 9 & I worry about everything. & .68 & .79 & -.08 & .01 & .08 & -.11 \\
\hline PSWQ-C 7 & $\begin{array}{l}\text { I find it hard to quit worrying when I } \\
\text { want to. }\end{array}$ & .67 & .53 & .09 & .07 & -.08 & .13 \\
\hline PSWQ-C 3 & I worry about a lot of things. & .66 & .67 & .02 & .03 & .08 & .07 \\
\hline
\end{tabular}


DIMENSIONS OF NEGATIVE THINKING

\begin{tabular}{|c|c|c|c|c|c|c|c|}
\hline PSWQ-C 4 & $\begin{array}{l}\text { I know I shouldn't worry so much, but I } \\
\text { just can't help it. }\end{array}$ & .63 & .72 & .12 & .08 & -.02 & . \\
\hline PSWQ-C 11 & $\begin{array}{l}\text { I notice that I have been worrying } \\
\text { about things. }\end{array}$ & .62 & .63 & .03 & .10 & .13 & 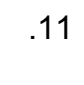 \\
\hline PSWQ-C 5 & When I'm under pressure I worry a lot. & .59 & .58 & .12 & .08 & -.02 & \\
\hline PSWQ-C 1 & $\begin{array}{l}\text { I'm really bothered by the worrying I } \\
\text { do. }\end{array}$ & .54 & .63 & .10 & .15 & .09 & \\
\hline PSWQ-C 8 & $\begin{array}{l}\text { As soon as I finish something, I start } \\
\text { worrying about all kind of other things. }\end{array}$ & .52 & .64 & -.04 & -.05 & .09 & \\
\hline PSWQ-C 14 & $\begin{array}{l}\text { I'm always worrying about the things I } \\
\text { need to do, until they're finished. }\end{array}$ & .45 & .49 & .12 & .12 & .11 & \\
\hline CRSS 19 & $\begin{array}{l}\text { When I'm feeling sad, I think about } \\
\text { how I feel. }\end{array}$ & -.01 & -.02 & .71 & .79 & -.00 & \\
\hline CRSS 13 & $\begin{array}{l}\text { When I'm feeling sad, I think about } \\
\text { why it is I feel this way. }\end{array}$ & -.09 & -.06 & .68 & .67 & -.05 & \\
\hline CRSS 4 & $\begin{array}{l}\text { When I'm feeling sad, I withdraw and } \\
\text { think about why I feel that way. }\end{array}$ & .09 & .10 & .61 & .70 & -.07 & \\
\hline CRSS 16 & $\begin{array}{l}\text { When I'm feeling sad, I think about the } \\
\text { things that have happened over and } \\
\text { over again. }\end{array}$ & .11 & 14 & .60 & .58 & .04 & \\
\hline CRSS 20 & $\begin{array}{l}\text { When I'm feeling sad, I think about } \\
\text { something that happened and wish it } \\
\text { had gone better. }\end{array}$ & -.08 & .02 & .59 & .51 & 19 & \\
\hline CRSS 7 & $\begin{array}{l}\text { When I'm feeling sad, I isolate myself } \\
\text { to think about my feelings. }\end{array}$ & .05 & -.01 & .58 & .76 & -.01 & \\
\hline CRSS 11 & $\begin{array}{l}\text { When I'm feeling sad, I think about the } \\
\text { other times that things didn't go the } \\
\text { way I wanted. }\end{array}$ & .04 & .17 & .56 & .43 & .02 & \\
\hline CRSS 2 & $\begin{array}{l}\text { When I'm feeling sad, I think about } \\
\text { that I should have done things } \\
\text { differently. }\end{array}$ & .06 & .05 & .50 & .44 & .14 & \\
\hline CRSS 1 & $\begin{array}{l}\text { When I'm feeling sad, I think about the } \\
\text { other times that I felt this way. }\end{array}$ & .03 & 19 & 49 & .33 & 12 & \\
\hline CRSS 8 & $\begin{array}{l}\text { When I'm feeling sad, I think: why } \\
\text { can't I stop feeling this way? }\end{array}$ & .05 & .21 & .47 & .46 & .07 & \\
\hline SRRS-C & $\begin{array}{l}\text { I think about how terrible the stressful } \\
\text { event was. }\end{array}$ & -.00 & .15 & -.08 & -.11 & .76 & \\
\hline SRRS-C 5 & $\begin{array}{l}\text { I think about the stressful event and } \\
\text { wish it had gone better. }\end{array}$ & -.02 & .03 & .04 & .01 & .68 & \\
\hline SRRS-C & $\begin{array}{l}\text { I think about the causes of the } \\
\text { stressful event. }\end{array}$ & -.04 & -.11 & .01 & .11 & .60 & \\
\hline SRRS-C 6 & $\begin{array}{l}\text { I think about how the stressful event } \\
\text { will negatively affect my life. }\end{array}$ & .08 & .08 & .02 & 1 & .59 & \\
\hline SRRS-C 2 & $\begin{array}{l}\text { I think about what the occurrence of } \\
\text { the stressor means about me. }\end{array}$ & .03 & .12 & .04 & .11 & .53 & \\
\hline SRRS-C & $\begin{array}{l}\text { I think about how the stressful event } \\
\text { was all my fault. }\end{array}$ & .15 & .24 & .03 & -.04 & .50 & \\
\hline SRRS-C & $\begin{array}{l}\text { I think about how things like this } \\
\text { always happen to me. }\end{array}$ & .17 & .21 & .04 & .04 & .49 & \\
\hline SRRS-C 3 & $\begin{array}{l}\text { I think about how things could have } \\
\text { gone differently. }\end{array}$ & -.01 & -.02 & .16 & .09 & .48 & \\
\hline SRRS-C 8 & $\begin{array}{l}\text { I think about how important the } \\
\text { stressful event is for me. }\end{array}$ & .00 & -.07 & .05 & .02 & .46 & \\
\hline
\end{tabular}

Note. PSWQ-C = worry; CRSS = emotion-focused rumination; SRRS-C = stress-reactive rumination. Factor loadings on the corresponding factors are displayed in bold. 
rumination scale', whereas all SRRS-C items loaded on the third factor, the 'stressreactive rumination scale'. None of the items loaded significantly (i.e., >.30) on more than one factor. Factor loadings of all items are shown in Table 1.

The reliability in terms of internal consistency of the three dimensions was good (stress-reactive rumination: $\alpha=.84$, worry: $\alpha=.92$, and emotion-focused rumination: $\alpha=.86)$.

The factor analysis in the adolescent sample yielded comparable results. The first five eigenvalues obtained by factor analysis were 13.51, 2.64, 1.48, .99, and .94, while the first five random eigenvalues obtained by means of parallel analysis were $1.56,1.48,1.43,1.38$, and 1.34 . This means that also in the sample of adolescents, a three-factor structure with factors 'worry', 'stress-reactive rumination', and 'emotionfocused rumination' could be retained. Factor loadings are displayed in Table 1. All items loaded significantly $(>.30)$ on their corresponding factors. Communalities ranged from .27 to .63 . The three-factor model explained $48.8 \%$ of the variance. The reliability in terms of internal consistency of the three dimensions was good (stressreactive rumination: $\alpha=.85$, worry: $\alpha=.94$, and emotion-focused rumination: $\alpha=.90$ ).

Noteworthy to mention, we also carried out the factor analysis over the total group of children and adolescents aged $10-18$ years $(N=1606)$. Results were similar to those obtained in the child (10-13) and adolescent (14-18) samples separately: a three-factor structure emerged ('worry', 'stress-reactive rumination' and 'emotionfocused rumination'), with all items loading significantly (>.30) and exclusively on their corresponding factor.

General statistics, gender differences, and reliability

Descriptive statistics of the scales used in sample one and two are presented in Table 2 (p. 27). A number of remarks with respect to these findings need to be made. First, gender differences examined by means of t-tests showed that girls had significantly higher scores than boys on all questionnaires except for the CDI (alpha at .05). Second, a series of t-tests showed that individuals who completed the questionnaires on the internet had significantly higher scores on the CRSS and PSWQ (alpha at .05) compared to those who used the paper-and-pencil version. Third, reliability in terms of internal consistency is adequate to good and is displayed in Table 2. Finally, total scores on the CDI were positively skewed and showed positive kurtosis and were therefore subjected to a root square transformation which 'normalised' the total scores of these variables.

\section{Discriminant validity of the SRRS-C}

Stress-reactive rumination (SRRS-C) correlated highly with worry (PSWQ-C), $r=.70$, and with emotion-focused rumination (CRSS), $r=.65$ (see Table 3 p. 28). When correcting the correlation coefficients for attenuation (unreliability), the correlation 
coefficient between SRRS-C and PSWQ-C was .77 and the correlation coefficient between SRRS-C and CRSS was .74. Thus, correcting for the attenuation effect did not result in a nearly perfect association, which indicates that the factors measure distinct constructs. Thus, the SRRS-C, PSWQ-C, and the CRSS are three forms of repetitive thinking that have a certain degree of overlap but can still be distinguished.

Table 2: Descriptive statistics and internal consistency (alpha) for all questionnaires for sample $1(N=779-805)$ and sample $2(N=799-801)$, for the total sample, and for girls and boys separately

\begin{tabular}{|c|c|c|c|c|c|c|c|c|c|}
\hline & \multicolumn{3}{|c|}{ Total sample } & \multicolumn{2}{|l|}{ Girls } & \multicolumn{2}{|l|}{ Boys } & \multicolumn{2}{|c|}{$\begin{array}{l}\text { Gender } \\
\text { difference }\end{array}$} \\
\hline & $M$ & $S D$ & Alpha & $M$ & $S D$ & $M$ & $S D$ & $t$ & $p$ \\
\hline \multicolumn{10}{|l|}{ Sample 1} \\
\hline Depression (CDI) & 8.0 & 6.3 & .87 & 8.3 & 6.6 & 7.5 & 5.9 & 1.7 & .084 \\
\hline Trait anxiety (STAI-TC) & 30.5 & 7.9 & .91 & 31.6 & 8.0 & 28.9 & 7.4 & 4.7 & $<.001$ \\
\hline $\begin{array}{l}\text { Stress-reactive } \\
\text { rumination (SRRS-C) }\end{array}$ & 16.7 & 5.1 & .88 & 17.2 & 5.2 & 16.0 & 4.8 & 3.2 & .002 \\
\hline Worry (PSWQ-C) & 12.0 & 8.1 & .94 & 13.0 & 8.1 & 10.7 & 7.8 & 3.8 & $<.001$ \\
\hline $\begin{array}{l}\text { Emotion-focused } \\
\text { rumination (CRSS) }\end{array}$ & 16.4 & 7.7 & .87 & 17.5 & 7.3 & 14.9 & 7.9 & 4.8 & $<.001$ \\
\hline Age & 12.4 & 1.9 & - & 12.4 & 1.9 & 12.3 & 1.7 & 1.2 & .221 \\
\hline \multicolumn{10}{|l|}{ Sample 2} \\
\hline $\begin{array}{l}\text { Stress-reactive } \\
\text { rumination (SRRS-C) }\end{array}$ & 16.7 & 4.8 & .82 & 17.1 & 5.1 & 16.2 & 4.5 & 2.8 & .005 \\
\hline Worry (PSWQ-C) & 12.4 & 7.2 & .92 & 14.2 & 7.4 & 10.3 & 6.4 & 8.3 & $<.001$ \\
\hline $\begin{array}{l}\text { Emotion-focused } \\
\text { rumination (CRSS) }\end{array}$ & 15.6 & 8.0 & .88 & 17.7 & 7.7 & 13.2 & 7.7 & 8.0 & $<.001$ \\
\hline
\end{tabular}

Note. $\mathrm{CDI}=$ Children's Depression Inventory; STAI-TC = Spielberger State-Trait Anxiety Inventory for Children (trait version); SRRS-C = Stress-Reactive Rumination Scale for Children; PSWQ-C = Penn State Worry Questionnaire for Children; CRSS = Children's Response Styles Scale.

Concurrent criterion validity and relative predictive validity

Table 3 presents the zero-order correlation coefficients and partial correlation coefficients (in parentheses) between all self-report measures. As can be seen in Table 3, the three forms of repetitive thinking all show moderate to high associations with depressive and anxiety symptoms. The strongest relationships were found for worry (PSWQ-C), followed by stress-reactive rumination (SRRS-C), and emotionfocused rumination (CRSS). With respect to the partial correlation coefficients between the three forms of repetitive thinking on the one hand, and symptoms of depression and anxiety on the other hand, worry emerged as a significant and strong predictor of anxiety symptoms, whereas modest relations were found between worry and depression, and between stress-reactive rumination and symptoms of anxiety 
and depression ${ }^{2}$. Emotion-focused rumination was no longer associated with either depression or anxiety symptoms when worry and stress-reactive rumination were controlled. One may argue that controlling for highly interrelated variables may affect the findings with respect to partial correlations due to multicollinearity of the independent variables. Therefore, we ran a series of linear regression analyses with scores of the depression and anxiety scales as the dependent variables and the three forms of repetitive thinking as independent variables. Variance inflation factors (VIF) ranged between 1.83 and 2.93 indicating that multicollinearity did not influence the results.

Table 3: Associations between all self-report measures $(N=785-805)$. Partial correlations coefficients are presented in parentheses

\begin{tabular}{llllllll}
\hline & & 1. & 2. & 3. & 4. & 5. & 6. \\
\hline 1. & Depression (CDI) & - & & & & & \\
2. & Trait anxiety (STAI-TC) & $.69^{*}$ & - & & & & \\
3. Stress-reactive rumination (SRRS-C) & $.59^{*}\left(.16^{*}\right)$ & $.68^{*}\left(.17^{*}\right)$ & - & & & \\
4. Worry (PSWQ-C) & $.62^{*}\left(.11^{*}\right)$ & $.77^{*}\left(.46^{*}\right)$ & $.70^{*}$ & - & & \\
5. & Emotion-focused rumination (CRSS) & $.44^{*}(-.01)$ & $.55^{*}(.06)$ & $.65^{*}$ & $.58^{*}$ & - & \\
6. & Age & $.12^{*}$ & $.11^{*}$ & $.17^{*}$ & $.14^{*}$ & $.12^{*}$ & - \\
7. & Gender & .05 & $.17^{*}$ & $.11^{*}$ & $.14^{*}$ & $.17^{*}$ & .04 \\
\hline
\end{tabular}

Note. ${ }^{*} \mathrm{p}<.005 . \mathrm{CDI}=$ Children's Depression Inventory; STAI-TC $=$ Spielberger State-Trait Anxiety Inventory for Children (trait version); SRRS-C = Stress-Reactive Rumination Scale for Children; PSWQ-C = Penn State Worry Questionnaire for Children; CRSS = Children's Response Styles Scale.

\section{Discussion}

The current study sought to examine three forms of negative repetitive thinking in children and adolescents. More specifically, this study addressed (1) the degree to which stress-reactive rumination can be differentiated from other forms of repetitive thinking, such as emotion-focused rumination and worry in children and adolescents, and (2) the associations between the various indices of repetitive thinking and symptoms of anxiety and depression. The Stress-Reactive Rumination Scale for Children was developed for the purpose of this study and is a downward extension of the Stress-Reactive Rumination Scale used in adults (Robinson \& Alloy, 2003).

A joint exploratory factor analysis on items of three measures tapping stressreactive rumination (SRRS-C), emotion-focused rumination (CRSS), and worry

\footnotetext{
${ }^{2}$ An anonymous reviewer suggested controlling for negative cognitive style in order to ensure that the uncontrolled confound of negative cognitive style was not driving the associations between stressreactive rumination and depressive and anxiety symptoms. Negative cognitive style is a composite score of scales measuring the inferences about the globality and stability of the causes of a negative event, inferences about the consequences of an event, and inferences about the self (Hankin \& Abramson, 2002). When controlling for negative cognitive style, the partial correlations between stress-reactive rumination and symptoms of depression and anxiety remained significant $(p r=.13$, $p<.001$, and $p r=.16, p<.001$, respectively).
} 
(PSWQ-C) yielded a three-factor model both in children aged between 10 to 13 and adolescents aged between 14 to 18 years. Taking into account that the measures are intercorrelated, the results show that three forms of repetitive negative thinking can be distinguished in both age groups. These findings are in line with and add to previous findings concerning the degree to which rumination and worry can be differentiated (e.g., Fresco et al., 2002; Muris et al. 2004). More specifically, the results indicate that stress-reactive rumination is a unique form of repetitive thinking in addition to emotion-focused rumination and worry. Another implication of the finding that age did not seem to moderate the factor structure is that repetitive negative thinking as a vulnerability to depression can be applied to child and adolescent samples. These findings are in line with past research (e.g., Abela et al., 2007). However, it should be kept in mind that these findings may reflect the wording of the materials used such that items with "worry" in their description tend to group together, whereas items with "feeling sad", "think about" or "stressful events" in their description tend to group together as well. Despite this limitation of the use of questionnaires, the data provide evidence that stress-reactive rumination is independent from emotion-focused rumination and worry.

All three forms of repetitive negative thinking showed positive and significant associations with symptoms of depression and anxiety. In general, worry showed the strongest associations with depression and anxiety symptoms, followed by stressreactive rumination. In general, rumination as well as worry were equally strongly related to depressive symptoms as to anxiety symptoms, adding to past research showing that rumination and worry are not specific to depression and anxiety symptoms respectively (e.g., Blagden \& Craske, 1996; Fresco et al., 2002; Molina et al., 1998; Muris et al, 2005; Nolen-Hoeksema, 2000; Roberts et al., 1998; Sarin et al., 2005; Starcevic, 1995; Watkins, 2004). These findings support the viewpoint that repetitive negative thinking that takes the form of emotion-focused rumination, stressreactive rumination, or worry, can be seen as a transdiagnostic variable (e.g., Harvey et al., 2004).

In examining the relative contribution of the three forms of repetitive negative thinking controlling for the other two, worry and stress-reactive rumination were significantly associated with depression and anxiety symptoms. Thus, despite the significant zero-order correlation coefficients between emotion-focused rumination and symptoms of anxiety and depression, emotion-focused rumination was no longer significant when controlling for the effects of stress-reactive rumination and worry. The finding that emotion-focused rumination did not account for a significant portion of the variance in depression was not in line with our hypothesis. However, it does add to previous research showing that worry ruled out emotion-focused rumination as a predictor of depressive and anxiety symptoms (Muris et al., 2004). From a theoretical perspective, the response styles theory posits that emotion-focused 
rumination is implicated in the duration of negative mood and includes items that refer to the situation in which one is already feeling depressed (Nolen-Hoeksema, 1991). Stress-reactive rumination on the other hand is theoretically linked to the onset of depressive symptoms (see Robinson \& Alloy, 2003), while the occurrence of worry also is not necessarily dependent on a sad mood state. Therefore, stressreactive rumination and worry may be stronger predictors of depressive symptoms than emotion-focused rumination in a non-clinical sample as the current one, where significant negative mood states may be less prevalent. The role of emotion-focused rumination in clinical samples of depressed children suffering from negative mood states needs investigation.

The findings of the present study underscore the importance of targeting not only the content of thoughts, but also the thought process in interventions with depressed and anxious youth. For example, in cognitive therapy, it may be important to specifically challenge ruminative or worrisome thoughts. In this light, one may also wish to consider challenging positive (e.g., "Worry/rumination helps me overcome my problems") and negative metacognitions about worry and rumination (e.g., "Other children will reject me if I worry/ruminate that much" or "I may go crazy if I keep on worrying/ruminating") and to use strategies such as postponing worrying or rumination to test the (negative) metacognition that one has no control over repetitive thinking (see Wells \& Papageorgiou, 2004). Other approaches that have received a lot of attention recently are mindfulness-based interventions. These might be especially effective in reducing repetitive thought processes, by learning to emotionally disengage from recurrent negative thoughts instead of letting them affect one's mood. An example of a mindfulness based intervention is Mindfulness Based Cognitive Therapy (Segal, Williams, \& Teasdale, 2002).

This study has some limitations that need to be addressed. First, the study was cross-sectional in nature making it impossible to draw conclusions about causeeffect relations. More specifically, the cross-sectional nature of the study makes it difficult to discern whether high levels of repetitive thinking result in more anxiety and depression or whether high levels of anxiety and depression may lead to more repetitive thinking. Studies that employ prospective intervals are needed to examine the predictive value and the stability of the various forms of repetitive thinking (see Hankin, 2008). Experimental studies in which repetitive thinking can be manipulated are also warranted to determine the causal nature of repetitive thinking in depressive and anxiety symptoms. Second, the sample used in the current study was predominantly white European, which may limit the generalisability of the findings to other cultures. Furthermore, a minority (25\%) of the approached children and adolescents decided to participate. It is possible that this sample is biased in some way. However, as we did not gather demographic information about variables such 
as ethnicity or socio-economic status, it is not possible to compare the final sample to expected rates.

Despite these limitations, the results of the current study seem to indicate that stress-reactive rumination can be uniquely identified as a form of repetitive thinking in addition to emotion-focused rumination and worry. Future research should be aimed at bringing together various variables that are thought to play a role in juvenile depression and anxiety such as various forms of repetitive thinking, negative cognitive styles, and puberty. The inclusion of life events and daily hassles makes it possible to contribute to a further understanding of depression and anxiety in youth within a diathesis-stress account.

\section{References}

Abela, J. R. Z., Aydin, C., \& Auerbach, R. (2007). Responses to depression in children: Reconceptualizing the relation among response styles. Journal of Abnormal Child Psychology, 35, 913-927.

Abela, J. R. Z., Brozina, K., \& Haigh, E. (2002). An examination of the Response Styles Theory of depression in third and seventh grade children: a short term longitudinal study. Journal of Abnormal Child Psychology, 30(5), 515-527.

Abela, J. R. Z., \& Hankin, B. L. (2008). Cognitive vulnerability to depression in children and adolescents: a developmental psychopathology perspective. In J. R. Z. Abela \& B. L. Hankin (Eds.), Handbook of depression in children and adolescents (pp. 35-78). New York: The Guilford Press.

Abela, J. R. Z., Vanderbilt, E., \& Rochon, A. (2004). A test of the integration of the response styles and social support theories of depression in third and seventh grade children. Journal of Social and Clinical Psychology, 23(5), 653-674.

Abramson, L. Y., Metalsky, G., \& Alloy, L. B. (1989). Hopelessness depression: A theory-based subtype of depression. Psychological Review, 96(2), 358-372.

Alloy, L., Abramson, L., Hogan, M., Whitehouse, W., Rose, D., Robinson, M., et al. (2000). The Temple-Wisconsin cognitive vulnerability to depression project: lifetime history of axis I psychopathology in individuals at high and low cognitive risk for depression. Journal of Abnormal Psychology, 109(3), 403-418.

American Psychiatric Association (2000). Diagnostic and statistical manual of mental disorders (5th ed.). Washington DC: APA.

Bakker, F., van Wieringen, P., van der Ploeg, H., \& Spielberger, C. (1989). De Zelf-BeoordelingsVragenlijst voor kinderen. Lisse: Swets \& Zeitlinger.

Beck, A. (1967). Depression: Clinical, experimental and theoretical aspects. New York: Harper \& Row.

Blagden, J., \& Craske, M. (1996). Effects of active and passive rumination and distraction: a pilot replication with anxious mood. Journal of Anxiety Disorders, 10(4), 243-252.

Borkovec, T. (1994). The nature, functions, and origins of worry. In G. Davey \& F. Tallis (Eds.), Worrying: perspectives on theory, assessment and treatment (pp. 5-33). Chichester: John Wiley \& Sons.

Borkovec, T., Robinson, E., Pruzinsky, T., \& DePree, J. (1983). Preliminary exploration of worry: some characteristics and processes. Behaviour Research and Therapy, 21(1), 9-16. 
Burwell, R., \& Shirk, S. (2007). Subtypes of rumination in adolescence: associations between brooding, reflection, depressive symptoms, and coping. Journal of Clinical Child and Adolescent Psychology, 36(1), 56-65.

Calmes, C., \& Roberts, J. (2007). Repetitive thought and emotional distress: rumination and worry as prospective predictors of depressive and anxious symptomatology. Cognitive Therapy and Research, 30, 343-356.

Chorpita, B., Tracey, S., Brown, T., Collica, T., \& Barlow, D. (1997). Assessment of worry in children and adolescents: an adaptation of the Penn State Worry Questionnaire. Behaviour Research and Therapy, 35(6), 569-581.

Dugas, M., Freeston, M., Ladouceur, R., Rhéaume, J., Provencher, M., \& Boisvert, J.-M. (1998). Worry themes in primary GAD, secondary GAD, and other anxiety disorders. Journal of Anxiety Disorders, 12(3), 253-261.

Fresco, D., Frankel, A., Mennin, D., Turk, C., \& Heimberg, R. (2002). Distinct and overlapping features of rumination and worry: the relationship of cognitive production to negative affective states. Cognitive Therapy and Research, 26(2), 179-188.

Hankin, B. (2008). Stability of cognitive vulnerabilities to depression: a short-term prospective multiwave study. Journal of Abnormal Psychology, 117(2), 324-333.

Hankin, B. L., \& Abramson, L. Y. (2002). Measuring cognitive vulnerability to depression in adolescence: reliability, validity, and gender differences. Journal of Clinical Child and Adolescent Psychology, 31, 491-504.

Harvey, A., Watkins, E., Mansell, W., \& Shafran, R. (2004). Cognitive behavioral processes across psychological disorders: A transdiagnostic approach to research and treatment Oxford: Oxford University Press.

Hayton, J. C., Allen, D. G., \& Scarpello, V. (2004). Factor retention decisions in exploratory factor analysis: a tutorial on parallel analysis. Organizational Research Methods, 7(2), 191-205.

Hong, R. (2007). Worry and rumination: differential associations with anxious and depressive symptoms and coping behavior. Behaviour Research and Therapy, 45, 277-290.

Kovacs, M. (1981). Rating scales to assess depression in school-aged children. Acta Paedopsychiatrica, 46, 305-315.

Leen-Feldner, E., Feldner, M., Tull, M., Roemer, L., \& Zvolensky, M. (2006). An examination of worry in relation to anxious responding to voluntary hyperventilation among adolescents. Behaviour Research and Therapy, 44, 1803-1809.

Lyubomirsky, S., \& Tkach, C. (2004). The consequences of dysphoric rumination. In C. Papageorgiou \& A. Wells (Eds.), Depressive rumination: nature, theory, and treatment (pp. 21-41). Chichester: John Wiley \& Sons.

Molina, S., Borkovec, T., Peasley, C., \& Person, D. (1998). Content analysis of worrisome streams of consciousness in anxious and dysphoric participants. Cognitive Therapy and Research, 22(2), 109-123.

Muris, P. (2007). Normal and abnormal fear and anxiety in children and adolescents. Oxford: Elsevier.

Muris, P., Merckelbach, H., Ollendick, T., King, N., \& Bogie, N. (2002). Three traditional and three new childhood anxiety questionnaires: their reliability and validity in a normal adolescent sample. Behaviour Research and Therapy, 40, 753-772.

Muris, P., Roelofs, J., Meesters, C., \& Boomsma, P. (2004). Rumination and worry in nonclinical adolescents. Cognitive Therapy and Research, 28(4), 539-554.

Muris, P., Roelofs, J., Rassin, E., Franken, I., \& Mayer, B. (2005). Mediating effects of rumination and worry on the links between neuroticism, anxiety and depression. Personality and Individual Differences, 39, 1105-1111. 
Nolen-Hoeksema, S. (1987). Sex differences in unipolar depression: evidence and theory. Psychological Bulletin, 101(2), 259-282.

Nolen-Hoeksema, S. (1991). Responses to depression and their effects on the duration of depressive episodes. Journal of Abnormal Psychology, 100(4), 569-582.

Nolen-Hoeksema, S. (1998). Ruminative coping with depression. In J. Heckhausen \& C. Dweck (Eds.), Motivation and self-regulation across the life span (pp. 237-256). Cambridge: Cambridge University Press.

Nolen-Hoeksema, S. (2000). The role of rumination and depressive disorders and mixed anxiety/depressive symptoms. Journal of Abnormal Psychology, 109(3), 504-511.

Nolen-Hoeksema, S., \& Morrow, J. (1991). A prospective study of depression and posttraumatic stress symptoms after a natural disaster: the 1989 Loma Prieta earthquake. Journal of Personality and Social Psychology, 61(1), 115-121.

O'Connor, B. (2000). SPSS and SAS programs for determining the number of components using parallel analysis and Velicer's MAP test. Behavior Research Methods, Instrumentation, and Computers, 32, 396-402.

Papadakis, A. A., Prince, R. A., Jones, N. P., \& Strauman, T. J. (2006). Self-regulation, rumination, and vulnerability to depression in adolescent girls. Development and Psychopathology, 18, 815829.

Perrin, S., \& Last, C. (1997). Worrisome thoughts in children clinically referred for anxiety disorder. Journal of Clinical Child Psychology, 26(2), 181-189.

Roberts, J., Gilboa, E., \& Gotlib, I. (1998). Ruminative response style and vulnerability to episodes of dysphoria: gender, neuroticism, and episode duration. Cognitive Therapy and Research, 22(4), 401-423.

Robinson, M. (1997). The role of negative inferential style and stress-reactive rumination on negative inferences in the etiology of depression: Empirical investigation and clinical implications. Unpublished doctoral dissertation, Temple University.

Robinson, M., \& Alloy, L. (2003). Negative cognitive styles and stress-reactive rumination interact to predict depression: a prospective study. Cognitive Therapy and Research, 27(3), 275-292.

Roemer, L., \& Borkovec, T. D. (1993). Worry: Unwanted cognitive activity that controls unwanted somatic experience. In D. M. Wegner \& J. W. Pennebaker (Eds.), Handbook of mental control (pp. 220-238). Englewood Cliffs, NJ: Prentice Hall.

Sarin, S., Abela, J., \& Auerbach, R. (2005). The response styles theory of depression: a test of specificity and causal mediation. Cognition and Emotion, 19(5), 751-761.

Schwartz, J., \& Koenig, L. (1996). Response styles and negative affect among adolescents. Cognitive Therapy and Research, 20(1), 13-36.

Segal, Z., Williams, J., \& Teasdale, J. (2002). Mindfulness-based cognitive therapy for depression. A new approach to preventing relapse. New York: The Guilford Press.

Segerstrom, S., Tsao, J., Alden, L., \& Craske, M. (2000). Worry and rumination: repetitive thought as a concomitant and predictor of negative mood. Cognitive Therapy and Research, 24(6), 671-688.

Spielberger, C., Edwards, D., Lushene, R., Montuori, J., \& Platzek, D. (1973). State-Trait Anxiety Inventory for Children. Palo Alto: Consulting Psychologists Press.

Spielberger, C., Gorsuch, R., \& Lushene, R. (1970). STAI Manual for the State-Trait Anxiety Inventory. Palo Alto, California: Consulting Psychologists Press.

Starcevic, V. (1995). Pathological worry in major depression: a preliminary report. Behaviour Research and Therapy, 33(1), 55-56.

Timbremont, B., \& Braet, C. (2001). Psychometrische evaluatie van de Nederlandstalige Children's Depression Inventory [Psychometric evaluation of the Dutch Children's Depression Inventory]. Gedragstherapie, 34(3), 229-242. 


\section{CHAPTER 2}

Timbremont, B., \& Braet, C. (2002). Children's Depression Inventory: Nederlandstalige versie [Children's Depression Inventory: Dutch version]. Lisse: Swets \& Zeitlinger.

Timbremont, B., Braet, C., \& Dreessen, L. (2004). Assessing depression in youth: Relation between the Children's Depression Inventory and a structured interview. Journal of Clinical Child and Adolescent Psychology, 33, 149-157.

Watkins, E. (2004). Appraisals and strategies associated with rumination and worry. Personality and Individual Differences, 37, 679-694.

Watkins, E. (2008). Constructive and unconstructive repetitive thought. Psychological Bulletin, 134(2), 163-206.

Watkins, E., Moulds, M., \& Mackintosh, B. (2005). Comparisons between rumination and worry in a non-clinical population. Behaviour Research and Therapy, 43, 1577-1585.

Weems, C., Silverman, W., \& La Greca, A. (2000). What do youth referred for anxiety problems worry about? Worry and its relation to anxiety and anxiety disorders in children and adolescents. Journal of Abnormal Child Psychology, 28(1), 63-72.

Wells, A., \& Papageorgiou, C. (2004). Metacognitive therapy for depressive rumination. In C. Papageorgiou \& A. Wells (Eds.), Depressive rumination: nature, theory and treatment (pp. 259273). Chichester: John Wiley \& Sons Ltd.

Ziegert, D., \& Kistner, J. (2002). Response styles theory: Downward extension to children. Journal of Clinical Child and Adolescent Psychology, 31(3), 325-334. 


\title{
Chapter 3
}

\section{The influence of emotion-focused rumination and distraction on depressive symptoms in non-clinical youth: a meta-analytic review ${ }^{1}$}

Lea Rood, Jeffrey Roelofs, Susan M. Bögels, Susan Nolen-Hoeksema,

Erik Schouten

\begin{abstract}
This review examined evidence for some core predictions of the response styles theory (RST) concerning the relation between response styles and symptoms of depression and gender differences in the use of response styles in non-clinical children and adolescents. In summarizing the literature, effect sizes (pooled correlation coefficients) were calculated for cross-sectional and longitudinal studies. Stability of the obtained effect sizes was evaluated by means of a fail-safe $\mathrm{N}$ analysis. Results indicated that stable and significant effect sizes were found for rumination being associated with concurrent and future levels of depression. When controlling for baseline levels of depression, effect sizes for rumination and distraction were not stable, indicating that these findings should be interpreted with considerable caution. Finally, significant and stable effect sizes for gender differences in response styles were found only for rumination among adolescents. Taken together, the findings partly support the predictions of the response styles theory examined in this meta-analysis and may implicate that rumination is a cognitive vulnerability factor for depressive symptoms among adolescents.
\end{abstract}

\footnotetext{
${ }^{1}$ Published in: Clinical Psychology Review, 29, 607-616.
} 


\section{Introduction}

Depression is common among youth. Several epidemiological studies have revealed point-prevalence rates of major depressive disorder ranging from $0.4 \%$ to $2.5 \%$ in children and $0.4 \%$ to $8.3 \%$ in adolescents (e.g., Birmaher et al., 1996; Lewinsohn, Rohde, \& Seeley, 1998). The same picture emerges for dysthymic disorder, with rates of $0.6 \%$ to $1.7 \%$ in children and $1.6 \%$ to $8.0 \%$ in adolescents (e.g., Birmaher et al., 1996). Lewinsohn et al. (1998) reported in their large scale epidemiologic study, lifetime prevalence rates of major depression of about $20 \%$ in 14-18 year old adolescents. Further, depression onset rates are considered equally distributed in young boys and girls but begin to rise in girls (compared to boys) during adolescence (e.g., Kessler, McConagle, Swartz, Blazer, \& Nelson, 1993; Lewinsohn et al., 1998). The gender difference in rates of depression is also found in adults with women being about twice as likely as men to experience a lifetime episode of major depression (see for a review Kuehner, 2003). Relapse and recurrence rates for depression are estimated at $30-70 \%$ for children and $20-54 \%$ in adolescents (e.g., Birmaher, Arbelaez, \& Brent, 2002). Thus, these numbers indicate that depression in youth is prevalent and warrants examination of factors that contribute to the onset and maintenance of depressive symptoms.

\section{Rumination as a form of negative thinking}

Since the pioneering work of Beck $(1967,1979)$, cognitive approaches have become highly influential in the conceptualization and treatment of depression. In the past decade, there has been an increased interest in examining negative thinking processes such as rumination, as a concomitant of depression (see special issue Cognitive Therapy and Research, 2004). A number of definitions of rumination have been proposed (see Papageorgiou \& Wells, 2004). Nolen-Hoeksema (1991) conceptualizes rumination in the context of a depressive mood (i.e., emotion-focused rumination) by referring to rumination as "repetitively focusing on the fact that one is depressed, on one's symptoms of depression, and on the causes, meanings, and consequences of depressive symptoms" (Nolen-Hoeksema, 1991, p. 569). Despite some overlap, emotion-focused rumination can be distinguished from related constructs such as negative automatic thoughts, self-focused attention, and private self-consciousness (see for a review Papageorgiou \& Wells, 2004).

Of particular interest is the difference between other forms of repetitive thinking that are unconstructive (Watkins, 2008), such as stress-reactive rumination and worry. Stress-reactive rumination refers to the tendency to ruminate in response to daily hassles and/or life-events and has been associated with concurrent depressive symptoms (Garnefski, Boon, \& Kraaij, 2003; Jose \& Brown, 2008;

Kennedy, 2006; Li, DiGiuseppe, \& Froh, 2006) as well as with increases in 
A META-ANALYTIC REVIEW

depressive symptoms (Robinson \& Alloy, 2003; Skitch \& Abela, 2008). With respect to worry, there is overlap in content between rumination and worry (Borkovec, 1994) in the sense that these constructs may seem similar with respect to thought process (repetitive, negative, unproductive thoughts) and problem-solving qualities (e.g., Carver, 1996; Davey, 1994). However, they differ with respect to content and goal orientation (e.g., Segerstrom, Tsao, Alden, \& Craske, 2000; Watkins, Moulds, \& Mackintosh, 2005). That is, rumination is thought to be past-oriented, while worrying is much more future-oriented (Watkins et al., 2005). Further, although from a theoretical point of view, rumination would be specifically associated with depression and worry with anxiety, there is evidence from several studies conducted in adult samples as well as in youth that rumination is also related to anxiety and/or that worry is also linked to depression (e.g., Calmes \& Roberts, 2007; Fresco, Frankel, Mennin, Turk, \& Heimberg, 2002; Hong, 2007; McLaughlin, Borkovec, \& Sibrava, 2007; Muris, Roelofs, Meesters, \& Boomsma, 2004; Segerstrom et al., 2000; Starcevic, 1995; Watkins, 2004; Watkins et al., 2005).

The Response Styles Theory (RST) in adults

Nolen-Hoeksema (1987) argued that one reason women have higher levels of depression than men is because women are more likely to ruminate when confronted with negative mood, whereas men engage in distracting activities. A ruminative response style maintains or may even exacerbate a depressive mood. The response styles theory posits another coping strategy to deal with negative mood, namely distraction. Individuals who engage in distraction might experience an alleviation of depressive mood states (Nolen-Hoeksema, 1987). A number of studies have found support for the predictions of the response styles (i.e., rumination and distraction) in adult samples. There is good evidence for the prediction that rumination maintains and exacerbates a depressive mood in adults (e.g., Just \& Alloy, 1997; NolenHoeksema, 2000; Nolen-Hoeksema \& Morrow, 1993; Nolen-Hoeksema, Morrow, \& Fredrickson, 1993). Rumination is also associated with negatively biased thinking, poor problem solving, impaired motivation, and inhibition of instrumental behaviour (see Lyubomirsky \& Tkach, 2004 for a review). The hypothesized beneficial influence of distraction on depressive symptoms has not been clearly demonstrated (e.g., Just \& Alloy, 1997; Nolen-Hoeksema \& Morrow, 1993).

Some authors have divided the concept of emotion-focused rumination into two specific forms of emotion-focused rumination, brooding and reflective pondering. Brooding reflects "a passive comparison of one's current situation with some unachieved standard" (Treynor, Gonzalez, \& Nolen-Hoeksema, 2003; p. 256), and can be regarded as maladaptive, while reflective pondering refers to "a purposeful turning inward to engage in cognitive problem solving to alleviate one's depressive symptoms" (Treynor et al., 2003; p. 256) and seems to represent the adaptive 
component of rumination. Indeed, there is some evidence to suggest that brooding is positively related to negative mood whereas reflection shows a negative relation to negative mood over time (Treynor et al., 2003). Interestingly, some studies have found support for the idea that rumination subfactor 'reflective pondering' might be beneficial with respect to current and future mood state (Roelofs, Huibers, Peeters \& Arntz, 2008; Treynor et al., 2003) or that it might have relatively more adaptive features with respect to cognitive biases, compared to brooding (Joormann, Dkane, \& Gotlib, 2006).

Another prediction of the RST relates to gender differences in the use of rumination and distraction. Most studies found that women have a greater tendency to ruminate than men (e.g., Butler \& Nolen-Hoeksema, 1994; Nolan, Roberts, \& Gotlib, 1998; Nolen-Hoeksema, Larson, \& Grayson, 1999; Nolen-Hoeksema et al., 1993). However, the assumption that men have a greater tendency to engage in distractive activities in response to sad mood is less frequently supported, with some studies supporting this assumption (e.g., Conway, Giannopoulos, \& Steifehofer, 1990), and others not (e.g., Butler \& Nolen-Hoeksema, 1994; Nolen-Hoeksema et al., 1993).

A ruminative response style has also been examined in respect to other forms of psychopathology in adult populations. Emotion-focused rumination seems to predict levels of anxiety (e.g. Fresco et al., 2002; Muris, Roelofs, Rassin, Franken, \& Mayer, 2005; Nolen-Hoeksema, 2000; Roberts, Gilboa, \& Gotlib, 1998; Watkins, 2004), and is associated with hypomania (Knowles, Tai, Christensen, \& Bentall, 2005), pathological gambling (Washington, 2006), social anxiety (Harvey, Ehlers, \& Clark, 2005; Kocovski, Endler, Rector, \& Flett, 2005), and maintenance of posttraumatic stress symptoms (Michael, Halligan, Clark, \& Ehlers, 2007; NolenHoeksema \& Morrow, 1991). Rumination is also related to lower subjective general sleep quality, even when controlling for depression, anxiety and anger, and to longer subjective sleep latency (Kirkegaard Thomsen, Mehlsen, Christensen, \& Zachariae, 2003), and sleep disturbance (Carney, Edinger, Meyer, Lindman, \& Istre, 2006). Finally, rumination has been related to binge drinking and symptoms of alcohol abuse in adults (e.g., Nolen-Hoeksema \& Harrell, 2002) and adolescent girls (e.g., NolenHoeksema, Stice, Wade, \& Bohon, 2007), and to self-injurious behaviours and suicidal ideation (e.g., Hilt, Cha, \& Nolen-Hoeksema, 2008; Miranda \& NolenHoeksema, 2007; Smith, Alloy, \& Abramson, 2006). Thus, these studies support the notion that rumination might be a transdiagnostic variable (see Harvey, Watkins, Mansell, \& Shafran, 2004).

The present review

During the last two decades, the majority of studies examining the role of rumination in the development of depression have been conducted in adults. However, there 
have also been a number of studies that have examined the predictions of the RST in youth samples. The aim of this meta-analytic review is to bring together the various research on the relation between emotion-focused rumination and distraction, and symptoms of depression in non-clinical youth, thereby testing some core predictions of the RST. We do not only review the various studies but also pool the effect sizes from individual studies into an overall weighted effect size. The purpose of this review was to answer the following three questions:

1. To what extent are emotion-focused rumination and distraction related to concurrent levels of depressive symptoms?

2. To what extent are rumination and distraction related to depressive symptoms over time (with and without controlling for initial levels of depressive symptoms)?

3. To what extent do boys and girls differ with respect to levels of rumination and distraction?

In examining these research questions, we provide an overview of cross-sectional and longitudinal studies. In order to examine the extent to which rumination and distraction are related to depressive symptoms (i.e., research questions 1 and 2), we relied on zero-order correlation coefficients as an index of effect size. In the case necessary information was not reported in a paper, the authors were kindly requested to provide the missing information. In the computation of the overall effect-size weighted by sample size, we included the Pearson correlation coefficients between rumination and depressive symptoms and between distraction and depressive symptoms separately. In order to answer question 2, we pooled the partial Pearson correlation coefficients when controlling for initial symptoms of depression. For research question 3 , mean differences were calculated for rumination and distraction separately between boys and girls. These mean differences and standard deviations were transformed into a Cohen's $d$ for each study and were then pooled into a common Cohen's $d$. With regard to the stability of the effect-sizes, we used the failsafe $\mathrm{N}$ procedure to assess the number of non-significant studies which would be needed to change a statistically significant effect-size to a statistically non-significant effect-size (Long, 2001). More specifically, we used the Orwin's Fail-Safe N procedure using effect size measures (Orwin, 1983). The formula is as follows:

$N_{f s}=N_{o}\left(d_{o}-d_{e}\right) / d_{e}-d_{f s}$

where

$\mathrm{N}_{\mathrm{fs}}=$ the number of studies needed to reverse the statistically significant findings

$\mathrm{N}_{\mathrm{o}}=$ the number of studies used in the meta-analysis

$\mathrm{d}_{\mathrm{o}}=$ the mean effect size obtained for the meta-analysis 


$$
\begin{aligned}
& d_{e}=\text { the criterion effect size value of the fail-safe studies } \\
& d_{f s}=\text { the mean effect size of the fail-safe studies }
\end{aligned}
$$

In line with suggestions from Orwin (1983), we used the Cohen's specifications of .5 as a "medium" effect size as criterion effect size $\left(d_{e}\right)$. The $d_{f s}$ is usually assigned a value of 0 .

\section{Method}

In order to identify relevant papers, we have searched Embase, Medline, Online Contents, ERIC, PsycArticles, PsycINFO, PubMed, SocINDEX (EBSCO), and Web of Science, on keywords 'ruminat', 'child", 'adolescen*', 'response styles' and 'depression' until May 2008. In addition to this search strategy, we applied reference tracking to identify (un)published papers that have not been identified on the world wide web. Only articles on emotion-focused rumination and distraction (as postulated by the RST) were included in this meta-analytic review. Some studies have included other variables in addition to rumination and depression. In these instances, we will briefly review these findings but the main focus will be on the three research questions.

It is noteworthy to mention that a handful of studies have examined predictions of the RST in clinical youth samples thereby prelimarily focusing on the role of emotion-focused rumination (i.e., Goodyer, Herbert \& Tamplin, 2003; Kuyken, Watkins, Holden, \& Cook, 2006; Park, Goodyer, \& Teasdale, 2005; Wilkinson \& Goodyer, 2006). We decided not to include these studies in this meta-analytic review, because these studies differ in methodological respect by using different study designs and selected samples (e.g., individuals at risk for depression). As a consequence, the effect sizes might not be comparable with effect sizes from nonclinical studies.

Note that from this point forward we will use 'rumination' when referring to the concept of emotion-focused (or depressed) rumination.

\section{Evidence from cross-sectional studies}

A number of studies have examined the cross-sectional relations between rumination (and distraction) and symptoms of depression in children (Abela, Vanderbilt, \& Rochon, 2004; Dancho, 2004; Grant et al., 2004; Ziegert \& Kistner, 2002; Weir \& Jose, 2008) and adolescents (Muris et al., 2004; Muris, Fokke, \& Kwik, 2009; Papadakis, Prince, Jones, \& Strauman, 2006). We will review the findings from these studies below. 
A META-ANALYTIC REVIEW

Cross-sectional studies in child samples

Ziegert and Kistner (2002) found that rumination was positively related to concurrent depressive symptoms $(r=.25)$, whereas distraction was negatively related to depressive symptoms ( $r=-.16)$. Interestingly, the study also examined the interaction between rumination and distraction in a regression equation predicting depressive symptoms. The combination of a strong tendency to ruminate and a low ability to distract oneself were hypothesized to predict high depression scores, but this interaction was not statistically significant. Dancho (2004) also found that rumination and depression were significantly related ( $r=.59$ ), and Grant et al. (2004) found a significant association between rumination and mixed depressive and anxiety symptoms in African-American girls $(r=.48)$. Moreover, Grant et al. (2004) found evidence to suggest that rumination mediated the relation between sex and depressive symptoms. That is, (female) sex positively predicted ruminative response style, which in turn positively predicted the level of depressive symptoms. Abela et al. (2004) examined the relation between rumination, distraction, problem solving, and symptoms of depression in third graders and seventh graders. Rumination was significantly related to depressive symptoms in both groups ( $r=.34$ and $r=.49$ respectively). Both distraction and problem solving were unrelated to depressive symptoms in third graders ( $r=.01$ and $r=-.12$, respectively), but were negatively related to depressive symptoms in seventh graders ( $r=-.25$ and $r=-.42$ respectively). This might indicate that third graders might utilize different styles compared to seventh graders as the response styles to sad mood have not been developed in a consistent way (cf. Driscoll, 2004; Turner \& Cole, 1994). Abela et al. (2004) went one step further by examining the role of social support in relation to rumination and depressive symptoms. In third graders, there was no significant mediational relation between rumination and social support and depressive symptoms. As hypothesized, social support partially mediated the relation between rumination and depressive symptoms in seventh graders, and, in turn, rumination partially mediated the relation between low social support and depressive symptoms. Finally, Weir and Jose (2008) found that rumination was significantly associated with concurrent levels of depressive symptoms $(r=.57)$. Furthermore, rumination partly mediated the relationship between stress and depressive symptoms, but this mediating effect disappeared when perceived control was added as a second mediating variable.

\section{Cross-sectional studies in adolescent samples}

Muris et al. (2004) examined the relations between rumination and depression and included attributional style and worry in the prediction of depressive and anxiety symptoms. They found that rumination and depression were positively correlated $(r=.34)$, whereas distraction was significantly negatively related to depression ( $r=-$ .35). Another study by Muris et al. (2009) found that rumination and level of 
depressive symptoms were positively related $(r=.49)$. Based on the work of Treynor et al. (2003), who found support for a two-factor model of rumination, Papadakis et al. (2006) investigated the influence of the two rumination components (i.e., brooding and reflective pondering) on depressive symptoms and found that both brooding and reflective pondering correlated significantly with depressive symptoms ( $r=.51$ and $r=.20$ respectively).

\section{Statistical pooling and conclusion}

Table 1 displays an overview of the study characteristics and effect-sizes (Pearson correlation coefficients) of the studies described here. Note that the longitudinal studies (see 4.1 and 4.2) also have reported cross-sectional findings. These findings

Table 1: Overview of the effect-sizes (zero-order correlations) found in cross-sectional studies examining the relations between rumination and distraction and depressive symptoms

\begin{tabular}{lllll}
\hline & $N$ & Mean age & Rumination & Distraction \\
\hline Abela et al., 2002* & 130 & $8.8^{1}$ & .23 & -.07 \\
Abela et al., 2004 & 184 & $12.8^{2}$ & .53 & -.08 \\
& 70 & $8.3^{1}$ & .34 & .01 \\
Abela et al., 2007* & 190 & $12.3^{2}$ & .49 & -.25 \\
Broderick \& Korteland, 2004* & 140 & $9.8^{1}$ & .33 & -.24 \\
Burwell \& Shirk, 2007* & 79 & $10.1^{1}$ & .38 & - \\
Dancho, 2004 & 168 & $13.6^{2}$ & .66 & - \\
Driscoll, 2004* & 31 & $10.4^{1}$ & .59 & - \\
Grabe et al., 2007* & 303 & $4.8^{1}$ & .16 & -.12 \\
Grant et al., 2004 & 316 & $11.2^{1}$ & .41 & - \\
Hankin, 2008 & 622 & $12.7^{2}$ & .48 & - \\
Muris et al., 2004 & 350 & $14.5^{2}$ & .28 & - \\
Muris et al., 2009 & 337 & $14.0^{2}$ & .34 & -.35 \\
Nolen-Hoeksema et al., 2007* & 231 & $15.3^{2}$ & .49 & - \\
Papadakis et al., 2006 & 486 & $13.5^{2}$ & $.52^{3}$ & - \\
Schwartz \& Koenig, 1996 & 223 & $14.5^{2}$ & $.51^{3}$ & - \\
Weir \& Jose, 2008 & 397 & $16.0^{2}$ & .58 & - \\
Ziegert \& Kistner, 2002 & 310 & $10.5^{1}$ & .57 & - \\
\hline
\end{tabular}

Note. *cross-sectional findings from longitudinal studies (correlation between baseline measurement of rumination and depressive symptoms); 'sample regarded as 'child sample'; 'sample regarded as 'adolescent sample'; ${ }^{3}$ correlations between component brooding and depressive symptoms.

have been included in the estimation of the overall effect size for cross-sectional studies. We computed a mean effect size for the cross-sectional findings using zeroorder correlations. The pooled effect size showed that the strength of the association between rumination and depression was moderate to high ( $r=.44,95 \%$ Confidence Interval $=.42$ to $.47, \mathrm{~N}_{\mathrm{fs}}=65$ ). The pooled correlation for distraction was modest ( $r=-$ 
$.19,95 \%$ Confidence Interval= -.24 to $-.14, \mathrm{~N}_{\mathrm{fs}}=7$ ). As the effect sizes for children seemed to be substantially lower than those for adolescents, we decided to pool the correlation coefficients for child and adolescent samples separately. Regarding the cross-sectional findings, the mean effect size for rumination was moderate $(r=.36$, $95 \%$ Confidence Interval= .31 to $.40, \mathrm{~N}_{\mathrm{fs}}=23$ ) for the child samples, whereas for the adolescent samples, the mean effect size was moderate to high $(r=.48,95 \%$ Confidence Interval= .46 to $\left..51, \mathrm{~N}_{\mathrm{fs}}=38\right)$. The pooled correlation for distraction was low $\left(r=-.13,95 \%\right.$ Confidence Interval= -.20 to $\left.-.06, \mathrm{~N}_{\mathrm{fs}}=2\right)$ for the child samples and low to moderate ( $r=-.26,95 \%$ Confidence Interval= -.32 to $\left.-.19, \mathrm{~N}_{\mathrm{fs}}=5\right)$ for the adolescent samples. The evidence from the overall pooling of findings from crosssectional studies reviewed here seems to indicate that rumination and distraction are indeed significantly related to depressive symptoms in children and adolescents. The fail-safe $\mathrm{N}$ procedure indicates that one may have confidence in the stability of the effect sizes pertaining to rumination. However, the effect sizes for distraction should be interpreted with considerable caution as it is conceivably possible that 2, 5 or 7 studies with non-significant findings could have been overlooked because of their failure to be published or as a matter of oversight in the literature review.

\section{Evidence from longitudinal studies}

Although cross-sectional studies are important for examining relationships between the various variables involved in the RST, it is important to note that emotion-focused rumination is postulated as a variable that is thought to maintain or worsen depressive mood state. Therefore, longitudinal studies are necessary to further understand the influence of emotion-focused rumination on depressive mood.

A number of longitudinal studies have addressed the influence of rumination and distraction on depression in children (Abela, Brozina, \& Haigh, 2002; Abela, Aydin \& Auerbach, 2007; Broderick \& Korteland, 2004; Driscoll, 2004; Grabe, Shibley Hyde, \& Lindberg, 2007) and adolescents (Burwell \& Shirk, 2007; Hankin, 2008; Nolen-Hoeksema et al., 2007; Schwartz \& Koenig, 1996). Note that we report zeroorder correlations as well as partial correlations when controlling for initial levels of depressive symptoms. The longitudinal studies vary with respect to the intervals between baseline and follow-up measurement(s), ranging from five weeks to three years. Consequently, we reported effect sizes (correlation coefficients) for the smallest and widest time-windows (see Table 2) as well as the effect sizes of crosssectional findings (see Table 1). We will review the findings from child and adolescent samples below. 


\section{Longitudinal studies in child samples}

Broderick and Korteland (2004) found that rumination and depressive symptoms were associated cross-sectionally $(r=.38)$ as well as longitudinally at one-year followup ( $r=.11$, partial $r=-.17)$ and at two-year follow-up $(r=.20$, partial $r=.02)$. The study of Abela et al. (2002) showed that baseline rumination was significantly related to concurrent levels of depressive symptoms in third graders $(r=.23)$ and in seventh graders $(r=.53)$. The associations between baseline rumination and depressive symptoms six weeks later were modest in third graders $(r=.21)$ and substantial in seventh graders ( $r=.54)$. Rumination predicted increases in depressive symptoms over a six week period equally in third graders and seventh graders ( $p r=.17$ for the entire sample). From a developmental point of view, these results suggest that rumination might even make young children vulnerable to depression. Distraction was not significantly related to concurrent depressive symptoms in third and seventh graders ( $r=-.07$ and $r=-.08$, respectively). The use of a distractive response style was not significantly related to a decrease of depressive symptoms over time in both age groups ( $r=-.07$ and $r=-.11$, respectively). The partial correlation for the entire sample was not significant ( $p r=-.01$ ). Abela et al. (2002) further found that hopelessness and low self-esteem partially mediated the relation between rumination and increases in depressive symptoms over time (six weeks). This means that children who have a strong tendency to ruminate in response to depressive feelings are likely to gradually experience more feelings of hopelessness and/or low self-esteem over time, which in turn leads to increases in depressive symptoms. The authors suggest an integration of the Response Styles Theory and the Hopelessness Theory of Abramson, Metalsky, and Alloy (1989) in children.

Another study by Abela et al. (2007) tested the response styles theory in a sample of children of parents with a history of depression. Although children with a depressed parent might be at greater risk for depression than other children, we included this study because the sample comprises a community sample and the study design did not differ methodologically from the other studies included in the present review. Rumination was significantly related to concurrent depressive symptoms ( $r=.33)$ and to depressive symptoms six weeks later $(r=.39)$. Rumination significantly predicted increases in depressive symptoms $(p r=.20)$. A combined scale of distraction and problem-solving was negatively related to concurrent $(r=-.24)$ and to follow-up depressive symptoms $(r=-.28)$, and significantly predicted decreases in depressive symptoms over time ( $p r=-.27)$. Interestingly, Abela and colleagues computed ratio scores of response styles by dividing rumination scores by distraction/problem solving scores, and examined the effects of high ratio scores (high rumination/low distraction) and low ratio scores (low rumination/high distraction) on levels of depression. They found that the ratio of high rumination and low 
distraction/problem solving was more strongly related to increases in depressive symptoms than either response style alone.

Grabe and colleagues (2007) found that baseline rumination was significantly associated with concurrent depressive symptoms $(r=.41)$ and two-year follow-up depressive symptoms $(r=.38)$. The partial correlation was, however, not significant ( $p r=-.07)$. Further, the authors tested a mediation model in which rumination and body shame were found to mediate the relation between self-surveillance (having a constant focus on one's physical appearance) and depressive symptoms in early adolescent girls.

Driscoll (2004) tested the predictions from the response styles theory in second to seventh grade children in a longitudinal design with a baseline and one follow-up measurement at 9 to 11 months. The correlation between baseline rumination and concurrent depressive symptoms was quite modest for the entire sample $(r=.16)$. The correlations between baseline rumination and the level of depressive symptoms at follow-up were significant for the entire sample $(r=.13$, $p r=.04)$ and for the $6^{\text {th }} / 7^{\text {th }}$ graders $(r=.20)$, but not for the $2 / 3^{\text {rd }}$ graders and $4^{\text {th }} / 5^{\text {th }}$ graders ( $r=.09$ and $r=.12$ respectively). Baseline distraction significantly related to concurrent depressive symptoms ( $r=-.12)$. Distraction was however not significantly related to follow-up depressive symptoms ( $r=-.05$ and $p r=.03)$. Regression analyses showed that neither rumination nor distraction significantly predicted changes in depressive symptoms for all age groups over time. To conclude, there is mixed evidence for rumination and distraction to predict increases in depression over time.

\section{Longitudinal studies in adolescent samples}

Schwartz and Koenig (1996) found that rumination was related to concurrent depressive symptoms $(r=.58)$. Controlling for initial depressive symptoms, distraction, attributional style, and self-consciousness, rumination made a unique but modest contribution to the prediction of increases in depressive symptoms over a time period of six weeks $(p r=.15)$. Interestingly, when including gender as a moderator in the analysis, rumination predicted future depressive symptoms only in girls. Controlling for baseline depressive symptoms, attributional style, self-consciousness and rumination, distraction was not significantly related to changes in depression scores over time $(p r=.01)$. The required effect sizes, i.e., the zero-order correlation coefficients between baseline rumination and follow-up depressive symptoms, and the zero-order correlations between baseline distraction and baseline/follow-up depression were not reported in the study and could not be provided by the original authors.

Burwell and Shirk (2007) investigated the relationship of the 'brooding' and 'reflection' components of rumination with depressive symptoms in adolescents over a time period of 1.5 years with time intervals of 6 to 8 months. A moderated 
mediational model with gender as a moderating variable was also examined. The authors found that brooding was related cross-sectionally $(r=.69)$ and longitudinally $(r=.53)$ to depressive symptoms. When controlling for baseline depressive symptoms, brooding was moderately associated with depressive symptoms ( $p r=.33$ ).

Table 2: Overview of the effect-sizes (zero-order correlations) found in longitudinal studies examining the relations between rumination and distraction and depressive symptoms. Partial correlation coefficients are presented in parentheses

\begin{tabular}{lllll}
\hline Longitudinal findings & $N$ & Mean age & Rumination & Distraction \\
\hline Abela et al., 2002 & 123 & $8.8^{1}$ & .21 & -.07 \\
& 184 & $12.8^{2}$ & .54 & -.11 \\
Abela et al., 2007 & 307 & & {$[.17]$} & {$[-.01]$} \\
Broderick \& Korteland, 2004 & 140 & $9.8^{1}$ & $.39[.20]$ & $-.28[-.27]$ \\
Burwell \& Shirk, 2007 & 79 & $10.1^{1}$ & $.11 / .20^{\mathrm{a}}[-.17 / .02]^{\mathrm{a}}$ & - \\
Driscoll, 2004 & 127 & $13.6^{2}$ & $.50[.10]$ & - \\
Grabe et al., 2007 & 279 & $4.8^{1}$ & $.13[.04]$ & $-.05[.03]$ \\
& 374 & $11.2^{1}$ & $.38[-.07]$ & - \\
Hankin, 2008 & {$[295]$} & & & - \\
Nolen-Hoeksema et al., 2007 & $303 /$ & $14.5^{2}$ & $.22 / .23^{\mathrm{a}}[.02 / .06]^{\mathrm{a}}$ & - \\
& 345 & & & $-34 / .21^{3 . \mathrm{a}}[.08 / .01]^{\mathrm{a}}$ \\
Schwartz \& Koenig, 1996 & 478 & $13.5^{2}$ & - & - \\
\hline
\end{tabular}

Note. 'sample regarded as 'child sample'; ${ }^{2}$ sample regarded as 'adolescent sample'; ${ }^{3}$ correlations between component brooding and depressive symptoms; ${ }^{a}$ correlation between baseline rumination and follow-up depressive symptoms for the smallest/widest time intervals.

Brooding alone, and the interaction between gender and brooding, significantly predicted increases in depressive symptoms over time. In girls, brooding mediated the relation between depressive symptoms at baseline and at follow-up, suggesting that brooding contributes to the maintenance of female depression. The subfactor reflective pondering however did not significantly predict changes in depression. On request, we received the correlations for the total rumination scale from the original author. The correlations between baseline rumination, and baseline and follow-up depressive symptoms were similar to the correlations with brooding $(r=.66$ and $r=.50$, respectively). The partial correlation between the total rumination scale and follow-up depressive symptoms was however substantially lower $(p r=.10)$ than the partial correlation between brooding and follow-up depressive symptoms. The correlations for the total rumination scale were included in the estimation of the overall effect size in order to be as consistent as possible with the other studies of which most use the total rumination scale. 
Nolen-Hoeksema et al. (2007) investigated the relationships between rumination subfactor brooding and depressive symptoms over a time period of four years in adolescent girls. Baseline brooding was highly related to concurrent depressive symptoms ( $r=.52$ ). The associations between baseline ruminative brooding and depressive symptoms over time were moderate at one-year $(r=.34, p r=.08)$, two-year $(r=.30)$, and three-year $(r=.21, p r=.01)$ follow-up. The effect of brooding predicting increases in depressive symptoms over time was not statistically significant. Depressive symptoms significantly predicted increases in brooding. Brooding was found to be a risk factor with a moderate effect size for onset of a major depressive episode (OR=2.23). Hankin (2008) aimed to examine the stability of the ruminative response style over a time period of five months (four measurements with five-week interval each), and found that rumination was moderately related to concurrent $(r=.28)$ and five month follow-up $(r=.23)$ depressive symptoms. The partial correlations were $p r=.02$ for the five-week and $p r=.06$ for the five-month time interval.

\section{Statistical pooling and conclusion}

With respect to the statistical pooling, a common weighted effect size of zero-order correlation coefficients was computed, followed by a pooling of the partial zero-order correlations, controlling for baseline depression levels. Two remarks need to be addressed. First, the necessary information for being able to pool the individual effect sizes was retrieved from the study or the original authors. The required effect sizes could be obtained for all studies, except one (i.e., Schwartz \& Koenig, 1996). In this particular study the zero-order correlation coefficient between baseline rumination and follow-up depressive symptoms, and the zero-order correlations between baseline distraction and baseline/follow-up depression were not reported and could not be provided by original authors. Second, in two studies (i.e., Abela et al., 2007; Schwartz \& Koenig, 1996), other covariates were included as well. We chose to include the reported partial correlations here, as controlling for covariates might decrease the amount of variance that can be accounted for by rumination or distraction, but on the other hand, covariates might also increase statistical power.

As the longitudinal studies have examined the influence of rumination on depressive symptoms over different time intervals, varying from weeks to years with several measuring moments, we decided to summarize the effect sizes (zero-order and partial correlations) for the smallest and the widest time intervals. The pooled effect size for the influence of rumination on depressive symptoms for the smallest time intervals (five weeks to one-and-a-half years) was moderate $(r=.32,95 \%$ Confidence Interval= .28 to $.36, \mathrm{~N}_{\mathrm{fs}}=20$ ). The pooled effect size for the influence of rumination on depressive symptoms for the widest time intervals (six weeks to three years) was moderate as well $\left(r=.30,95 \%\right.$ Confidence Interval= .26 to $.33, \mathrm{~N}_{\mathrm{fs}}=18$ ). We also pooled the effect sizes (zero-order correlations) for the child and adolescent 
samples separately. The mean effect size for rumination was low $(r=.27,95 \%$ Confidence interval= .21 to $\left..33, \mathrm{~N}_{\mathrm{fs}}=9\right)$ for the child samples and moderate $(r=.36$, $95 \%$ Confidence interval= .31 to $.42, \mathrm{~N}_{\mathrm{fs}}=13$ ) for the adolescent samples. The mean effect size of the zero-order correlations for distraction, included in only three studies, was low ( $r=-.11,95 \%$ Confidence Interval= -.19 to $-.04, \mathrm{~N}_{\mathrm{fs}}=1$ ). We did not pool separate effect sizes for child and adolescent samples because of the limited number of studies including distraction. The studies that included distraction used only one time-interval.

In a second step, the partial correlations were pooled. Only in the studies of Abela and colleagues $(2002$; 2007) partial correlations were reported. For the remaining studies, partial correlation coefficients were calculated on the basis of the zero-order correlations that were reported. The pooled partial correlation between rumination and follow-up depressive symptoms was significant but modest $(p r=.07$, $95 \%$ Confidence Interval= .03 to $.11, N_{\mathrm{fs}}=1$ ) for both the smallest and the widest time interval. The partial correlation between distraction and follow-up depressive symptoms was not significant ( $p r=-.03,95 \%$ Confidence Interval= -.09 to $.03, \mathrm{~N}_{\mathrm{fs}}=1$ ).

In sum, the pooled zero-order correlation coefficients showed that rumination is significantly and moderately related to symptoms of depression over time. This association is somewhat stronger in adolescent samples compared to child samples. When controlling for baseline depressive symptoms, rumination was still significantly but modestly related to depressive symptoms over time. With respect to the stability of the obtained effect-sizes, fail-safe $\mathrm{N}$ analysis showed that one can be confident with the effect sizes comprising the zero-order correlations for rumination. The effect sizes for the partial correlations for rumination and the effect sizes for distraction in general should be interpreted with considerable caution.

\section{Gender differences in rumination and distraction}

The response styles theory postulates that gender differences in depression severity can be accounted for by the coping strategy that is used. Girls are hypothesized to ruminate when confronted with negative mood, whereas boys are assumed to use distraction in reaction to a negative mood. We discuss the previously described studies with respect to gender differences in response styles in children and adolescents.

Evidence for gender differences in rumination and distraction

Of the previously described studies conducted in children, Ziegert and Kistner (2002) found that girls ruminated more than boys. Boys and girls did not differ on distraction scores. Similarly, Driscoll (2004) found that in the $6^{\text {th }} / 7^{\text {th }}$ grade, girls ruminated more than boys. In the lower grades there were no gender differences in rumination. 
Remarkably, however, the follow-up measurement one year later revealed no significant gender difference in rumination. Based on these findings, Driscoll suggests that response styles in young children seem to be instable, both across time and within a testing session. Other studies that have examined response styles in children have generally found no gender differences in rumination and distraction (Abela et al., 2002, 2004, 2007; Dancho, 2004; Weir \& Jose, 2008), with the exception of Abela et al. (2004), who found that $7^{\text {th }}$ grade boys had a stronger tendency to engage in distractive responses than $7^{\text {th }}$ grade girls. It may be that gender differences in rumination and distraction may not develop until preadolescence or (early) adolescence (Abela et al., 2002; 2004; 2007; Dancho, 2004). This makes sense as gender differences in rumination and distraction may cooccur or precede the gender difference in depressive symptoms that begins to rise in adolescence. Indeed, most studies that have examined response styles in adolescents show that girls have a stronger tendency to ruminate than boys (Grabe et al., 2007; Grant et al., 2004; Muris et al., 2004; Muris et al., 2009; Schwartz \& Koenig, 1996), with some exceptions (Burwell \& Shirk, 2007; Broderick \& Korteland, 2004). However, Burwell and Shirk (2007) did find that girls had significantly higher scores on 'reflective pondering' than boys. Broderick and Korteland (2004) explain their unexpected findings by the fact that a number of students with special learning needs were involved. No gender differences were found in the use of distractive responses for all studies in adolescents.

\section{Statistical pooling and conclusion}

In order to examine whether there are gender differences in the tendency to ruminate and distract across all studies, we pooled the mean differences on rumination and distraction. For two studies (i.e., Broderick \& Korteland, 2004; Hankin, 2008) necessary information could not be obtained from the authors. First, we computed Cohen's d's and the standard error of Cohen's d (SEd) as an index of effect size for each study. Subsequently we pooled the Cohen's d's and SEd's for child and adolescent samples separately because we expected that gender differences would be stronger in adolescent samples compared to child samples. For rumination, this resulted in a Cohen's $d=.14\left(\mathrm{SE} d=.05, \mathrm{~N}_{\mathrm{fs}}=4\right)$ for the child samples and a Cohen's $d=.36\left(\mathrm{SE} d=.04, \mathrm{~N}_{\mathrm{fs}}=26\right)$ for the adolescent samples. To examine whether these pooled effect sizes were significant we divided the pooled Cohen's $d$ by the pooled SEd for each sample. The pooled Cohen's $d$ divided by the pooled SEd was significant $(>1.96)$ for both samples, which means that the overall effect sizes show that girls ruminate significantly more than boys in child samples as well as in adolescent samples. For distraction, the pooled Cohen's $d$ for the child samples was $.02\left(\mathrm{SE} d=.07, \mathrm{~N}_{\mathrm{fs}}=1\right)$, while the pooled Cohen's $d$ for the adolescent samples was $.11\left(\mathrm{SE} d=.06, \mathrm{~N}_{\mathrm{fs}}=1\right)$. The pooled Cohen's $d$ divided by the pooled SE $d$ did not reach 
the level of significance $(<1.96)$ for both samples, which means that overall effect sizes show that there are no significant gender differences in distraction scores in child and adolescent samples.

Taken together, most studies have provided support for the hypothesis that girls report significantly more rumination than boys in adolescent samples. In child samples however, the findings regarding the occurrence of gender differences in rumination are mixed. No support was found for the gender difference in the tendency to distract in response to negative mood in children as well as in adolescents. The fail-safe $\mathrm{N}$ procedure showed that one can be confident about the gender difference for rumination in adolescents. The remaining effect sizes should be interpreted with considerable caution. Mean scores and standard deviations of rumination and distraction, and Cohen's $d$ 's and SEd's of the mean differences are presented in Table 3.

\section{General discussion}

This paper reviews the evidence for some core predictions of the Response Styles Theory in children and adolescents. More specifically, we examined (1) the extent to which rumination and distraction are related to concurrent levels of depressive symptoms; (2) the extent to which rumination and distraction are related to (changes in) depressive symptoms over time; and (3) the extent to which boys and girls differ with respect to levels of rumination and distraction. For this purpose, cross-sectional and longitudinal studies were identified in the literature and individual effect sizes were summarized into overall effect sizes weighted by sample size. The results can be summarized as follows. The results from the meta-analytic review indicate that rumination and lack of distraction were significantly associated with concurrent levels of depression, as well as the level of depressive symptoms over time. Despite the significant findings, stable effect-sizes were found for rumination but not for distraction. Thus, the findings with respect to distraction should be interpreted with considerable caution. When controlling for baseline levels of depression, rumination made a significant but modest contribution to changes in depressive symptoms, while distraction did not account for a significant portion of the variance in changes in depressive symptoms. However, the obtained effect-sizes were not stable indicating that these findings should also be interpreted with considerable caution. Thus, these findings partly lend credence to the prediction that response styles are associated with concurrent and future levels of depressive symptoms. Finally, significant gender differences in response styles were found only for rumination and effect sizes were found to be stable only in adolescents, which provides partial support for the prediction of gender differences in response styles. 
A META-ANALYTIC REVIEW

Table 3: Overview of the means and standard deviations of rumination/distraction scores for boys and girls separately. Cohen's $d$ and SEd are given for each study as an index of effect size

\begin{tabular}{|c|c|c|c|c|c|c|c|c|}
\hline \multirow[t]{2}{*}{ Study } & $N($ Girls $) /$ & \multicolumn{2}{|l|}{ Rumination } & \multicolumn{3}{|c|}{ Distraction } & \multicolumn{2}{|r|}{ Predictor/ } \\
\hline & & $\begin{array}{l}\text { Girls } \\
M(s d)\end{array}$ & $\begin{array}{l}\text { Boys } \\
M(s d)\end{array}$ & $\begin{array}{l}\text { Cohens } \\
d(\text { SEd) }\end{array}$ & $\begin{array}{l}\text { Girls } \\
M(s d)\end{array}$ & $\begin{array}{l}\text { Boys } \\
M(s d)\end{array}$ & $\begin{array}{l}\text { Cohens d } \\
\text { (SEd) }\end{array}$ & \\
\hline Abela et al., 2002 & $63 / 67$ & $16.42(6.97)$ & $14.31(7.01)$ & $.30(.18)$ & $10.80(4.10)$ & $11.32(4.74)$ & -.12 & CRSQ/CDI \\
\hline & $78 / 106$ & $14.70(8.07)$ & $13.88(7.62)$ & $.10(.15)$ & $7.90(3.95)$ & $8.45(3.60)$ & -.15 & CRSQ/CDI \\
\hline Abela et al., 2004 & $46 / 24$ & $14.08(6.18)$ & $13.08(5.81)$ & $.17(.25)$ & $10.15(3.83)$ & $7.13(3.78)$ & .79 & CRSQ/CDI \\
\hline & $145 / 45$ & $12.81(7.14)$ & $11.75(6.23)$ & $.15(.17)$ & $8.13(3.96)$ & $9.71(3.95)$ & -.40 & CRSQ/CDI \\
\hline Abela et al., 2007 & $71 / 69$ & $2.26(.66)$ & $2.15(.54)$ & $.18(.17)$ & $2.45(.75)$ & $2.40(.64)$ & .07 & CRSQ/CDI \\
\hline Broderick \&Korteland, 2004 & $48 / 31$ & $20.86(6.90)$ & $21.21(5.43)$ & $-.06(.23)$ & - & - & - & RSQ/CDI \\
\hline Burwell \& Shirk, 2007 & $98 / 70$ & $1.78(.44)$ & $1.71(.37)$ & $.17(.16)$ & - & - & - & $\mathrm{RRS} / \mathrm{CDI}$ \\
\hline Dancho, 2004 & $18 / 13$ & $62.06(8.92)$ & $65.30(11.20)$ & $-.33(.36)$ & - & - & - & RQ/CES-DC \\
\hline Driscoll, 2004 & $142 / 137$ & $5.01(1.97)$ & $4.62(2.09)$ & $.19(.12)$ & $5.29(2.26)$ & $5.44(2.45)$ & -.06 & CRSS/CDI \\
\hline Grabe et al., 2007 & $158 / 141$ & $1.82(.53)$ & $1.80(.58)$ & $.04(.12)$ & - & - & - & Short RRS/CDI \\
\hline Grant et al., 2004 & $330 / 292$ & $42.59(12.82)$ & $40.06(12.12)$ & $.20(.08)$ & - & - & - & RDQ-RS/YSR \\
\hline Muris et al., 2004 & $172 / 165$ & $30.80(6.45)$ & $26.57(6.41)$ & $.66(.11)$ & $27.17(6.65)$ & $28.72(6.91)$ & -.23 & CRSS/CDI \\
\hline Muris et al., 2009 & $133 / 98$ & $17.80(8.68)$ & $12.10(7.47)$ & $.70(.13)$ & - & - & - & CRSS/RCADS \\
\hline Muris et al., 2009 & $133 / 98$ & $6.22(6.44)$ & $4.33(5.38)$ & $.32(.13)$ & - & - & - & RSQ/RCADS \\
\hline Schwartz \& Koenig, 1996 & $245 / 152$ & $43.44(14.46)$ & $36.69(15.34)$ & $.46(.10)$ & $18.89(5.15)$ & $18.17(4.69)$ & .14 & $\mathrm{RSQ} / \mathrm{BDI}$ \\
\hline Weir \& Jose, 2008 & $172 / 138$ & $25.44(8.31)$ & $24.84(8.35)$ & $.07(.11)$ & - & - & - & Short RRS/CDI \\
\hline Ziegert \& Kistner, 2002 & $105 / 96$ & $5.29(1.72)$ & $4.56(1.89)$ & $.41(.14)$ & $5.60(2.02)$ & $5.75(1.99)$ & -.07 & CRSS/CDI \\
\hline
\end{tabular}

Note. $\mathrm{BDI}=$ Beck Depression Inventory. $\mathrm{CDI}=$ Children's Depression Inventory. CES-DC = Center for Epidemiological Studies - Depression Child. CRSQ = Children's Response Style Questionnaire. CRSS = Children's Response Styles Scale. RCADS = Revised Children's Anxiety and Depression Scale. $R D Q-R S=$ Responses to Depression Questionnaire - Rumination Scale. $R Q=$ Rumination Questionnaire. RSQ $=$ Response Style Questionnaire. RRS = Ruminative Response Scale (RSQ). YSR = Youth Self-Report. For longitudinal studies only means at baseline are reported. 


\section{CHAPTER 3}

Response styles and depressed mood

With respect to the findings of response styles and the relation to depressed mood, it is noteworthy to mention that the magnitude of the effect size seemed to depend on the type of study (cross-sectional studies yielded larger effect sizes), the type of sample (generally larger effect sizes were found in adolescents), and the response style being investigated (rumination yielded larger effect sizes than distraction). A number of explanations may account for these findings. To begin with, larger effect sizes were obtained in cross-sectional studies compared to longitudinal studies. Although it may be the case that these effect sizes are not the same, one may also expect that effect sizes for cross-sectional studies are larger due to the fact that these measures are completed at the same time in cross-sectional studies resulting in a shared variance. Despite this methodological explanation, there is also support for the notion that there is a reciprocal relationship between rumination and depressive symptoms (e.g., Moberly \& Watkins, 2008; Nolen-Hoeksema et al., 2007), which may indicate that rumination might also be part of the depressive symptomatology, rather than being a vulnerability factor alone. Currently, there is a need for experimental studies that manipulate either response styles or depressed mood. For example, Park, Goodyer and Teasdale (2004) conducted a mood induction experiment in line with Nolen-Hoeksema and Morrow (1993) to examine the effects of response styles on depressed mood. The results showed that rumination increased depressive mood in controls and clinically depressed and partially remitted adolescents. For distraction, a decrease in negative mood state was found in controls only. The current meta-analysis comprised studies with unselected samples. From the perspective of a diathesis-stress account, rumination might not be expected to show large associations with depression outside the experience of some kind of stressor. That stressor may be a depressive episode itself. As such, one may expect that associations between rumination and depressive symptoms may be larger in clinical samples.

An interesting finding was that effect sizes for rumination were larger in adolescents compared to children. This finding may implicate that response styles, in particular rumination, could be considered within a developmental timeline. The use of rumination as a coping strategy for dealing with stress or negative mood states has been shown to increase from late childhood through adolescence (Hampel \& Petermann, 2005). In this light, some researchers have pointed out that children may not have developed stable response styles yet (Abela et al., 2002; 2004). The findings from the current meta-analysis suggest that rumination is a stronger risk factor for depressive symptoms among adolescents compared to children. This finding is in line with recent research showing that cognitive variables such as attributional style may be less important for predicting depressive symptoms in younger children but more important as children age (e.g., Cole et al., 2008). 
With respect to the difference in effect size between response styles it may be that distraction might not be functional in all situations. That is, if someone engages in numerous different distractive activities for a short period of time in response to depressive feelings, one might not be able to set ones mind to the distractive activities. This way, distraction can eventually become an ineffective strategy despite the fact that these individuals have high distraction scores. Recently, NolenHoeksema, Wisco, and Lyubomirsky (2008) have concluded that distraction can only be an effective response to depression when one is sufficiently able to focus, concentrate, and dedicate oneself to the distractive activity. It might also be that distraction is actually not a response to a negative mood itself, but rather to the ruminative thoughts that occur in response to a negative mood. More specifically, high levels of distraction could serve as a buffer for the detrimental effects of rumination on mood. According to Abela et al. (2007), testing the predictions from the RST in the 'traditional' way becomes statistically problematic when individuals have high scores on both rumination and distraction, as high rumination is expected to relate to high levels of depressive symptoms, while high distraction is supposed to be associated with low levels of depression. To tackle this problem, Abela et al. (2007) suggest that a more adequate way to examine response styles is by applying a ratio approach. In this approach, the ratio of the rumination score divided by the distraction score serves as a predictor of depressive symptoms. Examining the ratio score between rumination and distraction in the prediction of depressive symptoms might be an interesting avenue for future research. A last explanation for the lack of evidence for an association between distraction and depressed mood concerns avoidance. It might be that the most adaptive way for youth to deal with depressed moods, which are a normal phenomenon in adolescence, is to "be with" the depressed mood, rather than to distract oneself from such moods. Only in case the depressed moods become chronic and dysfunctional, distraction might become an adaptive coping technique. As most of the studies reviewed did not investigate youth with clinical depression, this issue remain to be investigated.

Gender differences in response styles

Nolen-Hoeksema and Girgus (1994) have argued that 'sex differences in response styles precede the emergence of sex differences in depressive symptoms in adolescence' (p. 332). Thus, if gender differences in rumination are to explain gender differences in depression, gender differences in response style should ideally precede gender differences in depressive symptoms. Recent findings by Jose and Brown (2008) have shown that in a large community sample, gender differences in rumination in response to stress started to emerge at age 12 , while sex differences in depression emerged one year later, at age 13. Furthermore, two studies found that rumination mediated the relation between gender and depressive symptoms, which 
means that gender predicts depression through rumination (Grant et al., 2004; Jose \& Brown, 2008). In other words, the finding that girls report more depressive symptoms than boys might be explained by their stronger tendency to ruminate. As for gender differences in depressive symptoms, most studies of adolescents showed that girls reported significantly more depressive symptoms than boys. Almost all studies of child samples showed no gender differences in depressive symptoms. Overall, these findings are largely consistent with the theory that gender differences in depression rates emerge after the onset of adolescence (at or above age 13) around Tanner phase III, in mid-puberty (Angold, Costello, \& Worthman, 1998). The question whether the gender difference in ruminative response style is related to first onset, but not duration, of depressive symptoms, is an interesting one to be answered in future research.

\section{Clinical implications}

The findings from the present review may have clinical implications. A recent metaanalysis of Weisz, McCarty, and Valeri (2006) on the effects of psychotherapy for depression in youngsters revealed that in general, treatment methods for depression are less effective than for other disorders. This means that there is room for improvement regarding the treatment of depressive symptoms in children and adolescents. Nowadays, cognitive-behavioural therapies are quite popular for the treatment of depression in youth (Weisz et al., 2006). Based on their meta-analysis reviewing studies in samples with a mean age under 19, Weisz and colleagues (2006) suggest however that the emphasis on altering dysfunctional cognitions in youth might not be the most effective treatment of their depression. Recently, a preliminary study in depressed adolescents showed that cognitive-behavioural therapy (CBT) reduced brooding more than treatment as usual, while depression scores were equally reduced in both treatment groups. In remitted adolescents, the level of brooding was reduced even to levels of never-depressed adolescents in the cognitive-behavioural treatment group. The authors suggest that although CBT was

not superior to treatment as usual with respect to depressive symptoms, by reducing ruminative thought, CBT can play a role in relapse prevention of depression in adolescents (Wilkinson \& Goodyer, 2008).

Recent studies have rekindled interest in behavioural activation (BA) as a primary intervention for depression by showing that BA produced more remission in adults with major depression than cognitive therapy or antidepressants (Dimidjian et al., 2007). Behavioural interventions are favoured over more purely cognitive interventions for children with many disorders because they do not rely as much on the cognitive sophistication of a child in being able to understand the therapists' suggestions (Kazdin \& Weisz, 2003). Given concerns about the effectiveness of cognitive therapy for depression in children raised by Weisz et al. (2006), testing 
behavioural activation as an intervention for depressed youth who ruminate seems potentially fruitful.

Other treatment methods have been proposed aimed at reducing rumination and depression in adults, which could be suitable for children and adolescents as well. There is some preliminary evidence for the effectiveness of Attention Training in depressed patients (Papageorgiou \& Wells, 2000). Furthermore, Mclntosh (1996) suggests that rumination could be reduced by focusing on the present, which is an element in meditation, Zen Buddhism, and mindfulness (e.g. Segal, Williams \& Teasdale, 2002). In recurrently depressed but remitted adult patients, MindfulnessBased Cognitive Therapy (MBCT) has shown to be a promising preventive intervention, reducing risk of relapse or recurrence. MBCT aims at reducing typically depressive thinking processes such as rumination by encouraging the depressive client to 'observe' depressive thoughts instead of dwelling on them, this way disengaging from the thought (Teasdale et al., 2000). Watkins and colleagues (2007) recently provided preliminary evidence that an adaptation of MCBT specifically focused on reducing ruminations was an efficacious treatment for medicationrefractory residual depression in adults.

Broderick and Korteland (2004) have suggested examining the effectiveness of mindfulness-based approaches in the treatment of ruminative coping in children and adolescents. There is some preliminary evidence on the effectiveness of mindfulness techniques as an intervention to reduce depression in undergraduate students. That is, mindfulness has shown to be more effective compared to distraction in alleviating depressive symptoms (Broderick, 2005). Screening on rumination in early adolescence and consequently offering a mild mindfulness-based intervention could help reduce the risk for the development of major depressive disorder in early adulthood. The effectiveness of interventions that aim to reduce rumination and thereby depression in youngsters might be an important avenue for future prevention and treatment research.

\section{Future research}

Some recommendations for future research can be made. First, in most studies age ranges were restricted, with studies covering ages 8 to 12 and 12 to 18 . For future research, it is important to include a broader age range from childhood to late adolescence in order to be able to capture developmental changes in cognitive abilities, response styles and depression, in girls and in boys, taking gender differences into account. An interesting variable to include might be puberty, as it is known that puberty is correlated with the rise in rates of depression. Second, future research should include multiple predictors of depression and compare the relative contribution of each of these variables to the explanation of depressive symptomatology. Variables of interest here are other forms of negative thinking such 
as worrying as well as attribution style and life-events/daily hassles. Another interesting and relatively new construct is stress-reactive rumination, which refers to the tendency to ruminate on negative inferences following stressful life events (Alloy et al., 2000; Robinson \& Alloy, 2003). Sleeping problems, which have originally been related to worrying and anxiety, but recently to ruminative tendencies as well (e.g. Kirkegaard Thomsen et al., 2003), is another relevant variable. A study by Van Lang, Ferdinand and Verhulst (2007) showed that sleeping problems in early adolescence is a long-term predictor of depressive disorder in early adulthood in girls. As such, depressive symptoms might be the result of a vicious cycle, likely to develop in early adolescence, in which bed-time rumination may cause sleeping difficulties. Consequently, in the short-term, problems sleeping may lead not only to worsening of mood and increased ruminative activity, but also to cognitive impairments in concentration, attention and information processing, which interfere with the ability to adequately engage in absorbing and distractive activities. This, in turn, can lead to more rumination and the development of more serious, persistent depressive symptoms and maybe even to major depressive disorder in the long-term, but only if one is unable to adequately break the rumination cycle.

\section{Conclusion}

The findings of this meta-analytic review provide good to moderate support for the predictions of the RST, regarding the role of rumination in childhood depression. Findings show that rumination is significantly associated with (changes in) depressed mood and that girls ruminate more than boys. Quite modest support was found for the role of distraction. Future research should bring together various paradigms (e.g., puberty, cognitive vulnerability, attention models) in order to gain a better understanding of the pathways that lead to depression and maintain depressed mood in youth from a diathesis-stress account.

\section{References}

Abela, J., Brozina, K., \& Haigh, E. (2002). An examination of the Response Styles Theory of depression in third and seventh grade children: a short term longitudinal study. Journal of Abnormal Child Psychology, 30(5), 515-527.

Abela, J., Vanderbilt, E., \& Rochon, A. (2004). A test of the integration of the response styles and social support theories of depression in third and seventh grade children. Journal of Social and Clinical Psychology, 23(5), 653-674.

Abela, J., Aydin, C., \& Auerbach, R. (2007). Responses to depression in children: Reconceptualizing the relation among response styles. Journal of Abnormal Child Psychology, 35, 913-927.

Abramson, L., Metalsky, G., \& Alloy, L. (1989). Hopelessness depression: A theory-based subtype of depression. Psychological Review, 96(2), 358-372. 
A META-ANALYTIC REVIEW

Alloy, L., Abramson, L., Hogan, M., Whitehouse, W., Rose, D., Robinson, M., et al. (2000). The Temple-Wisconsin cognitive vulnerability to depression project: lifetime history of axis I psychopathology in individuals at high and low cognitive risk for depression. Journal of Abnormal Psychology, 109(3), 403-418.

Angold, A., Costello, E., \& Worthman, C. (1998). Puberty and depression: the roles of age, pubertal status and pubertal timing. Psychological Medicine, 28, 51-61.

Beck, A. (1967). Depression: Clinical, experimental and theoretical aspects. New York: Harper \& Row.

Beck, A., Rush, A., Shaw, B., \& Emery, G. (1979). Cognitive therapy of depression. New York: Guilford.

Birmaher, B., Ryan, N. D., Williamson, D. E., Brent, D. A., Kaufman, J., Dahl, R. E., et al. (1996). Childhood and adolescent depression: a review of the past 10 years. Part I. Journal of American Academy of Child and Adolescent Psychiatry, 35(11), 1427-1439.

Birmaher, B., Arbelaez, C., \& Brent, D. (2002). Course and outcome of child and adolescent major depressive disorder. Child and Adolescent Psychiatric Clinics North America, 11, 619-637.

Borkovec, T. (1994). The nature, functions, and origins of worry. In G. Davey \& F. Tallis (Eds.), Worrying: perspectives on theory, assessment and treatment (pp. 5-33). Chichester: John Wiley \& Sons

Broderick, P. (2005). Mindfulness and coping with dysphoric mood: contrasts with rumination and distraction. Cognitive Therapy and Research, 29(5), 501-510.

Broderick, P., \& Korteland, C. (2004). A prospective study of rumination and depression in early adolescence. Clinical Child Psychology and Psychiatry, 9(3), 383-394.

Burwell, R., \& Shirk, S. (2007). Subtypes of rumination in adolescence: associations between brooding, reflection, depressive symptoms, and coping. Journal of Clinical Child and Adolescent Psychology, 36(1), 56-65.

Butler, L., \& Nolen-Hoeksema, S. (1994). Gender differences in responses to depressed mood in a college sample. Sex Roles, 30(5/6), 331-346.

Calmes, C., \& Roberts, J. (2007). Repetitive thought and emotional distress: rumination and worry as prospective predictors of depressive and anxious symptomatology. Cognitive Therapy and Research, 30, 343-356.

Carney, C., Edinger, J., Meyer, B., Lindman, L., \& Istre, T. (2006). Symptom-focused rumination and sleep disturbance. Behavioral Sleep Medicine, 4(4), 228-241.

Carver, C. (1996). Goal engagement and the human experience. In R. J. Wyer (Ed.), Ruminative thoughts (Vol. IX, pp. 49-61). Mahwah, New Jersey: Lawrence Erlbaum Associates, Inc.

Cole, D. A., Ciesla, J. A., Dallaire, D. H., Jacquez, F. M., Pineda, A. Q., LaGrange, B., et al. (2008). Emergence of attributional style and its relation to depressive symptoms. Journal of Abnormal Psychology, 117, 16-31.

Conway, M., Giannopoulos, C., \& Stiefenhofer, K. (1990). Response styles to sadness are related to sex and sex-role orientation. Sex Roles, 22(9/10), 579-587.

Dancho, L. (2004). The relationship between children's beliefs about the stability of traits, rumination, and negative affect. Graduate Student Journal of Psychology, 6, 24-31.

Davey, G. (1994). Pathological worrying as exacerbated problem-solving. In G. Davey \& F. Tallis (Eds.), Worrying: Perspectives on Theory, Assessment, and Treatment. Chichester: Wiley \& Sons.

Dimidjian, S., Hollon, S., Dobson, K., Schmaling, K., Kohlenberg, R., Addis, M., et al. (2006). Randomized trial of behavioral activation, cognitive therapy, and antidepressant medication in the acute treatment of adults with major depression. Journal of Consulting and Clinical Psychology, 74(4), 658-670. 
Driscoll, K. A. (2004). Children's response styles and risk for depression and anxiety: developmental and sex differences. Unpublished Dissertation, Florida State University.

Fresco, D., Frankel, A., Mennin, D., Turk, C., \& Heimberg, R. (2002). Distinct and overlapping features of rumination and worry: the relationship of cognitive production to negative affective states. Cognitive Therapy and Research, 26(2), 179-188.

Garnefski, N., Boon, S., \& Kraaij, V. (2003). Relationships between cognitive strategies of adolescents and depressive symptomatology across different types of life event. Journal of Youth and Adolescence, 32(6), 401-408.

Goodyer, I., Herbert, J., \& Tamplin, A. (2003). Psychoendocrine antecedents of persistent first-episode major depression in adolescents: a community-based longitudinal enquiry. Psychological Medicine, 33, 601-610.

Grabe, S., Shibley Hyde, J., \& Lindberg, S. (2007). Body objectification and depression in adolescents: the role of gender, shame, and rumination. Psychology of Women Quarterly, 31, 164-175.

Grant, K., Lyons, A., Finkelstein, J.-A., Conway, K., Reynolds, L., O'Koon, J., et al. (2004).

Gender differences in rates of depressive symptoms among low-income, urban, African American youth: a test of two mediational hypotheses. Journal of Youth and Adolescence, 33(6), 523-533.

Hampel, P., \& Petermann, F. (2005). Age and gender effects on coping in children and adolescents. Journal of Youth and Adolescence, 34, 73-83.

Hankin, B. (2008). Stability of cognitive vulnerabilities to depression: a short-term prospective multiwave study. Journal of Abnormal Psychology, 117(2), 324-333.

Harvey, A., Ehlers, A., \& Clark, D. (2005). Learning history in social phobia. Behavioural and Cognitive Psychotherapy, 33(3), 257-271.

Harvey, A., Watkins, E., Mansell, W., \& Shafran, R. (2004). Cognitive behavioral processes across psychological disorders: A transdiagnostic approach to research and treatment. Oxford: Oxford University Press.

Hilt, L., Cha, C., \& Nolen-Hoeksema, S. (2008). Non-suicidal self-injury in young adolescent girls: Moderators of the distress-function relationship. Journal of Consulting and Clinical Psychology, 76(1), 63-71.

Hong, R. (2007). Worry and rumination: differential associations with anxious and depressive symptoms and coping behavior. Behaviour Research and Therapy, 45, 277-290.

Joormann, J., Dkane, M., \& Gotlib, I. (2006). Adaptive and maladaptive components of rumination? Diagnostic specificity and relation to depressive biases. Behavior Therapy, 37, 269-280.

Jose, P., \& Brown, I. (2008). When does the gender difference in rumination begin? Gender and age differences in the use of rumination by adolescents. Journal of Youth and Adolescence, 37, 180-192.

Just, N., \& Alloy, L. (1997). The response styles theory of depression: tests and an extension of the theory. Journal of Abnormal Psychology, 106(2), 221-229.

Kazdin, A. E., \& Weisz, J. R. (2003). Evidence-based psychotherapies for children and adolescents. New York: Guilford Press.

Kennedy, E. (2006). The role of stress-reactive rumination in the relationship between peer victimization and depressive symptoms in adolescence. Unpublished Dissertation, Saint Louis University.

Kessler, R. C., McGonagle, K. A., Swartz, M., Blazer, D. G., \& Nelson, C. B. (1993). Sex and depression in the National Comorbidity Survey. I: Lifetime prevalence, chronicity and recurrence. Journal of Affective Disorders, 29(2-3), 85-96.

Kirkegaard Thomsen, D., Mehlsen, M., Christensen, S., \& Zachariae, R. (2003). Rumination relationship with negative mood and sleep quality. Personality and Individual Differences, 34, 1293-1301. 
Knowles, R., Tai, S., Christensen, I., \& Bentall, R. (2005). Coping with depression and vulnerability to mania: a factor analytic study of the Nolen-Hoeksema (1991) Response Styles Questionnaire. British Journal of Clinical Psychology, 44, 99-112.

Kocovski, N., Endler, N., Rector, N., \& Flett, G. (2005). Ruminative coping and post-event processing in social anxiety. Behaviour Research and Therapy, 43, 971-984.

Kuehner, C. (2003). Gender differences in unipolar depression: an update of epidemiological findings and possible explanations. Acta Psychiatrica Scandinavica, 108, 163-174.

Kuyken, W., Watkins, E., Holden, E., \& Cook, W. (2006). Rumination in adolescents at risk for depression. Journal of Affective Disorders, 96, 39-47.

Lang, v. N., Ferdinand, R., \& Verhulst, F. (2007). Predictors of future depression in early and late adolescence. Journal of Affective Disorders, 97, 137-144.

Lewinsohn, P., Rohde, P., \& Seeley, J. (1998). Major depressive disorder in older adolescents: prevalence, risk factors, and clinical implications. Clinical Psychology Review, 18(7), 765-794.

Li, C. E., DiGiuseppe, R., \& Froh, J. (2006). The roles of sex, gender, and coping in adolescent depression. Adolescence, 41(163), 409-415.

Long, J. (2001). An introduction to and generalization of the "Fail-Safe N. Paper presented at the annual meeting of the Southwest Educational Research Association (New Orleans, LA, February 1-3).

Lyubomirsky, S., \& Tkach, C. (2004). The consequences of dysphoric rumination. In C. Papageorgiou \& A. Wells (Eds.), Depressive rumination: nature, theory, and treatment (pp. 21-41). Chichester: John Wiley \& Sons.

Mclntosh, W. (1996). When does goal nonattainment lead to negative emotional reactions, an when doesn't it?: the role of linking and rumination. In L. Martin \& A. Tesser (Eds.), Striving and feeling. Interactions among goals, affect, and self-regulations (pp. 53-77). Mahwah, New Jersey: Lawrence Erlbaum Associates.

McLaughlin, K., Borkovec, T., \& Sibrava, N. (2007). The effects of worry and rumination on affect states and cognitive activity. Behavior Therapy, 38, 23-38.

Michael, T., Halligan, S., Clark, D., \& Ehlers, A. (2007). Rumination in posttraumatic stress disorder. Depression and Anxiety, 24, 307-317.

Miranda, R., \& Nolen-Hoeksema, S. (2007). Brooding and reflection: Rumination predicts suicidal ideation at one-year follow up in a community sample. Behaviour Research and Therapy, 45, 3088-3095.

Moberly, N., \& Watkins, E. (2008). Ruminative self-focus and negative affect: an experience sampling study. Journal of Abnormal Psychology, 117(2), 314-323.

Muris, P., Roelofs, J., Meesters, C., \& Boomsma, P. (2004). Rumination and worry in nonclinical adolescents. Cognitive Therapy and Research, 28(4), 539-554.

Muris, P., Roelofs, J., Rassin, E., Franken, I., \& Mayer, B. (2005). Mediating effects of rumination and worry on the links between neuroticism, anxiety and depression. Personality and Individual Differences, 39, 1105-1111.

Muris, P., Fokke, M., \& Kwik, D. (2009). The ruminative response style in adolescents: An examination of its specific link to symptoms of depression. Cognitive Therapy and Research, 33, 21-32.

Nolan, S., Roberts, J., \& Gotlib, I. (1998). Neuroticism and ruminative response style as predictors of change in depressive symptomatology. Cognitive Therapy and Research, 22(5), 445-455.

Nolen-Hoeksema, S. (1987). Sex differences in unipolar depression: evidence and theory. Psychological Bulletin, 101(2), 259-282.

Nolen-Hoeksema, S. (1991). Responses to depression and their effects on the duration of depressive episodes. Journal of Abnormal Psychology, 100(4), 569-582. 
Nolen-Hoeksema, S. (2000). The role of rumination and depressive disorders and mixed anxiety/depressive symptoms. Journal of Abnormal Psychology, 109(3), 504-511.

Nolen-Hoeksema, S., \& Girgus, J. (1994). The emergence of gender differences in depression during adolescence. Psychological Bulletin, 115(3), 424-443.

Nolen-Hoeksema, S., \& Harrell, Z. (2002). Rumination, depression, and alcohol use: Tests of gender differences. Journal of Cognitive Psychotherapy, 16, 391-403.

Nolen-Hoeksema, S., Larson, J., \& Grayson, C. (1999). Explaining the gender difference in depressive symptoms. Journal of Personality and Social Psychology, 77(5), 1061-1072.

Nolen-Hoeksema, S., \& Morrow, J. (1991). A prospective study of depression and posttraumatic stress symptoms after a natural disaster: the 1989 Loma Prieta earthquake. Journal of Personality and Social Psychology, 61(1), 115-121.

Nolen-Hoeksema, S., \& Morrow, J. (1993). Effects of rumination and distraction on naturally occurring depressed mood. Cognition and Emotion, 7, 561-570.

Nolen-Hoeksema, S., Morrow, J., \& Fredrickson, B. (1993). Response styles and the duration of episodes of depressed mood. Journal of Abnormal Psychology, 102(1), 20-28.

Nolen-Hoeksema, S., Stice, E., Wade, E., \& Bohon, C. (2007). Reciprocal relations between rumination and bulimic, substance abuse, and depressive symptoms in female adolescents. Journal of Abnormal Psychology, 116(1), 198-207.

Nolen-Hoeksema, S., Wisco, B. E., \& Lyubomirsky, S. (2008). Rethinking rumination. Perspectives on Psychological Science, 3, 400-424.

Orwin, R. G. (1983). A fail-safe N for effect size in meta-analysis. Journal of Educational Statistics, 8 , 157-159.

Papadakis, A. A., Prince, R. A., Jones, N. P., \& Strauman, T. J. (2006). Self-regulation, rumination, and vulnerability to depression in adolescent girls. Development and Psychopathology, 18, 815829.

Papageorgiou, C., \& Wells, A. (2000). Treatment of recurrent major depression with Attention Training. Cognitive and Behavioral Practice, 7, 407-413.

Papageorgiou, C., \& Wells, A. (2004). Depressive rumination: Nature, Theory and Treatment. Chichester: John Wiley \& Sons.

Park, R., Goodyer, I. M., \& Teasdale, J. (2004). Effects of induced rumination and distraction on mood and overgeneral autobiographical memory in adolescent Major Depressive Disorder and controls. Journal of Child Psychology and Psychiatry, 45(5), 996-1006.

Park, R., Goodyer, I., \& Teasdale, J. (2005). Self-devaluative dysphoric experience and the prediction of persistent first-episode major depressive disorder in adolescents. Psychological Medicine, 35, 539-548.

Roberts, J., Gilboa, E., \& Gotlib, I. (1998). Ruminative response style and vulnerability to episodes of dysphoria: gender, neuroticism, and episode duration. Cognitive Therapy and Research, 22(4), 401-423.

Robinson, M., \& Alloy, L. (2003). Negative cognitive styles and stress-reactive rumination interact to predict depression: a prospective study. Cognitive Therapy and Research, 27(3), 275-292.

Roelofs, J., Huibers, M., Peeters, F., \& Arntz, A. (2008). Effects of neuroticism on depression and anxiety: Rumination as a possible mediator. Personality and Individual Differences, 44, 576-586.

Schwartz, J., \& Koenig, L. (1996). Response styles and negative affect among adolescents. Cognitive Therapy and Research, 20(1), 13-36.

Segal, Z., Williams, J., \& Teasdale, J. (2002). Mindfulness-Based Cognitive Therapy for Depression. A new approach to preventing relapse. New York: The Guilford Press

Segerstrom, S., Tsao, J., Alden, L., \& Craske, M. (2000). Worry and rumination: repetitive thought as a concomitant and predictor of negative mood. Cognitive Therapy and Research, 24(6), 671-688. 
Skitch, S., \& Abela, J. R. Z. (2008). Rumination in response to stress as a common vulnerability factor to depression and substance misuse in adolescence. Journal of Abnormal Child Psychology, 36, 1029-1045.

Smith, J., Alloy, L., \& Abramson, L. (2006). Cognitive vulnerability to depression, rumination, hopelessness, and suicidal ideation: Multiple pathways to self-injurious thinking. Suicide and Life-threatening Behavior, 36, 443-454.

Starcevic, V. (1995). Pathological worry in major depression: a preliminary report. Behaviour Research and Therapy, 33(1), 55-56.

Teasdale, J., Williams, J., Soulsby, J., Segal, Z., Ridgeway, V., \& Lau, M. (2000). Prevention of relapse/recurrence in major depression by Mindfulness-Based Cognitive Therapy. Journal of Consulting and Clinical Psychology, 68(4), 615-623.

Treynor, W., Gonzalez, R., \& Nolen-Hoeksema, S. (2003). Rumination reconsidered: a psychometric analysis. Cognitive Therapy and Research, 27(3), 247-259.

Turner, J. J., \& Cole, D. (1994). Developmental differences in cognitive diatheses for child depression. Journal of Abnormal Child Psychology, 22(1), 15-32.

Washington, F. (2006). The relationship among rumination and distraction in pathological gamblers. Unpublished Dissertation, University of Northern Colorado.

Watkins, E. (2004). Appraisals and strategies associated with rumination and worry. Personality and Individual Differences, 37, 679-694.

Watkins, E. (2008). Constructive and unconstructive repetitive thoughts. Psychological Bulletin, 134, 163-206.

Watkins, E., Moulds, M., \& Mackintosh, B. (2005). Comparisons between rumination and worry in a non-clinical population. Behaviour Research and Therapy, 43, 1577-1585.

Watkins, E., Scott, J., Wingrove, J., Rimes, K., Bathurst, N., Steiner, et al. (2007). Ruminationfocused cognitive behaviour therapy for residual depression: A case series. Behaviour Research and Therapy, 45, 2144-2154.

Weir, K., \& Jose, P. (2008). A comparison of the Response Styles Theory and the Hopelessness Theory of depression in preadolescents. The Journal of Early Adolescence, 28, 356-374.

Weisz, J., McCarty, C., \& Valeri, S. (2006). Effects of psychotherapy for depression in children and adolescents: a meta-analysis. Psychological Bulletin, 132(1), 132-149.

Wilkinson, P., \& Goodyer, I. (2006). Attention difficulties and mood-related ruminative response style in adolescents with unipolar depression. Journal of Child Psychology and Psychiatry, 47(12), 1284-1291.

Wilkinson, P., \& Goodyer, I. (2008). The effects of cognitive-behavioural therapy on mood-related ruminative response style in depressed adolescents. Child and Adolescent Psychiatry and Mental Health, 2(3).

Ziegert, D., \& Kistner, J. (2002). Response Styles Theory: Downward extension to children. Journal of Clinical Child and Adolescent Psychology, 31(3), 325-334. 



\title{
Chapter 4
}

\section{The influence of rumination and distraction on depressed and anxious mood: A prospective examination of the Response Styles Theory in children and adolescents ${ }^{1}$}

\author{
Jeffrey Roelofs, Lea Rood, Cor Meesters, Valérie te Dorsthorst, Susan Bögels,
} Lauren B. Alloy, Susan Nolen-Hoeksema

\begin{abstract}
The present study sought to test predictions of the response styles theory in a sample of children and adolescents. More specifically, a ratio approach of response styles was utilized to examine the effects on residual change scores in depression and anxiety. Participants completed a battery of questionnaires including measures of rumination, distraction, depression, and anxiety at baseline (Time 1) and 8-10 weeks follow-up (Time 2). Results showed that the ratio score of rumination and distraction was significantly associated with depressed and anxious symptoms over time. More specifically, individuals who have a greater tendency to ruminate compared to distracting themselves have increases in depression and anxiety scores over time, whereas those who have a greater tendency to engage in distraction compared to rumination have decreases in depression and anxiety symptoms over time. These findings indicate that a ratio approach can be used to examine the relation between response styles and symptoms of depression and anxiety in nonclinical children and adolescents. Implications of the results may be that engaging in distractive activities should be promoted and that ruminative thinking should be targeted in juvenile depression treatment.
\end{abstract}

\footnotetext{
${ }^{1}$ Published in: European Child and Adolescent Psychiatry, 18, 635-642.
} 


\section{Introduction}

Depressive symptoms are commonly experienced among youth. Various psychological theories have been proposed to explain individual differences in vulnerability for depression. A cognitive vulnerability account of depression has been outlined by Nolen-Hoeksema in the Response Styles Theory [41-43]. The Response Styles Theory (RST) posits two main styles of responding to depressive mood: rumination and distraction. Rumination is a stable trait-like, emotion-focused coping style that involves behaviors and thoughts that focus one's attention on depressive symptoms and the implications and consequences of these symptoms [41]. In contrast, distraction refers to the diversion of attention away from the depressed mood and turning it onto neutral or pleasant thoughts and actions [48]. According to the RST, engaging in ruminative responses to depressed mood will intensify and prolong depressive symptoms, whereas engaging in a distracting response style will lead to less intense and acute symptoms. The RST further assumes that sex differences in response styles emerge prior to sex differences in depression [45] and that women have a greater tendency to engage in ruminative responses to depressed mood, whereas men are more likely to use distraction when confronted with depressed mood.

Empirical research has addressed the predictions of the RST concerning the effects of rumination and distraction on depressed mood in adult populations. These studies have found that engaging in ruminative responses to depressed moods is related to both the onset of depressive episodes [27, 32, 44, 57], as well as to amplified and prolonged periods of depressed mood states in adult populations [14, $30,41-43,52]$. There is also good evidence for the relation between a ruminative response style and depressive symptoms in children and adolescents. A number of studies have found support for the prediction that youngsters who engage in ruminative responses to depressed mood display increased levels of concurrent depressive symptoms [2, 4, 38, 53] and rumination may also predict increases in depressive symptoms and the onset of major depressive disorder in adolescents [2, $11,49,53]$.

The findings for distraction are less clear. Studies examining the effects of distraction on depressed mood in adult populations have been inconclusive with some studies reporting beneficial effects in dysphoric individuals [12, 31, 34, 35, 37], and others not $[27,30,48]$. In youngsters, the effects of distraction on depressed mood are also inconclusive. Some studies have found support for distraction being associated with lower concurrent levels of negative mood states [38, 53, 64], whereas other studies did not [2, 4]. With respect to longitudinal studies, some support has been found for distraction to be associated with decreases in depressive symptoms over time [1, 2, 53, 64]. 
A PROSPECTIVE EXAMINATION OF THE RST

Although the RST was originally designed to explain individual differences in depression, there have been several attempts to investigate response styles (in particular rumination) to other negative mood states. The majority of studies has shown a clear relationship between rumination and anxiety in adults [5, 8, 13, 19-21, $28,39,47,55,61-63$ ] as well as in children and adolescents [17, 38, 40, 53], whereas some studies did not find meaningful associations between rumination and anxiety $[16,60]$. As an aside, rumination has also been linked to increases in binge drinking and symptoms of alcohol abuse in adults [46] and adolescent girls [49], and to self-injurious behaviors and suicidal ideation [24, 36, 56]. Thus, rumination seems to be involved in a number of psychopathological disorders and behaviors and might be considered a transdiagnostic variable [22].

Traditional tests of the RST involve an examination of the response styles separately. A potential problem might be the contradictory predictions of rumination and distraction with respect to the effects on depressive symptoms. To overcome this problem, Abela et al. [1] utilized an additive or ratio approach to response styles. More specifically, the rationale behind a ratio approach assumes that multiple vulnerability factors independently influence depressive symptomatology and that the effect of one such variable can either add to or cancel out the effect of another variable and can be combined in a linear fashion. For example, high levels of distraction can cancel out the effects of high levels of rumination [1]. Applying ratio scores to response styles involves dividing rumination scores by the distraction scores of individuals. As such, high ratio scores indicate a greater tendency to be involved in rumination compared to distraction, whereas low ratio scores are indicative of a greater tendency to engage in distraction compared to rumination. In line with the prediction, high ratio scores of rumination and distraction/problemsolving were related to increased levels of depressive symptoms over time, whereas low ratio scores predicted decreases in depressive symptoms in children at risk for depression. The authors concluded that ratio scores were best for examining response styles [1].

This study sought to test predictions of the RST in a large community sample of children and adolescents. We utilized a ratio approach to determine whether the findings from Abela and colleagues [1] can be generalized to an unselected sample of children and adolescents. The association of ratio scores of response styles with symptoms of depression and anxiety was examined prospectively. We hypothesized that high ratio scores (greater rumination) would be positively associated with residual change in depressive and anxiety symptoms, whereas low ratio scores (greater distraction) would be negatively associated with residual change in symptoms of depression and anxiety. The current study applied a wide age range in order to be able to examine moderating effects of age on the relation between ratio scores and increases in symptoms of depression and anxiety over time. Finally, in 
line with past research, we examined also whether sex moderated the association between ratio scores and symptoms of depression and anxiety. A second aim of the study was to examine internal consistency and test-retest stability of the response styles.

\section{Methods}

\section{Participants and Procedures}

A total of 830 children and adolescents were recruited from regular primary and secondary schools in the Southern part of The Netherlands. The youngsters and their parents were informed about the purpose of the study (i.e., they were told that this study aimed to gain insight into the relation between negative thinking and depressed and anxious feelings), after which written consent was obtained from them. A total of 803 individuals agreed to participate, of which 770 children and adolescents (355 boys and 415 girls) completed a battery of self-report questionnaires (see measures) at baseline (Time 1) and follow-up (Time 2) assessment 8 to 10 weeks later. The mean age of the sample was 12.9 years ( $S D=2.1$, range $10-17$ years). Although ethnicity was not assessed, it was estimated that more than $95 \%$ of the youngsters were Caucasian. The self-report measures were completed during regular class time. The teacher and a research assistant were available to answer questions and to ensure confidential responding. The experimental protocol was approved by a local IRB.

\section{Measures}

Rumination and distraction - The Children's Response Style Scale (CRSS) is an instrument that measures response styles in youth [64]. It consists of 20 items, half of the items dealing with rumination (e.g., "When I feel sad, I think back to other times I felt this way"), the other half reflecting distractive response styles (e.g., "When I feel sad, I think about something I did a little while ago that was a lot of fun"). Items are rated on a five-point frequency scale with $1=$ 'never' and $5=$ 'always'. Total rumination and distraction scores range between 10 and 50 . The CRSS is considered reliable in terms of internal consistency and test-retest stability, and validity is supported by significant associations with depression and alternative indices of repetitive negative thinking $[38,64]$.

Depression - The Children's Depression Inventory (CDI) is a self-report instrument that assesses symptoms of depression in children and adolescents aged between 7 and 17 years [29]. It consists of 27 items that are rated on a 3-point Likert scale with $0=$ 'not true', 1 = 'somewhat true' and 2 = 'very true'. Items are indicative of the cognitive, affective, and behavioral aspects of depression (e.g., "I am sad all the 
A PROSPECTIVE EXAMINATION OF THE RST

time"). Total scores range from 0 to 52 . The CDI possesses high levels of reliability and validity $[2,29]$.

Trait anxiety - The trait version of the State-Trait Anxiety Inventory for Children (STAI-C) is a self-report instrument that assesses trait anxiety [58]. Trait anxiety addresses the frequency and intensity of anxious symptoms. Individuals scoring high on this scale tend to interpret situations as more threatening and dangerous than do individuals with lower scores. The STAI-C consists of 20 items, determining how individuals generally feel (e.g., "I feel confident"), which are rated on a 4-point Likert type scale ranging from $1=$ 'almost never' to $4=$ 'almost always' [58]. Total STAI-C scores range between 20 and 80 . The STAI-C is a valid and reliable instrument of anxiety symptoms in children. Reliability in terms of internal consistency is good and test-retest reliability is adequate $[18,58]$.

\section{Data Analysis}

The Statistical Package for Social Sciences (SPSS version 13.0) was used for computing descriptive statistics, correlations, carrying out t-tests (i.e., to explore sex differences on the questionnaire scores), and to carry out the regression analyses. A series of regression analyses was carried out to investigate the association of the ratio scores with symptoms of depression and anxiety over time. Residual change scores were calculated for each individual, which involves a regression analysis to predict Time $2 \mathrm{CDI}$ or STAI-C from Time $1 \mathrm{CDI}$ or STAI-C scores. The Time 2 predicted CDI or STAI-C scores are subtracted from the actual Time 2 CDI or STAI-C scores. What remains is the residual gain score (i.e., the amount of gain that is not due to the influence of the initial Time 1 score) [59]. In accordance with the study of Abela and colleagues [1], the association between the ratio scores and the dependent variables were examined for children with low ratio scores (1.5 SD below the sample mean) and high ratio scores (1.5 SD above the sample mean). More specifically, a negative association between ratio scores and symptoms of depression and anxiety was expected in the first group, whereas a positive association between these variables was expected for the latter group. Further, the moderating effects of sex and age on the association between the ratio scores and symptoms of depression and anxiety were examined. Test-retest stability was assessed by means of intra-class correlation coefficients. The index alpha was set to $1 \%$ for all analyses. 


\section{Results}

\section{General findings}

Before presenting the main results of the study, some general points need to be addressed. First, the assumptions for parametric statistics were evaluated. Homogeneity of variances as indicated by Levene's test and linearity were not violated. Further, all variables were normally distributed (i.e., skewness and kurtosis between -1 and +1) except for total CDI depression scores at T1 and T2. These total scores were positively skewed and were subjected to a square root transformation. This transformation was successful in 'normalizing' the depression scores. All variables were standardized prior to analyses.

Second, for individuals with more than $10 \%$ missing values on a questionnaire, total scores on that particular questionnaire were not computed. In the case of less than $10 \%$ missing values, a regression technique was used to replace the missing value with an expected value on the basis of how that particular individual responded to the other items of this questionnaire as well as how other individuals responded to the item on which a score was missing. As a consequence, the total number of individuals differs slightly between the various analyses (i.e., from 764 to 770). Third, mean scores on age and the questionnaires for the total group as well as for boys and girls separately are presented in Table 1. Except for age and distraction, significant sex differences were found on all self-report measures, with girls displaying higher scores on these variables than boys. Effect sizes for the sex differences (i.e., partial í2) were moderate (see Table 1).

Table 1: Descriptive statistics for the questionnaires at Time 1 and Time 2 (8 to 10 weeks later) for the total group and for boys and girls

\begin{tabular}{|c|c|c|c|c|c|c|c|c|c|c|}
\hline & \multicolumn{3}{|c|}{ Total group } & \multicolumn{2}{|l|}{ Boys } & \multicolumn{5}{|l|}{ Girls } \\
\hline $\begin{array}{l}\text { Self-report } \\
\text { measure }\end{array}$ & Mean & SD & Alpha & Mean & SD & Mean & SD & $\mathrm{t}$ & $p$ & $\eta 2$ \\
\hline Age & 12.9 & 2.1 & - & 12.9 & 2.1 & 12.9 & 2.0 & .55 & .58 & .001 \\
\hline CRSS & 25.6 & 8.0 & .88 & 23.2 & 7.7 & 27.7 & 7.7 & 8.3 & $<.001$ & .07 \\
\hline Rumination & & & & & & & & & & \\
\hline CRSS & 27.4 & 8.5 & .91 & 26.7 & 9.1 & 27.9 & 7.9 & 2.0 & .05 & .005 \\
\hline Distraction & & & & & & & & & & \\
\hline Ratio score & 1.03 & .50 & - & .96 & .45 & 1.09 & .53 & 3.8 & $<.001$ & .02 \\
\hline Time $1 \mathrm{CDI}$ & 7.9 & 7.3 & .90 & 7.1 & 6.5 & 8.6 & 7.9 & 3.0 & .003 & .01 \\
\hline Time 1 STAI-C & 31.4 & 7.3 & .88 & 29.4 & 6.5 & 33.1 & 7.5 & 7.2 & $<.001$ & .06 \\
\hline Time 2 CDI & 6.9 & 7.2 & .91 & 6.1 & 6.6 & 7.6 & 7.7 & 2.8 & .005 & .01 \\
\hline Time 2 STAI-C & 30.0 & 7.5 & .90 & 28.0 & 6.5 & 31.6 & 7.9 & 6.8 & $<.001$ & .06 \\
\hline
\end{tabular}

Note: CRSS $=$ Children's Response Style Scale; CDI = Children's Depression Inventory; STAI-C = State-Trait Anxiety Inventory for children. 
A PROSPECTIVE EXAMINATION OF THE RST

Reliability of response styles

All self-report measures showed good internal consistency (see Table 1). Test-retest stability coefficients (i.e., intra-class correlation coefficients) for the response styles were reasonable for rumination (ICC=.72), distraction (ICC=.67), and the ratio score $(\mathrm{ICC}=.70)$. Finally, Pearson correlation coefficients between the various questionnaires are depicted in Table 2. Significant associations were found between all variables except for distraction ${ }^{2}$.

Table 2: Correlation matrix of the various questionnaires

\begin{tabular}{lllllll}
\hline & 1. & 2. & 3. & 4. & 5. & 6. \\
\hline 1. CRSS Rumination & - & & & & & \\
2. CRSS Distraction & $.14^{*}$ & - & & & & \\
3. Ratio score & $.59^{*}$ & $-.62^{*}$ & - & & & \\
4. Time 1 CDI & $.53^{*}$ & -.10 & $.49^{*}$ & - & & \\
5. Time 1 STAI-C & $.59^{*}$ & -.04 & $.46^{*}$ & $.78^{*}$ & - & \\
6. Time 2 CDI & $.46^{*}$ & -.12 & $.46^{*}$ & $.80^{*}$ & $.65^{*}$ & - \\
7. Time 2 STAI-C & $.57^{*}$ & -.04 & $.45^{*}$ & $.70^{*}$ & $.80^{*}$ & $.78^{*}$ \\
\hline
\end{tabular}

Note: CRSS = Children's Response Style Scale; CDI = Children's Depression Inventory; STAI-C = State-Trait Anxiety Inventory for children. * $p<.001$.

\section{An empirical test of the RST}

Separate hierarchical multiple regression analyses were conducted with Time 2 CDI or Time 2 STAI-C as the dependent variable. In both analyses, age and sex were entered in the first step, followed by Time $1 \mathrm{CDI}$ or Time 1 STAI-C in the second step. To examine this relationship in more detail, residual change scores of depressive and anxiety symptoms were calculated. Low ratio scores were associated with decreases in symptoms of depression (predicted residual change score $=-.98$ ) and anxiety (predicted residual change score $=-1.15$ ), whereas high ratio scores were related to increases in levels of depressive symptoms (predicted residual change score $=.92$ ) and anxiety (predicted residual change score $=1.10$ ). Thus, in line with the response styles theory, individuals who have a greater tendency to ruminate compared to distraction show an increase in depressive symptoms over time, whereas a greater tendency to distract oneself compared to rumination results in a decrease in

\footnotetext{
${ }^{2}$ The association between depression (CDI) and anxiety (STAI-C) was relatively high, possibly threatening the discriminant validity of the scales. To deal with this issue, we conducted an exploratory factor analysis on items of the CDI and the STAI-C in order to obtain relatively pure depression and anxiety factors (see [7]). Items with salient double loadings (i.e., >.30) were removed. In total, 18 out of 20 STAI-C items and 22 out of $27 \mathrm{CDI}$ items were retained. The correlation coefficient between the reduced scales was .65 indicating less overlap. All analyses were conducted for the original scales as well as for the reduced scales. Similar results were found for the original and reduced scales. Therefore, the original scales were used in all analyses in order to be able to compare our findings to previous research.
} 
depressive symptoms over time. None of the interaction terms reached statistical significance indicating that the effects of the ratio scores on symptoms of depression and anxiety were not moderated by sex or age.

Table 3: Associations of ratio score with symptoms of depression and anxiety over time

\begin{tabular}{|c|c|c|c|c|c|c|c|}
\hline & & $\begin{array}{l}\text { Dependent } \\
\text { variable }\end{array}$ & Predictor variable & $\beta$ & SE $(\beta)$ & $\mathrm{t}$ & $\mathrm{p}$ \\
\hline \multirow{2}{*}{$\begin{array}{l}\text { Step } \\
\left(R^{2}=.02\right)\end{array}$} & 1 & Time 2 CDI & Sex & .10 & & 2.74 & .006 \\
\hline & & & Age & -.13 & .04 & -3.54 & $<.001$ \\
\hline $\begin{array}{l}\text { Step } \\
\left(R^{2}=.59\right)\end{array}$ & 2 & & Time $1 \mathrm{CDI}$ & .79 & & 35.21 & $<.001$ \\
\hline $\begin{array}{l}\text { Step } \\
\left(R^{2}=.60\right)\end{array}$ & 3 & & Ratio score & .12 & & 4.66 & $<.001$ \\
\hline \multirow{3}{*}{$\begin{array}{l}\text { Step } \\
\left(R^{2}=.60\right)\end{array}$} & 4 & & Ratio score $x$ sex & -.04 & .10 & -.44 & .66 \\
\hline & & & Ratio score $\mathrm{x}$ age & -.07 & & -.43 & .67 \\
\hline & & & Sex $x$ age & .02 & & .16 & .88 \\
\hline $\begin{array}{l}\text { Step } \\
\left(R^{2}=.60\right)\end{array}$ & 5 & & Ratio score $\mathrm{x}$ sex $\mathrm{x}$ age & .21 & & .32 & .75 \\
\hline \multirow{2}{*}{$\begin{array}{l}\text { Step } \\
\left(R^{2}=.07\right)\end{array}$} & 1 & Time 2 STAI-C & Sex & .24 & & 6.86 & $<.001$ \\
\hline & & & Age & -.11 & & -3.18 & .002 \\
\hline $\begin{array}{l}\text { Step } \\
\left(R^{2}=.62\right)\end{array}$ & 2 & & Time 1 STAI-C & .78 & & 34.60 & $<.001$ \\
\hline $\begin{array}{l}\text { Step } \\
\left(R^{2}=.64\right)\end{array}$ & 3 & & Ratio score & .13 & & 5.22 & $<.001$ \\
\hline \multirow{3}{*}{$\begin{array}{l}\text { Step } \\
\left(R^{2}=.64\right)\end{array}$} & 4 & & Ratio score $x$ sex & .06 & & .62 & .54 \\
\hline & & & Ratio score $\mathrm{x}$ age & .05 & & .29 & .77 \\
\hline & & & Sex $x$ age & -.15 & & -.99 & .32 \\
\hline $\begin{array}{l}\text { Step } \\
\left(R^{2}=.64\right)\end{array}$ & 5 & & Ratio score $x$ sex $x$ age & -.10 & & -.15 & .88 \\
\hline
\end{tabular}

Note: $\mathrm{CDI}=$ Children's Depression Inventory; STAI-C = State-Trait Anxiety Inventory for children $($ alpha $=1 \%)$.

\section{Discussion}

The current study sought to test predictions of the RST [42] in a large sample of nonclinical children and adolescents. More specifically, a ratio score of rumination and distraction scores was utilized to examine the effect on depressive and anxiety symptoms over time [1]. Furthermore, the moderating effects of sex and age were also examined. The main findings can be summarized as follows. First, results 
A PROSPECTIVE EXAMINATION OF THE RST

showed that girls had higher scores than boys on rumination, but no significant sex differences emerged on distraction scores. Second, the ratio score was significantly associated with symptoms of depression and anxiety. More specifically and in line with the expectation, high ratio scores were positively associated with symptoms of depression and anxiety. That is, individuals who have a greater tendency to ruminate compared to distract oneself have increased depression scores over time. As expected, low ratio scores significantly predicted depressive and anxiety symptoms. Thus, individuals who have a greater tendency to engage in distraction compared to rumination have decreased depression and anxiety symptoms over time. Age and sex did not moderate the relation between the ratio score and symptoms of depression and anxiety over time. Finally, test-retest stability of the response styles was reasonable.

The findings with respect to the association between the ratio score of response styles and symptoms of depression and anxiety are in line with the RST [42] and add to past research in two ways. First, findings of the current study concur with the findings of Abela and colleagues [1] and generalize to a community sample of children and adolescents. Note that the magnitude of the effects is somewhat smaller than obtained by Abela and colleagues. This may be due to the use of different self-report measures in both studies, the inclusion of problem-solving by Abela and colleagues in the ratio score, and to the differences in sample characteristics (e.g., high risk group versus non-clinical youth). Second, the findings demonstrate that the use of a ratio score of response styles also has relevance for anxiety.

The effect of the ratio score of rumination and distraction was not moderated by age or sex. This may have a number of implications. First, our data suggest that there is no critical age at which response styles become manifest in predicting residual change in symptoms of depression and anxiety, which parallels findings from past research [1]. This implies that cognitive theories of vulnerability to depression can be applied to child and adolescent populations [3]. Further, the associations between response styles and symptoms of depression and anxiety were not different for boys compared to girls, although significant sex differences were found on response styles with girls having higher scores on rumination compared to boys. Noteworthy to mention, the RST posits sex differences on mean scores of rumination and distraction, but does not assume that the relationships between response styles and symptoms of psychopathology are different for boys and girls.

This study also addressed test-retest stability of the response styles. According to the RST, response styles are considered stable, trait-like dispositions of responding to negative mood. Test-retest stability of response styles (i.e., rumination, distraction, and ratio score) over 8-10 weeks time was reasonable. Past research has mainly focused on the stability of rumination in adult populations. Our data on test- 
retest stability concur with findings from studies in which estimates of stability were largest in contexts where depression severity or depressed mood remained more or less the same over time [6].

The results from this study may have clinical implications. First, youngsters who are vulnerable to depression and anxiety should engage in distracting activities. Active distracting activities are already incorporated in behavioral activation interventions for depression [25, 33], which have shown efficacy [25, 26]. Other coping strategies that can be used to cognitively distract oneself from negative mood states should be examined, particularly with respect to attempts to escape from selffocused attention, which is common in rumination [10,50]. A good example is task concentration training which has shown efficacy in adults with social phobia [9]. Excessive rumination should be targeted in treatment by means of cognitive restructuring techniques of cognitive therapy, which involves teaching individuals to challenge and to replace ruminative thoughts with more rational and adaptive ones. Cognitive interventions might also be directed to gaining control over ruminative thinking. Thoughts about the (un)controllability of rumination are negative metacognitive beliefs [51], which seem to contribute to depressive symptoms in adults. It remains to be determined whether these beliefs can also be identified and modified in youngsters. Finally, mindfulness therapy [54] and acceptance-based approaches [23] might also be helpful in changing the impact of ruminative thoughts by noticing ruminative activities in the mind without following and without judging them. This might prevent the associative network of negative thoughts from becoming activated and spiraling into rumination and subsequent depressive mood [50].

A number of limitations of the current study should be mentioned. First, the sample of this study involved non-clinical children and adolescents. Although the current findings replicate and extent findings obtained in a high-risk group [1], it remains to be seen whether the results generalize to clinical populations. Second, rumination and distraction were assessed with questionnaires that measure a dispositional style to ruminate and distract. Whether such dispositional measures represent on the spot ruminative and distractive activities in response to a negative event remains to be investigated. Third, the present study relied solely on self-report measures of youngsters to obtain information about children and adolescents' levels of psychopathology. Future research could benefit from the inclusion of information from multiple informants (e.g., parents, school teachers) [15]. Finally, ethnicity of the participants and information about the parents such as social background, psychiatric diagnoses, and family composition were not assessed. Despite these limitations, the current data support the importance of rumination relative to distraction as a cognitive vulnerability factor for depression and anxiety. Future research should be aimed at bringing together various variables that are thought to play a role in juvenile 
A PROSPECTIVE EXAMINATION OF THE RST

depression and anxiety such as negative cognitive styles and puberty. The inclusion

of life events and daily hassles makes it possible to contribute to a further understanding of depression and anxiety in youth within a diathesis-stress account.

\section{References}

1. Abela JRZ, Aydin CM, Auerbach RP (2007) Responses to depression in children: Reconceptualizing the relation among response styles. J Abnormal Child Psychol 35: 913-927.

2. Abela JRZ, Brozina K, de Haigh EP (2002) An examination of the response styles theory of depression in third- and seventh-grade children: A short-term longitudinal study. J Abnormal Child Psychol 30: 515-527.

3. Abela JRZ, Hankin BL (2008) Cognitive vulnerability to depression in children and adolescents: A developmental psychopathology perspective. In: Abela JRZ, Hankin BL (eds) Childhood and adolescent depression: Causes treatment and prevention. New York, Guilford Press, pp 35-78.

4. Abela JRZ, Vanderbilt E, Rochon A (2004) A test of the integration of the response styles theory and social support theories of depression in third and seventh grade children. $J$ Soc Clin Psychol 5: 653-674.

5. Abbott MJ, Rapee RM (2004) Post-event rumination and negative self-appraisal in social phobia and after treatment. J Abnorm Psychol 113: 136-144.

6. Bagby RM, Rector NA, Bacchiochi JR, McBride C (2004) The stability of the response styles questionnaire rumination scale in a sample of patients with major depression. Cogn Ther Res 28: 527-538.

7. Bieling PJ, Antony MM, Swinson RP (1998) The State-Trait Anxiety Inventory, Trait version: structure and content re-examined. Behav Res Ther 36: 777-788.

8. Blagden JC, Craske MG (1996) Effects of active and passive rumination and distraction: A pilot replication with anxious mood. J Anx Dis 10: 243-252.

9. Bögels SM (2006) Task concentration training versus applied relaxation, in combination with cognitive therapy, for social phobia patients with fear of blushing, trembling, and sweating. Behav Res Ther 44: 1199-1210.

10. Bögels SM, Mansell W (2004) Attention processes in the maintenance and treatment of social phobia: Hypervigilance, avoidance and self-focused attention. Clin Psychol Rev 24: 827-856.

11. Burwell RA, Shirk SR (2007) Subtypes of rumination in adolescence: Associations between brooding, reflection, depressive symptoms, and coping. J Clin Child Adolescent Psychol 36: 5665.

12. Chang EC (2004) Distinguishing between ruminative and distractive responses in dysphoric college students: Does indication of past depression make a difference? Pers Indiv Diff 36: 845855.

13. Ciarrochi J, Scott G, Deane F, Heaven P (2003) Relations between social and emotional competence and mental health: a construct validation study. Pers Indiv Diff 35: 1947-1963.

14. Ciesla JA, Roberts JE (2002) Self-directed thought and response to treatment for depression: A preliminary investigation. $J$ Cogn Psychother 16: 435-453.

15. Comer JS, Kendall PC (2004) A symptom-level examination of parent-child agreement in the diagnosis of anxious youths. J Am Acad Child Adolesc Psychiatry 43:878-886

16. Cox BJ, Enns MW, Walker JR, Kjernisted K, Pidlubny SR (2001) Psychological vulnerability in patients with major depression versus panic disorder. Behav Res Ther 39: 567-573. 
17. Driscoll KA (2004) Children's response styles and risk for depression and anxiety: developmental and sex differences. Unpublished Dissertation, Florida State University.

18. Finch AJ Jr, Montgomery L, Deardorff P (1974) Reliability of state-trait anxiety with emotionally disturbed children. J Abnorm Child Psychol 2: 67-69.

19. Flett GL, Madorsky D, Hewitt PL, Heisel MJ (2002) Perfectionism cognitions, rumination, and psychological distress. J Rational-Emotive Cogn Behav Ther 20: 33-47.

20. Fresco DM, Frankel AN, Mennin DS, Turk CL, Heimberg RG (2002) Distinct and overlapping features of rumination and worry: The relationship of cognitive production to negative affective states. Cogn Ther Res 26: 179-188.

21. Harrington JA, Blankenship V (2002) Ruminative thoughts and their relation to depression and anxiety. J Applied Soc Psychol 32: 465-485.

22. Harvey A, Watkins E, Mansell W, Shafran R (2004) Cognitive behavioural processes across psychological disorders: a transdiagnostic approach to research and treatment. Oxford, Oxford University Press.

23. Hayes SC, Strosahl KD, Wilson KG (2003) Acceptance and commitment therapy: An experiential approach to behaviour change. New York, Guilford.

24. Hilt LM, Cha CB, Nolen-Hoeksema S (2008) Non-suicidal self-injury in young adolescent girls: Moderators of the distress-function relationship. J Consult Clin Psychol 76: 63-71.

25. Jacobson NS, Dobson KS, Truax PA, Addis ME, Koermer K, Gollan JK, Gortner E, Prince SE (1996) A component analysis of cognitive-behavioral treatment for depression. J Consult Clin Psychol 64: 295-304.

26. Jacobson NS, Martell CR, Dimidjian S (2001) Behavioral activation treatment for depression: Returning to contextual roots. Clin Psychol Sci Pract 8: 255-270.

27. Just N, Alloy LB (1997) The response styles theory of depression: Tests and an extension of the theory. J Abnorm Psychol 106: 221-229.

28. Kocovski NL, Endler NS, Rector NA, Flett GL (2005) Ruminative coping and post-event processing in social anxiety. Behav Res Ther 43: 971-984.

29. Kovacs M (1992) Children's Depression Inventory, CDI. Manual. Toronto (Ontario), Multi-Health Systems Inc.

30. Kuehner C, Weber I (1999) Responses to depression in unipolar depressed patients: An investigation of Nolen-Hoeksema's response styles theory. Psychol Med 29: 1323-1333.

31. Lam D, Smith S, Checkley S, Rijsdijk F, Sham P (2003) Effect of neuroticism, response style and information processing on depression severity in a clinically depressed sample. Psychol Med 33: 469-479.

32. Lara ME, Klein DN, Kasch KL (2000) Psychosocial predictors of the short-term course and outcome of major depression: A longitudinal study of a nonclinical sample with recent-onset episodes. J Abnorm Psychol 109: 644-650.

33. Lewinsohn PM, Antonuccio DO, Breckenridge JS, Teri L (1984) The coping with depression course. Eugene OR, Castalia.

34. Lyubomirsky S, Nolen-Hoeksema S (1993) Self-perpetuating properties of dysphoric rumination. J Pers Soc Psychol 65: 339-349.

35. Lyubomirsky S, Tucker KL, Caldwell ND, Berg K (1999) Why ruminators are poor problem solvers: Clues from the phenomenology of dysphoric rumination. J Pers Soc Psychol 77: 10411060.

36. Miranda R, Nolen-Hoeksema S (2007). Brooding and reflection: Rumination predicts suicidality at one-year follow up in a community sample. Behav Res Ther 45: 3088-3095.

37. Morrow J, Nolen-Hoeksema S (1990) Effects of responses to depression on the remediation of depressive affect. J Pers Soc Psychol 58: 519-527. 
38. Muris P, Roelofs J, Meesters C, Boomsma P (2004) Rumination and worry in nonclinical adolescents. Cogn Ther Res 28: 539-554.

39. Muris P, Roelofs J, Rassin E, Franken I, Mayer B (2005) Mediating effects of rumination and worry on the links between neuroticism, anxiety, and depression. Pers Indiv Diff 39: 1105-1111.

40. Muris P, Fokke M, Kwik D (2009) The ruminative response style in adolescents: An examination of its specific link to symptoms of depression. Cogn Ther Res. 33:21-32

41. Nolen-Hoeksema $S$ (1987) Sex differences in unipolar depression: Evidence and theory. Psychol Bull 101: 259-282.

42. Nolen-Hoeksema $S$ (1991) Responses to depression and their effects on the duration of depressive episodes. J Abnorm Psychol 100: 569-582.

43. Nolen-Hoeksema S (1998) Ruminative coping with depression. In: Heckhausen J, Dweck CS (eds) Motivation and self-regulation across the life span. New York, Cambridge University Press, pp. 237-256.

44. Nolen-Hoeksema $S$ (2000) The role of rumination in depressive disorder and mixed anxiety/depressive symptoms. J Abnorm Psychol 109: 504-511.

45. Nolen-Hoeksema S, Girgus JS (1994) The emergence of gender differences in depression during adolescence. Psychol Bull 115: 424-443.

46. Nolen-Hoeksema S, Harrell ZA (2002) Rumination, depression, and alcohol use: Tests of gender differences. J Cogn Psychother 16: 391-403.

47. Nolen-Hoeksema S, Morrow J (1991) A prospective study of depression and posttraumatic stress symptoms after a natural disaster: The 1989 Loma Prieta earthquake. J Pers Soc Psychol 61: 115-121.

48. Nolen-Hoeksema S, Morrow J (1993) Effects of rumination and distraction on naturally occurring depressed mood. Cogn Emot 7: 561-570.

49. Nolen-Hoeksema S, Stice E, Wade E, Bohon C (2007) Reciprocal relations between rumination and bulimic, substance abuse and depressive symptoms in female adolescents. J Abnorm Psychol 116: 198-207.

50. Nolen-Hoeksema S, Wisco BE, Lyubomirsky S (2008) Rethinking Rumination. Persp Psychol Sci 3: 400-424.

51. Papageorgiou C, Wells A (2004) Depressive rumination: nature, theory and treatment. Chichester, Wiley.

52. Robinson LA, Alloy LB (2003) Negative cognitive styles and stress-reactive rumination interact to predict depression: A prospective study. Cogn Ther Res 27: 275-292.

53. Schwartz JAJ, Koenig LJ (1996) Response styles and negative affect among adolescents. Cogn Ther Res 20: 13-36.

54. Segal ZV, Williams JMG, Teasdale JD (2002) Mindfulness-based cognitive therapy for depression: A new approach to preventing relapse. New York, Guilford.

55. Segerstrom SC, Tsao JCl, Alden LE, Craske MG (2000) Worry and rumination: Repetitive thought as a concomitant and predictor of negative mood. Cogn Ther Res 24: 671-688.

56. Smith JM, Alloy LB, Abramson LY (2006) Cognitive vulnerability to depression, rumination, hopelessness, and suicidal ideation: Multiple pathways to self-injurious thinking. Suicide LifeThreatening Behav 36: 443-454.

57. Spasojevic J, Alloy LB (2001) Rumination as a common mechanism relating depressive risk factors to depression. Emotion 1: 25-37.

58. Spielberger CD (1973) Manual for the State-Trait Anxiety Inventory for Children. Palo Alto CA, Consulting Psychologists Press.

59. Vaus D (2001) Research designs in social research. Sage Publications Ltd, London 


\section{CHAPTER 4}

60. Vickers KS, Vogeltanz-Holm ND (2003) The effects of rumination and distraction tasks on psychophysiological responses and mood in dysphoric and nondysphoric individuals. Cogn Ther Res 27: 331-348.

61. Ward A, Lyubomirsky S, Sousa L, Nolen-Hoeksema S (2003) Can't quite commit: Rumination and uncertainty. Pers Soc Psychol Bull 29: 96-107.

62. Watkins E (2004) Appraisals and strategies associated with rumination and worry. Pers Indiv Diff 37: 679-694.

63. Wood JV, Saltzberg JA, Neale JM, Stone AA, Rachmiel TB (1990) Self-focused attention, coping responses, and distressed mood in everyday life. J Pers Soc Psychol 58: 1027-1036.

64. Ziegert DI, Kistner JA (2002) Response styles theory: Downward extension to children. J Clin Child Adolescent Psychol 31: 325-334. 


\title{
Chapter 5
}

\section{Stress-reactive rumination, negative cognitive style, and stressors in relationship to depressive symptoms in non-clinical youth $^{1}$}

Lea Rood, Jeffrey Roelofs, Susan M. Bögels, Cor Meesters

\begin{abstract}
The role of cognitive vulnerability in the development of depressive symptoms in youth might depend on age and gender. The current study examined cognitive vulnerability models in relationship to depressive symptoms from a developmental perspective. For that purpose, 805 youth (aged 10-18, 59.9\% female) completed selfreport measures. Stress-reactive rumination was strongly related to depressive symptoms. Negative cognitive style (i.e., tendency to make negative inferences) in the domains of achievement and appearance was more strongly and consistently related to depressive symptoms in girls compared to boys. Negative cognitive style in the interpersonal domain was positively related to depressive symptoms in both girls and boys, except in early adolescent girls reporting few stressors. To conclude, the cognitive vulnerability-stress interaction may be moderated by the combination of age and gender in youth, which may explain inconsistent findings so far. Current findings highlight the importance of taking into account domain specifity when examining models of depression in youth.
\end{abstract}

\footnotetext{
${ }^{1}$ Accepted in: Journal of Youth and Adolescence.
} 


\section{Introduction}

Developmental models of depression in adolescence have conceptualized cognitive vulnerability within the context of a diathesis-stress account (see Hankin \& Abramson, 2001; Hyde, Mezulis, \& Abramson, 2008), in which cognitive vulnerability represents the diathesis. The cognitive vulnerability-stress model proposes that cognitive vulnerability factors are more likely to lead to depression in the presence of stressors. A cognitive vulnerability factor that has been hypothesised to interact with stressors in the prediction of depression is negative cognitive style (see Abramson, Metalsky, \& Alloy, 1989). Negative cognitive style can be defined as the general tendency to make negative attributions and inferences about the causes, consequences, and implications of stressful events. More specifically, these attributions and inferences include the tendencies to view (1) the causes of negative events as global and stable, (2) negative events as having many disastrous consequences, and (3) the self as flawed and deficient after the occurrence of negative events. Stressors in youth have been defined as "environmental events or chronic conditions that objectively threaten the physical and/or psychological health or well-being of individuals [...]" (Grant, Compas, Stuhlmacher, Thurm, McMahon, \& Halpert, 2003, p. 450). Stressful negative life events and daily hassles (generally taken together) have represented the stress-component in cognitive vulnerabilitystress models in youth (e.g., Abela, 2001; Abela \& Payne, 2003, Hankin, Abramson, \& Siler, 2001). Major life events are related especially to the onset of depression (Brown \& Harris, 1978; Kendler, Thornton, \& Gardner, 2001; Kessler, 1997; Monroe \& Harkness, 2005) whereas daily hassles predict increases in psychological symptoms (Kanner, Coyne, Schaefer, \& Lazarus, 1981) and may be related to the recurrence of depression (see Monroe \& Harkness, 2005).

A variable closely related to negative cognitive style is stress-reactive rumination, which is defined as "the tendency to ruminate on the negative inferences following stressful events" (Robinson \& Alloy, 2003, p. 276). Alloy and colleagues (Alloy, Abramson, Hogan, Whitehouse, Rose, Robinson et al., 2000; Robinson \& Alloy, 2003) introduced the concept of stress-reactive rumination to explain the onset and duration of depression, hypothesising that the effect of negative inferences (i.e., a negative cognitive style) on depression is more detrimental when these inferences are actively rehearsed (i.e., ruminated upon). Indeed, Alloy and colleagues found that individuals who have a negative cognitive style, combined with a tendency to ruminate on negative inferences, were particularly vulnerable to develop depressive episodes (Alloy et al., 2000; Robinson \& Alloy, 2003). Whether stress-reactive

rumination moderates the relationship between negative cognitive style and depressive symptoms has not been examined in youth to the authors' best knowledge. The examination of the potential interplay between two cognitive 
vulnerability factors, one reflecting negative thought content, and the other the repetition of the negative content, may contribute to knowledge on the pathogenesis of depression and on how to target cognitive vulnerability to depression in youth. Finally, stress-reactive rumination may worsen the effects of stressors on depressive symptoms in the context of a cognitive vulnerability-stress model. This hypothesis also has not yet been tested.

When testing cognitive models of depression in youth, developmental factors should be taken into account. Cognitive diatheses have been thought to become stable predictors of depressive symptoms during adolescence, when cognitive capacities are further developing and maturing (see Cole, Ciesla, Dallaire, Jacquez, Pineda, LaGrange et al., 2008; Turner \& Cole, 1994). Recent longitudinal studies involving youth samples indicate that age might moderate the relationship between the cognitive variables and depressive symptoms (Cole et al., 2008; Turner \& Cole, 1994). Empirical support for cognitive vulnerability-stress models is stronger in adolescent samples compared to child samples (Abela \& Hankin, 2008; Joiner \& Wagner, 1995; Lakdawalla, Hankin, \& Mermelstein, 2007). The interaction between cognitive vulnerability and stressors may occur somewhere between the ages of 11 and 15 (see Cole et al., 2008; Hyde et al., 2008). Furthermore, Abela and Hankin (2008) have suggested that cognitive factors may be relatively independent factors in childhood, but may become more interrelated in adolescence, during which a solid combination of these factors may make an individual vulnerable to develop depressive symptoms. This may imply that stress-reactive rumination, negative cognitive style, and age interact in adolescence.

Studies so far have examined the moderating effect of age on cognitive variables, with age being indicative of the level of development or maturation. However, it may be interesting to examine another variable that may reflect the level of maturity more closely, i.e., puberty. Studies have shown that the gender difference in depression rates emerges in puberty, with girls reporting more depressive symptoms than boys (see Hankin, Wetter, \& Cheeley, 2008). Pubertal status has been linked to the increase in depressive symptoms in girls (Angold \& Costello, 2006). Angold, Costello, and Worthman (1998) found that after mid-puberty, girls had higher rates of clinical depression compared to boys. Age did not significantly moderate this relationship, which could suggest that the emergence of the gender difference in depression rates is caused by puberty-related, rather than age-related changes. The moderating role of pubertal status instead of age in the testing of cognitive vulnerability-stress models has not yet been examined to our knowledge.

Further, models explaining gender differences in depression have proposed that cognitive vulnerability factors combined with high levels of stressors may be related more strongly to depressive symptoms in girls compared to boys (see Hankin \& Abramson, 2001; Nolen-Hoeksema \& Girgus, 1994). Empirical support for the 
moderating role of gender is mixed. Prospective studies in child and early adolescent samples (range of mean ages of the samples: 8.9-12.9) have shown that cognitive vulnerability moderates the effects of stressors on depressive symptoms only in girls (Abela \& McGirr, 2007; partial support in Abela, 2001), whereas other studies involving adolescents (range of mean ages: 11.9-18.1) have found support for a cognitive vulnerability-stress model only in boys (Hankin et al., 2001; Morris, Ciesla, \& Garber, 2008; Stone, Gibb, \& Coles, 2010). In sum, findings indicate that the moderating roles of both age and gender, as well as their potential interplay, should be included in the examination of cognitive models of depression in youth. Finally, researchers (Hyde et al., 2008; Mezulis, Abramson, \& Hyde, 2002; Mezulis \& Funasaki, 2009) have argued that domain specificity of vulnerability factors should be taken into account when examining models of depression. Findings show that women have a stronger tendency to ruminate on stressors related to physical appearance and interpersonal problems than men (Mezulis et al., 2002), and may be more likely to develop negative cognitive styles in the domains of interpersonal relationships and physical appearance. How domain specificity of cognitive vulnerability factors is related to depressive symptoms in adolescence has not been examined yet from a developmental viewpoint.

\section{The Current Study}

This study aimed to examine three cognitive vulnerability models for depressive symptoms in non-clinical youth from a developmental viewpoint. First, it was hypothesized that stress-reactive rumination would moderate (i.e., exacerbate) the relationship between negative cognitive style and depressive symptoms (Model 1). Second, stress-reactive rumination was hypothesized to moderate (i.e., exacerbate) the relationship between stressors and depressive symptoms (Model 2). Third, it was hypothesized that negative cognitive style would moderate (i.e., exacerbate) the relationship between stressors and depressive symptoms (Model 3). Regarding domain specificity, it was explored whether different results would be obtained when examining specific domains of negative cognitive style instead of the aggregate score for negative cognitive style.

Age and gender were taken into account as potential moderators in the examination of these three cognitive models. More specifically, it was expected that cognitive vulnerability factors (negative cognitive style/stress-reactive rumination) and stressors would worsen each other's relationship with depressive symptoms more strongly as age increases. Furthermore, as evidence regarding the moderating role of gender is mixed (i.e., some studies show a significant interaction between cognitive vulnerability and stressors only in girls and other studies only in boys) the moderating role of gender was explored in combination with the moderating role of age. Further, 
it was examined whether pubertal status would be a more sensitive moderator in these models compared to age.

\section{Methods}

\section{Participants and Procedure}

Participants were recruited at 35 primary and 6 secondary schools in the southern regions of The Netherlands. Principals of schools were approached and informed about the purpose of the study. When given permission to recruit at their school, the researchers came into the classrooms during regular class and held a 10-minute talk in front of all pupils. In this talk, the purpose of this study was explained and informed consent forms were handed out and returned two weeks later. On average, $25 \%$ of the children who were approached agreed to participate. We obtained written informed consent from all parents and from all children aged 12 and above, in accordance with formal regulations. A total number of 805 participants completed the questionnaires. Some had more than $10 \%$ missing values on one of the measures and were therefore excluded from that measure. As a consequence, sample size ranged between 751 and 805 across the various analyses.

The mean age of the sample was 12.4 years $(S D=1.9$; age range $10-18)$; $59.9 \%$ was female. Age at baseline was skewed towards the younger ages (\%boys/\%girls): $15 \% / 17 \%$ was age $10,25 \% / 22 \%$ was age $11,23 \% / 17 \%$ was age 12 , $15 \% / 15 \%$ was age $13,12 \% / 13 \%$ was age $14,7 \% / 9 \%$ was age 15 , and $4 \% / 6 \%$ was age 16-18. About half of the participants $(47.8 \%, N=385)$ received secondary education, of which $38.2 \%(N=147)$ were in pre-university education, $37.1 \%(N=$ $143)$ in school of higher general secondary education, and $24.7 \%(N=95)$ in lower professional secondary education. Ethnicity was not reported, but considering the ethnic constellation of the southern regions of the Netherlands, it is acceptable to assume that about $95 \%$ of the sample were Caucasian. Participants completed a battery of questionnaires at home. They did not receive compensation for their participation. Little information is available on how the study's participants differed from those who did not participate. The proportion of the sample that exhibited clinically significant levels of depressive symptoms was $12.9 \%$ (CDI cut off score $\geq$ 16; see Timbremont, Braet, \& Dreessen, 2004). The research protocol was approved by a local Institutional Review Board.

\section{Measures}

Depressive Symptoms

The Children's Depression Inventory (CDI; Kovacs, 1981; Dutch/Flemish version: Timbremont \& Braet, 2001; 2002) is based on the Beck Depression Inventory for adults. The CDI is a widely used self-report questionnaire which aims to measure the 
level of depressive symptoms in children. For each of the 27 items three statements are given, of which the subject has to choose one (e.g., "I am sad sometimes / I am often sad / I am always sad") that represents best how he or she has been feeling the last two weeks. Reliability in terms of internal consistency is good and the convergent validity of the CDI is supported (Timbremont \& Braet, 2001).

Stress-Reactive Rumination (from here referred to as "SR-rumination")

The Dutch version of the Stress-Reactive Rumination Scale for children (SRRS-C) is a downward extension of the SRRS developed for adults (Robinson, 1997; Robinson \& Alloy, 2003). The SRRS-C was translated into Dutch, and subsequently back translated by a native English speaker and then was approved by the original authors. The SRRS-C aims to measure the frequency of negative thoughts about negative inferences following stressful events (e.g., "I think about how the stressful event was totally my fault"). The SRRS-C consists of nine items which are scored on a four-point Likert type scale (i.e., 1 = almost never, 2 = sometimes, 3 = often, $4=$ almost all the time). Reliability $(\alpha=.82)$ and concurrent criterion validity of the SRRS$\mathrm{C}$ are adequate to good; furthermore, SR-rumination can meaningfully be distinguished from emotion-focused rumination and worry (Rood, Roelofs, Bögels, \& Alloy, 2010).

Negative Cognitive Style (from here referred to as "NCS")

The Adolescent Cognitive Styles Questionnaire (ACSQ; Hankin \& Abramson, 2002) measures inferential styles in response to negative events. The original ACSQ consists of 12 hypothetical negative event scenarios covering the domains of academic/scholar achievements and interpersonal relations. In the current study, we used a version which also contains a third domain particularly relevant for adolescence, i.e. "physical appearance" (4 items). Examples of hypothetical event scenarios in the different domains are: "You want to go to a big party, but nobody invites you" (interpersonal), "Someone says something bad about how you look" (appearance), and "You take a test and get a bad grade" (achievement). Each hypothetical event scenario is accompanied by five questions, measuring internal/external attribution of the cause, inferences about stability and globality of the cause, and inferences about consequences and self-worth, rated on a seven-point scale. An aggregate score can be computed by summing up scores on all scales, with high scores defining a high NCS. The psychometric properties (reliability, testretest reliability, and construct validity) of the ACSQ are supported (Hankin \& Abramson, 2002). 


\section{Stressors}

The Children's Life Events Scale (CLES; as described in Abela \& VéronneauMcArdle, 2002) is composed of two questionnaires. The first 37 items are derived from the Children's Hassles Scale (Kanner, Feldman, Weinberger, \& Ford, 1987) and describe daily hassles (e.g. "You had to clean up your room"). Responses are rated on a four-point scale, with $0=$ "when it didn't happen"; 1 = "when it occasionally happened"; 2 = "when it often happened"; and 3 = "when it happened all the time". The other 22 items, taken from the Coddington Life Stress Scale (Coddington, 1972), describe relatively serious life events (e.g., "Your mother or father lost her / his job"). One can answer "yes" or "no" dependent on whether the life event occurred the past year. For the current study the two scales were collapsed into one single scale labeled "stressors", which is consistent with previous studies (e.g., Abela \& Sarin, 2002). For that purpose, the daily hassles items were dichotomized, with original scores 1, 2 and 3 recoded in 1 ("it happened"), and original score 0 remaining 0 ("it didn't happen").

\section{Pubertal Status}

The Physical Development Scale (PDS; Petersen, Crockett, Richards, \& Boxer, 1988 ) is a self-report questionnaire measuring perceived pubertal status. The PDS consists of multiple choice questions regarding growth spurt, skin changes, and pubic hair. An example of an item is: "Have you noticed any skin changes?". The items have four answering options, ranging from " 1 = not yet..." to " 4 = seems completed". A high total score on the questionnaire indicates a high pubertal status. The version for girls also includes items on the menarche and breast growth, while the version for boys includes items on voice changes and facial hair growth. The PDS is acceptably reliable in terms of internal consistency; validity however needs further investigation (see for reviews Coleman \& Coleman, 2002; Schmitz, Hovell, Nichols, Irvin, Keating, Simon et al., 2004). Studies have shown that youth are capable of making a rough estimation of their pubertal status (Bond, Clements, Bertalli, Evans-Whipp, McMorris, Patton et al., 2006; Coleman \& Coleman, 2002; Petersen et al., 1988; Schmitz et al., 2004). It should be emphasized that self-perception of pubertal status is measured rather than actual pubertal status (Dorn, Dahl, Woodward, \& Biro, 2006). The original (English) version was translated into Dutch for this study.

\section{Statistical Analysis}

The data were analysed using SPSS version 18.0. For individuals with less than $10 \%$ missing values on a single self-report measure, a regression technique was used to impute the missing values by estimating the value on the basis of the scores of that individual on the remaining items, as well as on the scores of others on the item for which a value was missing. Cases with more than $10 \%$ missing values on one of the 
measures were excluded from that specific measure. Binary logistic regression analyses were performed to check whether scores on questionnaires were missing at random or missing not at random (i.e., whether missing scores could be explained by the independent and dependent variables). Missing ACSQ total scores were significantly predicted by age $(\operatorname{Exp} \beta=1.20, p=.04)$, indicating that the older the participant, the more likely the ACSQ was completed. The ACSQ was the last questionnaire in the battery and therefore may not have been completed by some of the younger participants due to tiredness or boredom.

Because the sample was nested within schools, the intra-class correlation was checked in order to determine whether intra-unit dependency needed be controlled for. The ICC indicated low homogeneity of depressive symptoms within schools (ICC $=.02$ ), which justified regular regression analyses. Before carrying out the analyses, assumptions were checked. The total scores on the CDI were not normally distributed and therefore underwent a square root transformation, resulting in skewness and kurtosis values between -1.0 and +1.0 (for all variables skewness range: -.01 to .90 ; kurtosis range: -1.10 to .50). Examination of plots of the standardized residuals against the standardized predicted values, partial plots, and normal probability plots of the residuals for each regression model indicated no violations of the assumptions of homogeneity of variances, homoscedastity, and linearity. All variables were standardized prior to creating interactions.

We carried out normal regression analyses with depressive symptoms as dependent variable. The models were tested separately from each other, following a top-down procedure starting with a full model (i.e., the four-way interaction) and subsequently eliminating interactions that were not significant. The starting models were as follows: (1) four-way interaction between NCS, SR-rumination, age, and gender; (2) four-way interaction between SR-rumination, stressors, age, and gender; and (3) four-way interaction between NCS, stressors, age, and gender. Domain specificity of NCS was examined by re-running the analyses for Models 1 and 3, with NCS in the domains of scholar achievement, interpersonal relations, and physical appearance separately (from here referred to as "NCS-achievement", "NCSinterpersonal", "NCS-appearance"), instead of the aggregate score for NCS. Finally, we tested alternative models repeating the same series of analyses with pubertal status instead of age.

\section{Results}

\section{General Findings}

Descriptive statistics for the total sample as well as for boys and girls separately are presented in Table 1, together with the reliability coefficients of all measures. 
Table 1: Descriptive Statistics (Raw Means and Standard Deviations), Internal Consistency Ratings, and Gender Differences ( $N=754-805)$

\begin{tabular}{lllllllllll}
\hline & Variable & \multicolumn{3}{c}{ Total sample } & \multicolumn{1}{c}{ Girls } & \multicolumn{1}{c}{ Boys } \\
\hline & & Mean & $S D$ & $\alpha$ & Mean & $S D$ & Mean & $S D$ & $t$ & $d f$ \\
\hline 1. & $\begin{array}{l}\text { Depressive symptoms } \\
\text { (CDI) }\end{array}$ & 8.0 & 6.3 & .86 & 8.3 & 6.6 & 7.5 & 5.9 & 1.48 & 786 \\
2. & $\begin{array}{l}\text { Stress-reactive } \\
\text { rumination (SRRS-C) }\end{array}$ & 16.7 & 5.1 & .88 & 17.2 & 5.2 & 16.0 & 4.8 & $3.19^{*}$ & 792 \\
3. & $\begin{array}{l}\text { Negative cognitive style } \\
\text { (ACSQ) }\end{array}$ & 122.5 & 51.5 & $.89^{1}$ & 124.6 & 51.4 & 119.4 & 51.6 & 1.38 & 752 \\
4. & Stressors (CLES) & 26.2 & 7.9 & .85 & 26.1 & 7.7 & 26.5 & 8.3 & .76 & 800 \\
5. & Pubertal status (PDS) & 11.3 & 4.2 & .84 & 12.4 & 4.2 & 9.8 & 3.5 & $9.22^{*}$ & 764 \\
6. & Age & 12.4 & 1.9 & - & 12.4 & 1.9 & 12.3 & 1.7 & 1.23 & 736 \\
\hline
\end{tabular}

Note. ${ }^{*} p<.001$. ${ }^{1}$ The reliability coefficient of the aggregate score of the ACSQ was computed by averaging the reliability coefficients for the inferential styles (without internality) separately. CDI = Children's Depression Inventory. SRRS-C = Stress-Reactive Rumination Scale for Children. ACSQ = Adolescent Cognitive Styles Questionnaire. CLES = Children's Life Events Scale. PDS = Physical Development Scale.

All questionnaires showed good reliability in terms of internal consistency. Girls scored higher on SR-rumination and pubertal status compared to boys. The ACSQ subscales stability, globality, consequences, and self-worth were substantially related to depressive symptoms ( $r s=.44-.51)$, whereas the internality scale correlated low with depressive symptoms $(r=.17)$. All ACSQ subscales were highly interrelated ( $r$ s $=.42-.86)$. For the internality scale the correlations with depressive symptoms and the other ACSQ subscales were substantially lower than for the other subscales ( $p$ s $<$.001). Therefore, the internality dimension was not included in the composite scale of the ACSQ. SR-rumination, NCS, and stressors were all strongly associated with depressive symptoms; while age and pubertal status were modestly related to depressive symptoms (see Table 2).

Table 2: Pearson Correlation Coefficients between the (if necessary transformed) Variables $(\mathrm{N}=753-805)$

\begin{tabular}{llllllll}
\hline & & 1. & 2. & 3. & 4. & 5. & 6. \\
\hline 1. & Depressive symptoms (CDI) & - & & & & & \\
2. & Stress-reactive rumination (SRRS-C) & $.59^{* *}$ & - & & & & \\
3. Negative cognitive style (ACSQ) & $.51^{* *}$ & $.45^{\star *}$ & - & & & \\
4. & Stressors (CLES) & $.55^{* *}$ & $.42^{* *}$ & $.35^{\star *}$ & - & & \\
5. Pubertal status (PDS) & $.16^{* *}$ & $.21^{* *}$ & $.17^{* *}$ & .04 & - & \\
6. Age & $.12^{* *}$ & $.17^{* *}$ & $.14^{* *}$ & .01 & $.75^{* *}$ & - \\
7. & Gender & .05 & $.11^{* *}$ & .05 & -.03 & $.30^{* *}$ & .04 \\
\hline
\end{tabular}

Note. ${ }^{*} p<.05,{ }^{* *} p \leq .001$ (two-tailed). CDI = Children's Depression Inventory. SRRS-C = StressReactive Rumination Scale for Children. ACSQ = Adolescent Cognitive Styles Questionnaire. CLES = Children's Life Events Scale. PDS = Physical Development Scale. 


\section{Model 1: NCS Moderated by SR-Rumination}

The interaction between NCS and SR-rumination was not significant, nor did age and gender moderate the relationships between the variables (independently and in interaction with each other) and depressive symptoms. Only the main effects of SRrumination and NCS were significant, indicating that both variables are related to depressive symptoms independently of each other. Age and sex were not significantly related to depressive symptoms when controlling for NCS and SRrumination. The final (reduced) model is displayed in Table 3. The analyses with NCS per domain yielded almost identical findings, i.e., significant main effects were found for NCS per domain and SR-rumination. Results are therefore not reported.

Table 3: Results of the Final Regression Models in Association with Depressive Symptoms $(\mathrm{N}=752-785)$

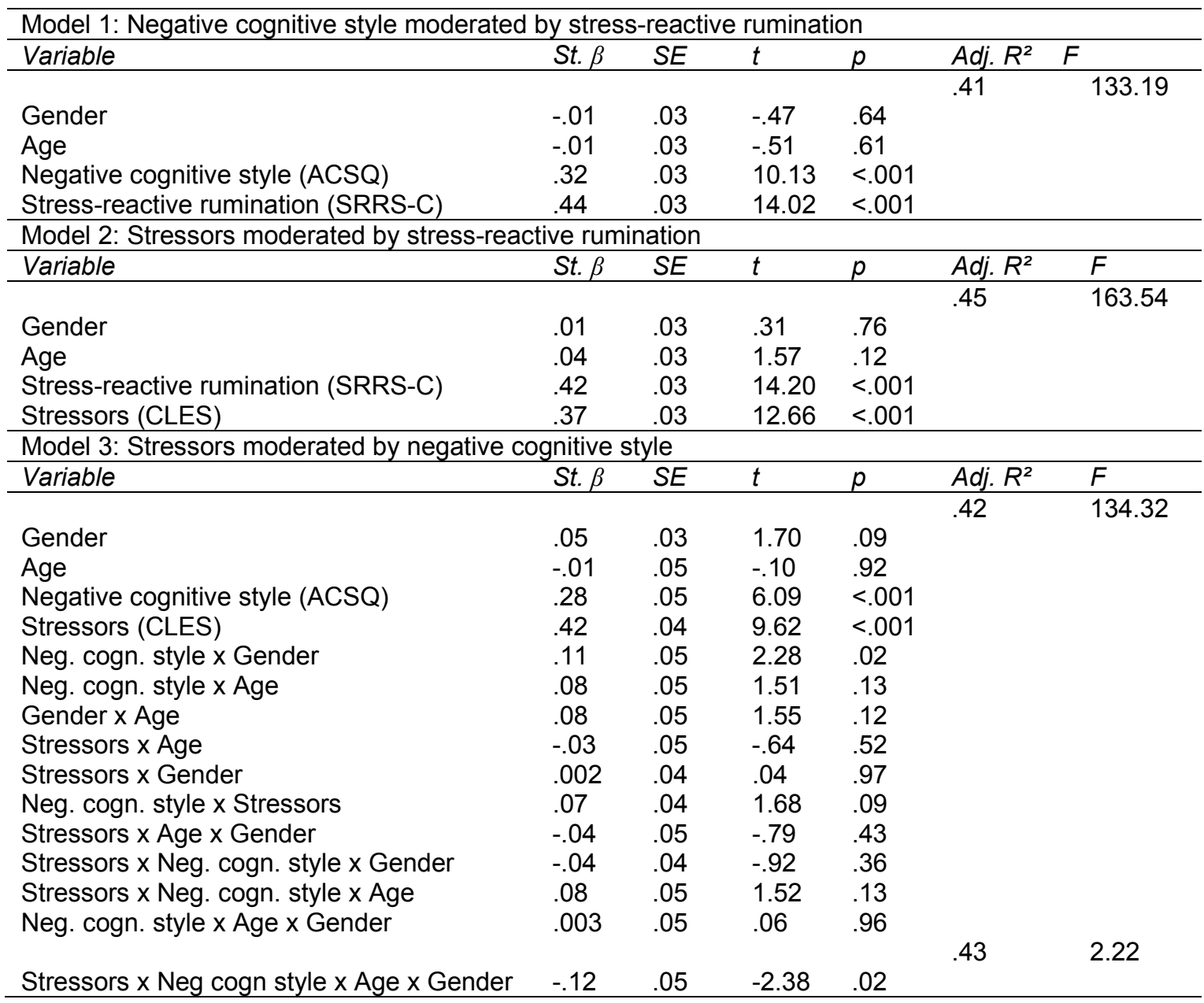

Note. $A C S Q=$ Adolescent Cognitive Styles Questionnaire. SRRS-C = Stress-Reactive Rumination Scale for Children. CLES = Children's Life Events Scale. 


\section{Model 2: Stressors Moderated by SR-Rumination}

The interaction between stressors and SR-rumination was not significant, nor did age and gender moderate the relationships between the variables and depressive symptoms. Only the main effects of SR-rumination and stressors were significant, indicating that both variables were independently related to depressive symptoms. The final model is displayed in Table 3.

\section{Model 3: Stressors Moderated by NCS}

The four-way interaction between NCS, stressors, gender, and age was significant ( $\beta$ $=-.12, p=.02$ ), see Table 3 . The four-way interaction was examined more closely by splitting the data on high/low age (mean +/- $1 \mathrm{SD}$ ) and on gender. The interaction term between NCS and stressors was significant only in middle to late adolescent boys $(\beta=.33, p=.03)$. NCS related to depressive symptoms at the level of a trend in middle to late adolescent boys reporting many (mean $+1 \mathrm{SD})$ stressors $(\beta=.81, p=$ .10), whereas this relationship was not significant in middle to late adolescent boys reporting few (mean $-1 S D$ ) stressors $(\beta=.30, p=.37$ ). In early adolescent boys, stressors were significantly associated with depressive symptoms $(\beta=.59, p=.001)$, whereas NCS was not $(\beta=.11, p=.39)$. In girls, NCS $(\beta=.41, p=.001)$ and stressors $(\beta=.39, p=.001)$ were independently related to depressive symptoms, meaning that the strength of the relationship between one variable and depressive symptoms is not conditional on the other variable.

Regarding the domain specificity of $\mathrm{NCS}^{2}$, results showed a significant fourway interaction between stressors, NCS-achievement, age, and gender $(\beta=-.11, p=$ .02 ) in a similar way as with the aggregate NCS: NCS-achievement and depressive symptoms were significantly related in middle to late adolescent boys reporting many stressors $(\beta=.99, \mathrm{p}=.001)$, but not in those reporting few stressors $(\beta=.02, \mathrm{p}=$ .95). In early adolescent boys, stressors $(\beta=.59, \mathrm{p}<.001)$ were significantly related to depressive symptoms, whereas NCS-achievement was not $(\beta=.13, p=.31)$. In girls, NCS-achievement $(\beta=.35, \mathrm{p}<.001)$ and stressors $(\beta=.41, \mathrm{p}<.001)$ were related to depressive symptoms, independently of each other.

The four-way interaction between NCS-interpersonal, stressors, age, and gender was significant $(\beta=-.10, \mathrm{p}=.04)$. The interaction was split on gender and next on high/low (mean $\pm 1 S D$ ) events. The interaction between NCS-interpersonal and age was significant for girls reporting few stressors $(\beta=.36, p=.02)$, indicating that NCS-interpersonal and depressive symptoms were positively related in middle to late adolescent girls reporting few stressors $(\beta=.59, \mathrm{p}=.30)$, and negatively related in early adolescent girls reporting few stressors $(\beta=-.30, p=.47)$. NCS-interpersonal and depressive symptoms were significantly related in girls reporting many stressors

\footnotetext{
${ }^{2}$ T-tests revealed no gender differences on the scores on NCS in the different domains. Reliability was sufficient: $\alpha=.71$ for NCS-achievement; $\alpha=.73$ for NCS-interpersonal; $\alpha=.76$ for NCS-appearance.
} 
$(\beta=.49, \mathrm{p}<.001)$. NCS-interpersonal $(\beta=.26, \mathrm{p}<.001)$ and stressors $(\beta=.47, \mathrm{p}<$ .001 ) were independently related to depressive symptoms in boys.

The four-way interaction with NCS-appearance was not significant; instead, NCS-appearance interacted with gender $(\beta=.12, p=.01)$, indicating a stronger relationship between NCS-appearance and depressive symptoms in girls $(\beta=.35$, $\mathrm{p}=.001)$ compared to boys $(\beta=.22, \mathrm{p}=.001)$.

\section{Pubertal Status versus Age}

The analyses with pubertal status instead of age yielded different results with regard to the main models. The four-way interaction between NCS, stressors, pubertal status, and gender approached significance $(\beta=-.10, p=.08)$, indicating that the interaction between NCS and stressors was only significant in boys who perceived their pubertal status as high $(\beta=.42, p=.007)$. NCS was more strongly related to depressive symptoms in boys with high pubertal status that reported many (mean +1 $S D)$ stressors $(\beta=.73, p=.16)$ compared to boys with high pubertal status reporting few stressors $(\beta=.21, p=.74)$. In boys who reported low pubertal status, both NCS $(\beta=.48, p=.001)$ and stressors $(\beta=.27, p=.002)$ were significantly associated with depressive symptoms. The relationship between NCS and depressive symptoms was moderated by pubertal status in both Model $1(\beta=.07, p=.01)$ and Model $3(\beta=.07$, $p=.01$ ), indicating that NCS was more strongly related in participants reporting high pubertal status (mean $+1 \mathrm{SD} ; \beta=.68, p=.001$ ) compared to participants reporting low pubertal status (mean $-1 \mathrm{SD}, \beta=.47, p=.001$ ). Next to SR-rumination and stressors, pubertal status was modestly related to depressive symptoms $(\beta=.06, p=$ .03 ), indicating that participants reported more depressive symptoms as they perceived their pubertal status as higher.

\section{Discussion}

Stress-reactive rumination in combination with negative cognitive style may predict onset of depression in adults (Robinson \& Alloy, 2003). Not much is known about whether these two cognitive vulnerability factors interact in relationship to depressive

symptoms in youth. Furthermore, research has shown that cognitive vulnerabilitystress interactions in relationship to depressive symptoms emerge somewhere between the ages of 11-15 (Hyde et al., 2008). Studies suggest that the interaction between cognitive vulnerability and stressors may function differently in girls and boys during adolescence; however, evidence is inconsistent and may point to moderation by a combination of age and gender. This study aimed to examine three cognitive vulnerability models for depressive symptoms in non-clinical youth from a developmental viewpoint. The first model proposes that stress-reactive rumination moderates the relationship between negative cognitive style and depressive 
symptoms; the second model hypothesizes that stress-reactive rumination moderates the relationship between stressors and depressive symptoms; and the third model hypothesizes that negative cognitive style moderates the relationship between stressors and depressive symptoms. The potentially moderating effects of age, pubertal status, and gender were examined in all models. Domain specificity of negative cognitive style was explored.

Stress-reactive rumination ("SR-rumination") was related to depressive symptoms, independently of negative cognitive style ("NCS") or stressors, of which main effects were significant in both boys and girls. Second, NCS and stressors were both related to depressive symptoms in girls, independently of each other. The relationship between NCS and depressive symptoms approached level of significance in middle to late adolescent boys, but only in the presence of many stressors, supporting a cognitive vulnerability-stress model in middle to late adolescent boys. However, the examination of domain specificity of NCS yielded different results: NCS in the appearance domain was more strongly related to depressive symptoms in girls compared to boys, indicating that negative attributions and inferences about appearance may be associated with depressive symptoms in girls particularly. Furthermore, NCS in the interpersonal domain was related to depressive symptoms in boys and girls, except in early adolescent girls reporting few stressors, thus supporting a cognitive vulnerability-stress model in early adolescent girls.

With regard to the extension of the model of Robinson and Alloy (2003) to a youth sample, findings showed that NCS and SR-rumination accounted for a significant portion of the variance in depressive symptoms independently of each other. Our findings are thus not in line with Robinson and Alloy (2003) and Alloy et al. (2000), who found that SR-rumination worsens the effects of NCS on depression in adults. NCS and SR-rumination may not yet interact in youth because rumination has not stabilised yet in middle adolescence (Hankin, 2008).

The finding that SR-rumination did not moderate the relationship between stressors and depressive symptoms is inconsistent with earlier studies demonstrating moderation of stressors by general forms of rumination (Kraaij, Garnefski, de Wilde, Dijkstra, Gebhardt, Maes et al., 2003; Skitch \& Abela, 2008). An explanation might be that SR-rumination is specifically focused on negative inferences and attributions and as such, is hypothesized to worsen the effect of NCS rather than the effect of stressors. One may argue that SR-rumination does not worsen the relationship between stressors and depressive symptoms in participants that do not have a highly NCS, suggesting a three-way interaction between these variables. Therefore, the three-way interaction between NCS, SR-rumination, and stressors was tested posthoc, which was not significant. More research is needed to examine the possible 
interaction between NCS, SR-rumination, and stressors, for example in prospective high-risk designs.

Current findings provide support for a cognitive vulnerability-stress model (indicating that the aggregate NCS was only related to depressive symptoms in combination with many stressors) in middle to late adolescent boys, but not in girls and early adolescent boys. These findings are partially consistent with Cole et al. (2008) and Turner and Cole (1994) regarding the moderating role of age. However, present findings show that the moderating role of age only appeared in boys (and thus depended on gender). These findings are partially consistent with studies supporting the cognitive vulnerability-stress model for boys only (Hankin et al., 2001; Stone et al., 2010). It is important to note that the prospective studies of Hankin et al. and Stone et al. were conducted with middle to late adolescents, whereas other studies that found support for the interaction only in girls examined younger samples (e.g., Abela \& McGirr, 2007). Thus, current findings suggest that inconsistent results regarding the cognitive vulnerability-stress model in youth so far may be due to the moderating role of gender being dependent on age.

Current findings implicate that middle to late adolescent boys with a high NCS may only be vulnerable to develop depressive symptoms when experiencing many stressors, whereas girls with a high NCS may be vulnerable to depressive symptoms even without experiencing stressors. This might explain why girls after the age of 13 are more vulnerable to develop depressive symptoms compared to boys (see Kessler, 2003; Kuehner, 2003). Current findings regarding domain specificity also suggest that the moderating roles of age and gender depend on which domain of cognitive vulnerability is examined in interaction with stressors, supporting the plea of Hyde et al. (2008) and Mezulis et al. (2002) for the importance of examining domain specificity of cognitive vulnerability factors in developmental models of depression. To conclude, the cognitive vulnerability-stress interaction may be moderated by the combination of age and gender in youth, which may explain inconsistent findings so far.

\section{Age versus Pubertal Status}

When controlling for SR-rumination and stressors, age was not significantly associated with depressive symptoms; whereas pubertal status was, indicating that depressive symptoms increase as pubertal status increases. The two-way interaction age (or pubertal status) by gender (included in all models under test) was not significant; whereas it would be expected that girls report more depressive symptoms as level of maturation (age/pubertal status) increases compared to boys. Results showed that although the four-way interaction between NCS, stressors, gender, and age was significant while the four-way interaction with pubertal status was marginally significant, the interpretation of these interactions was largely similar, i.e., NCS and 
depressive symptoms were significantly related only in the presence of many stressors in middle to late adolescent boys (or in boys reporting a high pubertal status).

In the model with SR-rumination, the relationship between NCS and depressive symptoms was stronger in adolescents who perceived their pubertal status as high, whereas age did not moderate this relationship. Perceived pubertal status, reflecting the subjective experience of morphological changes related to puberty (Angold \& Costello, 2006), may be a more sensitive moderator of NCS than age. However, contrary to age, how pubertal status is perceived and reported may also be influenced by depressive symptoms. When examining models of depression from a developmental perspective, age may be preferred over pubertal status, as age is a less complex variable. However, the current results do not seem to rule out that pubertal status may have additional value in examining cognitive models in youth.

\section{Strengths and Limitations}

This study has notable strengths that concern the large sample size, the wide age range, and the introduction of SR-rumination. The large sample size allows testing higher-order interactions, and thus testing models from a developmental perspective by including the potentially moderating roles of age and gender. The age range of the study sample captures the transition from childhood to adolescence and covers all phases of pubertal development. Theoretically, the introduction of SR-rumination is novel and contributes to existing research on cognitive vulnerability in youth. Moreover, the moderating role of SR-rumination was examined in two models. Furthermore, the inclusion of pubertal status as an alternative to age is explored. Finally, examining domain specificity of NCS in youth is a new important avenue of research which can shed more light on the development of the gender difference in depressive symptoms.

The most important limitations of the current study concern the reliance on self-report measures, the cross-sectional design, and the representativeness of the sample. A problem with the Coddington Life Events Scale (and the Daily Hassles subscale in particular) may be that this self-report measure may reflect the selfperceived experience of stressors rather than actual experienced stressors. However, Wagner, Abela and Brozina (2006) demonstrated that ratings on the CLES (assessing stressful life events and daily hassles) did not differ from an objectively rated interview assessing stressful life events in terms of over-reporting as a function of depression. Another limitation is the cross-sectional design, which merely allows drawing conclusions on associations between variables. Moreover, problematic issues such as construct overlap and shared method variance cannot be adequately handled. Furthermore, the low consent rates may have introduced a certain bias in the current sample, limiting the extent to which current results can be generalised to 
the Dutch youth population and to clinically depressed youth. Therefore, future research should focus on examining these relationships in representative community samples and in clinically depressed youth.

\section{Clinical and Theoretical Implications}

The findings from the current study may have some implications for future research and clinical practice. For future research, it would be interesting to investigate the developmental nature of the models using longitudinal designs, taking into account domain specificity of vulnerability factors. Prospective low/high-risk designs and experimental research can shed more light on causal relationships between stressors, SR-rumination, NCS, and depressive symptoms. With respect to clinical implications, we recommend that psychological treatment of depressive symptoms in youth should target ruminative thinking, and focus on altering NCS, both of which can be emphasized in cognitive therapy; and improve problem-solving or coping with stressors, which is targeted in behavioral activation therapy (Dimidjian, Hollon, Dobson, Schmaling, Kohlenberg, Addis et al., 2006). An interesting new approach to the treatment of depressive symptoms is mindfulness-based therapy (see Segal, Williams, \& Teasdale, 2002), which helps dealing with ruminative thinking and NCS. There is evidence that mindfulness techniques incorporated into dialectic behavior therapy are helpful in decreasing suicidality and depressed mood in depressed adolescents (Miller, Rathus, \& Linehan, 2007).

\section{Final Conclusion}

Stress-reactive rumination was strongly related to depressive symptoms. The strength of this relationship was similar for boys and girls, and did not differ as a function of age. Stress-reactive rumination did not moderate the effects of negative cognitive style, nor the effects of stressors in the association with depressive symptoms. Stress-reactive rumination and negative cognitive style may not interact in youth as cognitive vulnerability factors may not have stabilised yet. Negative cognitive style in the domains of achievement and appearance was more strongly and consistently related to depressive symptoms in girls compared to boys, independently of stressors. Negative cognitive style in the interpersonal domain was related to depressive symptoms in both girls and boys, except for early adolescent girls reporting few stressors, thus supporting a diathesis-stress pattern only in early adolescent girls. Negative cognitive style in the achievement domain was only significantly related to depressive symptoms in middle to late adolescent boys reporting many stressors, thus supporting a diathesis-stress pattern only in older boys. Moderation by pubertal status instead of age yielded slightly different results, that is, in the model with stress-reactive rumination, the relationship between 
negative cognitive style and depressive symptoms was stronger in adolescents who perceived their pubertal status as high, whereas age did not moderate this relationship. Current findings highlight the importance of taking into account domain specifity of vulnerability factors in the examination of developmental models of depression in youth.

\section{References}

Abela, J. R. Z. (2001). The hopelessness theory of depression: a test of the diathesis-stress and causal mediation components in third and seventh grade children. Journal of Abnormal Child Psychology, 29, 241-254.

Abela, J. R. Z., \& Hankin, B. L. (2008). Cognitive vulnerability to depression in children and adolescents: a developmental psychopathology perspective. In J. R. Z. Abela \& B. L. Hankin (Eds.), Handbook of depression in children and adolescents (pp. 35-78). New York: The Guilford Press.

Abela, J. R. Z., \& McGirr, A. (2007). Operationalizing cognitive vulnerability and stress from the perspective of the hopelessness theory: A multi-wave longitudinal study of children of affectively ill parents. British Journal of Clinical Psychology, 46, 377-395.

Abela, J. R. Z., \& Payne, A. V. L. (2003). A test of the integration of the hopelessness and self-esteem theories of depression in schoolchildren. Cognitive Therapy and Research, 27, 519-535.

Abela, J. R. Z. \& Sarin, S. (2002). Cognitive vulnerability to hopelessness depression: a chain is only as strong as its weakest link. Cognitive Therapy and Research, 26, 811-829.

Abela, J. R. Z., \& Véronneau-McArdle, M.-H. (2002). The relationship between self-complexity and depressive symptoms in third and seventh grade children: A short-term longitudinal study. Journal of Abnormal Child Psychology, 30, 155-166.

Abramson, L. Y., Metalsky, G., \& Alloy, L. B. (1989). Hopelessness depression: A theory-based subtype of depression. Psychological Review, 96, 358-372.

Alloy, L. B., Abramson, L. Y., Hogan, M. E., Whitehouse, W. G., Rose, D. T., Robinson, M. S., Kim, R. S., \& Lapkin, J. B. (2000). The Temple-Wisconsin cognitive vulnerability to depression project: lifetime history of axis I psychopathology in individuals at high and low cognitive risk for depression. Journal of Abnormal Psychology, 109, 403-418.

Angold, A., \& Costello, E. J. (2006). Puberty and depression. Child and Adolescent Psychiatric Clinics of North America, 15, 919-937.

Angold, A., Costello, E., \& Worthman, C. (1998). Puberty and depression: the roles of age, pubertal development and pubertal timing. Psychological Medicine, 28, 51-61.

Bond, L., Clements, J., Bertalli, N., Evans-Whipp, T., McMorris, B. J., Patton, G. C., Toumbourou, J. W., \& Catalano, R. F. (2006). A comparison of self-reported puberty using the Pubertal Development Scale and the Sexual Maturation Scale in a school-based epidemiologic survey. Journal of Adolescence, 29, 709-720.

Brown, G. W., \& Harris, T. O. (1978). Social origins of depression: A study of psychiatric disorder in women. New York: Free Press.

Coddington, R. D. (1972). The significance of life events as etiologic factors in the diseases of children, II: A study of a normal population. Journal of Psychosomatic Research, 16, 205-213.

Cole, D. A., Ciesla, J. A., Dallaire, D. H., Jacquez, F. M., Pineda, A. Q., LaGrange, B., Truss, A. E., Folmer, A. S., Tilghman-Osborne, C., \& Felton, J. W. (2008). Emergence of attributional style and its relation to depressive symptoms. Journal of Abnormal Psychology, 117, 16-31. 
Coleman, L., \& Coleman, J. (2002). The measurement of puberty: a review. Journal of Adolescence, $25,535-550$.

Dimidjian, S., Hollon, S. D., Dobson, K. S., Schmaling, K. B., Kohlenberg, R. J., Addis, M. E., Gallop, R., McGlinchey, J., Markley, D., Gollan, J., Atkins, D., Dunner, D., \& Jacobson, N. (2006). Randomized trial of behavioral activation, cognitive therapy, and antidepressant medication in the acute treatment of adults with major depression. Journal of Consulting and Clinical Psychology, 74, 658-670.

Dorn, L. D., Dahl, R. E., Woodward, H. R., \& Biro, F. (2006). Defining the boundaries of early adolescence: a user's guide to assessing pubertal status and pubertal timing in research with adolescents. Applied Developmental Science, 10, 30-56.

Grant, K. E., Compas, B. E., Stuhlmacher, A. F., Thurm, A. E., McMahon, S. D., \& Halpert, J. A. (2003). Stressors and child and adolescent psychopathology: Moving from markers to mechanisms of risk. Psychological Bulletin, 129, 447-466.

Hankin, B. L. (2008). Stability of cognitive vulnerabilities to depression: a short-term prospective multiwave study. Journal of Abnormal Psychology, 117(2), 324-333.

Hankin, B. L., \& Abramson, L. Y. (2001). Development of gender differences in depression: an elaborated cognitive vulnerability-transactional stress theory. Psychological Bulletin, 127, 773796.

Hankin, B. L., Abramson, L. Y., \& Siler, M. (2001). A prospective test of the hopelessness theory of depression in adolescence. Cognitive Therapy and Research, 25, 607-632.

Hankin, B. L., \& Abramson, L. Y. (2002). Measuring cognitive vulnerability to depression in adolescence: reliability, validity, and gender differences. Journal of Clinical Child and Adolescent Psychology, 31, 491-504.

Hankin, B. L., Wetter, E., \& Cheeley, C. (2008). Sex differences in child and adolescent depression: a developmental psychopathological approach. In J. R. Z. Abela \& B. L. Hankin (Eds.), Handbook of depression in children and adolescents (pp. 377-414). New York: The Guilford Press.

Hyde, J. S., Mezulis, A. H., \& Abramson, L. Y. (2008). The ABCs of depression: Integrating affective, biological, and cognitive models to explain the emergence of the gender difference in depression. Psychological Review, 115, 291-313.

Joiner, T. E., \& Wagner, K. D. (1995). Attributional style and depression in children and adolescents: a meta-analytic review. Clinical Psychology Review, 15, 777-798.

Kanner, A. D., Coyne, J. C., Schaefer, C., \& Lazarus, R. S. (1981). Comparison of two modes of stress measurement: daily hassles and uplifts versus major life events. Journal of Behavioral Medicine, 4, 1-39.

Kanner, A. D., Feldman, S. S., Weinberger, D. A., \& Ford, M. E. (1987). Uplifts, hassles, and adaptational outcomes in early adolescents. Journal of Early Adolescence, 7, 371-394.

Kendler, K. S., Thornton, L. M., \& Gardner, C. O. (2001). Genetic risk, number of previous depressive episodes, and stressful life events in predicting onset of major depression. American Journal of Psychiatry, 158, 582-586.

Kessler, R. C. (1997). The effects of stressful life events on depression. Annual Review of Psychology, $48,191-214$.

Kessler, R. C. (2003). Epidemiology of women and depression. Journal of Affective Disorders, 74, 513.

Kovacs, M. (1981). Rating scales to assess depression in school-aged children. Acta Paedopsychiatrica, 46, 305-315.

Kraaij, V., Garnefski, N., de Wilde, E. J., Dijkstra, A., Gebhardt, W., Maes, S., \& ter Doest, L. (2003). Negative life events and depressive symptoms in late adolescence: bonding and cognitive coping as vulnerability factors? Journal of Youth and Adolescence, 32, 185-193. 
Kuehner, C. (2003). Gender differences in unipolar depression: an update of epidemiological findings and possible explanations. Acta Psychiatrica Scandinavia, 108, 163-174.

Lakdawalla, Z., Hankin, B. L., \& Mermelstein, R. (2007). Cognitive theories of depression in children and adolescents: a conceptual and quantitative review. Clinical Child and Family Psychological Review, 10, 1-24.

Mezulis, A. H., Abramson, L. Y., \& Hyde, J. S. (2002). Domain specificity of gender differences in rumination. Journal of Cognitive Psychotherapy: An International Quarterly, 16, 421-433.

Mezulis, A. H., \& Funasaki, K. (2009). Modeling the gender difference in depression: A commentary on Cambron, Acitelli, and Pettit. Sex Roles, 61, 762-768.

Miller, A. L., Rathus, J. H., \& Linehan, M. M. (2007). Dialectical behavior therapy with suicidal adolescents. New York: The Guilford Press.

Monroe, S. M., \& Harkness, K. L. (2005). Life stress, the "kindling" hypothesis, and the recurrence of depression: Considerations from a life stress perspective. Psychological Review, 112, 417-445.

Morris, M. C., Ciesla, J. A., \& Garber, J. (2008). A prospective study of the cognitive-stress model of depressive symptoms in adolescents. Journal of Abnormal Psychology, 117, 719-734.

Nolen-Hoeksema, S., \& Girgus, J. S. (1994). The emergence of gender differences in depression during adolescence. Psychological Bulletin, 115, 424-443.

Petersen, A., Crockett, L., Richards, M., \& Boxer, A. (1988). A self-report measure of pubertal development: reliability, validity, and initial norms. Journal of Youth and Adolescence, 17, 117133.

Robinson, M. (1997). The role of negative cognitive style and stress-reactive rumination on negative inferences in the etiology of depression: Empirical investigation and clinical implications. Unpublished doctoral dissertation, Temple University.

Robinson, M., \& Alloy, L. (2003). Negative cognitive styles and stress-reactive rumination interact to predict depression: a prospective study. Cognitive Therapy and Research, 27, 275-292.

Rood, L., Roelofs, J., Bögels, S. M., \& Alloy, L. B. (2010). Dimensions of negative thinking and the relations with symptoms of depression and anxiety in children and adolescents. Cognitive Therapy and Research, 34, 333-342.

Schmitz, K. E., Hovell, M. F., Nichols, J. F., Irvin, V. L, Keating, K., Simon, G. M., Gehrman, C., \& Jones, K. L. (2004). A validation study of early adolescents' pubertal self-assessments. Journal of Early Adolescence, 24, 357-384.

Segal, Z., Williams, J., \& Teasdale, J. (2002). Mindfulness-Based Cognitive Therapy for Depression. A new approach to preventing relapse. New York: The Guilford Press.

Skitch, S., \& Abela, J. R. Z. (2008). Rumination in response to stress as a common vulnerability factor to depression and substance misuse in adolescence. Journal of Abnormal Child Psychology, 36, 1029-1045.

Stone, L. B., Gibb, B. E., \& Coles, M. E. (2010). Does the hopelessness theory account for sex differences in depressive symptoms among young adults? Cognitive Therapy and Research, 34, 177-187.

Timbremont, B., \& Braet, C. (2001). Psychometrische evaluatie van de Nederlandstalige Children's Depression Inventory [Psychometric evaluation of the Dutch Children's Depression Inventory]. Gedragstherapie, 34, 229-242.

Timbremont, B., \& Braet, C., (2002). Children's Depression Inventory: Nederlandstalige versie [Children's Depression Inventory: Dutch version]. Lisse: Swets \& Zeitlinger.

Timbremont, B., Braet, C., \& Dreessen, L. (2004). Assessing depression in youth: Relation between the Children's Depression Inventory and a structured interview. Journal of Clinical Child and Adolescent Psychology, 33, 149-157. 


\section{CHAPTER 5}

Turner, J. J., \& Cole, D. (1994). Developmental differences in cognitive diatheses for child depression. Journal of Abnormal Child Psychology, 22, 15-32.

Wagner, C., Abela, J. R. Z., \& Brozina, K. (2006). A comparison of stress measures in children and adolescents: a self-report checklist versus an objectively rated interview. Journal of Psychopathology and Behavioral Assessment, 28, 251-261. 


\title{
Chapter 6
}

\section{The interplay between cognitive vulnerability factors and stressors in relation to the development of depressive symptoms over time in youth}

\author{
Lea Rood, Jeffrey Roelofs, Susan M. Bögels, Jan Schepers, Arnoud Arntz
}

\begin{abstract}
This study examined co-variation as well as predictive relationships between rumination, negative cognitive style, stressors, and depressive symptoms from a developmental perspective. Youth $(N=800)$ aged 10-18 completed questionnaires once a year for two years. The co-variation model showed that rumination co-varied more strongly with depressive symptoms in participants reporting few life events compared to those reporting many life events. Negative cognitive style co-varied more strongly with depressive symptoms in girls compared to boys. Relationships within persons were not as strong as cross-sectional studies may suggest. The prospective model showed that rumination predicted depressive symptoms. Negative cognitive style predicted depressive symptoms only in participants reporting few life events, suggesting two pathways to depressive symptoms: through high negative cognitive style or high levels of life events. Co-variations and predictive relationships did not increase with age.
\end{abstract}




\section{Introduction}

Developmental models of depression in adolescence have conceptualized cognitive vulnerability within the context of a diathesis-stress model (see Hankin \& Abramson, 2001; Hyde, Mezulis, \& Abramson, 2008), with cognitive vulnerability factors representing the diathesis, which is more likely to lead to depression when stressors occur. One such cognitive vulnerability factor with a prominent role in the hopelessness theory of depression (HT; Abramson, Metalsky, \& Alloy, 1989) is negative cognitive style, which can be defined as the tendency to make negative causal attributions and negative inferences about consequences and self-worth in following stressful events (Abramson et al., 1989). The interaction between cognitive vulnerability and stress predicting depressive symptoms may occur somewhere between the ages of 11 and 15 (see Hyde et al., 2008).

Regarding the stress component of the model, studies have shown that life events are related especially to the (first) onset of depression (Monroe \& Harkness, 2005; Stroud, Davila, \& Moyer, 2008); whereas daily hassles predict increases in psychological symptoms (Kanner, Coyne, Schaefer, \& Lazarus, 1981) and may be related to the recurrence of depression (Monroe \& Harkness, 2005).

Another cognitive variable hypothesized to interact with stress is rumination, as conceptualized in the response styles theory (RST). The RST posits that emotionfocused rumination (defined as repetitively thinking about a depressed mood and its causes, implications and consequences) may maintain or even worsen depressive symptoms (Nolen-Hoeksema, 1991). Emotion-focused rumination is associated with depressive symptoms in youth (see Rood, Roelofs, Bögels, Nolen-Hoeksema, \& Schouten, 2009). The reconceptualization of the RST into a diathesis-stress model (Nolen-Hoeksema, 1994) proposes that during early adolescence, girls start to ruminate more on their feelings and experience more stressors compared to boys. The increased experience of stressors combined with the stronger tendency for girls to ruminate may lead to a stronger increase of depressive symptoms in girls compared to boys. Longitudinal studies have yielded inconsistent results for this proposed interaction model, with Hankin (2009) finding support, whereas Abela, Parkinson, Stolow, and Starrs (2009) and Schwartz and Koenig (1996) did not.

Stress-reactive rumination is a specific form of rumination which can be defined as repetitively thinking about the negative attributions and inferences in response to stressful events, and is thought to predict the onset of depressive symptoms in interaction with negative cognitive style. Stress-reactive rumination may be a better predictor of depression than emotion-focused rumination (Robinson \& Alloy, 2003). This interaction model has not been examined in youth.

Recently, Abela et al. (2009) examined an integration of the HT and the RST, which hypothesizes that rumination worsens the effects of the interaction between 
negative cognitive style and stressful events on depressive symptoms over time. Abela et al. (2009) did not find support for a three-way interaction between negative cognitive style, stressors, and emotion-focused rumination, and suggested that the model should be tested with stress-reactive rumination instead of emotion-focused rumination.

When examining cognitive vulnerability for depression in youth, it is important to investigate possible moderating roles of gender and age. Studies involving child samples have shown that the cognitive style-stress interaction predicts depressive symptoms in girls but not in boys (Abela \& McGirr, 2007; Abela, 2001), whereas studies involving adolescent samples have found a significant cognitive vulnerabilitystress interaction only in boys (Hankin, Abramson, \& Siler, 2001; Morris, Ciesla, \& Garber, 2008; Stone, Gibb, \& Coles, 2010). Furthermore, Abela and Hankin (2008) have suggested that cognitive factors may be relatively independent factors in childhood, but may become more interrelated in adolescence, increasing vulnerability to depression. This may imply that rumination worsens the effects of a negative cognitive style on depressive symptoms more strongly as age increases.

This study aimed to investigate the relationships between negative cognitive style, rumination, and stressors in isolation and in interaction with each other, and depressive symptoms in a large sample of youth, integrating the HT and RST. The developmental nature of these models was examined by including age and gender as moderating variables. A three-wave longitudinal design was applied with one-year time intervals over a two-year period, including a wide age range in order to capture the transition from childhood to adolescence. The three-wave design offers the opportunity to examine (1) the extent to which cognitive vulnerability factors and stress co-vary with depressive symptoms across three time-points within the same person; and (2) the extent to which negative cognitive style, rumination, and stressors predict depressive symptoms one year after. The current paper addresses both issues by applying two different statistical models to the same data.

\section{Hypotheses on Co-variation}

Rumination, negative cognitive style, and stressors co-vary with depressive symptoms; moreover, the combination of high rumination, high cognitive style, and high levels of stressors is related to the highest level of depressive symptoms. Furthermore, the interaction between rumination, negative cognitive style and stressors was expected to be more pronounced with increasing age. Because of the mixed evidence, the moderating role of gender was explored in combination with the moderating role of age (five-way interaction: rumination $x$ negative cognitive style $x$ stressors $\mathrm{x}$ age $\mathrm{x}$ gender). 


\section{Hypotheses on Predictive Relationships}

Rumination, negative cognitive style, and stressors predict depressive symptoms one year later after adjusting for preceding depressive symptoms with the combination of high rumination, high negative cognitive style, and high levels of stressors predicting highest levels of depressive symptoms one year later. Whether the predictive value of the interactive model was dependent on age and gender was examined by means of a higher-order interaction (five-way interaction: rumination $x$ negative cognitive style $\mathrm{x}$ stressors $\mathrm{x}$ age $\mathrm{x}$ gender). More specifically, it was expected that the effect of the predictor variables on depressive symptoms one year later would be stronger with increased age. The moderating role of gender was explored in combination with the moderating role of age.

For both statistical models, the specificity of the type of stressor (i.e., daily hassles versus life events) as well as the specificity of type of rumination (stressreactive rumination versus emotion-focused rumination) were assessed as recommended by other authors (Abramson et al., 1989; Mclntosh, Gillanders, \& Rodgers, 2010, Robinson \& Alloy, 2003).

\section{Method}

\section{Participants and Procedure}

Participants were recruited at 35 primary and 6 secondary schools in the Southern regions of the Netherlands. The purpose of the study was explained in terms of the relation between how the way of thinking may influence how one feels. On average, $25 \%$ of the children who were approached agreed to participate. Written informed consent was obtained from all parents and from all children aged 12 and above, in accordance with formal regulations. Participants with more than $10 \%$ missing values on one of the measures were excluded from that specific measure. As a consequence, sample size ranged between 753 and 805 across the various analyses on the baseline measurement (T1), 664 to 688 for the first follow-up (T2; 85\% response rate), and 572 to 593 for the second follow-up (T3; $73 \%$ response rate). Participants that missed a follow-up measurement were contacted by telephone in order to obtain information on the reason of incompletion or drop-out. Commonly reported reasons for drop-out were lack of time, too busy with school, and boredom with filling out the questionnaires.

The mean age of the sample at baseline was 12.4 years $(S D=1.9$; age range $10-18 ; 59.8 \%$ girls). The sample was skewed towards the younger ages. Ethnicity was not reported, but it is acceptable to assume that about $95 \%$ of the sample were Caucasian. Table 1 presents an overview of demographic information of the sample. Participants completed questionnaires at home via an internet based-program $(78.3 \%)$ or when preferred they received a paper-and-pencil version $(21.7 \%)$. 
Participants received a voucher of $5 €$ for each completed follow-up measurement. The protocol was approved by the local Institutional Review Board.

Table 1: Demographic information on participants at each measurement

\begin{tabular}{lllll}
\hline \multicolumn{5}{c}{ Measurement moment } \\
\hline Variable & & $\mathrm{T} 1(N=805)$ & $\mathrm{T} 2(\mathrm{~N}=688)$ & $\mathrm{T} 3(\mathrm{~N}=588)$ \\
\hline Age & $\mathrm{M}(\mathrm{SD})$ & $12.4(1.9)$ & $13.3(1.8)$ & $14.2(1.7)$ \\
Girls & $(\mathrm{N}) \%$ & $481(59.8 \%)$ & $417(60.6 \%)$ & $371(63.5 \%)$ \\
Severe levels of CDI & $\mathrm{CDI} \geq 16(\%)$ & $102_{1788}(12.9 \%)$ & $77_{1683}(11.3 \%)$ & $67_{1588}(11.4 \%)$ \\
Educational level & Primary school & $417(51.8 \%)$ & $198(28.9 \%)$ & $6(1.0 \%)$ \\
& LPSE & $88(10.9 \%)$ & $113(16.4 \%)$ & $128(21.8 \%)$ \\
& HGSE & $130(16.1 \%)$ & $128(18.6 \%)$ & $158(26.9 \%)$ \\
& PUE & $167(20.7 \%)$ & $225(32.7 \%)$ & $272(46.3 \%)$ \\
& Other & - & $24(3.4 \%)$ & $24(4.0 \%)$ \\
\hline
\end{tabular}

Note. Number of CDI completions is given in subscript. CDI=Children's Depression Inventory. LPSE=lower professional/general secondary education. HGSE=higher general secondary education. PUE=pre-university education.

\section{Measures}

Depressive Symptoms. The Children's Depression Inventory (CDI; Kovacs, 1981; Dutch version: Timbremont \& Braet, 2001) is a widely used self-report questionnaire which aims to measure the level of depressive symptoms in children. For each of the 27 items three statements are given, of which the subject has to choose one (e.g., "I am sad sometimes / I am often sad / I am always sad") that represents best how he or she has been feeling the last two weeks. Reliability in terms of internal consistency is good and the convergent validity of the CDI is supported (Timbremont \& Braet, 2001).

Stress-Reactive Rumination (form here referred to as "SR-rumination"). The Dutch version of the Stress-Reactive Rumination Scale for children (SRRS-C; Rood, Roelofs, Bögels, \& Alloy, 2010) is a downward extension of the SRRS for adults (Robinson, 1997), which aims to measure the frequency of negative thoughts about the negative inferences following stressful events (e.g., "I think about how the stressful event was my entire fault"). The SRRS-C consists of nine items scored on a four-point Likert-scale (1=almost never ... 4=almost all the time). Reliability and concurrent criterion validity of the SRRS-C are adequate to good (Rood et al., 2010).

Emotion-Focused Rumination (form here referred to as "EF-rumination"). The Children's Response Styles Scale (CRSS; Ziegert, \& Kistner, 2002; Dutch version: Muris, Roelofs, Meesters, \& Boomsma, 2004) is a self-report questionnaire that measures the tendencies to ruminate and to seek distraction in response to sad 
mood in children. The rumination subscale consists of 10 items and measures thoughts and behaviours that maintain the focus on emotions (e.g., "When I'm feeling sad, I think about the other times I felt that way"). Items are rated on a five-point Likert-scale (1=never ... 5=always). Reliability of the CRSS in terms of internal consistency is good $(\alpha=.81)$ and validity is adequate to good (Muris et al., 2004; Ziegert \& Kistner, 2002).

Negative Cognitive Style. The Adolescent Cognitive Styles Questionnaire (ACSQ; Hankin \& Abramson, 2002) aims to measure negative attribution and inferential styles in response to negative events. The ACSQ consists of 12 hypothetical negative event scenarios in the domains of scholar achievements, interpersonal relations, and physical appearance; which are accompanied by five questions measuring internal/external attribution of the cause, inferences about stability and globality of the causes, and inferences about consequences and self-worth, rated on a seven-point scale. The psychometric properties of the ACSQ are well supported (Hankin \& Abramson, 2002). For the current study, we used a shortened version containing six items in order to reduce the risk of drop-out or incompletion. Correlations between the original version and the shortened version were high for the subscales (rs=.94$.96)$ and for the composite scores $(r=.97)$. The reliability of the shortened version was $\operatorname{good}(\alpha=.82)$.

Stressors: Daily Hassles and Life Events. The Children's Life Events Scale (CLES) is composed of two questionnaires. The first 37 items are derived from the Children's Hassles Scale (Kanner, Feldman, Weinberger, \& Ford, 1987) and describe daily hassles (e.g., "You fought with a classmate"). Responses are rated on a four-point scale, with $0=$ when it didn't happen to 3=when it happened all the time. The other 22 items are taken from the Coddington Life Stress Scale (Coddington, 1972), describing relatively serious life events (e.g. "A family member or someone you know well died"). One can answer "yes" or "no" dependent on whether the life event occurred the past year or not. The CLES used in this study was slightly revised (updated).

\section{Design}

The current study had a longitudinal design with three within-subject measurements using 10 to 12 month intervals. The design was unbalanced due to two sources of missing data. First, because individuals started at different ages at T1, data was not available for each individual at all ages. Second, non-response caused additional missing values. 
Statistical Analysis

A more conservative alpha of .01 was used to avoid Type I errors. Assumptions for regression analysis were checked. CDI and CLES-Life events were not normally distributed and therefore successfully underwent square root transformations. Binary logistic regression analyses were performed in order to determine whether missing data were random. Drop-out of study was predicted by baseline depressive symptoms, SR-rumination, life events, gender, and age, which were all included as covariates in the study, so that drop-out can be considered Missing At Random, allowing multilevel testing.

Multilevel mixed models (Linear Mixed Model, SPSS 18.0) can handle missing data due to unbalanced designs. A marginal mixed model with time-varying covariates (i.e., rumination, negative cognitive style, stressors) and one fixed covariate (gender) was estimated to make group-level inferences regarding the different slopes. The first level represents the observations (i.e., repeated measurements), and the second level represents the subjects ${ }^{1}$. As the number of time-points was restricted to three, and because there was sufficient power, an unstructured residual covariance matrix was chosen. Only fixed effects were specified.

The models were examined following a top-down procedure, starting with the five-way interaction between SR-rumination, negative cognitive style, life events, age, and gender; and subsequently stepwise removing the interactions that were not significant from the model. To examine specificity of type of rumination and type of stressors, the model was re-run with EF-rumination instead of SR-rumination, and with daily hassles instead of life events.

Statistical model 1 examines co-variation between variables, illustrated by the following regression equation: $Y_{i j}=B 0+B 1^{*} X 1_{i j}+B 2^{*} X 2_{i j}+[\ldots]$, with the ${ }_{i}$ representing the individual, and ${ }_{j}$ time-point. $Y_{i j}$ represents level of depressive symptoms for person $i$ at time-point $\mathrm{j}$, and $\mathrm{X}_{\mathrm{ij}}$ represents level of e.g. rumination of person $\mathrm{i}$ at time-point $\mathrm{j}$.

Statistical model 2 examines prospective relationships over a one-year time interval, resulting from a combined estimation of two one-year lagged intervals within persons, illustrated by the following regression equation: $Y_{i j}=B 0+B 1^{*} Y_{i j-1}+B 2^{*} X 1_{i j-}$ ${ }_{1}+[. .$.$] . It is important to note that the depression score (Y)$ of individual $i$ at time-point $\mathrm{j}-1$ is included in the equation and that $\mathrm{Y}_{\mathrm{ij}}$ is predicted based on the $\mathrm{Y}$-score of individual $i$ at time-point $j-1$. Hence, the covariates $(X)$ predict depressive symptoms one year later after adjusting for preceding depressive symptoms.

The fit of the final models was indicated by a pseudo R-square (Singer \& Willett, 2003). All variables were grand-mean centered. The effect of a covariate (B

\footnotetext{
${ }^{1}$ The ICC indicated low homogeneity of depressive symptoms within schools (ICC $=.02$ ) on the baseline data, indicating that taking into account nesting within schools through multilevel modeling was not required.
} 
Est.) should be interpreted as follows: as the $X$ score increases with 1 point, the $Y$ score increases with "B" points.

\section{Results}

Reliability was good $(\alpha>$.77) for all questionnaires except for CLES-Life events $(\alpha=.60-.68)$. Zero-order correlations showed moderate to high associations between the predictors and depressive symptoms on all time-points (see Table 2 for descriptive statistics, reliability coefficients, and correlations). Interactions are only reported when significant.

Results Statistical Model 1: Co-variation (see Table 3).

The five-way interaction between rumination, negative cognitive style, stressors, age, and gender was not significant. SR-rumination interacted with life events in the association with depressive symptoms, $F(1,1764)=7.93, p=.005$, which was examined more closely by computing the regression coefficients for SR-rumination splitting on high/low (1.5 SD \pm mean) life events, leaving negative cognitive style in the model. SR-rumination and depressive symptoms co-varied more strongly in participants reporting few life events, $b=.06, S E=.02, p=.002$, compared to many life events, $b=.05, S E=.02, p=.005$. Negative cognitive style and depressive symptoms co-varied as well. Age and gender did not act as moderators, nor were they significantly related to depressive symptoms. When re-running the model with daily hassles instead of life events, only significant main effects were found for age, SRrumination, negative cognitive style, and daily hassles, and no interaction effects between them. The significant positive effect for age indicates that the level of depressive symptoms increases with age.

When re-running the analyses with EF-rumination instead of SR-rumination, a significant interaction between negative cognitive style and gender emerged, $F(1$, 1949) $=9.07, p=.003$, in addition to an interaction between EF-rumination and life events, $F(1,1805)=17.09, p<.001$. The interactions were more closely examined by means of two follow-up analyses: negative cognitive style and depressive symptoms co-varied more strongly in girls $(b=.02, S E=.001, p<.001)$ compared to boys $(b=.01$, $\mathrm{SE}=.001, \mathrm{p}<.001)$. EF-rumination significantly co-varied with depressive symptoms in participants reporting few life events, $b=.03, S E=.01, p=.007$, but not in participants reporting many life events, $b=.03, S E=.01, p=.03$. When replacing life events with daily hassles, only main effects were found for EF-rumination, daily hassles, and age; negative cognitive style interacted with gender in a similar way as with life events instead of daily hassles in the model. 
Table 2: Pearson correlations between all (if necessary transformed) variables on the three measurements, and raw (i.e., untransformed) means and standard deviations of the variables on all three time-points

\begin{tabular}{|c|c|c|c|c|c|c|c|c|c|c|c|c|c|c|c|c|c|c|c|c|c|c|}
\hline Variable & 2. & 3. & 4. & 5. & 6. & 7. & 8. & 9. & 10. & 11. & 12. & 13. & 14. & 15. & 16. & 17. & 18. & 19. & 20. & M & SD & $\alpha$ \\
\hline 3. T3 CDI & & 1 & .38 & .44 & .57 & .30 & .35 & .40 & .33 & .43 & .51 & .42 & .49 & .59 & .26 & .28 & .36 & .06 & $.10^{*}$ & 7.65 & 6.42 & .88 \\
\hline 5. T2 SRRSC & & & & 1 & .64 & .49 & .70 & .55 & .34 & .51 & .39 & .33 & .47 & .36 & .21 & .34 & .29 & .14 & .17 & 16.44 & 5.17 & .89 \\
\hline 6. T3 SRRSC & & & & & 1 & .47 & .56 & .73 & .34 & .41 & .50 & .30 & .37 & .47 & .22 & .28 & .31 & .19 & .16 & 17.18 & 5.47 & .90 \\
\hline 7. T1 CRSS & & & & & & 1 & .58 & .53 & .38 & .35 & .31 & .41 & .32 & .21 & .27 & .24 & .16 & .17 & .12 & 16.43 & 7.69 & .87 \\
\hline 8. T2 CRSS & & & & & & & 1 & .69 & .28 & .41 & .36 & .25 & .37 & .30 & .16 & .30 & .26 & .26 & .16 & 15.40 & 7.97 & .89 \\
\hline 11. T2 ACSQ & & & & & & & & & & 1 & .62 & .33 & .45 & .37 & .18 & .27 & .19 & .13 & .07 & 62.81 & 26.83 & .82 \\
\hline 12. T3 ACSQ & & & & & & & & & & & 1 & .27 & .32 & .39 & .14 & .18 & .19 & .08 & .06 & 64.36 & 26.74 & .82 \\
\hline 13. T1 DH & & & & & & & & & & & & 1 & .61 & .51 & .52 & .38 & .32 & -.01 & .04 & 26.58 & 10.15 & .87 \\
\hline 14. T2 DH & & & & & & & & & & & & & 1 & .63 & .35 & .53 & .38 & .07 & .03 & 23.48 & 9.70 & .87 \\
\hline 15. T3 DH & & & & & & & & & & & & & & 1 & .33 & .43 & .54 & .05 & .01 & 23.75 & 9.92 & .88 \\
\hline 16. T1 LE & & & & & & & & & & & & & & & 1 & .45 & .38 & -.04 & .05 & 5.07 & 3.05 & .68 \\
\hline
\end{tabular}

Note. All correlations $\geq 11$ are significant at the .01 level (2-tailed). For correlations $\leq .10:{ }^{*}$ correlations are significant at the .05 level (2-tailed). Gender: $0=$ boys, $1=$ girls. $\mathrm{CDI}=$ Children's Depression Inventory. SRRS-C $=$ Stress-Reactive Rumination Scale for Children. CRSS $=$ Children's Response Styles Scale. ACSQ = Adolescent Cognitive Styles Questionnaire. DH = Daily Hassles subscale of the Children's Life Events Scale. LE = Life Events subscale of the CLES. 


\section{CHAPTER 6}

Table 3: The final models regarding co-variation with depressive symptoms

\begin{tabular}{|c|c|c|c|c|c|}
\hline \multicolumn{6}{|c|}{ SR-rumination $x$ negative cognitive style $x$ life events $x$ age $x$ gender $\left(R^{2=} 45.3 \%\right)$} \\
\hline Variable & $B$ (Est.) & SE & $t$ & $F$ & $d f$ \\
\hline Intercept & -.02 & .03 & -.58 & .12 & 817 \\
\hline Gender & .02 & .05 & .39 & .15 & 773 \\
\hline Age & .02 & .01 & 1.72 & 2.94 & 822 \\
\hline SR-rumination & .06 & .004 & 14.98 & $224.33^{* *}$ & 1921 \\
\hline Negative cognitive style & .01 & .001 & 16.33 & $266.59^{\star *}$ & 1938 \\
\hline Life events & .24 & .03 & 8.91 & $79.43^{* *}$ & 1859 \\
\hline SR-rumination $x$ life events & .01 & .005 & 2.82 & $7.93^{*}$ & 1764 \\
\hline \multicolumn{6}{|c|}{ SR-rumination $x$ negative cognitive style $x$ daily hassles $x$ age $x$ gender $\left(R^{2=} 53.3 \%\right)$} \\
\hline Variable & $B$ (Est.) & SE & $t$ & $F$ & $d f$ \\
\hline Intercept & .004 & .03 & .13 & .01 & 760 \\
\hline Gender & -.003 & .05 & -.06 & .003 & 771 \\
\hline Age & .03 & .01 & 2.79 & $7.80^{*}$ & 822 \\
\hline SR-rumination & .05 & .004 & 11.60 & $134.50^{\star \star}$ & 1928 \\
\hline Negative cognitive style & .01 & .001 & 14.54 & $211.30^{* *}$ & 1939 \\
\hline Daily hassles & .04 & .002 & 18.37 & $337.28^{\star \star}$ & 1931 \\
\hline \multicolumn{6}{|c|}{ EF-rumination $x$ negative cognitive style $x$ life events $x$ age $x$ gender $\left(R^{2=} 40.3 \%\right)$} \\
\hline Variable & $B$ (Est.) & SE & $t$ & $F$ & $d f$ \\
\hline Intercept & -.03 & .04 & -.94 & .48 & 812 \\
\hline Gender & .03 & .06 & .51 & .26 & 795 \\
\hline Age & .03 & .01 & 2.32 & 5.38 & 822 \\
\hline EF-rumination & .03 & .003 & 9.13 & $83.37^{\star *}$ & 1946 \\
\hline Negative cognitive style & .02 & .001 & 17.89 & $340.49^{\star \star}$ & 1937 \\
\hline Life events & .27 & .03 & 9.68 & $93.63^{* \star}$ & 1856 \\
\hline Negative cognitive style $\mathrm{x}$ gender & -.005 & .002 & -3.01 & $9.07^{*}$ & 1949 \\
\hline EF-rumination $x$ life events & .01 & .003 & 4.13 & $17.09^{* *}$ & 1805 \\
\hline \multicolumn{6}{|c|}{ EF-rumination $x$ negative cognitive style $x$ daily hassles $x$ age $x$ gender $\left(\mathrm{R}^{2=} 50.8 \%\right)$} \\
\hline Variable & $B$ (Est.) & SE & $t$ & $F$ & $d f$ \\
\hline Intercept & -.0003 & .03 & -.01 & .01 & 771 \\
\hline Gender & -.005 & .05 & -.09 & .01 & 794 \\
\hline Age & .04 & .01 & 3.46 & $11.97^{\star *}$ & 820 \\
\hline EF-rumination & .02 & .003 & 6.32 & $39.90^{\star *}$ & 1905 \\
\hline Negative cognitive style & .01 & .001 & 15.36 & $251.53^{* *}$ & 1937 \\
\hline Daily hassles & .04 & .002 & 20.62 & $425.03^{\star \star}$ & 1938 \\
\hline Negative cognitive style $x$ gender & -.004 & .001 & -2.65 & $7.04^{*}$ & 1912 \\
\hline
\end{tabular}

Note. ${ }^{*} p<.01,{ }^{* *} p<.001$. Gender is coded as $0=$ boys and $1=$ girls. 
Results Statistical Model 2: Prospective Relations (see Table 4)

The five-way interaction between SR-rumination, negative cognitive style, life events, gender, and age was not significant. Negative cognitive style interacted with life events in the prediction of depressive symptoms one year later (after adjusting for preceding depressive symptoms), $F(1,1050)=7.78, p=.005$. Follow-up analyses showed that negative cognitive style predicted depressive symptoms one year later in subjects reporting few life events $(b=.02, S E=.005, p<.001)$, whereas it did not significantly predict depressive symptoms one year later in participants reporting many life events $(b=.005, S E=.006, p=.43)$; and vice versa, life events predicted depressive symptoms only in participants reporting low negative cognitive style. See Fig. 1 for a graphical representation of this interaction.

Figure 1: Graphical representation of the interaction between negative cognitive style and life events predicting depressive symptoms

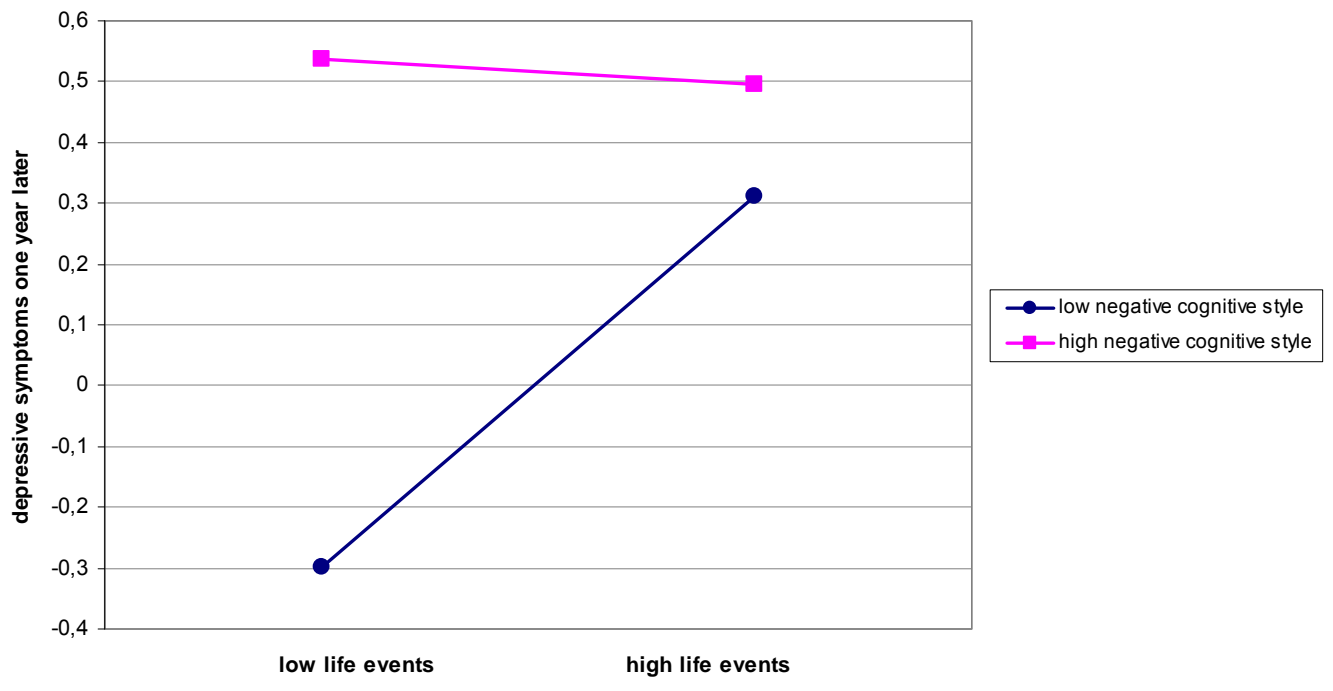

SR-rumination and preceding depressive symptoms each contributed to the prediction of depressive symptoms one year later. Age and gender did not significantly predict depressive symptoms one year later. With daily hassles in the model, only main effects for daily hassles, SR-rumination, negative cognitive style, and preceding depressive symptoms were significant. Results with EF-rumination instead of SR-rumination were almost identical. 


\section{CHAPTER 6}

Table 4: The final models regarding the prediction of depressive symptoms (1-year lag)

\begin{tabular}{|c|c|c|c|c|c|}
\hline \multicolumn{6}{|c|}{ SR-rumination $x$ negative cognitive style $x$ life events $x$ age $x$ gender $\left(R^{2=} 44.0 \%\right)$} \\
\hline Variable & $B$ (Est.) & SE & $t$ & $F$ & $d f$ \\
\hline Intercept & 26 & .04 & 7.50 & $62.38^{\star *}$ & 535 \\
\hline Gender & -.07 & .05 & -1.32 & 1.74 & 455 \\
\hline Age & .02 & .01 & 1.37 & 1.88 & 498 \\
\hline Depressive symptoms & .48 & .03 & 18.41 & $338.83^{* *}$ & 1121 \\
\hline SR-rumination & .02 & .006 & 3.90 & $15.23^{* *}$ & 961 \\
\hline Negative cognitive style & .005 & .001 & 4.17 & $17.37^{\star *}$ & 944 \\
\hline Life events & .11 & .04 & 2.78 & $7.70^{*}$ & 975 \\
\hline Negative cognitive style $x$ life events & -.004 & .001 & -2.79 & $7.78^{*}$ & 1050 \\
\hline \multicolumn{6}{|c|}{ SR-rumination $x$ negative cognitive style $x$ daily hassles $x$ age $x$ gender $\left(\mathrm{R}^{2=} 43.8 \%\right)$} \\
\hline Variable & $B$ (Est.) & SE & $t$ & $F$ & $d f$ \\
\hline Intercept & .23 & .03 & 6.67 & $48.02^{\star \star}$ & 538 \\
\hline Gender & -.07 & .05 & -1.28 & 1.64 & 463 \\
\hline Age & .03 & .01 & 1.95 & 3.81 & 511 \\
\hline Depressive symptoms & .44 & .03 & 15.68 & $245.71^{\star *}$ & 1154 \\
\hline SR-rumination & .02 & .006 & 2.88 & $8.26^{*}$ & 931 \\
\hline Negative cognitive style & .004 & .001 & 3.59 & $12.86^{\star *}$ & 946 \\
\hline Daily hassles & .02 & .003 & 5.57 & $30.99^{* *}$ & 925 \\
\hline \multicolumn{6}{|c|}{ EF-rumination $x$ negative cognitive style $x$ life events $x$ age $x$ gender $\left(\mathrm{R}^{2=} 44.6 \%\right)$} \\
\hline Variable & $B$ (Est.) & SE & $t$ & $F$ & $d f$ \\
\hline Intercept & .26 & .04 & 7.30 & $66.01^{* *}$ & 516 \\
\hline Gender & -.05 & .05 & -.92 & .84 & 455 \\
\hline Age & .02 & .01 & 1.70 & 2.90 & 479 \\
\hline Depressive symptoms & .50 & .03 & 19.56 & $382.59^{\star *}$ & 1094 \\
\hline EF-rumination & .01 & .004 & 3.37 & $11.34^{* *}$ & 850 \\
\hline Negative cognitive style & .005 & .001 & 4.49 & $20.16^{\star \star}$ & 975 \\
\hline Life events & .11 & .04 & 2.93 & $8.58^{*}$ & 974 \\
\hline Negative cognitive style $x$ life events & -.004 & .001 & -2.62 & $6.88^{*}$ & 1054 \\
\hline \multicolumn{6}{|c|}{ EF-rumination $x$ negative cognitive style $x$ daily hassles $x$ age $x$ gender $\left(\mathrm{R}^{2=} 44.8 \%\right)$} \\
\hline Variable & $B$ (Est.) & SE & $t$ & $F$ & $d f$ \\
\hline Intercept & .23 & .04 & 6.46 & $49.90^{\star *}$ & 524 \\
\hline Gender & -.05 & .05 & -.92 & .85 & 466 \\
\hline Age & .03 & .01 & 2.23 & 4.96 & 497 \\
\hline Depressive symptoms & .44 & .03 & 16.16 & $261.05^{* *}$ & 1148 \\
\hline EF-rumination & .01 & .004 & 2.77 & $7.65^{*}$ & 845 \\
\hline Negative cognitive style & .004 & .001 & 3.73 & $13.90^{* *}$ & 975 \\
\hline Daily hassles & .02 & .003 & 5.85 & $34.18^{\star \star}$ & 946 \\
\hline
\end{tabular}

Note ${ }^{*} p<.01,{ }^{* *} p<.001$. Gender is coded as $0=$ boys and $1=$ girls. 


\section{Discussion}

The present three-wave longitudinal study examined an integration of the RST and the HT in youth from a developmental perspective. The aim was to investigate the extent to which negative cognitive style, rumination, and stressors (in interaction and in isolation) co-varied with depressive symptoms across three time-points; and predicted depressive symptoms after a one-year interval (after adjusting for preceding depressive symptoms), and whether age and gender acted as moderators.

\section{Co-variations}

Results indicated that (EF-/SR-)rumination and depressive symptoms co-varied more strongly in participants reporting low levels of life events. It is possible that in participants reporting few life events, scores on rumination and depressive symptoms are also likely to be low and do not vary much across time-points; whereas in participants reporting many life events, rumination and depression scores may vary more independently of each other across time-points as a result of a dynamic process between the variables influencing each other (see Hankin \& Abramson, 2001; Nolen-Hoeksema, Stice, Wade, \& Bohon, 2007). It is also possible that rumination, which has not stabilized yet as a vulnerability factor in middle adolescence (Hankin, 2008), destabilizes as a function of life events, and fluctuates more than depressive symptoms, which are more stable (Hankin, 2008). Rumination, negative cognitive style, and stressors co-varied with depressive symptoms to a similar extent from the age of 10 . Results indicated a more stable relationship between negative cognitive style and depressive symptoms across time in girls compared to boys, in line with Hankin (2008), who found that negative cognitive style is a relatively stable vulnerability factor in adolescence.

\section{Predictions}

The interaction between rumination, negative cognitive style, and stressors did not significantly predict depressive symptoms one year later (after adjusting for preceding depressive symptoms); nor was this interaction moderated by gender and age, consistent with Abela et al. (2009). Negative cognitive style predicted depressive symptoms one year later in participants reporting few life events, and vice versa (i.e., life events predicted depressive symptoms only in participants reporting low negative cognitive style). This remarkable finding is consistent with Lewinsohn, Joiner, and Rohde (2001), who showed that attribution style combined with low stress predicted depression one year later in late adolescents. An explanation may be a ceiling effect for high negative cognitive style (or high life events), in that further increases in depressive symptoms caused by additional life events were not possible. Alternatively, these results may suggest two pathways to depression: through high 
negative cognitive style, or high life events. It may be that cognitive factors worsen the effect of stressors within a certain time-frame. The time-frame of one year may yield different results compared to the more commonly applied 6-week intervals.

Rumination significantly predicted depressive symptoms one year later, next to stressors and negative cognitive style. The finding that rumination did not worsen the effects of stressors is not in line with a diathesis-stress account (Nolen-Hoeksema, 1994), and inconsistent with Hankin (2009). Again, the time-frame of one year may have been too large; however, it is consistent with other 6-week prospective studies not supporting the interaction (Abela et al. 2009; Schwartz \& Koenig, 1996). Rumination did not worsen the effect of negative cognitive style on depressive symptoms one year later, inconsistent with Robinson and Alloy (2003), but consistent with Abela et al. (2009). It might not be until adulthood that cognitive factors start to aggravate each other's effects (Abela \& Hankin, 2008), because rumination has not stabilised yet in middle adolescence (Hankin, 2008). Preceding depressive symptoms were the strongest predictor of depressive symptoms, which is a common finding (Hankin, 2008).

\section{Specificity of Type of Stressor and Type of Rumination}

Current findings may plea for examining life events and daily hassles separately rather than using aggregate scores for stressors. Daily hassles was independently related to depressive symptoms. It may be that daily hassles are more likely to worsen the effects of cognitive vulnerability factors on depressive symptoms in already sensitized individuals (Morris, Ciesla \& Garber, 2010), rather than in nonclinical youth. Current findings do not add to the suggestion that SR-rumination is a better predictor of depressive symptoms than EF-rumination; nor do they point toward different roles for each type in the development of depressive symptoms within a diathesis-stress account in youth (Robinson \& Alloy, 2003).

\section{Developmental Factors}

The co-variation model showed that depressive symptoms increase with age, similarly for boys and girls. Rumination co-varied with depressive symptoms to the same extent over the entire age range of the sample, similarly for boys an girls. The prospective model showed that from the age of 10 , rumination, negative cognitive style, and stressors predicted depressive symptoms one year later, in girls and boys similarly. In contrast to expectation (see Hyde et al., 2008), no significant three-way interaction between negative cognitive style, life events, and age was found. None of the interaction effects were more pronounced in girls as suggested in recent theoretical models of depression (Hankin \& Abramson, 2001; Hyde et al., 2008), only negative cognitive style co-varied with depressive symptoms one year later more 
strongly in girls. Gender did not moderate the relationship between rumination and depressive symptoms one year later, inconsistent with Grant et al. (2004).

\section{Strengths and Limitations}

Strengths of this study are the large sample with a broad age range; the three-wave prospective design; the assessment of SR-rumination in youth; and the examination of specificity of types of rumination and stressors. Important limitations concern the reliance on self-report measures and the representativeness of the sample. The relatively low consent rates may introduce a certain selection bias. Furthermore, shared method variance could be driving the strength of the relationships. Level of depression may lead to over-reporting of daily hassles, as the daily hassles scale may be confounded with psychological symptoms (Dohrenwend, Dohrenwend, Dodson, \& Shrout, 1984).

\section{Implications for Research, Policy, and Practice}

Although effects were modest, the models seem to fit the data well. The co-variation model yielded modest effects, which is interesting since cross-sectional studies show high correlations between EF-rumination and depressive symptoms (see for a metaanalysis Rood et al., 2009). This suggests that especially baseline scores of rumination and depression are related. Thus individuals who have a tendency to ruminate, have a tendency to feel depressed; however, depression and rumination do not necessarily co-vary over time within persons. The finding that SR-rumination significantly predicted depressive symptoms even after a one-year interval in addition to other variables, suggests that rumination is indeed an interesting variable in relation to depressive symptoms in youth. The effect size for EF-rumination is comparable to that found in Nolen-Hoeksema et al. (2007), who also examined oneyear time-lags, suggesting that results can be considered robust. More research is needed to examine the possible interaction between negative cognitive style, SRrumination, and stressors, e.g., in prospective high-risk designs. Studies in community samples and clinically depressed youth are warranted in order to replicate current findings. Furthermore, future research should focus on examining reciprocal relationships between cognitive factors, stressors, and depressive symptoms in youth (see Hankin \& Abramson, 2001; Nolen-Hoeksema et al., 2007).

Prevention programs for youth vulnerable to depression should focus on improving coping skills, on altering negative cognitive style, and on the process of rumination. Given the generally disappointing effect sizes of existing cognitivebehavioral interventions for depressed youth (e.g., Weisz, McCarty, \& Valeri, 2006) already designed to target these factors, CBT programs could be improved by incorporating specific techniques to help breaking ruminative cycles such as behavioural activation interventions (Cuijpers, van Straten, \& Warmerdam, 2007). 


\section{Final Conclusion}

The present study examined the integration of the hopelessness theory and response styles theory from a developmental perspective in a large sample of children and adolescents, hypothesizing that stress-reactive rumination may worsen the effects of a negative cognitive style on depressive symptoms, especially when confronted with many stressors. The three-wave design allowed examining covariation as well as predictive relations. To conclude, current findings show that rumination, negative cognitive style, and stressors (daily hassles and life events) significantly co-varied with depressive symptoms, but are not as strongly related to depressive symptoms over time within persons as cross-sectional studies may suggest. Negative cognitive style co-varied more strongly with depressive symptoms in girls compared to boys, independently of age. Rumination fluctuated more strongly with depressive symptoms in participants reporting few life events compared to many life events (and vice versa), similarly for girls and boys and independently of age. Negative cognitive style only significantly predicted depressive symptoms in the presence of low levels of life events and vice versa, suggesting a dual risk model rather than diathesis-stress model. The time-frame of one year may yield different results regarding diathesis-stress models compared to the more commonly applied 6week intervals. Stress-reactive rumination was not a better predictor of depressive symptoms compared to emotion-focused rumination. The predictive relationships were not moderated by age and gender. Rumination and negative cognitive style may not interact in the prediction of depressive symptoms until early adulthood.

\section{References}

Abela, J.R.Z. (2001). The hopelessness theory of depression: a test of the diathesis-stress and causal mediation components in third and seventh grade children. Journal of Abnormal Child Psychology, 29, 241-254.

Abela, J.R.Z., \& Hankin, B.L. (2008). Cognitive vulnerability to depression in children and adolescents: a developmental psychopathology perspective. In J.R.Z. Abela \& B.L. Hankin (Eds.), Handbook of depression in children and adolescents (pp. 35-78). New York: The Guilford Press.

Abela, J.R.Z., \& McGirr, A. (2007). Operationalizing cognitive vulnerability and stress from the perspective of the hopelessness theory: A multi-wave longitudinal study of children of affectively ill parents. British Journal of Clinical Psychology, 46, 377-395.

Abela, J.R.Z., Parkinson, C., Stolow, D., \& Starrs, C. (2009). A test of the integration of the hopelessness and response styles theories of depression in middle adolescence. Journal of Clinical Child and Adolescent Psychology, 38, 354-364.

Abramson, L., Metalsky, G., \& Alloy, L. (1989). Hopelessness depression: A theory-based subtype of depression. Psychological Review, 96(2), 358-372.

Coddington, R. D. (1972). The significance of life events as etiologic factors in the diseases of children, II: A study of a normal population. Journal of Psychosomatic Research, 16, 205-213. 
Cuijpers, P., van Straten, A., \& Warmerdam, L. (2007). Behavioral activation treatments of depression: A meta-analysis. Clinical Psychology Review, 27, 318-326.

Dohrenwend, B., Dohrenwend, B.P., Dodson, M., \& Shrout, P.E. (1984). Symptoms, hassles, social supports, and life events: Problem of confounded measures. Journal of Abnormal Psychology, 93, 222-230.

Grant, K.E., Lyons, A.L., Finkelstein, J.-A.S., Conway, K.M., Reynolds, L.K., O'Koon, J.H., Waitkoff, G.R., \& Hicks, K.J. (2004). Gender differences in rates of depressive symptoms among lowincome, urban, African American youth: a test of two mediational hypotheses. Journal of Youth and Adolescence, 33(6), 523-533.

Hankin, B.L. (2008). Stability of cognitive vulnerabilities to depression: a short-term prospective multiwave study. Journal of Abnormal Psychology, 117(2), 324-333.

Hankin, B.L. (2009). Development of sex differences in depressive and co-occurring anxious symptoms during adolescence: Descriptive trajectories and potential explanations in a multiwave prospective study. Journal of Clinical Child \& Adolescent Psychology, 38, 460-472.

Hankin, B.L., \& Abramson, L.Y. (2001). Development of gender differences in depression: an elaborated cognitive vulnerability-transactional stress theory. Psychological Bulletin, 127, 773796.

Hankin, B.L., \& Abramson, L.Y. (2002). Measuring cognitive vulnerability to depression in adolescence: reliability, validity, and gender differences. Journal of Clinical Child and Adolescent Psychology, 31, 491-504.

Hankin, B.L., Abramson, L.Y., \& Siler, M. (2001). A prospective test of the hopelessness theory of depression in adolescence. Cognitive Therapy and Research, 25, 607-632.

Hyde, J.S., Mezulis, A.H., \& Abramson, L.Y. (2008). The ABCs of depression: Integrating affective, biological, and cognitive models to explain the emergence of the gender difference in depression. Psychological Review, 115, 291-313.

Kanner, A.D., Coyne, J.C., Schaefer, C., \& Lazarus, R.S. (1981). Comparison of two modes of stress measurement: daily hassles and uplifts versus major life events. Journal of Behavioral Medicine, 4, 1-39.

Kanner, A.D., Feldman, S.S., Weinberger, D.A., \& Ford, M.E. (1987). Uplifts, hassles, and adaptational outcomes in early adolescents. Journal of Early Adolescence, 7, 371-394.

Kovacs, M. (1981). Rating scales to assess depression in school-aged children. Acta Paedopsychiatrica, 46, 305-315.

Lewinsohn, P.M., Joiner, T.E., \& Rohde, P. (2001). Evaluation of cognitive diathesis-stress models in predicting major depressive disorder in adolescents. Journal of Abnormal Psychology, 110, 203215.

Mclntosh, E., Gillanders, D., \& Rodgers, S. (2010). Rumination, goal linking, daily hassles and life events in major depression. Clinical Psychology and Psychotherapy, 17, 33-43.

Monroe, S.M., \& Harkness, K.L. (2005). Life stress, the "kindling" hypothesis, and the recurrence of depression: Considerations from a life stress perspective. Psychological Review, 112, 417-445.

Morris, M.C., Ciesla, J.A., \& Garber, J. (2008). A prospective study of the cognitive-stress model of depressive symptoms in adolescents. Journal of Abnormal Psychology, 117, 719-734.

Morris, M.C., Ciesla, J.A., \& Garber, J. (2010). A prospective study of stress autonomy versus stress sensitization in adolescents at varied risk for depression. Journal of Abnormal Psychology, 119, 341-354.

Muris, P., Roelofs, J., Meesters, C., \& Boomsma, P. (2004). Rumination and worry in nonclinical adolescents. Cognitive Therapy and Research, 28(4), 539-554.

Nolen-Hoeksema, S. (1991). Responses to depression and their effects on the duration of depressive episodes. Journal of Abnormal Psychology, 100(4), 569-582. 
Nolen-Hoeksema, S. (1994). An interactive model for the emergence of gender differences in depression in adolescence. Journal of Research on Adolescence, 4, 519-534.

Nolen-Hoeksema, S., Stice, E., Wade, E., \& Bohon, C. (2007). Reciprocal relations between rumination and bulimic, substance abuse, and depressive symptoms in female adolescents. Journal of Abnormal Psychology, 116(1), 198-207.

Robinson, M. (1997). The role of negative inferential style and stress-reactive rumination on negative inferences in the etiology of depression: Empirical investigation and clinical implications. Unpublished doctoral dissertation, Temple University.

Robinson, M., \& Alloy, L. (2003). Negative cognitive styles and stress-reactive rumination interact to predict depression: a prospective study. Cognitive Therapy and Research, 27(3), 275-292.

Rood, L., Roelofs, J., Bögels, S.M., \& Alloy, L.B. (2010). Dimensions of negative thinking and the relations with symptoms of depression and anxiety in children and adolescents. Cognitive Therapy and Research, 34, 333-342.

Rood, L., Roelofs, J., Bögels, S.M., Nolen-Hoeksema, S., \& Schouten, E. (2009). The influence of emotion-focused rumination and distraction on depressive symptoms in non-clinical youth: a meta-analytic review. Clinical Psychology Review, 29, 607-616.

Schwartz, J., \& Koenig, L. (1996). Response styles and negative affect among adolescents. Cognitive Therapy and Research, 20(1), 13-36.

Singer, J.D., \& Willett, J.B. (2003). Applied longitudinal data analysis: Modeling change and event occurrence. New York: Oxford University Press.

Stone, L.B., Gibb, B.E., \& Coles, M.E. (2010). Does the hopelessness theory account for sex differences in depressive symptoms among young adults? Cognitive Therapy and Research, 34, 177-187.

Stroud, C.B., Davila, J., \& Moyer, A. (2008). The relationship between stress and depression in first onsets versus recurrences: A meta-analytic review. Journal of Abnormal Psychology, 117, 206213.

Timbremont, B., \& Braet, C. (2001). Psychometrische evaluatie van de Nederlandstalige Children's Depression Inventory [Psychometric evaluation of the Dutch Children's Depression Inventory]. Gedragstherapie, 34(3), 229-242.

Weisz, J., McCarty, C., \& Valeri, S. (2006). Effects of psychotherapy for depression in children and adolescents: a meta-analysis. Psychological Bulletin, 132(1), 132-149.

Ziegert, D., \& Kistner, J. (2002). Response Styles Theory: Downward extension to children. Journal of Clinical Child and Adolescent Psychology, 31(3), 325-334. 


\title{
Chapter 7
}

\section{Causal-analysis of stressful events, not focus on negative inferences, increases anxious affect compared to focus on contextual facts}

\author{
Lea Rood, Jeffrey Roelofs, Susan M. Bögels, Arnoud Arntz
}

\begin{abstract}
The purpose of the present experimental study was to compare the effects of components of stress-reactive rumination, i.e., focus on negative inferences and causal-analytical reasoning, on negative affect. Using a between-subjects design, female university students were given instructions to think about a recent stressful event in a particular way: by focusing on the negative inferences, by thinking in a causal-analytical way, or by focusing on contextual facts. A qualitative manipulation check showed that the manipulations succeeded. Sad affect increased in all conditions to a similar degree. Anxious affect increased significantly more after causal-analytic reasoning compared to contextual facts processing. To conclude, not the focus on negative inferences, but the causal-analytical component caused significant increases in anxious affect relative to thinking about the factual aspects of the event. This would imply that dwelling on causes is the particularly harmful component of stress-reactive rumination. The long-term effects of causal-analytical rumination need further investigation.
\end{abstract}




\section{Introduction}

Extensive research has demonstrated that repetitive thinking in the form of rumination plays a role in the development of symptoms of depression and anxiety (Watkins, 2008). The most prominent conceptualization of rumination that plays a key role in the Response Styles Theory of depression (Nolen-Hoeksema, 1987, 1991) is emotion-focused rumination. Emotion-focused rumination can be defined as repetitive thinking about the symptoms, causes, meanings, and consequences of depressed mood, and has been proposed to predict the maintenance and exacerbation of depressive symptoms (Nolen-Hoeksema, 1987, 1991). Emotionfocused rumination has been found to be related to the development of depression and anxiety (see review Nolen-Hoeksema, Wisco, \& Lyubomirsky, 2008). Whereas emotion-focused has been hypothesized to play an important role in the maintenance of depression, another type of rumination, stress-reactive rumination, is theoretically linked to the onset of depressive mood (Alloy et al., 2000; Robinson \& Alloy, 2003). Stress-reactive rumination, defined as repetitively thinking about the inferences that are made about the causes, meanings, and consequences of stressful events, can meaningfully be distinguished from emotion-focused rumination (Rood, Roelofs, Bögels, \& Alloy, 2010) and has been shown to be a better predictor of depression than emotion-focused rumination (Robinson \& Alloy, 2003).

Whereas the causal effect of emotion-focused rumination on the maintenance and exacerbation of depressed mood has been examined experimentally, showing that compared to distraction, emotion-focused rumination prolongs and worsens depressed and anxious mood states in dysphoric but not in non-dysphoric participants (see for a review Nolen-Hoeksema et al., 2008), the causal effect of stress-reactive rumination on the onset of negative mood has never been studied before. Therefore, this study is the first aiming to examine whether stress-reactive rumination leads to increases in sad and anxious affect.

Since Treynor, Gonzalez, and Nolen-Hoeksema (2003) suggested that emotion-focused rumination consists of a maladaptive form, brooding (defined as passively dwelling on depressive symptoms), and a more adaptive, analytical form, reflective pondering (defined as an intentional attempt at cognitive problem-solving in order to restore mood), studies have shown that brooding is indeed more strongly related to depressive symptoms compared to reflective pondering (e.g., Burwell \& Shirk, 2007; Miranda \& Nolen-Hoeksema, 2007; Moberly \& Watkins, 2008; Raes \& Hermans, 2008; Roelofs, Huibers, Peeters, \& Arntz, 2008). Thus, reflective pondering may be less maladaptive compared to brooding when already in a depressed mood. However, the effects of a reflective process on the onset of depressive symptoms are unknown. Although stress-reactive rumination is focused on negative attributions and 
AN EXPERIMENTAL MANIPULATION OF RUMINATION

inferences, it seems to contain a causal-analytical component as well ('why does this always happen to me?').

More specifically, the aim of this study was to experimentally manipulate the causal-analytical reasoning component of stress-reactive rumination and the ruminative focus on negative inferences, in order to examine whether these components are differentially related to increases in sad and anxious affect, compared to a control condition. In the focus on negative inferences condition (from here referred to as ' $\mathrm{Nl}$-focus'), negative emotions are provoked by inducing a ruminative focus on negative inferences regarding self-worth, feelings of guilt, and the impact and consequences of a stressful event. In the causal-analytical reasoning condition (from here referred to as 'CA-reasoning'), analysis of the causes and occurrence of the stressful event in a non-judgmental way was induced, based on Rude, Maestas, and Neff (2007), who suggested that the degree of negative evaluative judgment (including for example self-criticism and difficulties accepting reality) may distinguish the maladaptive brooding from the more adaptive reflective pondering. The control condition, labeled 'contextual facts processing' (from here referred to as 'CF-processing') consisted of a focus on emotionally non-threatening and factual aspects of the stressful event. This way, the focus was on the stressful event as it was in the other conditions, however, it is controlled by focusing on factual information in order to prevent participants from engaging in rumination. See Appendices $A$ and $B$ for the specific instructions per condition.

We expected that $\mathrm{Nl}$-focus and CA-reasoning would cause significantly stronger increases in sad and anxious affect compared to CF-processing, providing support for the causal role of stress-reactive rumination in the onset of depressive and anxious symptoms. Furthermore, because of the higher degree of negative evaluative judgment in $\mathrm{Nl}$-focus compared to the $\mathrm{CA}$-condition we expected that the increase in negative affect states would be highest in the $\mathrm{Nl}$-focus condition, which we expected to be the most maladaptive component of stress-reactive rumination relative to causal-analytical thinking. The dispositional tendency to ruminate was included as a covariate to control for the effects of this variable.

\section{Method}

\section{Participants}

Participants $(N=111)$ were female undergraduate students in psychology $(47.7 \%)$, health sciences and medicine (49.5\%), and other (2.8\%). Age range was 18 to 26 , with a mean age of $21.4(S D=1.7)$. We chose for a homogenous sample of females, because we expected that the effect of the manipulations would be stronger in females compared to males, as females have a stronger tendency to ruminate (Nolen-Hoeksema, Larson, \& Grayson, 1999; Nolen-Hoeksema, Morrow, \& 
Fredrickson, 1993; Rood, Roelofs, Bögels, Nolen-Hoeksema, \& Schouten, 2009). Subjects with a score of $\geq 29$ on the BDI-II (indicative of severe levels of depressive symptoms; Van der Does, 2002) were excluded from participation for ethical reasons.

\section{Procedure}

Participants were recruited at Maastricht University, actively by handing out flyers, and passively through advertisements. They were not fully informed about the exact purpose and nature of the study to minimize the risk of demand effects. Subjects were told that the purpose of the study was to investigate 'the relation between the interpretation of stressful events and negative emotions', and they were instructed to bring a piece of music of which they had good memories. Written informed consent was obtained from all participants. Before starting the experiment, participants were screened on the level of depressive symptoms. They then completed a self-report measure of trait rumination and visual analogue scales (VAS). Subsequently, participants were instructed to think about a current or recent stressful experience about which they had to think a lot (see Appendix A for full instructions). In addition, they were given six cards with different instructions and questions, depending on the condition, with the aim of keeping individuals in a certain thinking mode (see appendix B). Participants were specifically instructed to "... use these questions to think as detailed as possible about all negative aspects that were associated with the stressful event" in the $\mathrm{Nl}$-focus condition; to "... use these questions to gain more insight in yourself and the situation so that you can better understand yourself' in the CA-reasoning condition; and: "These questions are intended to make you think about the stressful event(s)" in the CF-processing condition. All instructions were read aloud and given paper.

After checking whether the instructions were well understood, the research assistant left the room, so that the participant could think in private. After 5 minutes, the research assistant returned and indicated delicately without words that the participant could continue on the computer, then leaving again. A second set of VAS measuring negative affect states was administered, followed by a qualitative and quantitative manipulation check (see 2.4.4. and 2.4.5.).

Finally, all participants received a positive mood induction, which consisted of listening to and talking about a favourite piece of music that they had brought to the experiment. Whether affect had returned to baseline was examined with a final series of VAS. The entire procedure took 45 minutes. Participants received a gift voucher worth $€ 5$ and/or course credits for their participation. Furthermore, they received a thorough debriefing in writing. The experiment was approved by a local IRB. 
AN EXPERIMENTAL MANIPULATION OF RUMINATION

Design

This experiment had a between-subjects design, with repeated measures within subjects. There were three conditions: NI-focus $(N=37)$, CA-reasoning $(N=39)$, and CF-processing $(N=35)$. Participants were assigned to one of three conditions by a block-randomization procedure.

\section{Measurement instruments}

Depressive symptoms

The BDI-II (Beck Depression Inventory II: Beck, Steer, \& Brown, 1996; Dutch version: Van der Does, 2002) consists of 21 items and aims to measure the severity of depressive symptoms in adults. Each item (e.g.: worthlessness) is accompanied by four sentences indicating the severity of the symptom (I feel completely worthless $=3$ I I do not feel worthless = 0). The Dutch BDI-II possesses good psychometric properties (Van der Does, 2002).

\section{Stress-reactive rumination}

The SRRS (Stress-Reactive Rumination Scale; Robinson, 1997) consists of nine items and intends to measure the tendency to ruminate on the negative inferences in response to stressful events. The participant is instructed to indicate how often he/she acts a certain way when experiencing something stressful. An example is: 'Think about how the stressful event was entirely your fault'. Answers are scored on an 11-point scale, with $0=$ 'never' and $10=$ 'always'. The reliability of the original version is acceptable to good (Alloy et al., 2000; Robinson \& Alloy, 2003). The original version of the SRRS was translated into Dutch, then back translated into English, and subsequently approved by one of the original authors (Lauren B. Alloy).

\section{Negative affect states}

VAS (0-100 mm) were used to measure anxious and sad affect states. An example of an item is: 'How sad do you feel at the moment?'. Affect was rated from 0 = 'not at all' to $100=$ 'very much'. Filler items measuring other affect states were included as well to hide the purpose of this study.

\section{Qualitative manipulation check}

Participants were asked to describe what thoughts (words and images) exactly went through their mind during the experimental task, and to be as complete as possible in their description. The resulting qualitative data in the form of short texts were rated independently by two bachelor students blind to condition and hypotheses. The raters were given a short description of the experiment together with the instructions, and received a brief training. They assessed the content of the texts as a whole with respect to the degree of $\mathrm{NI}$-focus, CA-reasoning, and CF-processing on VAS. The 
raters were allowed to rate the content of the text on more than one thinking style if appropriate. Furthermore, they assessed the content of the written texts with regard to the degree of self-focus, negative self-referential thoughts, and images on VAS with left of the scale $(0)$ indicated 'not at all', whereas right of the scale (100) indicated 'all the time' (see Table 2 for the items in full). Condition was also categorically assessed in a forced choice format.

\section{Quantitative manipulation check}

Participants indicated the degree of $\mathrm{NI}$-focus and CA-reasoning during the task on VAS. The degree of ruminative NI-focus was assessed by "During the task I had to think about how terrible the stressful event is for me over and over again, and how this event influences me", while the degree of CA-reasoning was assessed by "During the task I tried to gain insight into myself and in the way I cope with such events, by thinking about the stressful event". "During the task I thought about the stressful event" was added to check whether participants in the CF-processing condition had thought about the event to a similar degree as the participants in the other conditions. Left of the scale (0) indicated 'not at all', whereas right of the scale indicated 'all the time' (100).

\section{Statistical analysis}

Differences between groups on all measurements were analysed by means of oneway ANOVAs and Kruskal-Wallis tests. Before carrying out the analyses of variance, the assumption of normality was checked for all variables by means of skewness and kurtosis values, and visually by histograms with normal curve. Not normally distributed variables were transformed, or if not appropriate, examined with the Kruskal-Wallis test for non-parametric data with Mann-Whitney tests for pair wise comparisons, which were also used in case the assumption of homogeneity of variances was violated. To check the assumption of homogeneity of regression slopes, the interaction term between condition and trait-rumination (SRRS) was included in the models, and excluded (and not reported) when not significant. Regression analyses with dummy-coded variables for condition were carried out in order to detect potentially influential outliers (cases for which the standardized residual was above 3 ).

To compare the effects of the conditions on increases in negative affect, ANCOVAs were carried out with condition as a fixed factor, and the change score of sad/anxious affect as the dependent variable. To create change scores, we subtracted the pre-manipulation measurement of negative affect state from the postmanipulation measurement. Trait rumination (SRRS) was added as a covariate. Simple contrasts were used for pair wise comparisons. Additionally, Cohen's $d$ effect sizes were computed to examine the relevance of the differences between the pairs 
AN EXPERIMENTAL MANIPULATION OF RUMINATION

of conditions. For that purpose, ANOVAs were carried out with dummy-coded variables for condition as covariates. In case of non-parametric data, Cohen's ds were computed by hand with the following formula: $r=z / \sqrt{ }\left(z^{2}+n-2\right)$, and subsequently converting the $r$ into $d$. Because of the ongoing debate on the use of raw change scores vs. residual change scores, data were also analysed with residual change scores (viz., ANCOVA with first measurement of affect as covariate and postmanipulation measurement of affect as dependent variable). Residual change scores take into account that the amount of change can be dependent on the baseline score. ANOVAs with raw change scores are more insightful and therefore reported; results with residual change scores will be reported in case these diverge from those with raw change scores.

\section{Results}

\section{General statistics and preparatory analyses}

The type of stressful events participants thought about can be classified as follows: interpersonal problems $(48.2 \%)$, death of a loved one $(11.4 \%)$, intrapersonal problems $(11.4 \%)$, study achievement $(20.2 \%)$, and other $(8.8 \%)$. There were no missing values because all questionnaires were administered through a computerized program, which did not allow skipping items. Reliability coefficients of the SRRS $(\alpha=.89)$ and BDI $(\alpha=.84)$ were high. Skewness and kurtosis values for all variables fell within the acceptable range of -1.5 to +1.5 , except for the VAS measuring anxious and sad affect. Therefore, these variables underwent a natural log and a square root transformation respectively, which successfully normalized the data. The regression analysis with the change score for sad affect as dependent variable showed one outlier. As removal of the outlier did not alter the results and since no seriously deviating scores were detected on the sad affect variables for this case, it was included in the analyses. Throughout the results section, the NI-focus condition is referred to as 'NIF', the CA-reasoning condition as 'CAR', and the CFprocessing condition as 'CFP'.

\section{Qualitative manipulation check}

The level of agreement between the two raters' classification of condition based on the written reports and actual experimental condition was substantial (see Landis \& Koch, 1977), with $\kappa \mathrm{S}=.59$ and .69; as was the level of agreement between the two raters, $\kappa=.74$, indicating that our manipulations succeeded fairly well ${ }^{1}$. With regard to the rated content of the texts, results showed that the interrater reliability for the items

\footnotetext{
${ }^{1}$ The ANOVA models with condition as agreed between raters $(\mathrm{N}=85$, of which 33 in NIF, 23 in CAR, 29 in CFP) instead of actual condition as independent variable showed a comparable pattern of results.
} 
ranged from moderate to good. The raters identified significantly more rumination in NIF compared to CAR $(U=249.00, z=4.92, p=.001, d=1.14)$ and CFP $(U=$ 128.00, $z=5.86, p=.001, d=1.40)$, and more reflection in CAR compared to NIF ( $U$ $=446.50, z=2.86, p=.004, d=.67)$ and CFP $(U=391.50, z=3.15, p=.002, d=$ .74). The rated degree of CF-processing was higher in CFP compared to NIF $(U=$ 146.50, $z=5.97, p=.001, d=1.43)$ and $\operatorname{CAR}(U=169.00, z=5.80, p=.001, d=$ 1.37). In sum, qualitative data suggest that our manipulations succeeded.

The degree of self-focused attention did not differ significantly between groups. However, content ratings revealed significantly more negative self-referential thoughts in NIF compared to CAR $(U=527.50, z=2.08, p=.04, d=.48)$ and to CFP $(U=430.00, z=2.50, p=.01, d=.60)$. The degree of images was rated highest in CFP compared to NIF $(U=300.50, z=3.93, p=.001, d=.94)$ and CAR $(U=356.50$, $z=3.55, p=.001, d=.84)$. Means, statistics and ICCs are displayed in Table 1.

\section{Quantitative manipulation check}

Unexpectedly, the ANOVA showed no significant group differences on the selfreported degree of focus on negative inferences during the experiment. In fact, in all conditions an average level of ruminative thoughts was reported. The Kruskal-Wallis test showed significant main effect for condition on self-reported degree of causal-

Table 1: Qualitative manipulation check: differences between conditions on content of thoughts as assessed by two independent blind raters

\begin{tabular}{|c|c|c|c|c|c|c|c|}
\hline & \multicolumn{7}{|l|}{ Condition } \\
\hline & NI-focus & $\begin{array}{l}\text { CA- } \\
\text { reasoning }\end{array}$ & CF-processing & & & & \\
\hline $\begin{array}{l}\text { Mean rater scores } \\
\text { (VAS) }\end{array}$ & $M(S D)$ & $M(S D)$ & $M(S D)$ & $\begin{array}{l}H \\
(d f=2)\end{array}$ & $p$ & $r$ & $I C C$ \\
\hline $\begin{array}{l}\text { Degree of focus on } \\
\text { negative inferences }\end{array}$ & $67.46(28.47)$ & $32.50(26.28)$ & $18.44(18.34)$ & 42.05 & .001 & .52 & .69 \\
\hline $\begin{array}{l}\text { Degree of causal- } \\
\text { analytic reasoning }\end{array}$ & $38.64(21.25)$ & $56.81(29.54)$ & $34.27(27.78)$ & 12.79 & .002 & .33 & .51 \\
\hline $\begin{array}{l}\text { Degree of focus on } \\
\text { contextual facts }\end{array}$ & $3.20(8.67)$ & $4.41(10.33)$ & $51.90(38.34)$ & 50.03 & .001 & .77 & .91 \\
\hline Degree of self-focus & $61.50(31.23)$ & $58.81(30.34)$ & $47.67(30.42)$ & 4.82 & .090 & .55 & .72 \\
\hline $\begin{array}{l}\text { Degree of neg. self- } \\
\text { reference }\end{array}$ & $27.45(32.15)$ & $18.92(30.91)$ & $10.51(19.41)$ & 7.14 & .028 & .71 & .85 \\
\hline Degree of images & $16.20(21.24)$ & $20.32(22.72)$ & $47.19(33.60)$ & 18.88 & .001 & .51 & .66 \\
\hline
\end{tabular}

Note. Degree of NI-focus/CA-reasoning/CF-processing = 'Indicate the degree to which the text fits the $\mathrm{NI}$-focus/CA-reasoning/CF-processing condition according to you'. Degree of self-focus = 'To what extent is the subject focused on herself?'. Degree of neg. self-reference = 'To what extent does the subject think and write about herself in a negative manner?'. Degree of images = 'To what extent do the thoughts of the participant exist of images?'. 
AN EXPERIMENTAL MANIPULATION OF RUMINATION

analytic reflection $(H=17.83, d f=2, p<.001)$, with more reflection in CAR compared to those in NIF $(U=510.00, z=2.20, p=.028, d=.51)$ and CFP $(U=303.00, z=$ 4.11, $p=.001, d=.97)$. As intended, subjects in CFP thought about the stressful event to a similarly high $(>80)$ degree as in the other conditions. See Table 2 for descriptives and statistics.

\section{Pre-existing group differences}

There were no significant group differences on the baseline VAS of sad and anxious affect, trait measure of stress-reactive rumination, and level of depressive symptoms (see Table 2).

Table 2: Means, standard deviations, and the results of one-way ANOVAs for all self-report variables

\begin{tabular}{|c|c|c|c|c|c|}
\hline \multirow[b]{2}{*}{ Variable } & \multirow{2}{*}{$\begin{array}{l}\text { NI-focus } \\
(N=37) \\
M(S D)\end{array}$} & \multirow{2}{*}{$\begin{array}{l}\text { CA-reasoning } \\
(N=39) \\
M(S D)\end{array}$} & \multirow{2}{*}{$\begin{array}{l}\text { CF-processing } \\
(N=35) \\
M(S D)\end{array}$} & \multicolumn{2}{|c|}{ Group effect } \\
\hline & & & & $F$ & $p$ \\
\hline $\mathrm{Nl}$-focus check & $60.51(24.92)$ & $54.72(23.77)$ & $52.63(28.20)$ & .93 & .40 \\
\hline CA-reasoning check & $52.38(25.95)$ & $66.00(22.03)$ & $37.69(26.72)$ & $11.93^{2}$ & $.01^{*}$ \\
\hline CF-processing/control check & $81.87(15.69)$ & $81.44(14.63)$ & $83.73(12.18)$ & .28 & .76 \\
\hline BDI-II & $5.84(5.35)$ & $6.82(4.93)$ & $6.63(5.88)$ & .35 & .71 \\
\hline SRRS & $48.76(17.99)$ & $42.54(17.90)$ & $46.60(13.02)$ & 1.39 & .25 \\
\hline Sadness 1 & $18.51(21.55)$ & $16.05(17.35)$ & $14.49(16.88)$ & $1.22^{1}$ & .30 \\
\hline Sadness 2 & $38.19(25.72)$ & $38.21(24.96)$ & $35.89(25.38)$ & $.08^{1}$ & .92 \\
\hline Change in sadness & $19.68(23.42)$ & $22.15(21.23)$ & $21.40(21.03)$ & $.98^{1}$ & .38 \\
\hline Anxiety 1 & $8.30(13.88)$ & $7.31(12.26)$ & $8.03(15.45)$ & $.23^{1}$ & .79 \\
\hline Anxiety 2 & $22.76(26.70)$ & $25.05(27.38)$ & $15.23(20.49)$ & $1.81^{1}$ & .17 \\
\hline Change in anxiety & $14.46(22.57)$ & $17.74(25.76)$ & $7.20(13.20)$ & $3.49^{1}$ & $.03^{*}$ \\
\hline
\end{tabular}

Note. ${ }^{*} p<.05 ;{ }^{1}$ Table displays raw means and standard deviations for all variables, $F$ and $p$ statistics are given for the results of the ANOVA on the log or square root transformed variables. ${ }^{2}$ Results of non-parametric testing are given in the text. NI-focus check = During the task I had to think about how terrible the stressful event is for me over and over again, and how this event influences me; CAreasoning check $=$ During the task I tried to gain insight into myself and in the way I cope with such events, by thinking about the stressful event; CF-processing/control check = During the task I thought about the stressful event; BDI-II = Beck Depression Inventory; SRRS = Stress Reactive Rumination Scale; Sadness 1 = pre-induction measurement of sad affect (VAS); Sadness 2 = post-induction measurement of sad affect (VAS); Anxiety $1=$ pre-induction measurement of anxious affect (VAS); Anxiety 2 = post-induction measurement of anxious affect (VAS).

The effect of condition on change in sad affect

The main effect of condition on change in sad affect was not significant, $F(2,107)=$ $.66, p=.52$, partial $\eta^{2}=.01$, nor was the effect of covariate trait stress-reactive rumination, $F(1,107)=2.40, p=.13$, partial $\eta^{2}=.02$. The Cohen's $d$ effect sizes of the group differences between NIF and CFP $(d=.05)$, and between CAR and CFP $(d=.18)$ were low. The effect size for the difference between NIF and CAR $(d=.26)$ indicated a modest but clinically relevant higher increase in sad affect after CAR 
compared to NIF. Using residual change scores, a significant effect of covariate trait rumination on the increase in sad affect state was found: $F(1,111)=6.63, p=.01$, $d=.50$, indicating that the higher tendency to ruminate, the more strongly sad affect increases after the manipulations. As the interaction term between condition and trait rumination was not significant, the effect of trait rumination was similar across conditions.

The effect of condition on change in anxious affect

The main effect of condition was significant, $F(2,107)=3.50, p=.03$, partial $\eta^{2}=.06$, whereas the effect of covariate trait stress-reactive rumination was not, $F(1,107)=$ $.07, p=.79$, partial $\eta^{2}=.001$. Simple contrasts showed a significantly higher increase in anxious affect after CAR compared to CFP $(t=2.64, d f=2, p=.01, d=.51)$, see Figure 1. The effect size of the group difference between CAR and CFP can be considered a clinically and practically relevant effect (see Cohen, 1988). There were no significant differences between NIF and $\operatorname{CAR}(t=1.43, d f=2, p=.16, d=.26)$, and NIF and CFP $(t=1.22, d f=2, p=.23, d=.24)$.

Figure 1: Graphic representation of the increase in sad and anxious affect (raw change scores)

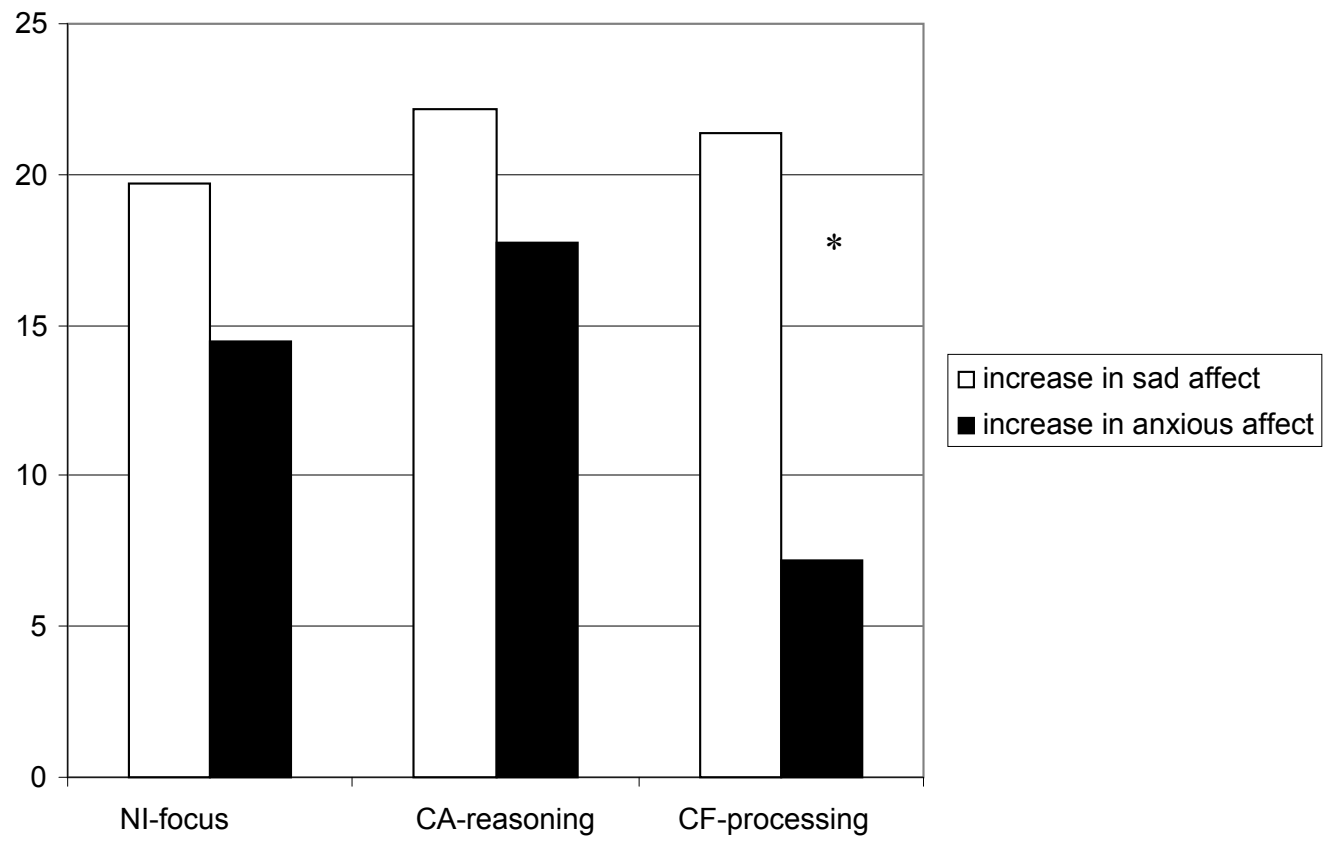


AN EXPERIMENTAL MANIPULATION OF RUMINATION

\section{Discussion}

The purpose of this study was to compare the short-term effects of stress-reactive rumination in the forms of focus on negative inferences and causal analytical reasoning, and a control condition on sad and anxious affect. The results were as follows.

\section{Effect of the manipulations on change in sad affect}

There were no group differences regarding the increase in sad affect. This was an unexpected finding, since at least a difference in sadness was expected between NIfocus and CA-reasoning on the one hand and CF-processing on the other hand. It is possible that in the present design without preceding mood induction, subjects were actually assigned to perform a dual task, being instructed to think about a stressful event and at the very same time having to think about the event in a particular way. This way, thinking about the stressful event, which is inherently a mood induction, could have overshadowed the effect of the induced thinking style. Furthermore, it is possible that the manipulation of CF-processing unintentionally evoked negatively laden emotional imagery by its focus on environmental (and visual) aspects of the stressful event, making the memory of the stressful event more vivid and confronting (see Borkovec, Ray, \& Stöber, 1998; Holmes \& Mathews, 2010). In favor of this explanation is that the rated degree of images in thought content was substantially higher in the CF-processing condition compared to the other conditions.

\section{Effect of the manipulations on change in anxious affect}

In line with our hypotheses, participants in the CA-reasoning condition reported significantly higher increases in anxious affect compared to those in the CFprocessing condition. These findings concur with findings from McLaughlin, Borkovec, and Sibrava (2007), who showed that induced (non-specific) rumination on past mistakes or failures caused increases in anxiety. In contrast with our hypotheses, CA-reasoning did relatively worse than $\mathrm{NI}$-focus with regard to increase in anxious and sad affect $(d=.26)$. This finding is remarkable as the degree of negative thought content and self-judgment was highest in the NI-focus manipulation. An explanation for this unexpected result may be that reflection (i.e., CA-reasoning) implies coming to terms with a stressful event, which may be confronting and stressful at first. It may be possible that reflecting on the causes, meanings, and consequences of stressful events and going over the role of self and others elicits feelings of uncertainty, self-doubt and stress; and therefore may lead to anxiety in healthy subjects in the short-term. However, it may result in a relief from symptoms of depression and anxiety in the long-term, once cognitive and emotional processing of the event has taken place. In addition, it may be speculated that rumination on 
negative inferences leads to some kind of meekness, resulting in relatively lower anxiety levels than causal-analytical reasoning.

These findings do not correspond with earlier findings regarding the relative adaptability of emotion-focused rumination subcomponent reflective pondering compared to brooding (e.g., Moberly \& Watkins, 2008; Raes \& Hermans, 2008). However, emotion-focused rumination and stress-reactive rumination are conceptually different constructs (see Rood et al., 2010), and therefore their subtypes may have different roles: once in a depressed mood, reflective pondering might be relatively adaptive compared to brooding, whereas reflection in response to stressful events outside the context of a depressed mood may increase the risk of falling into a ruminative cycle.

\section{Manipulation check}

It needs to be remarked that whereas the qualitative manipulation check showed that all manipulations succeeded, the self-report manipulation check indicated that the manipulation of $\mathrm{NI}$-focus might not have been strong enough. These contradictory findings may indicate that either the self-report items were not sensitive enough to capture thought process and content as effectively as the observer ratings (which demonstrated good reliability), or that the manipulation of $\mathrm{NI}$-focus did not completely succeed which could explain why the expected group differences were not found.

\section{Limitations and strengths}

This study has some important limitations. First, the effect of thinking style on sad affect might have been overshadowed by the negative effect of thinking about a stressful experience; therefore the experimental manipulations of thinking style should follow after a short period of thinking about the stressful event without instructions, to avoid dual tasking. Second, this study did not include an adequate self-report manipulation check for the CF-processing condition. Third, only the shortterm effects of the manipulations were examined, without follow-up measurements.

Strong points of the study were the use of an experimental manipulation to assess the causal effects of $\mathrm{NI}$-focus, CA-reasoning, and CF-processing on sad and anxious affect, and the inclusion of self-report as well as observer-rated manipulation checks. To the authors' best knowledge, this study is the first to attempt to experimentally examine the causal effect of different stress-reactive rumination styles on negative affect states. An innovative aspect of this study is that ruminative thinking styles were compared to a control condition as opposed to a distraction condition which most studies examining the effect of emotion-focused rumination have used (see for a review Nolen-Hoeksema et al., 2008). With respect to the similarly high increases in sad affect across conditions, focus on contextual facts may not have been a successful control condition, in the sense that distraction would have 
AN EXPERIMENTAL MANIPULATION OF RUMINATION

been a more powerful contrast condition in reducing sad affect. However, CFprocessing keeps the focus of attention within the context of the event, which elicits different cognitive and emotional processes in contrast to a form of distraction aimed to divert the attention away from a stressful experience. Experiential techniques that keep the focus within the stressful experience may be therapeutically more relevant to examine, because they facilitate the event to be reprocessed and to become less negatively emotionally laden.

\section{Clinical implications and recommendations for future research}

Although perhaps premature, an intriguing clinical implication of these results may be that causal-analytical reasoning (i.e., going over the causes of a stressful event again and again) has a more detrimental effect on negative affect compared to dwelling on the negative inferences. It would be interesting to examine the long-term effects of CA-reasoning and $\mathrm{Nl}$-focus in response to stressful events, either by means of experimental designs or high/low risk designs, or by investigating the effects of a training in these thinking styles on mood and on other variables, such as attentional processes or over-general memory. Furthermore, other interesting approaches to examine the effects of reflective/ruminative thinking processes on mood are that of Kross, Ayduk, and Mischel (2005), and Watkins (2008). Kross et al. (2005) have investigated the effects of 'why' vs. 'how' self-reflective thinking from a self-distanced vs. self-immersed perspective in dealing with feelings of anger, finding that the distant-why coping strategy is most effective. It would be interesting to examine the effects of these types of reflective/ruminative thinking on mood in dealing with stressful events, thus focused on analysis of the event besides only the accompanying emotions. Watkins and colleagues (Moberly \& Watkins, 2006; Rimes \& Watkins, 2005; Watkins \& Moulds, 2005; Watkins \& Teasdale, 2004) have examined the influence of abstract vs. concrete level of processing in response to emotions and events, finding that concrete thinking has a more beneficial effect on psychological functioning.

\section{Final conclusion}

To conclude, the causal-analytical component of stress-reactive rumination caused significant increases in anxious affect relative to thinking about the factual aspects of the event. This would imply that dwelling on causes in particular is the maladaptive component of stress-reactive rumination, rather than the repetition of negative inferences. The long-term effects of ruminative and reflective processes on the onset of depressive mood need further investigation, as causal-analytical reasoning may have a beneficial effect on negative mood over time. The current study can be seen as a starting point for further experimental research on the roles of maladaptive and 
relatively adaptive components of stress-reactive rumination in the onset of depressive symptoms.

\section{References}

Alloy, L. B., Abramson, L., Hogan, M., Whitehouse, W., Rose, D., Robinson, M., et al. (2000). The Temple-Wisconsin cognitive vulnerability to depression project: lifetime history of axis I psychopathology in individuals at high and low cognitive risk for depression. Journal of Abnormal Psychology, 109(3), 403-418.

Beck, A. T., Steer, R. A., \& Brown, G. K. (1996). The Beck Depression Inventory-II (BDI-II). Manual for Beck Depression Inventory-II. San Antonio: TX: Psychological Corporation.

Borkovec, T. D., Ray, W. J., \& Stöber, J. (1998). Worry: a cognitive phenomenon intimately linked to affective, physiological, and interpersonal behavioral processes. Cognitive Therapy and Research, 22(6), 561-576.

Burwell, R., \& Shirk, S. (2007). Subtypes of rumination in adolescence: associations between brooding, reflection, depressive symptoms, and coping. Journal of Clinical Child and Adolescent Psychology, 36(1), 56-65.

Cohen, J. (1988). Statistical power analysis for the behavioral sciences (2nd ed.). Hillsdale, NJ: Lawrence Erlbaum Associates.

Holmes, E. A., \& Mathews, A. (2010). Mental imagery in emotion and emotional disorders. Clinical Psychology Review. 30, 349-362.

Kross, E., Ayduk, Ö., \& Mischel, W. (2005). When asking "why" does not hurt: distinguishing rumination from reflective processing of negative emotions Psychological Science, 16(9), 709715.

Landis, J. R., \& Koch, G. G. (1977). The measurement of observer agreement for categorical data. Biometrics, 33, 159-174.

McLaughlin, K. A., Borkovec, T., D., \& Sibrava, N. J. (2007). The effects of worry and rumination on affect states and cognitive activity. Behavior Therapy, 38(1), 23-38.

Miranda, R., \& Nolen-Hoeksema, S. (2007). Brooding and reflection: Rumination predicts suicidal ideation at 1-year follow-up in a community sample. Behaviour Research and Therapy, 45, 3088-3095.

Moberly, N. J., \& Watkins, E. R. (2006). Processing mode influences the relationship between trait rumination and emotional vulnerability. Behavior Therapy, 37, 281-291.

Moberly, N. J., \& Watkins, E. R. (2008). Ruminative self-focus and negative affect: an experience sampling study. Journal of Abnormal Psychology, 117(2), 314-323.

Nolen-Hoeksema, S. (1987). Sex differences in unipolar depression: evidence and theory. Psychological Bulletin, 101(2), 259-282.

Nolen-Hoeksema, S. (1991). Responses to depression and their effects on the duration of depressive episodes. Journal of Abnormal Psychology, 100(4), 569-582.

Nolen-Hoeksema, S., Larson, J., \& Grayson, C. (1999). Explaining the gender difference in depressive symptoms. Journal of Personality and Social Psychology, 77(5), 1061-1072.

Nolen-Hoeksema, S., Morrow, J., \& Fredrickson, B. (1993). Response styles and the duration of episodes of depressed mood. Journal of Abnormal Psychology, 102(1), 20-28.

Nolen-Hoeksema, S., Wisco, B. E., \& Lyubomirsky, S. (2008). Rethinking rumination. Perspectives on Psychological Science, 3, 400-424. 
AN EXPERIMENTAL MANIPULATION OF RUMINATION

Raes, F., \& Hermans, D. (2008). On the mediating role of subtypes of rumination in the relationship between childhood emotional abuse and depressed mood: brooding versus reflection. Depression and Anxiety, 25, 1067-1070.

Rimes, K. A., \& Watkins, E. (2005). The effects of self-focused rumination on global negative selfjudgements in depression. Behaviour Research and Therapy, 43, 1673-1681.

Robinson, M. (1997). The role of negative inferential style and stress-reactive rumination on negative inferences in the etiology of depression: Empirical investigation and clinical implications. Unpublished doctoral dissertation, Temple University.

Robinson, M., \& Alloy, L. (2003). Negative cognitive styles and stress-reactive rumination interact to predict depression: a prospective study. Cognitive Therapy and Research, 27(3), 275-292.

Roelofs, J., Huibers, M., Peeters, F., \& Arntz, A. (2008). Effects of neuroticism on depression and anxiety: Rumination as a possible mediator. Personality and Individual Differences, 44, 576-586.

Rood, L., Roelofs, J., Bögels, S. M., \& Alloy, L. B. (2010). Dimensions of negative thinking and the relations with symptoms of depression and anxiety in children and adolescents. Cognitive Therapy and Research, 34, 333-342.

Rood, L., Roelofs, J., Bögels, S. M., Nolen-Hoeksema, S., \& Schouten, E. (2009). The influence of emotion-focused rumination and distraction on depressive symptoms in non-clinical youth: a meta-analytic review. Clinical Psychology Review, 29, 607-616.

Rude, S., Maestas, K., \& Neff, K. (2007). Paying attention to distress: What's wrong with rumination? Cognition and Emotion, 21(4), 843-864.

Treynor, W., Gonzalez, R., \& Nolen-Hoeksema, S. (2003). Rumination reconsidered: a psychometric analysis. Cognitive Therapy and Research, 27(3), 247-259.

Van der Does, A. J. W. (2002). Manual of the Dutch Version of the Beck Depression Inventory (BDI-IINL). Amsterdam: Harcourt Publishers.

Watkins, E. R. (2008). Constructive and unconstructive repetitive thoughts. Psychological Bulletin, 134, 163-206.

Watkins, E. R., \& Moulds, M. (2005). Distinct modes of ruminative self-focus: Impact of abstract versus concrete rumination on problem solving in depression. Emotion, 5(3), 319-328.

Watkins, E. R., \& Teasdale, J. D. (2004). Adaptive and maladaptive self-focus in depression. Journal of Affective Disorders, 82, 1-8. 


\section{Appendix A: Instruction of manipulation}

"Now we would like you to think about a current or recent stressful event/situation that you have recently experienced and which you have to think about a lot. You can for example think of a conflict you're having with someone, about problems at work, disappointing study results, relational problems, lacking friendships, etc. If you can't think of anything, think about something stressful that happened longer ago, or a stressful event that is (possibly) still going to happen. Of course, it could be that subsequently more stressful events or situations come to mind. You may decide yourself whether you think of one or multiple events. Let your thoughts guide you. You can think of these stressful event(s) in words, but also in images. We ask you to try as best as you can not to let your thoughts wander off the stressful event(s). You have also received a number of cards with questions on them. $\left({ }^{*}\right)$ Now we want you to use these questions to think as detailed as possible about all negative aspects that were associated with the stressful event. ${ }^{1}$ / Now we want you to use these questions to gain more insight in yourself and the situation so that you can better understand yourself!' $/$ These questions are intended to make you think about the stressful event(s). ${ }^{3}$ It is up to you how much time you spend on a question and when you pick the next card, as long as you try to answer the question for yourself. When you have gone through all the cards, pick up the first card again and try to answer the question once more, but then even in more detail. It could be that you find it hard to think this long about stressful things, but do try so anyway. The researcher will leave you alone with your thoughts for a while, and will indicate when you may stop thinking. Mind! After the experiment we will ask you to write down what went through your mind (thoughts and images) on the computer."

$\left({ }^{*}\right)$ Note. Specific instructions were added for each condition: ${ }^{1} \mathrm{Nl}$-focus; ${ }^{2} \mathrm{CA}$-reasoning; ${ }^{3} \mathrm{CF}-$ processing.

\section{Appendix B: Content of the cards}

NI-focus: Think about the impact of the stressful event on you and/or on others / Think about what the consequences of the stressful event could be for your future / Think about whether things like these always happen to you / Think about how it all could have had gone differently, if ... / Think about how you could have prevented this from happening / Think about whether the stressful event/situation could have been your fault.

CA-reasoning: Think about how come this stressful event affects or has affected you this much / Try to understand what the causes are of what has happened, and analyse what concurrence of circumstances has lead to the stressful event / Try to understand what your role has been in the occurrence of the stressful event, as well as what the role of the other person(s) has been / Try to understand your reaction to the stressful event/situation / Try to understand why this event occupies you so much / Think about what you can do differently to prevent a stressful event like this from happening again.

CF-processing: What was the environment where it happened like exactly? Try to imagine every little detail as precise as possible / At what date and time did the stressful event take place? How long did the actual event/situation last? / What were the weather conditions like at that moment? (Also if you were inside) / Were other people present when it happened? If yes, how did they look (e.g., how were they dressed?) / Describe how you looked precisely (e.g., what you were wearing)? / Describe as precisely as you can what was on the news that day. 


\title{
Chapter 8
}

\section{The effects of experimentally induced rumination, positive reappraisal, acceptance, and distancing when thinking about a stressful event on affect states in adolescents ${ }^{1}$}

\author{
Lea Rood, Jeffrey Roelofs, Susan M. Bögels, Arnoud Arntz
}

\begin{abstract}
The current study compares the effects of experimentally induced rumination, positive reappraisal, distancing, and acceptance on affect states in adolescents aged 13-18. Participants $(N=160)$ were instructed to think about a recent stressful event. Next, they received specific instructions on how to think about that event in each condition. Manipulation checks revealed that the manipulations were successful, except for acceptance. The two most reported events were "a fight" and "death of loved one". Results showed that positive reappraisal (i.e., thinking about the benefits and personal growth) caused a significantly larger increase in positive affect and decrease in negative affect compared to rumination, distancing, and acceptance. Current findings implicate that positive reappraisal seems an adequate coping strategy in the short-term, and therefore could be applied in interventions for youth experiencing difficulties managing negative affect. Future research should focus on long-term effects of these cognitive strategies and on more intensive training of acceptance.
\end{abstract}

\footnotetext{
${ }^{1}$ Accepted in: Journal of Abnormal Child Psychology.
} 


\section{Introduction}

Understanding how various cognitive strategies in response to stress impact affective states among adolescents is important, as it may shape intervention or prevention strategies for adolescents who are experiencing difficulties with managing negative affect related to personal stress (Compas, Connor-Smith, Saltzman, Harding Thomsen, \& Wadsworth, 2001). Various cognitive coping strategies have been described in the literature. The present study focuses on rumination, positive reappraisal, acceptance, and distancing.

Rumination can be defined as repetitively thinking about the causes, implications, and consequences of negative feelings (Nolen-Hoeksema, 1987; 1991) and stressful events (Robinson \& Alloy, 2003). Although people ruminate in an attempt to gain insight in their problems (Nolen-Hoeksema, 1991), rumination is likely to have unconstructive consequences because of its abstract-analytical nature, negative content, and its likelihood to occur in negative intrapersonal and situational context (Watkins, 2008). Cross-sectional studies have demonstrated that rumination is strongly associated with symptoms of depression and anxiety in adults as well as in adolescents (see reviews Nolen-Hoeksema, Wisco, \& Lyubomirsky, 2008, Rood, Roelofs, Bögels, Nolen-Hoeksema, \& Schouten, 2009; Watkins, 2008). Prospective studies have demonstrated that rumination predicts depression in adults (NolenHoeksema et al., 2008; Watkins, 2008), and changes in depressive symptoms over time in youth (Rood et al., 2009). Only one study so far has examined the effect of rumination on depressive mood state in an adolescent sample experimentally. Park, Goodyer, and Teasdale (2004) compared the effects of an 8-minute induction of selffocused rumination (i.e., a self-focus on emotions, body state, goals and attributes) to distraction in adolescents aged 12-17. Their findings showed that rumination as compared to distraction worsened depressive mood in clinically depressed adolescents and in community controls.

Positive reappraisal ${ }^{2}$ is a meaning-based type of coping that can be defined as reinterpreting events or situations in a positive manner (Folkman \& Moskowitz, 2000; Helgeson, Reynolds, \& Tomich, 2006), and includes elements such as attempting to find benefits and personal growth (see conceptualisation of Garnefski, Kraaij, \& Spinhoven, 2001). Positive reappraisal of stressful experiences increases awareness of important personal values in life, and encourages to act upon those values (Folkman \& Moskowitz, 2000), thereby changing the meaning of stressful

\footnotetext{
2 Please note that positive reappraisal should not be confused with James Gross' cognitive reappraisal, which he defines as "changing how we think about a situation in order to decrease its emotional impact" (p. 281, Gross, 2002). Although positive reappraisal and cognitive reappraisal seem similar cognitive processes in the sense that they aim to change interpretations and appraisals into more positive ones, in the current study design, positive reappraisal is considered a post-event coping strategy, and not an antecedent emotion-focused regulation strategy as conceptualised by Gross (2002).
} 
experiences. As a cognitive coping strategy in response to stressful events, positive reappraisal has been positively related to psychological wellbeing, and to a lesser extent, negatively related to depressive symptoms in adults (see review Helgeson et al., 2006), as well as in adolescents (Garnefski et al., 2001; Garnefski, Legerstee, Kraaij, van den Kommer, \& Teerds, 2002). Tugade and Fredrickson (2004) have suggested that especially people who have a low resiliency to stress might benefit from a training in the use of positive reappraisal, as it generates positive affect and facilitates adequate emotion regulation. Folkman (2008) stresses that the experience of positive emotions can play an important adaptive role in coping with stress, for example, by influencing the type of coping strategy that is employed, but also by "charging up the batteries". An elaborated theory on the role of positive emotions is provided by Fredrickson (2004), whose broaden-and-build theory posits that positive emotions generate a broader mindset (i.e., momentary thought-action repertoire), which can lead to an increase (build) in physical, social, psychological, and intellectual resources that later help form a buffer against stress. In the current study, the positive reappraisal condition aimed to induce a thinking process focused on benefits and personal growth as a consequence of the stressful event.

Another cognitive coping strategy which could be considered an adaptive alternative to rumination, is mindfulness-based acceptance of thoughts and feelings. Acceptance is one of the core elements of mindfulness (Germer, 2005; Williams, Teasdale, Segal, \& Kabat-Zinn, 2007). The purpose of acceptance in mindfulness practice is not to passively resign to unwanted experiences or emotions, but rather to become aware of thoughts and feelings, observe them as they are, and to accept their presence without judging them as good or bad (Baer, 2003; Williams et al., 2007). Mindfulness-based approaches have yielded promising results with regard to the treatment of a wide range of psychological problems in adults, such as dealing with chronic pain, depression, anxiety, and ADHD (Baer, 2003). The effects of mindfulness approaches have not yet been extensively studied in youth samples (see Burke, 2010); however, intervention studies so far show promising results in adolescents with a range of psychiatric disorders (Biegel, Brown, Shapiro, \& Schubert, 2009; Bögels, Hoogstad, van Dun, de Schutter, \& Restifo, 2008).

Experimental studies have demonstrated that mindfulness meditation (or mindful acceptance; Singer \& Dobson, 2007) was significantly more effective in recovering from a sad mood induction than rumination in undergraduate students (Broderick, 2005) and in remitted and currently depressed adults (Huffziger \& Kuehner, 2009; Singer \& Dobson, 2007). In contrast to these studies, Kuehner, Huffziger, and Liebsch (2009) found that mindfulness meditation did not have a beneficial effect on mood compared to rumination in a sample of undergraduate students. In sum, there is evidence that mindful self-focus or acceptance might be more effective than rumination when processing stressful experiences, though results 
so far are equivocal. In the present study, the acceptance condition was aimed to induce an attentional, experiential focus on thoughts about the stressful event.

Self-distancing (i.e., looking at self from an observer's perspective) has a beneficial effect on level of depression (Kross \& Ayduk, 2009) and may prevent rumination (Kross, Ayduk, \& Mischel, 2005). An observer's perspective may reduce emotional arousal when working through negative events, by looking more objectively at the circumstances (Kross et al., 2005; Nigro \& Neisser, 1983). However, the observer's perspective also plays a role in the maintenance of certain psychological disorders: as a maladaptive attentional process in social anxiety (see Bögels \& Mansell, 2004) and as a cognitive avoidance strategy in PTSD (Kenny \& Bryant, 2007). A distancing induction was included with the intention to make participants think about all negative aspects of the stressful event from an observer's perspective, thus in a non-ruminative (and non-verbal) manner. A neutral control condition was not included in our study, as a "think about anything" manipulation without instructions would allow participants to employ various types of coping strategies including the ones we wanted to manipulate in the other conditions (such as rumination), and would therefore not adequately serve as a control condition.

Whereas cross-sectional and longitudinal studies provide information on the strengths of relationships between variables, experimental studies enable a more direct examination of causal relationships. The purpose of this study was to compare the effects of various cognitive coping strategies i.e., rumination, positive reappraisal, acceptance, and distancing, on positive and negative affect states related to personal stress in a sample of non-clinical adolescents. We expected that (1) participants would show a greater increase in negative affect after the rumination induction compared to the acceptance, positive reappraisal, and distancing inductions; and (2) participants would show a stronger increase in positive affect, and a stronger decrease in negative affect, after the positive reappraisal induction compared to the other inductions. As the consequences of rumination have been found to be more unconstructive in the presence of other vulnerability factors such as low self-esteem and negative beliefs (see Watkins, 2008), we examined whether the effect of condition on affect states would be moderated by the level of trait-rumination (SRRSC; see 2.5 Measures). High trait-ruminators were expected to report a greater increase in negative affect after the rumination induction compared to low traitruminators. More speculatively, high trait-ruminators were expected to respond less favourably to the expected relatively beneficial effects of the acceptance and positive reappraisal manipulations, compared to the low trait-ruminators.

Additional hypotheses were formulated on differences between conditions regarding certain characteristics that may co-determine the outcome of cognitive strategies. Intrinsic to meaning-based coping, rumination and positive reappraisal are both abstract styles of thinking (Folkman, 2008; Watkins, 2008). There is some 
evidence that the beneficial effects of mindfulness are due to the reduction of abstract-evaluative thinking (Heeren \& Philippot, 2009). Therefore, the level of abstractness of thoughts was expected to be higher in the rumination and positive reappraisal conditions than in the acceptance and distancing conditions. As abstractness of thought may be related to a predominance of words over images in thought (see Stöber \& Borkovec, 2002), the ratio of words by images was expected to be higher in the rumination and positive reappraisal conditions than in the acceptance and distancing conditions. The level of concreteness of thoughts was expected to be highest in the distancing condition, which is likely to evoke imagery because of its visual focus. Furthermore, although a component of rumination, selffocused attention is not necessarily maladaptive. Self-focus in a positive intrapersonal and environmental context has been found to reduce negative affect (see Mor \& Winquist, 2002). There is some evidence that mindful self-focus improves sad mood (Huffziger \& Kuehner, 2009). The degree of self-focus was expected to be similar across conditions.

To the authors' best knowledge, the present study is the first study to compare the short-term effects of rumination, positive reappraisal, acceptance, and distancing on negative and positive affect states in adolescents in an experimentally controlled design. The examination of how different strategies to cope with stressful experiences influence negative and positive affect states in non-clinical adolescents may generate hypotheses regarding maintaining or exacerbating variables in depression, which is characterized by the combination of high negative affect and low positive affect (Watson, Clark, \& Carey, 1988).

\section{Method}

\section{Participants}

The study sample consisted of 160 non-clinical adolescents aged 13 to $18(M=$ $14.45, S D=1.10)$, of which 79 boys $(49.4 \%)$ and 81 girls. All levels of education were represented: lower professional / general secondary education $(N=76)$, higher general secondary education $(N=42)$, and pre-university education $(N=42)$. The nationality of the participants was predominantly Dutch (96.9\%). About one quarter of the participants $(24.4 \%)$ reported that their parents were divorced. Mean occupational level of both parents ${ }^{3}$ served as an indication of socio-economic status (SES): $27.5 \%$, $36.9 \%$ and $29.4 \%$ of the participants came from families with a respectively low, average, and high socio-economic background; whereas of $6.3 \%$ of the participants,

\footnotetext{
${ }^{3}$ Occupational level of both parents was assessed by means of the Standard Classification of Occupations 1992: Edition 2001, as provided by the Dutch Central Bureau of Statistics, and was based on occupation of parent as reported by the participant. Mean occupational level was rounded up, so that in case mother's occupational level was low, while father's occupational level was average, then mean occupational level of family is average.
} 
both parents were unemployed. Mean age did not differ across groups, $F(3,156)=$ $.11, p=.96$. $X^{2}$-tests showed that the four groups did not differ on demographic variables such as gender, educational level, nationality, divorce of parents, and SES (statistics obtainable from first author). There were two exclusion criteria: (1) recently being diagnosed with a mood disorder, for ethical reasons $(N=0)$, and (2) not being able to come up with a recent stressful event. This was checked verbally by the researcher prior to the manipulation of cognitive coping strategy $(N=2)$.

\section{Recruitment procedure}

The participants were recruited at a secondary school in the southern region of the Netherlands. In accordance with the school policy regarding the different educational levels involved, either the class mentors or the research assistant held a 5-minute talk to motivate the pupils to participate, and subsequently distributed information forms for parents and an adjusted version for adolescents. The pupils were not fully informed about the pupose of the study. Active written consent was obtained from participating adolescents and their parents. About 17.7\% $(N=275)$ of the approached pupils $(N=1552)$ and their parents agreed to participate. In order to have educational level, age, gender equally represented in the conditions, 160 pupils were effectively contacted, scheduled and eventually participated in the experiment.

With regard to the selection of participants (i.e., stratification by gender, age, and educational level), the procedure was as follows: informed consents were randomly sorted by gender, age, and educational level, as the research assistant did not have further background information on the participants. For example, a group of girls aged 13-14 in the lower educational level were scheduled and subsequently randomly assigned to one of the conditions. These procedures are not likely to have led to a systematic bias or reduced generalizability in the final sample. The experimental protocol was approved by a local Institutional Review Board.

\section{Design}

The study has a between-subjects design with four experimental conditions: rumination $(N=40)$, acceptance $(N=40)$, positive reappraisal $(N=41)$, and distancing $(N=39)$. A repeated measures within subjects approach was applied to asses positive and negative affect states at four time points. The baseline measurement (T1) took place at the start of the experiment before the stressinduction; the second measurement (T2) after the stress-induction and before the manipulation of coping strategy; and the third measurement (T3) after the manipulation of coping strategy. A fourth measurement (T4) of affect states took place after the positive distraction task at the end of the experiment. 


\section{Study procedure}

The research assistant tested all participating pupils during regular classes, in a private test room at school. First, participants completed self-report measures of the disposition to ruminate (SRRS-C) and depressive symptoms (CDI; see 2.5 Measures). Then baseline affect states were assessed by means of visual analogue scales (VAS; T1, see 2.5). In all conditions adolescents were asked to think about a current or recent stressful experience that was troubling them for about 3 minutes. They were specifically instructed to play the event in their head as a movie, and to bring up all thoughts and feelings that belonged to the event until they would see the event vividly before them and felt like they were in the middle of it again. Next, they were instructed to stop the movie at the most stressful moment, and to tell the researcher which stressful event had occurred to them. The full instructions of the stress-induction were given by vocal communication read aloud and on paper.

Then affect states were assessed again by VAS (T2). Subsequently, in order to manipulate the way of thinking about the stressful event, participants received instructions by vocal communication read aloud and using a set of four cards, specific to each condition. Participants were instructed to think about the stressful experience again, but now in a certain way, and to use the cards as a support to keep thinking the intended way. In the Appendix the instructions of the manipulations of cognitive coping strategy are given. The participant was left alone for 5 minutes. After the experimental manipulation, a third series of VAS assessing affect states were administered (T3). To assess whether, and to what extent, the manipulation of cognitive coping strategies had succeeded, we relied on a qualitative (administered first) as well as quantitative manipulation check (see 2.5.4. and 2.5.5.). At the end of the experiment, for ethical reasons participants were offered a positive mood induction task that consisted of listening to, and talking about, a favourite piece of music they had been instructed to bring to the experiment beforehand. The researcher checked by a fourth series of VAS (T4) whether participant's affect had restored to baseline level. The entire procedure took 45 minutes. Participants received a gift voucher worth $€ 5$ for their participation.

\section{Measures}

\section{Stress-reactive rumination}

The Stress-Reactive Rumination Scale for children (SRRS-C) is a downward extension of the SRRS for adults, adapted to youth (Robinson, 1997; authorized Dutch version: Rood, Roelofs, Bögels, \& Alloy, 2010). The SRRS-C aims to measure the extent to which negative inferences following stressful events are rehearsed. The SRRS-C consists of nine items (e.g., "I think about how the stressful event was totally my fault"). The frequency of each item is rated on a four-point Likert type scale (i.e., 1 = almost never, 2 = sometimes, 3 = often, 4 = almost all the time). Reliability of the 
SRRS-C is adequate; discriminative validity and concurrent criterion validity are supported (Rood et al., 2010).

\section{Depressive symptoms}

The Children's Depression Inventory (CDI; Kovacs, 1981; Dutch version: Timbremont \& Braet, 2001; 2002) aims to measure the level of depressive symptoms in children from 7 to 17 years old. It consists of 27 items, covering feelings of sadness, self-guilt, loss of appetite, insomnia, and adjustment to school. For each item, the subject chooses one of three statements (e.g., I am sad sometimes / I am often sad / I am always sad) that represents best how he or she has been feeling the last two weeks. Reliability in terms of internal consistency is good and the convergent validity of the CDI is supported (Timbremont \& Braet, 2001).

Measurement of affect states (VAS)

Negative and positive affect states (i.e., "gloomy", "sad", and "happy") were assessed by means of three VAS, e.g., "How gloomy do you feel at the moment?", using a horizontal line $(0-100 \mathrm{~mm})$, with at the left end of the continuum "not at all" $(0)$, and at the right end "very much" (100).

\section{Qualitative manipulation check (observer-rated VAS)}

First, participants were asked to describe in just a few words what stressful event(s) they had thought of, and to rate the severity of the event(s) on a five point Likert scale ("How bad was this event to you?" 1 = not bad [not terrible] ... $5=$ the worst I have ever experienced). Second, they were asked to describe what thoughts (words and images) exactly went through their mind during the experimental task, and to be as complete as possible in their descriptions. The resulting qualitative data in the form of short texts were rated by two independent observers (bachelor students) who were blind to condition. The observers rated the content of the texts as a whole with respect to the degree of rumination, positive reappraisal, distancing, and acceptance on VAS ("Indicate the degree to which the text fits the [rumination/distancing/positive reappraisal/acceptance] condition according to you") using a horizontal line (0-100 $\mathrm{mm}$ ), with at the left end of the continuum " $0 \%$ ", and at the right end " $100 \%$ ". They were allowed to rate the content of the text on more than one coping strategy if that seemed appropriate. Furthermore, the written texts were rated on the degree of selffocus, concreteness, and abstractness on VAS ("To what extent is the subject focused on himself/herself?", "Indicate the degree of concreteness of the content of the thoughts", and "Indicate the degree of abstractness of the content of the thoughts") using a horizontal line $(0-100 \mathrm{~mm})$, with at the left end of the continuum "0\%/neutral", and at the right end "100\%". 
A COMPARISON OF COGNITIVE STRATEGIES

Quantitative manipulation check (self-rated VAS)

VAS were used to examine the degree to which adolescents had had thoughts according to the instructions during the experimental period. Various aspects of the cognitive coping strategies were measured by several scales per experimental condition. Participants could indicate the degree to which they thought in a certain way about the stressful event during the task on a horizontal line $(0-100 \mathrm{~mm})$ with at the left end of the continuum "totally not", and at the right end "all the time". All items started with "During the experiment ...". The following items were used to measure the degree of rumination: "I thought about the negative aspects of the event over and over again (e.g., how stressful the event was)" / "I tried to understand what the causes are of the event, over and over again" / "I thought about the consequences of the event over and over again" $(\alpha=.64)$. The following item was used to measure the degree of distancing: "I looked at myself/the situation from a distance, as if I were somebody else". The following items were used to measure the degree of positive reappraisal: "I thought about the positive things that I could get out of the event/situation" / "I actually did get positive things out of the situation" / "I thought about how the event made me stronger" $(\alpha=.78)$. The following items were used to measure the degree of acceptance: "I tried to deal with my thoughts at great length, without finding them good or bad" / "I felt that it gradually became easier to accept my thoughts about the stressful event" ( $\alpha=.48$ ). Furthermore, some general items (all VAS) were added, i.e., "When you were thinking just now, did you especially think in words, thus that your thoughts consisted of sentences and words (as if you're talking to yourself?)" and "When you were thinking just now, did you especially think in images, thus as if you see before you what you think?". To check for the potentially constructive effect of a reflective form of rumination we added the following item to the manipulation check: "During the task I came to a better understanding of myself, and of the event".

\section{Brief overview of statistical analyses}

There were no missing data, because questionnaires were administered through a computer-based programme. AN(C)OVAs were conducted to examine the effect of condition on change in affect states and on content of thoughts (manipulation checks). In case the assumption of homogeneity or normality was violated, we carried out Kruskal-Wallis tests with Mann-Whitney tests for pair wise comparisons. Linear regression analyses revealed no influential outliers (i.e., cases with a standardized residual above 3 ). In addition to the examination of statistically significant differences, we computed Cohen's $d$ effect sizes to assess the magnitude of the differences between conditions (see APA, 2001). By including effect sizes, power analyses and comparisons to effects found in other studies can be made (Wilkinson \& the APA Task Force on Statistical Inference, 1999). Therefore, 
ANCOVAs were carried out with dummy-coded variables for condition and T1 affect state as covariates, and the change score for affect state (T3-T2) as dependent variable. Cohen's ds were also computed for the differences between conditions on the manipulation check items.

\section{Results}

\section{Manipulation check: general findings}

The stressful events that were reported by the participants were the following: fight with friend or loved one (26.9\%); death of a loved one $(22.5 \%)$; divorce or fights between parents (9.4\%); mental or physical illness of a loved one $(7.5 \%)$; disappointing school results (7.5\%); love troubles (6.9\%); bullying (5.6\%), and not classifiable (13.8\%). $X^{2}$-tests revealed no significant differences between the frequencies of event category per condition, meaning that categories of stressful events were equally reported across conditions (information obtainable from first author). To check for demand effects, at the very end of the experiment participants were asked to write down what they thought was the purpose of the current study. Answers showed that the participants appeared unaware of the true purpose of the study ${ }^{4}$.

\section{Qualitative manipulation check (observer-rated)}

Intraclass correlation coefficients were adequate to high with respect to the observerrated degrees of rumination, positive reappraisal, distancing, acceptance, self-focus, and concreteness/abstractness of thoughts (ICCs $=.78-.98$ ), indicating good to excellent agreement between observers. Therefore, mean rating scores were computed. Significant group differences were found on the mean rating scores for rumination, positive reappraisal, distancing, acceptance, and concreteness of thoughts. Table 1 displays ICCs, descriptives and test statistics. The observers identified significantly more ruminative thinking in the rumination condition (from here referred to as "RUM") compared to the distancing condition (from here referred to as "DIS"; $U=415.00, z=3.77, p<.001, d=.39$ ), acceptance condition (from here referred to as "ACC"; $U=350.00, z=4.28, p<.001, d=.44$ ) and positive reappraisal condition (from here referred to as "POS"; $U=241.50, z=5.70, p<.001, d=.53$ ).

\footnotetext{
${ }^{4}$ They thought that we wanted to examine: "what people feel / think about stressful events" $(47.5 \%)$; "influence of thoughts / memories on mood" (15.6\%); "how we cope with thoughts / feelings / events" (14.4\%); "influence of music on mood" (11.9\%); "don't know" (10.6\%). $X^{2}$-tests showed that the frequencies of answers per category did not significantly differ between conditions (information obtainable from first author).
} 
A COMPARISON OF COGNITIVE STRATEGIES

Table 1: Differences between Conditions on Observer-Rated Thought Content: Raw Means, Standard Deviations, ICCs, and Test Statistics

\begin{tabular}{|c|c|c|c|c|c|c|c|}
\hline & \multirow{2}{*}{\multicolumn{4}{|c|}{ Condition }} & & & \\
\hline & & & & & & & \\
\hline & $\begin{array}{l}\text { RUM } \\
(N=40)\end{array}$ & $\begin{array}{l}\text { DIS } \\
(N=40)\end{array}$ & $\begin{array}{l}\text { POS } \\
(N=41)\end{array}$ & $\begin{array}{l}\mathrm{ACC} \\
(N=39)\end{array}$ & & & \\
\hline Variable & $M(S D)$ & $M(S D)$ & $M(S D)$ & $M(S D)$ & $\chi^{2}(d f=3)$ & $r$ & $I C C$ \\
\hline Degree of rumination & $64.93(41.98)$ & $31.25(37.66)$ & $11.48(25.68)$ & $25.85(32.70)$ & $39.52^{* *}$ & .77 & .90 \\
\hline Degree of distancing & $20.19(32.41)$ & $43.54(41.54)$ & $13.36(31.46)$ & $36.83(38.46)$ & $16.67^{* *}$ & .80 & .87 \\
\hline Degree of positive reappraisal & $3.54(16.39)$ & $1.89(7.37)$ & $61.96(45.39)$ & $5.29(17.23)$ & $58.76^{* *}$ & .90 & .98 \\
\hline Degree of acceptance & $11.96(22.22)$ & $18.06(33.18)$ & $8.84(25.01)$ & $23.38(29.53)$ & $8.02^{*}$ & .66 & .80 \\
\hline Degree of self-focus & $61.98(31.69)$ & $56.84(34.81)$ & $69.21(29.67)$ & $55.77(36.69)$ & 3.35 & .66 & .78 \\
\hline Degree of abstractness of thoughts & $35.50(31.48)$ & $24.79(27.16)$ & $34.10(29.88)$ & $35.37(32.82)$ & 2.52 & .72 & .85 \\
\hline
\end{tabular}

Note. ${ }^{* *} p \leq .001,{ }^{*} p<.05$. Degree of rumination/distancing/positive reappraisal/acceptance = "Indicate the degree to which the text fits the rumination/distancing/positive reappraisal/acceptance condition according to you". Degree of self-focus = "To what extent is the subject focused on him/her self?". Degree of concreteness/abstractness of thoughts = "Indicate the degree of concreteness/abstractness of the content of the thoughts". 
Significantly more positive reappraisal was rated in POS compared to RUM $(U=307.50, z=5.53, p<.001, d=.53), \operatorname{ACC}(U=324.50, z=5.08, p<.001$, $d=.50)$, and DIS $(U=288.00, z=5.73, p<.001, d=.54)$. The degree of distancing was higher in DIS compared to RUM $(U=558.00, z=2.48, p=.01, d=.27)$ and POS $(U=482.50, z=3.56, p<.001, d=.37)$; but not ACC $(U=693.00, z=.88$, $p=.38, d=.10)$. The degree of acceptance was rated higher in ACC compared to POS $(U=554.00, z=2.81, p=.005, d=.30)$, but did not significantly differ from that in RUM $(U=628.50, z=1.66, p=.10, d=.19)$, and DIS $(U=652.50, z=1.43$, $p=.15, d=.16)$, the differences however were in the expected direction. In sum, these findings indicate that our manipulations were successful, except for acceptance. Conditions did not differ with regard to the ratings of degree of self-focus and abstractness of the thoughts. Level of concreteness was higher in DIS compared to POS $(U=612.50, z=1.97, p<.05, d=.22)$ and ACC $(U=542.00, z=2.35$, $p<.05, d=.26)$, and higher in RUM compared to ACC $(U=578.00, z=1.99, p<.05$, $d=.22)$.

\section{Quantitative manipulation check (self-report)}

Reliability coefficients of the composite checks for rumination and positive reappraisal were adequate ( $\alpha s=.64$ and .78 respectively, see Table 2 ). Reliability of the acceptance check scale, consisting of only two items, was low $(\alpha=.48)$. The Spearman-Brown prediction formula indicated a reliability of $\rho=.82$ should the scale have consisted of 10 items. ANOVAs and Kruskal-Wallis tests showed significant group differences on the manipulation checks for rumination, positive reappraisal, and distancing. Descriptives and statistics are displayed in Table 2. Participants in RUM reported significantly more rumination compared to those in POS, $t(156)=4.00$, $p=.001, d=.63$, and ACC, $t(156)=4.00, p=.001, d=.63$; whereas the degree of rumination did not significantly differ between RUM and DIS, $t(156)=2.25, p=.15$, $d=.36$; however, the direction of effect is more ruminations in RUM. Participants in POS reported significantly more positive reappraisal than those in RUM $(U=416.50$, $z=3.81, p<.001, d=.85), \operatorname{ACC}(U=323.00, z=4.59, p<.001, d=1.05)$, and DIS $(U=272.00, z=5.18, p<.001, d=1.16)$. In DIS, participants reported more distancing than those in RUM $(U=377.50, z=4.07, p<.001, d=.93)$, POS $(U=286.50, z=5.04, p<.001, d=1.14)$, and ACC $(U=267.00, z=5.03, p<.001$, $d=1.16)$. No significant group differences appeared on the acceptance manipulation check, indicating that the manipulation of acceptance did not result in higher numbers of acceptance ratings. 
A COMPARISON OF COGNITIVE STRATEGIES

Table 2: Differences between Conditions on Self-Rated Thought Content: Raw Means, Standard Deviations, and Test Statistics

\begin{tabular}{|c|c|c|c|c|c|c|c|}
\hline & \multicolumn{5}{|c|}{ Condition } & \multirow[b]{2}{*}{$d f=3$} & \\
\hline & & $\begin{array}{l}\text { RUM } \\
(N=40)\end{array}$ & $\begin{array}{l}\text { DIS } \\
(N=40)\end{array}$ & $\begin{array}{l}\text { POS } \\
(N=41)\end{array}$ & $\begin{array}{l}\text { ACC } \\
(N=39)\end{array}$ & & \\
\hline Variable & $\alpha$ & $M(S D)$ & $M(S D)$ & $M(S D)$ & $M(S D)$ & $F$ & $\chi^{2}$ \\
\hline Manipulation check rumination & .64 & $76.18(17.11)$ & $65.60(23.58)$ & $57.51(21.02)$ & $57.30(21.69)$ & $7.20^{* * *}$ & \\
\hline Manipulation check distancing & $\mathrm{N} / \mathrm{a}$ & $37.95(33.83)$ & $68.33(19.30)$ & $33.29(29.00)$ & $33.62(27.97)$ & & $33.98^{* * *}$ \\
\hline $\begin{array}{l}\text { Manipulation check pos. } \\
\text { reappraisal }\end{array}$ & .78 & $44.19(26.97)$ & $37.59(24.81)$ & $65.99(16.78)$ & $43.80(23.05)$ & & $32.96^{\star * *}$ \\
\hline Manipulation check acceptance & .48 & $63.19(17.87)$ & $62.51(20.02)$ & $63.89(19.68)$ & $61.79(18.24)$ & .09 & \\
\hline Manipulation check reflection & $\mathrm{N} / \mathrm{a}$ & $48.73(30.57)$ & $42.03(24.73)$ & $51.32(23.00)$ & $43.49(24.91)$ & 1.14 & \\
\hline Self-rated severity of the event & $\mathrm{N} / \mathrm{a}$ & $3.88(.82)$ & $3.95(.99)$ & $3.83(.92)$ & $3.67(.90)$ & .69 & \\
\hline Thinking in words & $\mathrm{N} / \mathrm{a}$ & $52.45(36.50)$ & $41.93(27.96)$ & $57.59(33.46)$ & $39.79(32.29)$ & & 7.32 \\
\hline Thinking in images & $\mathrm{N} / \mathrm{a}$ & $58.93(35.58)$ & $76.88(23.28)$ & $48.88(32.51)$ & $66.82(28.05)$ & & $15.36^{* *}$ \\
\hline Ratio words/images & $\mathrm{N} / \mathrm{a}$ & $8.63(23.14)$ & $1.86(7.83)$ & $9.22(23.12)$ & $4.31(16.55)$ & & $10.53^{*}$ \\
\hline
\end{tabular}

Note. ${ }^{* *} p \leq .001,{ }^{* *} p<.005,{ }^{*} p<.05$ (ANOVAs for parametric data and Kruskal-Wallis tests for non-parametric data). 
Groups did not significantly differ with respect to self-reported severity of the stressor, generally indicated as "quite severe". No group differences were found regarding the degree to which participants reported to have come to a better understanding of themselves and the situation. The ratio of thinking in words by images significantly differed between conditions, with a higher words/images ratio in POS compared to DIS $(U=502.00, z=3.00, p<.005, d=.32)$ and ACC $(U=532.50, z=2.57, p=.01$, $d=.28)$.

The effect of condition on change in negative and positive affect states ${ }^{1}$

Reliability in terms of internal consistency was high for all questionnaires ( $\alpha \mathrm{s}=.86$ .90 ), see Table 3 . The scores on the CDI were not normally distributed and therefore underwent a log linear transformation resulting in acceptable skewness and kurtosis values $(-1$ to +1$)$. One-way ANOVAs showed no pre-existing differences between conditions on the SRRS-C, CDI, and T1 affect states. Group means and test statistics on all questionnaires and affect measurements (T1, T2, T3) are displayed in Table 3. Change scores were created by subtracting the measurement of mood state before the manipulation of cognitive strategy (T2), from the measurement of mood state after manipulation of cognitive strategy (T3). Then we checked whether the means plots of the change scores for the state variables of gloominess and sadness displayed a similar trend across conditions. Subsequently, the VAS measuring sadness and gloominess were summed up into a composite score labelled "negative affect" $(\alpha=.63)$. In the ANCOVA model, condition was the fixed factor, with the change score on affect state as the dependent variable, controlling for traitrumination (SRRS-C), and T1 affect state. To examine whether the effect of condition was dependent on the degree of trait-rumination, the interaction term of condition with the level of trait-rumination was added to the model and removed when not significant.

\footnotetext{
1 ANCOVAs were also carried out with level of depressive symptoms (CDI) as a moderator of condition. Results showed that level of depressive symptoms did not influence the effect of condition on the change in affect states; nor did level of depressive symptoms influence the change in affect states after the manipulations. Furthermore, the moderating effect of gender on condition was examined. Results showed that gender did not influence the effect of condition, nor did gender influence the change in affect after the manipulations.
} 
A COMPARISON OF COGNITIVE STRATEGIES

Table 3: Group Differences on Depressive Symptoms, Trait-Rumination, and Negative and Positive Affect States

\begin{tabular}{|c|c|c|c|c|c|c|c|c|}
\hline & & \multirow{2}{*}{\multicolumn{7}{|c|}{ Condition }} \\
\hline & & & & & & & & \\
\hline & & $\begin{array}{l}\text { RUM } \\
(N=40)\end{array}$ & $\begin{array}{l}\text { DIS } \\
(N=40)\end{array}$ & $\begin{array}{l}\text { POS } \\
(N=41)\end{array}$ & $\begin{array}{l}\text { ACC } \\
(N=39)\end{array}$ & $d f=3$ & 156 & \\
\hline Variable & $\alpha$ & $M(S D)$ & $M(S D)$ & $M(S D)$ & $M(S D)$ & $F$ & $\chi^{2}$ & $p$ \\
\hline Depressive symptoms (CDI) & .86 & $8.58(6.50)$ & $8.00(5.94)$ & $7.90(5.20)$ & $6.97(5.65)$ & & 3.87 & .28 \\
\hline Rumination (SRRS-C) & .90 & $19.15(6.38)$ & $17.93(5.44)$ & $16.41(5.06)$ & $16.95(4.30)$ & 2.03 & & .11 \\
\hline T1 negative affect & .87 & $20.60(26.09)$ & $23.73(23.28)$ & $14.32(17.00)$ & $14.17(18.75)$ & 1.94 & & .13 \\
\hline T2 negative affect & .85 & $63.86(26.06)$ & $65.31(24.54)$ & $64.35(25.03)$ & $55.55(23.92)$ & 1.30 & & .28 \\
\hline T3 negative affect & .80 & $56.34(26.51)$ & $63.37(28.60)$ & $43.52(26.27)$ & $47.88(26.80)$ & 4.30 & & .006 \\
\hline Change score negative affect & .63 & $-7.53(20.96)$ & $-1.94(29.02)$ & $-20.83(23.01)$ & $-7.67(21.03)$ & 4.63 & & .004 \\
\hline T1 positive affect & $\mathrm{N} / \mathrm{a}$ & $70.30(23.62)$ & $67.58(24.96)$ & $71.27(22.14)$ & $75.97(23.91)$ & .86 & & .46 \\
\hline T2 positive affect & $\mathrm{N} / \mathrm{a}$ & 31.60 (23.59) & $30.90(20.58)$ & $32.02(26.77)$ & $41.82(26.39)$ & 1.76 & & .16 \\
\hline T3 positive affect & $\mathrm{N} / \mathrm{a}$ & $36.33(25.19)$ & $28.08(24.69)$ & $52.93(24.41)$ & $47.51(26.11)$ & 7.96 & & .001 \\
\hline Change score positive affect & $\mathrm{N} / \mathrm{a}$ & $4.73(20.05)$ & $-2.83(19.36)$ & $20.90(25.51)$ & $5.69(20.09)$ & 8.75 & & .001 \\
\hline
\end{tabular}

Note. Raw (untransformed) means are reported. CDI = Children's Depression Inventory; SRRS-C = Stress-reactive Rumination Scale for Children; Negative affect = composite gloomy and sad (VAS); Positive affect = happy (VAS). T1 = baseline; T2 = pre-manipulation; T3 = post-manipulation. 


\section{Effect of condition on negative affect state}

Trait-rumination did not moderate the effect of condition, $F(3,154)=.42, p=.74$. The main effect of condition was significant, $F(3,154)=4.13, p=.008$ (see Table 3 for groups means). Simple contrasts were used for pair wise comparisons, with a False Discovery Rate correction for the number of tests ( $p=.02$ for 6 tests; Narum, 2006). Contrasts showed that the decrease in negative affect was significantly stronger in POS compared to DIS, $t(156)=3.33, p<.001, d=.53$; POS to RUM, $t(156)=2.37$, $p=.019, d=.40$, and POS to ACC, $t(156)=2.49, p=.014, d=.40$. RUM did not differ from ACC, $t(156)=.09, p=.93, d=.00$, nor DIS, $t(156)=.94, p=.35, d=.15$; and DIS not from ACC $t(156)=.85, p=.40, d=.14$. Cohen's $d$ indicate small to medium differences between POS and the other conditions, with greater decreases in negative affect in POS. Covariate stress-reactive rumination did not have a significant influence on the change in negative affect, $F(1,154)=.04, p=.84$, nor did T1 negative affect, $F(1,154)=1.34, p=.25$. Figure 1a depicts the mean course of negative affect per condition over time.

Figure 1a: Mean Course of Negative Affect State per Condition

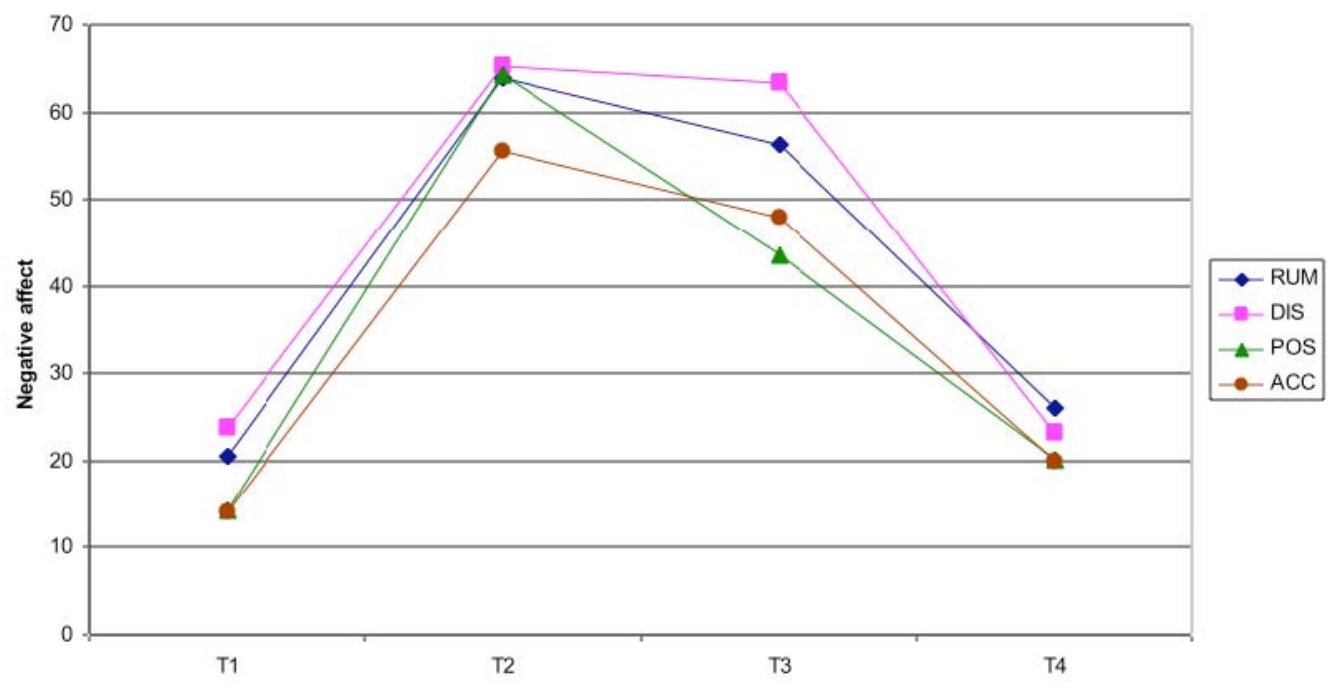

Note. T1-T2: Stress Induction; T2-T3: Cognitive Strategy; T3-T4: Positive Mood Induction

Effect of condition on positive affect state

Trait-rumination did not moderate the effect of condition, $F(3,154)=.51, p=.68$. The main effect of condition was significant, $F(3,154)=8.68, p<.001$ (see Table 3 for group means). Simple contrasts showed that the increase in positive affect was significantly stronger in POS compared to RUM, $t(156)=3.39, p=.001, d=.54$, POS to ACC, $t(156)=3.15, p=.002, d=.50$, and POS to DIS, $t(156)=4.97, p<.001$, $d=.80$, with medium to large effect sizes. Simple contrasts did not reveal any other statistically significant group differences regarding the change in positive affect: RUM 
did not differ from ACC, $t(156)=.26, p=.79, d=.00$. DIS did not differ from RUM, $t(156)=1.52, p=.13, d=.25$, nor from ACC, $t(156)=1.77, p=.08, d=.30$. Although statistically not significant, Cohen's $d s$ indicate a small but relevant greater increase in positive affect in RUM and ACC, compared to DIS. Covariate stress-reactive rumination did not have a significant influence on the change in positive affect, $F(1$, $154)=.14, p=.71$, nor did T1 positive affect, $F(1,154)=.01, p=.99$. Figure $1 \mathrm{~b}$ depicts the mean course of positive affect per condition over time.

Figure 1b: Mean Course of Positive Affect State per Condition

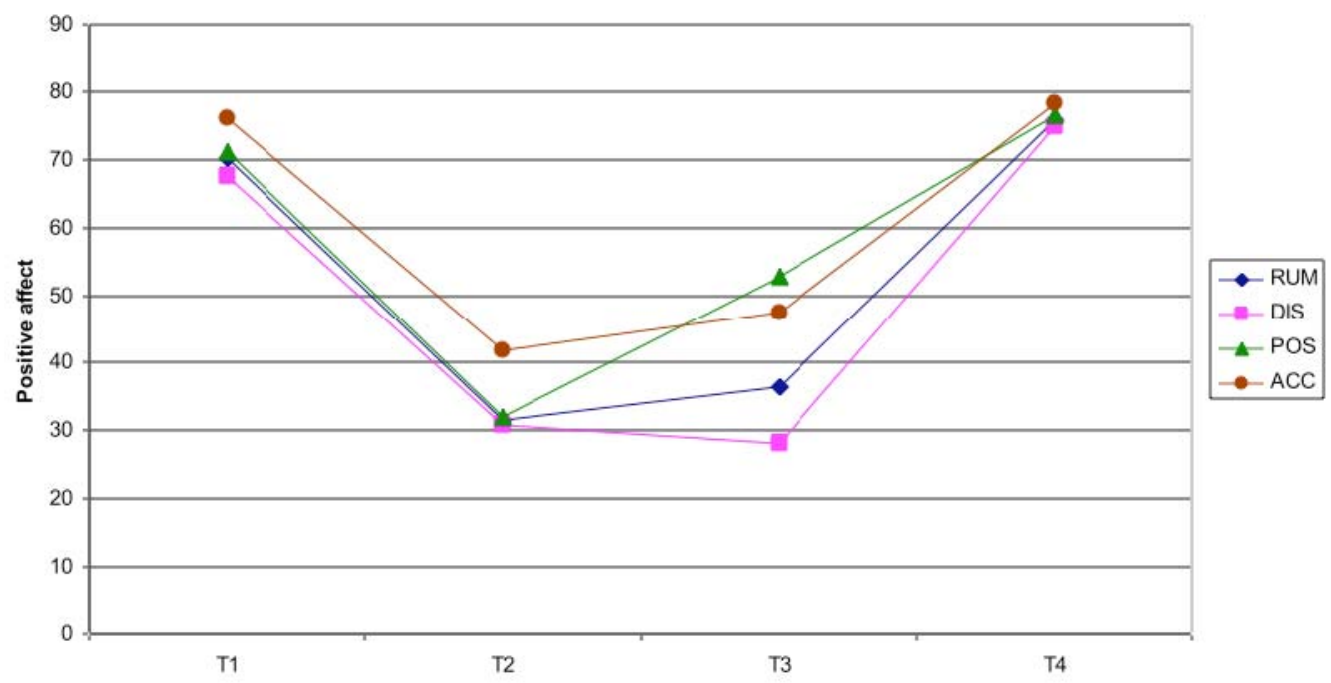

Note. T1-T2: Stress Induction; T2-T3: Cognitive Strategy; T3-T4: Positive Mood Induction

\section{Discussion}

The aim of the present study was to compare the effects of experimentally induced rumination, acceptance, distancing, and positive reappraisal on negative and positive affect states in a sample of adolescents. In sum, results showed that a brief manipulation of positive reappraisal in response to thinking about a recent stressful experience significantly increased positive affect, and decreased negative affect, compared to rumination, acceptance, and distancing. This means that after thinking about a personal stressor, adolescents' positive affect improved most, and negative affect decreased most, when they thought about what they learned from a stressful experience, and how it made them stronger. These findings are in line with earlier studies demonstrating a positive relationship between positive reappraisal and wellbeing (see Helgeson et al., 2006), and point to a beneficial role for positive reappraisal in influencing both positive and negative affect.

An interesting finding is that positive reappraisal seemed to be characterized by more verbal activity than imagery compared to the other conditions. The positive words/images ratio may be indicative of an abstract level of construal, which is 
intrinsic to meaning-based coping (Folkman, 2008), and which has been shown to be constructive in the context of positive mood with respect to motivation and goal setting (Labroo \& Patrick, 2009; Vasquez \& Buehler, 2007). As rumination may be a predominantly verbal and abstract activity (McLaughlin, Borkovec, \& Sibrava, 2007; Stöber \& Borkovec, 2002), positive reappraisal might be an attractive alternative coping strategy for predominantly "verbal" thinkers. However, the long-term effect of positive reappraisal on mood should be examined in order to check whether positive reappraisal is not some form of cognitive avoidance (see Borkovec, Ray, \& Stöber, 1998).

Unexpectedly, the short-term effect of acceptance of thoughts and feelings was not beneficial over the effect of rumination or distancing. This is inconsistent with Broderick (2005) and Singer and Dobson (2007); however, it is consistent with Kuehner et al. (2009), who found that the effect of mindful self-focus on mood did not differ from rumination in a non-clinical sample. There are three potential explanations for this null-finding. First, acceptance may be more effective in reducing negative mood states in (formerly) depressed individuals (Kuehner et al., 2009). Second, since groups did not differ on the manipulation checks for acceptance, our acceptance manipulation may have failed. Either the instructions were not effective, or adolescents have not yet developed the cognitive capacity or maturity to follow the acceptance instructions. Third, beneficial effects on mood are more likely to be expected after weeks of mindfulness training in which acceptance is practiced intensively (see Kabat-Zinn, 2003; Segal, Williams, \& Teasdale, 2002), or perhaps after a longer manipulation; acceptance implicates exposure to all (also negative) aspects of the event, which could explain why the short-term effect of acceptance was not beneficial over rumination.

Remarkable is the unexpected decrease in negative affect in the rumination condition. This finding is not in line with Park et al. (2004), who found that rumination increased depressed mood in non-clinical adolescents. First, it needs to be remarked that there seems to be a ceiling effect for negative affect after the stress-induction, as participants generally reported maximum levels of negative affect at $\mathrm{T} 2$, which makes it impossible to have higher rates of negative affect at T3 (post-manipulation). Second, it is possible that paradoxically the effect of naturally occurring rumination was attenuated, because the cards offer a certain degree of structure which would not be present in natural ruminative thinking, or that our instructions elicited also more constructive forms of rumination (see Treynor, Gonzalez, \& Nolen-Hoeksema, 2003); however, our manipulation checks showed that participants did not gain more insight after rumination compared to the other conditions. Another explanation could be that rumination in response to stress is not per se maladaptive in non-dysphoric subjects as has been found in adult samples (Nolen-Hoeksema et al., 2008). According to Watkins (2008), level of abstract processing and negative thought 
content determine whether the outcome of rumination is unconstructive and could lead to worsening of negative mood. It should be noted that the rumination condition was not characterized by reduced concreteness/increased abstractness of thoughts compared to the other conditions, moreover, the rated levels of abstractness were generally low (perhaps due to the level of cognitive development), which might explain why rumination did not maintain, but slightly improved negative affect.

Distancing maintained negative affect state, which is consistent with findings regarding the role of imagery in evoking emotions (see Holmes \& Mathews, 2010), and with the finding that taking an observer's perspective without engaging in reflection leads to negative affect (Kross et al., 2005).

The effect of condition was not dependent of a general tendency to ruminate. The current finding may implicate that non-clinical adolescents with a relatively stronger tendency to ruminate benefit from applying positive reappraisal when thinking about stressful events as much as other adolescents. However, considering the fact that the mean scores on the SRRS-C in this sample ranged between average (i.e., "sometimes") and below average, and that the standard deviations were relatively low, an alternative explanation for this null-finding may be that there was insufficient variability in trait-rumination scores to be able to compare high and low trait-ruminators. Thus, current questions should be examined in more clinically proximal ways.

As for clinical implications, Garnefski et al. (2002) showed that adults use significantly more positive reappraisal to cope with stressful events compared to adolescents, suggesting that positive reappraisal is a coping strategy that one learns to employ later in life. However, the current study demonstrates that adolescents have the capacity to apply this coping strategy, and that it works for them. Adolescents might benefit from being made aware of this strategy earlier in life by psycho-education; furthermore, positive reappraisal could be applied in intervention and prevention strategies for youth experiencing difficulties with affective functioning.

This study contributes to existing literature on the role of various cognitive coping strategies in the regulation of affect in youth by its experimentally controlled design. As yet, only Park et al. (2004) have examined the effect of rumination on the maintenance of depressed mood in youth experimentally. A strength of the present study is that a self-rated as well as an observer-rated manipulation check showed that our inductions of positive reappraisal, rumination, and distancing (but not acceptance) succeeded. Another strength is that participants were to select a personally relevant topic to cope with. Furthermore, the sample is relatively large and representative of Dutch youth in terms of educational level and SES.

Some limitations need to be addressed as well. First, the manipulations were short and there was no follow-up measurement. Second, we did not choose for a thinkaloud procedure during the cognitive coping manipulation, because we did not want 
to disturb the thinking process, but checked the effect of the manipulations through a writing assignment afterwards. As a result, the written texts might not represent all thoughts during the experiment. Moreover, we might not have captured the process of thinking, which may be equally important as the content of thoughts. Finally, although checks showed that participants did not guess the full purpose of the study, there is still a possibility that demand effects influenced the results, as we did not check whether they expected our instructions to be helpful.

Future experimental research should examine the long-term effects of rumination, positive reappraisal, acceptance, and distancing on the regulation of affect states in adolescents including psycho-physiological measures. It would be interesting to compare the effects of a short training in these cognitive coping strategies on the regulation of positive and negative affect states in response to stress. Furthermore, the effects of coping strategies on third variables, such as problem-solving ability, overgeneral memory, or attentional biases, need examination. Testing the current hypotheses in high risk and clinically depressed youth samples is warranted in order to further shape models of the pathogenesis of depression, as well as intervention and prevention programs. To conclude, when thinking about stressful events, positive reappraisal significantly enhances positive affect and decreases negative affect in the short-term, compared to rumination, acceptance, and distancing.

\section{References}

American Psychological Association (APA). (2001). Publication manual of the American Psychological Association (5th ed.). Washington, DC: Author.

Baer, R. A. (2003). Mindfulness training as a clinical intervention: a conceptual and empirical review. Clinical Psychology: Science and Practice, 10(2), 125-143.

Biegel, G. M., Brown, K. W., Shapiro, S. L., \& Schubert, C. M. (2009). Mindfulness-Based Stress Reduction for the treatment of adolescent psychiatric outpatients: a randomized clinical trial. Journal of Consulting and Clinical Psychology, 77(5), 855-866.

Bögels, S. M., Hoogstad, B., van Dun, L., de Schutter, S., \& Restifo, K. (2008). Mindfulness training for adolescents with externalizing disorders and their parents. Behavioural and Cognitive Psychotherapy, 36, 193-209.

Bögels, S. M., \& Mansell, W. (2004). Attention processes in the maintenance and treatment of social phobia: hypervigilance, avoidance and self-focused attention. Clinical Psychology Review, 24, 827-856.

Borkovec, T. D., Ray, W. J., \& Stöber, J. (1998). Worry: a cognitive phenomenon intimately linked to affective, physiological, and interpersonal behavioral processes. Cognitive Therapy and Research, 22(6), 561-576.

Broderick, P. C. (2005). Mindfulness and coping with dysphoric mood: contrasts with rumination and distraction. Cognitive Therapy and Research, 29(5), 501-510. 
A COMPARISON OF COGNITIVE STRATEGIES

Burke, C. A. (2010). Mindfulness-based approaches with children and adolescents: a preliminary review of current research in an emergent field. Journal of Child and Family Studies, 19, 133144.

Compas, B. E., Connor-Smith, J. K., Saltzman, H., Harding Thomsen, A., Wadsworth, M. E. (2001). Coping with stress during childhood and adolescence: problems, progress, and potential in theory and research. Psychological Bulletin, 127, 87-127.

Folkman, S. (2008). The case for positive emotions in the stress process. Anxiety, Stress, \& Coping, 21(1), 3-14.

Folkman, S., \& Moskowitz, J. T. (2000). Positive affect and the other side of coping. American Psychologist, 55(6), 647-654.

Fredrickson, B. L. (2004). The broaden-and-build theory of positive emotions. Philosophical Transactions of the Royal Society of London: Biological Sciences, 359, 1367-1377.

Garnefski, N., Kraaij, V., \& Spinhoven, P. (2001). Negative life events, cognitive emotion regulation and emotional problems. Personality and Individual Differences, 30, 1311-1327.

Garnefski, N., Legerstee, J., Kraaij, V., van den Kommer, T., \& Teerds, J. (2002). Cognitive coping strategies and symptoms of depression and anxiety: a comparison between adolescents and adults. Journal of Adolescence, 25, 603-611.

Germer, C. K. (2005). Mindfulness: What is it? What does it matter? In Germer, C. K., Siegel, R. D., Fulton, P. R. (Ed.), Mindfulness and Psychotherapy (pp. 3-27). New York: The Guilford Press.

Gross, J. J. (2002). Emotion-regulation: Affective, cognitive, and social consequences. Psychophysiology, 39, 281-291.

Heeren, A. \& Philippot, P. (2009). Changes in ruminative thinking mediate the clinical benefits of mindfulness. Poster session presented at the 39th Annual Meeting of the European Association for Behavioral and Cognitive Therapies, Dubrovnik, Croatia.

Helgeson, V. S., Reynolds, K. A., \& Tomich, P. L. (2006). A meta-analytic review of benefit finding and growth. Journal of Consulting and Clinical Psychology, 74(5), 797-816.

Holmes, E. A., \& Mathews, A. (2010). Mental imagery in emotion and emotional disorders. Clinical Psychology Review. 30, 349-362.

Huffziger, S., \& Kuehner, C. (2009). Rumination, distraction, and mindful self-focus in depressed patients. Behaviour Research and Therapy, 47, 224-230.

Kabat-Zinn, J. (2003). Mindfulness-based interventions in context: past, present, and future. Clinical Psychology: Science and Practice, 10(2), 144-156.

Kenny, L. M., \& Bryant, R. A. (2007). Keeping memories at an arm's length: Vantage point of trauma memories. Behaviour Research and Therapy, 45, 1915-1920.

Kovacs, M. (1981). Rating scales to assess depression in school-aged children. Acta Paedopsychiatrica, 46, 305-315.

Kross, E., \& Ayduk, Ö. (2009). Boundary conditions and buffering effects: Does depressive symptomatology moderate the effectiveness of self-distancing for facilitating adaptive emotional analysis? Journal of Research in Personality, 43, 923-927.

Kross, E., Ayduk, Ö., \& Mischel, W. (2005). When asking "why" does not hurt: distinguishing rumination from reflective processing of negative emotions Psychological Science, 16(9), 709715.

Kuehner, C., Huffziger, S., \& Liebsch, K. (2009). Rumination, distraction, and mindful self-focus: effects on mood, dysfunctional attitudes and cortisol response. Psychological Medicine, 39, 219-228.

Labroo, A. A., \& Patrick, V. M. (2009). Psychological distancing: why happiness helps you see the big picture. Journal of Consumer Research, 35, 800-809.

McLaughlin, K. A., Borkovec, T. D., \& Sibrava, N. J. (2007). The effects of worry and rumination on affect states and cognitive activity. Behavior Therapy, 38, 23-38. 
Mor, N., \& Winquist, J. (2002). Self-focused attention and negative affect: a meta-analysis. Psychological Bulletin, 128, 638-662.

Narum, S. R. (2006). Beyond Bonferroni: Less conservative analyses for conservation genetics. Conservation Genetics, 7, 783-787.

Nigro, G., \& Neisser, U. (1983). Point of view in personal memories. Cognitive Psychology, 15, 467482.

Nolen-Hoeksema, S. (1987). Sex differences in unipolar depression: evidence and theory. Psychological Bulletin, 101(2), 259-282.

Nolen-Hoeksema, S. (1991). Responses to depression and their effects on the duration of depressive episodes. Journal of Abnormal Psychology, 100(4), 569-582.

Nolen-Hoeksema, S., Wisco, B. E., \& Lyubomirsky, S. (2008). Rethinking rumination. Perspectives on Psychological Science, 3, 400-424.

Park, R. J., Goodyer, I. M., \& Teasdale, J. D. (2004). Effects of induced rumination and distraction on mood and overgeneral autobiographical memory in adolescent Major Depressive Disorder and controls. Jounal of Child Psychology and Psychiatry, 45(5), 996-1006.

Robinson, M. S. (1997). The role of negative inferential style and stress-reactive rumination on negative inferences in the etiology of depression: Empirical investigation and clinical implications. Unpublished doctoral dissertation, Temple University.

Robinson, M. S., \& Alloy, L. B. (2003). Negative cognitive styles and stress-reactive rumination interact to predict depression: a prospective study. Cognitive Therapy and Research, 27(3), 275-292.

Rood, L., Roelofs, J., Bögels, S. M., \& Alloy, L. B. (2010). Dimensions of negative thinking and the relations with symptoms of depression and anxiety in children and adolescents. Cognitive Therapy and Research, 34, 333-342.

Rood, L., Roelofs, J., Bögels, S. M., Nolen-Hoeksema, S., \& Schouten, E. (2009). The influence of emotion-focused rumination and distraction on depressive symptoms in non-clinical youth: a meta-analytic review. Clinical Psychology Review, 29, 607-616.

Segal, Z. V., Williams, J. M. G., \& Teasdale, J. D. (2002). Mindfulness-Based Cognitive Therapy for Depression. New York: The Guilford Press.

Singer, A. R., \& Dobson, K. S. (2007). An experimental investigation of the cognitive vulnerability to depression. Behaviour Research and Therapy, 45, 563-575.

Stöber, J., \& Borkovec, T. D. (2002). Reduced concreteness of worry in generalized anxiety disorder: findings from a therapy study. Cognitive Therapy and Research, 26(1), 89-96.

Timbremont, B., \& Braet, C. (2001). Psychometrische evaluatie van de Nederlandstalige Children's Depression Inventory. Gedragstherapie, 34(3), 229-242.

Timbremont, B., \& Braet, C. (2002). Children's Depression Inventory: Nederlandstalige versie [Children's Depression Inventory: Dutch version]. Lisse: Swets \& Zeitlinger.

Treynor, W., Gonzalez, R., \& Nolen-Hoeksema, S. (2003). Rumination reconsidered: a psychometric analysis. Cognitive Therapy and Research, 27(3), 247-259.

Tugade, M. M., \& Fredrickson, B. L. (2004). Resilient individuals use positive emotions to bounce back from negative emotional experiences. Journal of Personality and Social Psychology, 86(2), 320333.

Vasquez, N. A., \& Buehler, R. (2007). Seeing future success: does imagery perspective influence achievement motivation? Personality and Social Psychology Bulletin, 33, 1392-1405.

Watkins, E. (2008). Constructive and unconstructive repetitive thoughts. Psychological Bulletin, 134, 163-206.

Watson, D., Clark, L. A., \& Carey, G. (1988). Positive and negative affectivity and their relation to anxiety and depressive disorders. Journal of Abnormal Psychology, 97, 346-333. 
Wilkinson, L., \& the APA Task Force on Statistical Inference (1999). Statistical methods in psychology journals: Guidelines and explanations. American Psychologist, 54, 594-604.

Williams, M., Teasdale, J. D., Segal, Z., \& Kabat-Zinn, J. (2007). The mindful way through depression: freeing yourself from chronic unhappiness. New York: The Guilford Press. 


\section{Appendix: Instruction manipulation of cognitive coping strategy}

"You just thought of a stressful event. You are expected to think about that event again, but now in a certain way*: Now try to think about the causes of that stressful event over and over again, about the consequences, and about how the event moves you. ${ }^{1} /$ Now try to think about the positive sides of the stressful event. Examine what you have learned, and how it has made you stronger. ${ }^{2}$ / Now try to allow all thoughts about the stressful event, without thinking that a thought is bad or good. Accept that you have them, and see the thought as only a thought. Try to notice that your thoughts come and go. ${ }^{3}$ / Now try to describe the stressful event for yourself from beginning to end, but from a distance, as if you are a journalist, or a filmmaker, or a photographer. (You may) just think about the negative aspects of the event! ${ }^{4}$ You have been given cards by the researcher, which can help you get going. Use these cards to think about the stressful event(s). You may decide yourself how much time you spend with one card, as long as you try to answer the question on the card for yourself. If you have had all the cards, just pick the first card again and try to answer it again, but this time even more precisely. Of course it can be the case that you have to think about several stressful things. You may decide yourself whether you think about one event, or whether you bring up several events. Try to keep to the instructions! Try not to go and think about something else than the stressful events, even if that can be pretty difficult! Some people think in words, others see images before them. You may decide yourself whether you think in words or in images. The researcher will leave you alone with your thoughts for a while, and indicate when you can stop. Mind! After the experiment is over, we will ask you to write down on the computer what went through your mind (thoughts and images)."

${ }^{*}$ Note. Specific instructions were added for each condition: ${ }^{1}$ Rumination; ${ }^{2}$ Positive reappraisal; ${ }^{3}$ Acceptance; ${ }^{4}$ Distancing.

Examples of cards

Rumination: "Think about what the causes are of the event/situation"

Positive reappraisal: "Think about how this event has finally made you stronger"

Acceptance: "Notice that your thoughts come and go"

Distancing: "Think about what is said and thought by every 'actor' that is present on the set, and how [it is said and thought]" 


\section{Chapter 9}

\section{General discussion}

The present dissertation aimed to examine the influence of rumination on the development and maintenance of depressive symptoms in children and adolescents. Rumination is a type of negative thinking that is characterized by recurrence, repetitiveness, and unproductiveness of thoughts (see Ehring \& Watkins, 2008). Rumination is conceptually related to worry, a concept that stems from the anxiety literature and is a key feature of generalized anxiety disorder (APA, 2001). The main difference between rumination and worry is temporal orientation: whereas ruminative thoughts are past or present oriented and revolve around themes of loss, worrisome thoughts are future oriented and focus on threats and uncertainties (Borkovec, Robinson, Pruzinsky, \& DePree, 1983; Ehring \& Watkins, 2008; Nolen-Hoeksema, Wisco, \& Lyubomirsky, 2008). Rumination has predominantly been examined in the context of the Response Styles Theory of Nolen-Hoeksema (1987; 1991). The Response Styles Theory proposes that girls are more depressed than boys because girls have a stronger tendency to ruminate about negative feelings (emotion-focused rumination), whereas boys have a stronger tendency to seek distraction when they feel sad. Emotion-focused rumination, defined as repetitively thinking about one's depressive symptoms, and causes, implications, and meanings of these symptoms, is hypothesized to play a role in the maintenance and exacerbation of depressive symptoms (Nolen-Hoeksema, 1987; 1991).

The Response Styles Theory was extended by Alloy et al. (2000; Robinson \& Alloy, 2003), who introduced stress-reactive rumination, defined as repetitively thinking about negative attributions and inferences. Stress-reactive rumination is hypothesized to play a role in the onset of depression. There is evidence that stressreactive rumination is a better predictor of onset and maintenance of depression than emotion-focused rumination in adults (Robinson \& Alloy, 2003). The examination of stress-reactive rumination in youth is novel and may contribute to knowledge on the onset and development of depressive symptoms in youth.

The studies in the current dissertation focus on both emotion-focused rumination and stress-reactive rumination. The main research question concerned the extent to which both types of rumination are related to depressive symptoms in youth, and the causal nature of this relationship. One study examined whether stressreactive rumination, emotion-focused rumination, and worry are distinct types of repetitive thinking (Chapter 2). Empirical evidence regarding all studies so far that 
have examined the Response Styles Theory in youth samples was summarized in Chapter 3. Chapter 4 tested the Response Styles Theory with a new approach in a short-term prospective study, examining the extent to which a ratio score of emotionfocused rumination divided by distraction predicted depressive symptoms. Whether stress-reactive rumination moderated the relationships between domains of negative cognitive style and depressive symptoms, and between stressors and depressive symptoms, was investigated in a cross-sectional study from a developmental perspective (Chapter 5). Chapter 6 goes a step further, by investigating whether both types of rumination exacerbate the effects of negative cognitive style (see Robinson \& Alloy, 2003) or the effects of stressors (see Nolen-Hoeksema, 1994) on depressive symptoms in a multi-wave design. The study also tested an integrative model that proposes that both kinds of rumination exacerbate the effects of negative cognitive style, which leads to increases in depressive symptoms in the presence of high levels of stressors. The models were tested in a developmental perspective by taking into account the possible moderating roles of gender and age. Furthermore, the causal relationship between stress-reactive rumination and negative affect was examined in two experimental studies (Chapters $7 \& 8$ ). The aim of this final chapter is to present a discussion of the main findings of the current dissertation. This general discussion allows a critical evaluation of all studies, and more specifically, the measured constructs and experimentally manipulated concepts, strengths and limitations of study methods, conclusions and relevance of the effects, clinical and theoretical implications, and recommendations for future research.

The discussion section is organised as follows. The first subsection revolves around the question whether different types of repetitive thinking should be distinguished. The second subsection presents conclusions on the theoretical models based on the evidence, and discusses the modest effect sizes regarding the relationship between rumination and depression found in prospective studies. The third subsection discusses experimental studies on the causal nature of the rumination-depression relationship, and suggests directions for future research with respect to the examination of adaptive and maladaptive forms of rumination. A critical note on the Stress-Reactive Rumination Scale for Children is presented in the fourth subsection. The fifth subsection describes recommendations for future research with respect to the examination of cognitive vulnerability models from a developmental viewpoint, suggesting a biological and a psychosocial approach. The discussion closes with a final conclusion. Recommendations for future research and clinical implications are integrated in the sections. 


\section{On distinguishing different types of repetitive thinking}

\section{Similar processes, different focus of content?}

Results presented in Chapter 2 showed that stress-reactive rumination can be distinguished from worry and emotion-focused rumination in a statistically meaningful way. The factor analysis convincingly showed that all items of each questionnaire load exclusively $(>.40)$ on their corresponding factors. However, the finding that constructs can statistically be distinguished does not inform about the exact nature of this distinction. It may indicate that these constructs of repetitive thinking represent distinct thought processes, but it may also reflect the different content foci within the same thought process in line with a transdiagnostic view on repetitive thinking (Ehring \& Watkins, 2008; Harvey, Watkins, Mansell, \& Shafran, 2004). The focus of the process might driven by the intrapersonal context (e.g., "When I'm feeling sad, I think: why can't I stop feeling this way?") or environmental context (e.g., "I think about how terrible the stressful event was") in which rumination occurs (see Watkins, 2008), and not by the form of the thought process.

In line with the hypothesis that rumination and worry may share the same underlying thought process, there is evidence to suggest that emotion-focused rumination also serves an avoidance function like worry, by reduced concreteness of thoughts (Smith \& Alloy, 2009; Watkins \& Moulds, 2007). It has been proposed that by being a highly abstract and verbal cognitive activity, pathological worry may function as a cognitive avoidance response that either suppresses autonomic anxious arousal by reducing imagery, or serves as a distracter from more emotionally laden topics. This way, worry inhibits the adequate emotional processing of stressful experiences, maintaining anxiety in the long-term (Borkovec, Ray, \& Stöber, 1998). In order to determine whether rumination also serves an avoidance function like worry, it should be investigated whether rumination inhibits adequate emotional processing of stressful experiences related to loss and failure, compared to a visual, concrete mode of processing. The potential usefulness of distinguishing different types of repetitive thinking will be discussed in the next section.

\section{Evidence regarding specific roles of types of rumination}

Theoretically, it makes sense to distinguish different types of repetitive thinking, as these may have different roles in the development of depressive symptoms. NolenHoeksema $(1987 ; 1991)$ proposes that emotion-focused rumination plays a role in the maintenance or worsening of a depressed mood, whereas Alloy and colleagues $(2000 ; 2003)$ propose that stress-reactive rumination plays a role in the onset of depression. However, evidence so far shows that emotion-focused rumination may be a better predictor of onset rather than maintenance of depression (see NolenHoeksema et al., 2008), whereas stress-reactive rumination is a predictor of onset as 
well as maintenance (Alloy et al., 2000; Robinson \& Alloy, 2003). Findings from the present dissertation do not indicate that stress-reactive rumination is a stronger predictor of depressive symptoms over time than emotion-focused rumination (Chapter 6), contrary to what may be expected in a non-clinical (i.e., non-depressed) youth sample. The contribution of emotion-focused rumination to symptoms of depression and anxiety disappeared after controlling for worry and stress-reactive rumination (Chapter 2). This finding was interpreted as an indication that stressreactive rumination might play a more important role in relation to depressive symptoms in a non-clinical sample than emotion-focused rumination.

To conclude, results from the present dissertation do not unequivocally seem to indicate specific roles for different types of rumination in the development of depressive symptoms in non-clinical youth. Future research should focus on examining the different roles of stress-reactive rumination and emotion-focused rumination in the onset and maintenance of depression in youth more directly. This could be done in prospective designs, using depressive episodes assessed by diagnostic interviews as outcome measure. The results of the factor analysis and lack of evidence for different roles of rumination types do not rule out the possibility that the types of repetitive thinking share a common underlying process and only differ in terms of content. This may plead for an examination of a general disposition to uncontrollable repetitive thinking rather than specific formulations (see Ehring \& Watkins, 2008; Ehring et al., 2011).

With regard to the clinical relevance of distinguishing types of rumination, one can speculate that these types may be manifestations of different underlying pervasive psychological problems and therefore may function differently. Emotionfocused rumination with its introspective focus on emotions may serve as an avoidance mechanism, which inhibits dealing with confronting stressors evoking these emotions. In this light, emotion-focused rumination may be a potential manifestation of sub-assertiveness or helplessness (feelings of inadequacy to deal with stress). This line of thought is partly supported by Pearson, Watkins, and Mullan (2010), who found that brooding leads to depressive symptoms through a submissive interpersonal style, which is a passive style of sub-assertiveness and self-sacrifice. Stress-reactive rumination may be a manifestation of negative core beliefs and attitudes. Clinical implications of making a distinction between types of rumination could be that emotion-focused ruminators may benefit from learning how to cope with stressors more actively, and from improving emotion-regulation skills in order to increase assertiveness through for example dialectical behaviour modules (Linehan, 1993). Stress-reactive rumination, the process of rehearsing and thereby repeatedly activating negative inferences, may best be targeted by cognitive interventions that alter negative cognitions, and by increasing coping skills to deal with stressful events more effectively. The uncontrollable repetitive thinking process could be targeted by 
GenERAL DISCUSSION

mindfulness-based interventions (Kabat-Zinn, 1990; Williams, Teasdale, Segal, \& Kabat-Zinn, 2007).

\section{General conclusion}

To conclude, the results from the factor analysis provide a basis to further examine types of rumination and their relationships to depressive symptoms. Future research should focus on examining the different roles of stress-reactive rumination and emotion-focused rumination in the onset and maintenance of depression in youth. The possible avoidance function of rumination is interesting for future research and may contribute to the knowledge on the similarities between rumination and worry.

\section{Conclusion on the empirical evidence regarding the theoretical models}

\section{Response Styles Theory}

The role of emotion-focused rumination in relation to depressive symptoms

Findings from the current dissertation support the key hypotheses of the Response Styles Theory (RST). The cross-sectional studies showed that girls have stronger tendency to ruminate than boys (Chapters $2 \& 3$ ), which might explain the gender difference in depressive symptoms as hypothesized by Nolen-Hoeksema (1987). Results from studies so far as well as the studies in the current dissertation showed that emotion-focused rumination is substantially related to depressive symptoms (Chapter 6 \& 3). Furthermore, it significantly predicts depressive symptoms over time in non-clinical youth from the age as young as 10, in girls and in boys to a similar extent. Findings of the current dissertation do not support a moderating role of emotion-focused rumination in the context of the diathesis-stress account. Based on the evidence so far, the proposed re-conceptualisation of the RST by NolenHoeksema (1994) should be abandoned. It may be that emotion-focused rumination worsens the effects of a depressed mood rather than the effects of stressors. Future studies should examine whether emotion-focused rumination moderates the influence of initial levels of depressive symptoms on future depressive symptoms.

The role of distraction in relation to depressive symptoms in youth

No support was found for the role of distraction in the development of depressive symptoms, in that associations were non-significant and small and no gender differences were found (Chapter 3). This means for the RST that the role of distraction should be reconsidered. The RST has mostly been examined by including both rumination and distraction together as predictors in a regression analysis, expecting that rumination would predict increases in depressive symptoms, whereas distraction would predict decreases in depressive symptoms. This traditional test 
does not take into account that a strong tendency to distract may cancel out the effect of a strong tendency to ruminate, resulting in minimal changes in depression. The ratio approach (see Abela, Aydin, \& Auerbach, 2007) examines whether high ratio scores (more emotion-focused rumination compared to distraction) predict increases in depressive symptoms, and whether low ratio scores (more distraction compared to emotion-focused rumination) predict decreases in depressive symptoms. Therefore, the ratio approach may be a more precise test of the RST than the traditional approach ${ }^{1}$. Consistent with the RST, findings in Chapter 4 showed that a high ratio scores predicted increases in depressive symptoms 8-10 weeks later, while low ratio scores predicted decreases in depressive symptoms. Although a more refined test of the predictions of the RST, the ratio approach does not take away the difficulties with the assessment of adequate distraction (see Chapter 3). Moreover, when using a ratio approach, it is not clear what the exact effect of distraction is on depressive symptoms separate from rumination.

Therefore, before taking on the ratio approach, researchers need to examine how to measure an effective distractive response style more adequately, taking into account age appropriateness of the distractive responses. On the level of face validity, the cognitive and behavioural distraction items of the Children's Response Styles Scale (CRSS) seem open enough to leave room for own interpretation on what activity or thought may be of help in finding distraction. However, the items seem to tap a construct of resilience to stress and optimism ("When I feel sad, I... think about something fun I did/think about something I like to do/think about fun things/concentrate on something that makes me happy/seek distraction by doing something fun/go out to have fun/think about when I felt happier/do something fun/do something to feel better"), rather than distraction alone. In that light, the validity of the distraction scale is arguable. It may be recommended to take out the positive (optimistic trait-like) content out of the distraction items, and measure distractive activities that are likely to be common distractive strategies for children and adolescents; and perhaps more importantly, include an index of self-perceived effectiveness of engaging in that thought or behaviour. Another option is to leave distraction out of the RST and to focus entirely on the role of emotion-focused rumination

\footnotetext{
${ }^{1}$ Abela et al. (2007) also prefer the ratio approach over the interactional approach. The interactional approach hypothesizes that the combination of high rumination and low distraction (two vulnerability factors) predicts the highest increases in depressive symptoms, but also that individuals who score high on only one vulnerability factor (high RUM/high DIS or low RUM/low DIS) report equal changes in depressive symptoms compared to those who display low vulnerability on two factors (low RUM/high DIS). Abela et al. argue however that according to the RST, the combination of low RUM/high DIS should predict decreases in depressive symptoms compared to high RUM/high DIS and low RUM/low DIS; an effect that is not captured by the interactional approach. The ratio approach does allow examining whether high distraction scores compared to rumination scores lead to decreases in depressive symptoms.
} 
Conceptual extension of Response Styles Theory: The role of stress-reactive rumination in relation to depressive symptoms

Results (Chapter 2) showed that even when controlling for worry and emotionfocused rumination, stress-reactive rumination explains a unique part of symptoms of depression and anxiety, which may lie in its specific focus on negative attributions and inferences. Results provide support for the role of stress-reactive rumination as an independent risk factor for depressive symptoms in youth (Chapter 6). Results (Chapters $5 \& 6$ ) do not provide support for the model of Alloy and colleagues (Alloy et al., 2000; Robinson \& Alloy, 2003), suggesting that this model may not be applicable to non-clinical youth. Rumination and negative cognitive style may interact either in (sub-)clinically depressed or at risk youth, or they may not interact until adulthood. Before drawing conclusions on the applicability of the model of Alloy and colleagues to youth, it needs to be tested in (sub-)clinically depressed children and adolescents, using depressive episodes as outcome measure instead of a continuous measure of depressive symptoms.

Stress-reactive rumination did not worsen the effect of stressors on depressive symptoms either. The prospective study (Chapter 6) tested whether stress-reactive rumination would only worsen the effect of a high negative cognitive style on depressive symptoms in participants reporting high levels of stressors, in the form of a three-way interaction. Again, results did not support a moderating role for stressreactive rumination. It is possible that specific types of stressors are more likely to interact with rumination in the prediction of depressive symptoms, for example stressors in the domains of interpersonal problems and physical appearance, and that these specific stressors in interaction with cognitive vulnerability factors may explain the emergence of gender differences in depressive symptoms in adolescence (Hyde, Mezulis, \& Abramson, 2008; Mezulis, Abramson, \& Hyde, 2002). The next section discusses the relevance of the findings more closely.

\section{Relevance of effects}

When controlling for preceding depressive symptoms the overall effect size of the relationship between emotion-focused rumination and depressive symptoms is weak (Chapter 3). The effect size for the relationship between stress-reactive rumination and depressive symptoms over a one-year's time was also quite modest when controlling for preceding depressive symptoms (Chapter 6). This indicates that initial levels of depression almost fully explain the relationship between rumination and depressive symptoms over time. A possible explanation for the weak effect sizes for both types of rumination could concern the use of large time-frames, however, timeframes of 6 weeks do not produce large effect sizes either (see Chapter 3). NolenHoeksema (1994) suggested that emotion-focused rumination plays a significant role more as a moderator of the stressors-depression association than as an independent 
risk factor, which may explain modest effect sizes. If rumination is viewed as a relatively stable trait, other factors are necessary to trigger depressive symptoms. However, neither type of rumination moderated the effects of other variables on depressive symptoms; nor did age or gender moderate the rumination-depression relationship (Chapters $5 \& 6$ ).

Theoretically, emotion-focused rumination is hypothesized to worsen the effects of initial depressive symptoms, indicating reciprocity of relationships. Studies in adults and adolescents have shown that the relationship between emotion-focused rumination and depressive symptoms over time is reciprocal (Moberly \& Watkins, 2008; Nolen-Hoeksema, Larson, \& Grayson, 1999; Nolen-Hoeksema, Stice, Wade, \& Bohon, 2007). Reciprocity of relationships may explain the low effect sizes, in that rumination and depressive symptoms may influence each other more directly in the short-term, than in the long-term. For future research, it is recommended to examine the relationship between rumination and depressive symptoms in a diary study with short time intervals between measurements. An experience sampling methodology could be used, in which electronic diary data are collected by means of palmtop computers from high risk adolescents who are followed for one week.

Small effect sizes might also be related to limitations of our assessments. For example, one might question the validity of self-report instruments. In order to shed more light on the relationship between rumination and depression, it is recommended to focus on other methodological approaches to examine this relationship in youth. More emphasis should be placed on for example controlled experimental designs and intervention studies.

General conclusion on the Response Styles Theory and its conceptual extension Evidence presented in this thesis supports the role of emotion-focused rumination as an independent risk factor contributing to the development of depressive symptoms over time in non-clinical youth. Based on the evidence so far, the role of distraction in the RST should be reconsidered. First, distraction does not seem to play an explanatory role in the emergence of the gender difference in depression. Second, the validity of the distraction scale of the CRSS is arguable, and therefore the distraction scale needs revision before adopting the ratio approach. Stress-reactive rumination acts as an independent risk factor in the development of depressive symptoms. Either the model of Robinson and Alloy (2003) may be more applicable in (sub-)clinically depressed youth, or stress-reactive rumination and negative cognitive style may not interact until adulthood.

On the one hand, one could argue that the finding that both types of rumination predicted depressive symptoms even over a one-year's time indicates that rumination is an important variable to consider in research and treatment of juvenile depression. On the other hand, given the modest effect sizes for both types of 
rumination, negative cognitive style, and stressors (Chapters $3 \& 6$ ), one may question the practical relevance of the findings. The small effect sizes may raise fundamental questions on the causal nature of rumination. High concurrent associations combined with weak effect sizes for predictions could be indicative of rumination being symptomatic of depression or an epiphenomenon of depression, more than a risk factor. The next subsection deals with the issue of cause and effect concerning the rumination-depression relationship.

\section{The causal nature of rumination}

Although longitudinal studies are suitable for examining intricate theoretical models and relative contributions of variables, they do not allow drawing conclusions on whether the nature of these relationships is causal. Experimental designs in which effects of manipulated variables are measured can shed more light on causal relationships. Quite some experimental manipulation studies in adults and one study in adolescents (i.e., Park, Goodyer, \& Teasdale, 2004) have demonstrated that emotion-focused rumination worsens depressed mood (see Nolen-Hoeksema et al., 2008). The causal effect of stress-reactive rumination on depression has never been examined before. In two experimental studies in non-clinical youth (presented in Chapters $7 \& 8$ ) rumination was induced in response to a stressful event, in the context of explaining the involvement of stress-reactive rumination in the onset of depression.

Causal effects of components of stress-reactive rumination

The aim of the first experimental study (Chapter 7) was to compare the effects of a focus on negative inferences, causal-analytical reasoning, and perceptual details processing on negative affect, in the context of the current debate on adaptive and maladaptive components of rumination (see Treynor, Gonzalez, \& Nolen-Hoeksema, 2003; Watkins, 2008). Analogue to the maladaptive and adaptive components of emotion-focused rumination found in adults, i.e., brooding and reflective pondering (see Treynor et al., 2003), a focus on negative inferences and causal-analytical reasoning were induced as the maladaptive and adaptive component of stressreactive rumination. Results showed that sad affect increased in all conditions to a similar extent, whereas causal-analysis caused higher increases in anxious affect than perceptual details processing. A seemingly obvious conclusion may be that rumination does not worsen mood any more than other thinking styles, and that this finding does not support a causal relationship between rumination and negative affect in non-dysphoric participants. However, the design of the study carries difficulties that may have important implications for the interpretation of the findings. 
First, examining the role of stress-reactive rumination in the context of explaining the onset of depression, the manipulations were intentionally not preceded by a mood induction. As a result, the initial emotional reaction of sadness to thinking about a stressful event could have overshadowed the impact of instructed thinking style ${ }^{2}$. Second, focus on inferences and causal-analysis may affect mood differently only in the long-term. Third, the attempt to disentangle a potentially adaptive component of stress-reactive rumination (causal-analytical reasoning) from the maladaptive component (focus on negative inferences) may not have succeeded sufficiently to yield different effects.

The examination of the effects of adaptive and maladaptive ruminative styles within other theoretical frameworks, for example the elaborated control theory by Watkins (2008), may be more helpful. Watkins proposes that the outcome of repetitive thinking is most likely to have unconstructive consequences when valence of thought content is negative; when repetitive thinking occurs in reaction to a negative mood or experience, or in combination with a depressogenic personality factor; and when an abstract level of processing is adopted (see Watkins, 2008). Watkins and colleagues (Moberly \& Watkins, 2006; Rimes \& Watkins, 2005; Watkins \& Moulds, 2005; Watkins \& Teasdale, 2004) have found that concrete thinking has a more beneficial effect on psychological functioning than abstract thinking. Watkins et al. (2007) recommend altering thinking style, by changing an abstract processing mode into a more concrete one. Watkins' framework may carry interesting clinical implications for interventions aimed at reducing depressive rumination in youth as well. It would be interesting to examine to what extent (high risk) youth could benefit from an intervention promoting a concrete style of thinking, taking into account that the level of abstractness of the thinking process may still be in development during adolescence. Therefore, experimental studies are needed that examine the influence of concrete and abstract modes of processing on depressed mood in youth. Taking it a step further, the potentially aggravating influence of negatively valenced content on the effect of an abstract processing style could be examined in a two-by-two design

\footnotetext{
${ }^{2}$ An alternative explanation for the similar increase in sad affect may be that perceptual details processing of a stressful event may be confronting and equally as painful in the short-term (Holmes \& Mathews, 2010) as the ruminative thinking styles. However, a strength of this contrast condition is its focus on the stressful event, which allows examination of the effect of the process of rumination over and above a focus on the stressful event. Comparing the effects of rumination to a "classical" distraction condition (i.e., focus on non-relevant, neutral, factual information) that takes the focus outside the stressful event, leaves the question open as to whether the effect of rumination about a stressful event on affect is caused by the ruminative thought process and content, or by the focus on the stressful event. Moreover, the construct of distraction may be confounded with repression and avoidance, which may be constructive when it functions to divert the attention away from a depressed mood; however, in non-dysphoric individuals, or when having to deal with stressors, distraction may be counter-effective. The Response Styles Theory specifically posits that distraction may be helpful when feeling depressed.
} 
(concrete style - negative content, concrete style - neutral content, abstract style negative content, abstract style - neutral content).

Another theoretical approach to distinguish reflective and ruminative thinking processes on mood is that of Kross, Ayduk, and Mischel (2005), who include the role of perspective in the ruminative process. Kross et al. (2005) have investigated the effects of "why" vs. "how" self-reflective thinking from a self-distanced vs. selfimmersed perspective on feelings of anger. The authors found that the distant-why coping strategy was most effective in reducing anger. It would be interesting to examine the effects of these modes of reflective/ruminative thinking on depressed affect in youth, taking into account level of cognitive development. Again, this approach might help dealing with ruminative thinking in a more constructive way by altering thinking style instead of attempting to stop the natural tendency to think about stressful experiences.

The difficulties regarding the induction of stress-reactive rumination and the experimental design encountered in this first study were taken into account when setting up the design of the second study. It is important to note that the second study did not focus on adaptive and maladaptive forms of rumination. Instead, the aim was to examine the effect of rumination in response to stress on negative affect compared to other cognitive coping strategies in adolescents.

The causal effect of rumination compared to other cognitive strategies

The second study (Chapter 8) compared the effects of rumination, acceptance, positive reappraisal, and distancing in response to a stressful event on positive and negative affect in non-clinical adolescents. The experiment started with a 3-minute period of thinking about the stressful event without specific instructions in order to avoid an overshadowing effect of the powerful initial reaction to thinking about stressful events on the effects of the coping strategies. Abandoning the ambition to examine adaptive and maladaptive components of stress-reactive rumination, another change was made concerning the concept of rumination that was induced. When inducing a form of rumination explicitly involving negative thought content like stress-reactive rumination, it remains unclear whether increases in negative affect are due to the process of rumination, or to the negative content of thoughts related to depressed affect (i.e., inferences). Therefore, in order to examine the effects of the ruminative process, a more general concept of rumination in response to stress (defined as repetitively thinking about causes, implications, and consequences of stressful events) was induced. Findings showed that rumination caused a slight decrease in negative mood. However, the design of the study has important implications for the interpretation of this unexpected finding.

After the first induction period without specific instructions, negative affect increased to the maximum, only allowing negative affect to decrease or be 
maintained. Although the primary reaction to thinking about a stressful event seems to lead to the highest levels of negative affect, the way of responding may moderate the effects of stressful events leading to the onset of a depressed state in the longterm. The smaller decrease in negative affect after rumination compared to positive reappraisal may be indicative of a causal relationship between rumination and depression. Another explanation for the slight decrease in sad affect may be that the more general form of rumination in response to stress that was induced is less maladaptive than stress-reactive rumination, which inherently involves rehearsing negative thought content (i.e., negative attributions/inferences).

A more precise test of the causal effect of stress-reactive rumination as conceptualised within the framework of Alloy's studies (Alloy et al., 2000; Robinson \& Alloy, 2003) would consist of examining whether the repetition of negative inferences leads to higher levels of depressive symptoms in individuals with a highly negative cognitive style. This can be done in a controlled experimental design as follows. First, negative inferences regarding a stressful event are primed in two groups with participants selected on high levels of negative cognitive style. Second, rumination about these negative inferences is induced in one group, while a focus on perceptual details is induced in the other group. It would be expected that rumination on negative inferences would lead to higher increases in negative affect than focus on perceptual details.

General conclusions on the examination of the causal role of rumination

To conclude, the findings of the experimental studies seem to point to a causal role of rumination in the worsening and maintenance of negative affect in youth, however, only convincingly in comparison with positive reappraisal. The effect of rumination did not differ from the other strategies, and therefore, findings should be interpreted with caution. Future studies should focus on the characteristics that determine whether outcome of rumination will be unconstructive. The influence of concrete and abstract processing modes on depressed mood in youth could be examined by means of experimental designs and training formats. The role of perspective in reflective thinking could be included in experimental studies. Furthermore, it is recommended to compare the long-term effects of ruminative thinking styles (i.e., focus on negative inferences and causal-analytical reasoning) to focus on perceptual details in an experimental design including follow-up measurements. 
GeneRAL DISCUSSION

\section{Food for thought: Critical evaluation of the Stress-Reactive Rumination Scale for Children (SRRS-C) and the measurement of stress-reactive rumination}

The SRRS-C aims to measure the construct of stress-reactive rumination, which is defined as actively rehearsing the negative inferences following stressful events (Robinson \& Alloy, 2003). In order to distinguish the concept of stress-reactive rumination from negative attributions and inferences, it is crucial that the process of ruminating about these inferences is assessed. In the instruction of the SRRS-C is stated that participants should indicate how often one thinks a certain thought (i.e., negative inference) after a stressful event. Therefore, all items of the SRRS-C start with: "I think about..." following a negative inference, e.g., "how the stressful events was entirely my fault", with possible answers: almost never, sometimes, often, almost always. The answering possibilities "never" and "always", as well as the "I think about" leave room for interpretation. The "I think about" in the items seems to capture the repetitiveness characteristic to the ruminative process; however, when interpreted or misread as "I think", the item measures the negative inference instead of the ruminative process. This nuance difference may be too delicate for teenagers to notice. Furthermore, the answering possibilities "never" and "always" may be rather indicative of the likelihood of the inference being made, whereas it should reflect the frequency to which the thought is rehearsed. Answering possibilities like "this thought keeps running through my mind - hardly $[\ldots]$ all the time" may be more indicative of the degree of repetition of the inference.

These two concerns combined elicit the crucial question to what extent the items of the SRRS-C measure the process of rumination about the inferences, and to what extent it measures the frequency of the inferences being made in response to a stressful event. The Adolescent Cognitive Styles Questionnaire (ACSQ) and the SRRS-C show overlap but do not seem to measure the same construct $(r s=.45-51$; Chapter 6). It should be kept in mind that non-perfect associations between two questionnaires may be artifactual due to a wording effect or other biases. At the same time, if the SRRS-C and the ACSQ would measure a similar construct, the variables would cancel out each other's effects, which does not seem to be the case. The effect size of stress-reactive rumination was comparable to that of emotionfocused rumination found in the one-year interval study of Nolen-Hoeksema et al. (2007), which did not control for negative cognitive style.

The items of the SRRS-C may need to be reformulated. A more precise way to measure stress-reactive rumination would be to add to each item of the ACSQ a question to measure the extent to which the inference occupies the mind, as has been done by Mezulis et al. (2002). Another consideration regarding the assessment of stress-reactive rumination is that according to the cognitive theory of Beck, negative schemas and cognitions among which inferences and attributions are 
latently present in the individual, and should only become manifest or measurable when experiencing stress or displeasure (Beck \& Alford, 2009). In this light, the question arises to what extent negative cognitive style and stress-reactive rumination can be assessed accurately with self-report, when at the time of assessment no stressors are experienced. Measuring the degree of stress-reactive rumination after priming a negative cognitive style may provide a more accurate assessment of the tendency to ruminate about the negative inferences following stressful events.

Finally, the negative content of the items of the SRRS-C poses a problem: the level of depression could influence the way the questionnaire is filled out. High scores on the SRRS-C could represent high levels of depression rather than a high disposition to ruminate. A questionnaire measuring purely the process of repetitive, uncontrollable, and unproductive thinking without including disorder-specific content in the formulation of the items, for example the Perseverative Thoughts Questionnaire (Ehring et al., 2011), might be less confounded with depression.

\section{Future research regarding the developmental perspective}

\section{Biological viewpoint: direct measures of pubertal status}

Tanner phase III has been documented as a biological marker of the pubertal phase in which significantly more girls start to suffer from depressive episodes than boys (Angold, Costello, \& Worthman, 1998). Although a recent review of the literature on puberty and depression (Angold \& Costello, 2006) points towards a decisive role of biological factors in the development of gender differences in depression in puberty, empirical evidence with regard to the role of hormonal changes in the development of depression is inconsistent and unclear (Angold \& Costello, 2006; Hankin \& Abramson, 2001; Kessler, 2003; Nolen-Hoeksema, 1987; Nolen-Hoeksema \& Girgus, 1994). Other factors related to puberty, i.e., the maturation of the hypothalamopituitary-gonadal axis, pubertal timing, and pubertal status have been related to increases in depression in preadolescent girls; the latter two even more so than age (Angold \& Costello, 2006). Although age is an "objective" psycho-sociological indicator of maturation level, it is not the best indicator of biological maturation since time of pubertal onset as well as course of pubertal development differs greatly between individuals.

The Physiological Development Scale (PDS) assesses morphological changes related to puberty, which may indirectly be reflective of underlying biological changes related to pubertal development. A problem with the PDS as a self-report measure is that level of depressive symptoms may influence how pubertal status is perceived in terms of overestimation as well as underestimation. However, when the aim is to shed more light on the differences between relationships as a function of puberty, pubertal status is an interesting alternative to age. Findings in Chapter 5 
GENERAL DISCUSSION

demonstrated that perceived pubertal status instead of age yields slightly different results (moderating the negative cognitive style-depression relationship whereas age did not), which suggest that pubertal status may be a more sensitive moderator of cognitive vulnerability than age. Future studies of models of depression in youth may wish to include measures of hormonal levels associated with puberty in order to shed more light on the role of puberty in the emergence of gender differences in depression rates and in cognitive vulnerability to depression. Psychosocial factors seem to influence the effect of biological factors (Kessler, 2003). Future research should focus on the interplay between biological vulnerabilities, cognitive vulnerabilities, and stressful events.

\section{Psychosocial viewpoint: Co-rumination}

Findings from the cross-sectional data showed that negative attributions and inferences about interpersonal problems did not significantly relate to depressive symptoms in early adolescent girls experiencing few stressors (Chapter 5). It may be speculated that in early adolescence, a negative style in the interpersonal domain reflects insecurity in girls, which at that age in particular in combination with sociotropy (Beck, 1983) leads to co-rumination. Co-rumination is a phenomenon between persons characterised by discussing and analysing problems and negative feelings (Rose, 2002; Rose, Carlson, \& Waller, 2007). It is related to symptoms of anxiety and depression but also to intimacy and closeness in friendships. Corumination partly explains why girls have more internalizing symptoms than boys (Rose, 2002; Rose et al., 2007). When further speculating, co-rumination combined with a negative cognitive style regarding interpersonal problems may even have positive effects on mood in the absence of stressors as it is instrumental in building closer friendships in early adolescent girls.

For future research, examining the relationships between rumination, corumination, and stressors in different domains may inform on the rise in depressive symptoms in girls during adolescence. Examination of the qualities that underlie unconstructive and constructive consequences of co-rumination might contribute to the refinement of models explaining the emergence of gender differences in depression, as well may it carry clinical implications. Unconstructive co-rumination may be characterized by the same characteristics as repetitive thinking: negatively valenced thought content, abstract level of processing, and negative intrapersonal/environmental context (Watkins, 2008). The abilities to verbalize, identify, and analyze emotions (see Taylor, Bagby, \& Parker, 1997; Vorst \& Bermond, 2001) also may determine "successful" co-rumination (as well as successful processing of negative emotions on an individual level). 


\section{Concluding comments}

Based on the studies in the present dissertation, the following conclusions can be drawn with regard to the status and future of rumination research in youth. The current dissertation shows that stress-reactive rumination and emotion-focused rumination are statistically distinct types of repetitive thinking. Future prospective studies should investigate their hypothesized specific roles in the onset and development of depression as assessed by clinical interviews. In line with examining different roles, the (different) underlying functions of types of rumination could be explored. This may help determine the possible usefulness of distinguishing types of rumination, before taking on a transdiagnostic approach to rumination.

Stress-reactive rumination and emotion-focused rumination significantly contribute to the prediction of depressive symptoms even over a one-year's time in non-clinical youth. Neither stress-reactive rumination nor emotion-focused rumination seem to function as a vulnerability factor within a diathesis-stress account. The role of distraction in the Response Styles Theory should be reconsidered. The model of Alloy and colleagues $(2000 ; 2003)$ may not be applicable to non-clinical youth, and should be tested in high risk youth using a dichotomous outcome measure of depression. Furthermore, the items of the SRRS-C need to be reformulated. Stressreactive rumination may more adequately be assessed by adding items that measure frequency and repetition of negative attributions and inferences to the ACSQ, which assesses attributions and inferences. Regarding the developmental perspective, prospective examinations of reciprocal relationships between negative cognitive style, rumination, stressors and depressive symptoms can shed more light on how these variables influence each other during adolescence, and whether the strengths of reciprocal relationships differ between boys and girls.

Considering the modest effect sizes regarding the rumination-depression relationship in prospective studies and questions regarding causality, it is time to move forward and use other methodological designs to study the influence of rumination on depression. The causal nature of the rumination-depression relationship should be more closely examined from childhood to adolescence, for example in controlled experimental designs (i.e., manipulation studies) and in diary studies using experience sampling methodology. The constructive and unconstructive qualities of rumination are of special interest. Measuring the effects of training concrete and abstract modes of thinking in response to stressful experiences in children and adolescents would be innovative and may carry implications for prevention and treatment of juvenile depression. Altering thinking style may be more helpful in the long-term than distraction techniques or "stopping" interventions. 


\section{References}

Abela, J., Aydin, C., \& Auerbach, R. (2007). Responses to depression in children: Reconceptualizing the relation among response styles. Journal of Abnormal Child Psychology, 35, 913-927.

Alloy, L., Abramson, L., Hogan, M., Whitehouse, W., Rose, D., Robinson, M., et al. (2000). The Temple-Wisconsin cognitive vulnerability to depression project: lifetime history of axis I psychopathology in individuals at high and low cognitive risk for depression. Journal of Abnormal Psychology, 109, 403-418.

American Psychological Association (APA). (2001). Publication manual of the American Psychological Association (5th ed.). Washington, DC: Author.

Angold, A., \& Costello, E. J. (2006). Puberty and depression. Child and Adolescent Psychiatric Clinics of North America, 15, 919-937.

Angold, A., Costello, E., \& Worthman, C. (1998). Puberty and depression: the roles of age, pubertal development and pubertal timing. Psychological Medicine, 28, 51-61.

Beck, A. T. (1983). Cognitive therapy of depression: New perspectives. In P. Clayton \&J. E. Barrett (Eds.), Treatment of depression: Old controversies and new approaches (pp. 265-290). New York: Raven Press.

Beck, A. T., \& Alford, B. A. (2009). Depression: Causes and treatment. Philadelphia, PA: University of Pennsylvania Press.

Borkovec, T. D., Ray, W. J., \& Stöber, J. (1998). Worry: a cognitive phenomenon intimately linked to affective, physiological, and interpersonal behavioral processes. Cognitive Therapy and Research, 22(6), 561-576.

Borkovec, T., Robinson, E., Pruzinsky, T., \& DePree, J. (1983). Preliminary exploration of worry: some characteristics and processes. Behaviour Research and Therapy, 21(1), 9-16.

Ehring, T. \& Watkins, E.R. (2008). Repetitive negative thinking as a transdiagnostic process. International Journal of Cognitive Therapy, 1, 192-205.

Ehring, T., Zetsche, U., Weidacker, K., Wahl, K., Schönfeld, S. \& Ehlers, A. (2011). The Perseverative Thinking Questionnaire (PTQ): Validation of a content-independent measure of repetitive negative thinking. Journal of Behavior Therapy and Experimental Psychiatry, 42, 225-232.

Hankin, B.L., \& Abramson, L.Y. (2001). Development of gender differences in depression: an elaborated cognitive vulnerability-transactional stress theory. Psychological Bulletin, 127, 773796.

Harvey, A., Watkins, E., Mansell, W., \& Shafran, R. (2004). Cognitive behavioral processes across psychological disorders: A transdiagnostic approach to research and treatment. Oxford: Oxford University Press.

Holmes, E. A., \& Mathews, A. (2010). Mental imagery in emotion and emotional disorders. Clinical Psychology Review. 30, 349-362.

Hyde, J.S., Mezulis, A.H., \& Abramson, L.Y. (2008). The ABCs of depression: Integrating affective, biological, and cognitive models to explain the emergence of the gender difference in depression. Psychological Review, 115, 291-313.

Kabat-Zinn, J. (1990). Full catastrophe living: Using the wisdom of your body and mind to face stress, pain and illness. New York: Delacorte.

Kessler, R. C. (2003). Epidemiology of women and depression. Journal of Affective Disorders, 74, 513.

Kross, E., Ayduk, Ö., \& Mischel, W. (2005). When asking "why" does not hurt: distinguishing rumination from reflective processing of negative emotions Psychological Science, 16(9), 709715. 
Linehan, M. M. (1993). Skills training manual for treating borderline personality disorder. New York: Guilford Press.

Mezulis, A. H., Abramson, L. Y., \& Hyde, J. S. (2002). Domain specificity of gender differences in rumination. Journal of Cognitive Psychotherapy: An International Quarterly, 16, 421-433.

Moberly, N. J., \& Watkins, E. R. (2006). Processing mode influences the relationship between trait rumination and emotional vulnerability. Behavior Therapy, 37, 281-291.

Moberly, N., \& Watkins, E. (2008). Ruminative self-focus and negative affect: an experience sampling study. Journal of Abnormal Psychology, 117(2), 314-323.

Nolen-Hoeksema, S. (1987). Sex differences in unipolar depression: evidence and theory. Psychological Bulletin, 101(2), 259-282.

Nolen-Hoeksema, S. (1991). Responses to depression and their effects on the duration of depressive episodes. Journal of Abnormal Psychology, 100(4), 569-582.

Nolen-Hoeksema, S. (1994). An interactive model for the emergence of gender differences in depression in adolescence. Journal of Research on Adolescence, 4, 519-534.

Nolen-Hoeksema, S., \& Girgus, J. S. (1994). The emergence of gender differences in depression during adolescence. Psychological Bulletin, 115, 424-443.

Nolen-Hoeksema, S., Larson, J., \& Grayson, C. (1999). Explaining the gender difference in depressive symptoms. Journal of Personality and Social Psychology, 77(5), 1061-1072.

Nolen-Hoeksema, S., Stice, E., Wade, E., \& Bohon, C. (2007). Reciprocal relations between rumination and bulimic, substance abuse, and depressive symptoms in female adolescents. Journal of Abnormal Psychology, 116(1), 198-207.

Nolen-Hoeksema, S., Wisco, B. E., \& Lyubomirsky, S. (2008). Rethinking rumination. Perspectives on Psychological Science, 3, 400-424.

Park, R. J., Goodyer, I. M., \& Teasdale, J. D. (2004). Effects of induced rumination and distraction on mood and overgeneral autobiographical memory in adolescent Major Depressive Disorder and controls. Jounal of Child Psychology and Psychiatry, 45(5), 996-1006.

Pearson, K. A., Watkins, E. R., \& Mullan, E. G. (2010). Submissive interpersonal style mediates the effect of brooding on future depressive symptoms. Behaviour Research and Therapy, 48, 96673.

Rimes, K. A., \& Watkins, E. (2005). The effects of self-focused rumination on global negative selfjudgements in depression. Behaviour Research and Therapy, 43, 1673-1681.

Robinson, M., \& Alloy, L. (2003). Negative cognitive styles and stress-reactive rumination interact to predict depression: a prospective study. Cognitive Therapy and Research, 27(3), 275-292.

Rose, A. J. (2002). Co-rumination in the friendships of girls and boys. Child Development, 73, 18301843.

Rose, A. J., Carlson, W., \& Waller, E. M. (2007). Prospective associations of co-rumination with friendship and emotional adjustment: Considering the socioemotional trade-offs of corumination. Developmental Psychology, 43, 1019-1031.

Smith, J. M., \& Alloy, L. B. (2009). A roadmap to rumination: A review of the definition, assessment, and conceptualization of this multifaceted construct. Clinical Psychology Review, 29, 116-128.

Taylor, G. J; Bagby, R. M., \& Parker, J. D. A. (1997). Disorders of affect regulation: alexithymia in medical and psychiatric illness. Cambridge: Cambridge University Press.

Treynor, W., Gonzalez, R., \& Nolen-Hoeksema, S. (2003). Rumination reconsidered: a psychometric analysis. Cognitive Therapy and Research, 27(3), 247-259.

Vorst, H. C. M., \& Bermond, B. (2001). Validity and reliability of the Bermond-Vorst Alexithymia Questionnaire. Personality and Individual Differences, 30, 413-434.

Watkins, E. (2008). Constructive and unconstructive repetitive thoughts. Psychological Bulletin, 134, 163-206. 
Watkins, E. R., \& Moulds, M. (2005). Distinct modes of ruminative self-focus: Impact of abstract versus concrete rumination on problem solving in depression. Emotion, 5(3), 319-328.

Watkins, E., \& Moulds, M. (2007). Reduced concreteness of rumination in depression: A pilot study. Personality and Individual Differences, 43, 1386-1395.

Watkins, E., Scott, J., Wingrove, J., Rimes, K., Bathurst, N., Steiner, et al. (2007). Ruminationfocused cognitive behaviour therapy for residual depression: A case series. Behaviour Research and Therapy, 45, 2144-2154.

Watkins, E. R., \& Teasdale, J. D. (2004). Adaptive and maladaptive self-focus in depression. Journal of Affective Disorders, 82, 1-8.

Williams, M., Teasdale, J. D., Segal, Z., \& Kabat-Zinn, J. (2007). The mindful way through depression: freeing yourself from chronic unhappiness. New York: The Guilford Press. 



\section{Summary}

Chapter 1 provides a general introduction on the theoretical background of stressreactive rumination and emotion-focused rumination within the context of their theoretical frameworks (i.e., the Response Styles Theory and its conceptual extension by Alloy and colleagues). The hypothesized different roles of stressreactive rumination and emotion-focused rumination in the onset and maintenance of depressive symptoms are described, as well as the potential moderating role of rumination in the relationship between stressors and depressive symptoms, and in the relationship between negative cognitive style and depressive symptoms. Background information is given on the examination of cognitive vulnerability factors to depression from a developmental perspective, taking into account potential gender differences. The general introduction closes with an outline of the main aims and used methods of the studies presented in this thesis. The main research questions concerned the extent to which types of rumination are related to depressive symptoms, taking into account the possible moderating roles of age and gender; and whether rumination exerts its influence on depressive symptoms by moderating the effects of stressors or a negative cognitive style. Furthermore, the current dissertation focused on the causal nature of the rumination-depression relationship.

As stress-reactive rumination was not examined before in youth, Chapter 2 covers a psychometric evaluation of the child version of the Dutch Stress-Reactive Rumination Scale. Chapter 2 presents the first study on the baseline data, which sought to examine three forms of negative, repetitive thinking in non-clinical children and adolescents aged between 10 and $18(N=805)$. More specifically, this study addressed the degree to which stress-reactive rumination can be differentiated from other forms of repetitive thinking, such as emotion-focused rumination and worry, and the associations between the various indices of repetitive thinking and symptoms of anxiety and depression. Participants completed a battery of self-report questionnaires including measures of stress-reactive rumination, emotion-focused rumination, worry, and symptoms of anxiety and depression. Results showed that stress-reactive rumination, emotion-focused rumination and worry are related but distinct forms of repetitive negative thinking. Positive associations were found between all indices of repetitive thinking and symptoms of depression and anxiety, but the effects of emotion-focused rumination disappeared when controlling for the other forms of repetitive thinking. The findings are discussed in the light of current theories and previous research, and directions for future research are provided.

Chapter 3 examined evidence for some core predictions of the response styles theory concerning the relation between response styles and symptoms of 
depression and gender differences in the use of response styles in non-clinical children and adolescents. In summarizing the literature, effect sizes (pooled correlation coefficients) were calculated for cross-sectional and longitudinal studies. Stability of the obtained effect sizes was evaluated by means of a fail-safe $\mathrm{N}$ analysis. Results indicated that stable and significant effect sizes were found for rumination being associated with concurrent and future levels of depression. When controlling for baseline levels of depression, effect sizes for rumination and distraction were not stable, indicating that these findings should be interpreted with considerable caution. Finally, significant and stable effect sizes for gender differences in response styles were found only for rumination among adolescents, indicating that girls have a stronger tendency to ruminate than boys. Taken together, the findings partly support the predictions of the response styles theory examined in this meta-analysis and may implicate that rumination is a cognitive vulnerability factor for depressive symptoms among adolescents.

Chapter 4 comprises a short-term prospective study on the roles of emotionfocused rumination and distraction in the prediction of depressive symptoms over time, taking on a new approach. The ratio approach was investigated as a potentially more insightful and fine-tuned test of the Response Styles Theory. More specifically, it was expected that a high ratio score of emotion-focused rumination divided by distraction would be positively associated with residual change in depressive symptoms, whereas low ratio scores would be negatively associated with residual change in depressive symptoms. Participants $(N=770)$ completed a battery of questionnaires including measures of rumination, distraction, depression, and anxiety at baseline (Time 1) and 8-10 weeks follow-up (Time 2). Results showed that the ratio score of rumination and distraction was significantly associated with depressive and anxious symptoms over time. More specifically, individuals who have a greater tendency to ruminate compared to distracting themselves have increases in depression and anxiety scores over time, whereas those who have a greater tendency to engage in distraction compared to rumination have decreases in depression and anxiety symptoms over time. These findings indicate that a ratio approach can be used to examine the relation between response styles and symptoms of depression and anxiety in non-clinical children and adolescents. Implications of the results may be that engaging in distractive activities should be promoted and that ruminative thinking should be targeted in juvenile depression treatment.

Chapter 5 describes a study on the cross-sectional data that examines three theoretical models on cognitive vulnerability for depression in youth. The concept of stress-reactive rumination is introduced and tested within the context of two of the three theoretical models. First, it was hypothesized that stress-reactive rumination would exacerbate the relationship between negative cognitive style and depressive 
symptoms. Second, stress-reactive rumination was hypothesized to exacerbate the relationship between stressors and depressive symptoms. Third, it was hypothesized that negative cognitive style would exacerbate the relationship between stressors and depressive symptoms. A developmental perspective was taken by including the possibly moderating roles of age and gender. Domain specificity of negative cognitive style was explored as well. Furthermore, this study assessed whether pubertal development was a more sensitive moderator of the models than age. Youth $(N=805$; aged $10-18,59.9 \%$ female) completed self-report measures. Stress-reactive rumination was strongly related to depressive symptoms. Negative cognitive style (i.e., tendency to make negative inferences) in the domains of achievement and appearance was more strongly and consistently related to depressive symptoms in girls compared to boys. Negative cognitive style in the interpersonal domain was positively related to depressive symptoms in both girls and boys, except in early adolescent girls reporting few stressors. To conclude, the cognitive vulnerabilitystress interaction may be moderated by the combination of age and gender in youth, which may explain inconsistent findings so far. Findings highlight the importance of taking into account domain specifity when examining models of depression in youth.

Chapter 6 presents the results of a two-year multi-wave study in children and adolescents, which examined the integration of the Response Styles Theory and Hopelessness Theory. Specificity of type of rumination was assessed by examining stress-reactive rumination as well as emotion-focused rumination. It was expected that rumination, negative cognitive style, and stressors would co-vary with depressive symptoms, and that the combination of high rumination, high negative cognitive style, and high levels of stressors would be related to the highest level of depressive symptoms. Furthermore, the combination of high rumination, high negative cognitive style, and high levels of stressors was expected to predict the highest levels of depressive symptoms one year later. The moderating roles of age and gender were explored in combination with each other. Youth $(N=800)$ aged 10-18 completed questionnaires once a year for two years. The co-variation model showed that rumination co-varied more strongly with depressive symptoms in participants reporting few life events compared to those reporting many life events. Negative cognitive style co-varied more strongly with depressive symptoms in girls compared to boys. Relationships within persons were not as strong as cross-sectional studies may suggest. The prospective model showed that rumination predicted depressive symptoms. Negative cognitive style predicted depressive symptoms only in participants reporting few life events, suggesting two pathways to depressive symptoms: through high negative cognitive style or high levels of life events. Covariations and predictive relationships did not increase with age.

In order to examine the causal nature of the relationship between rumination and depression, two experimental studies were carried out in non-clinical youth. 
Chapter 7 consists of an explorative experimental study comparing the causal effects of three types of processing of negative personal events, (1) focus on negative inferences, (2) causal-analytical reasoning, and (3) perceptual details processing, on negative affect in university students $(N=112)$. A focus on negative inferences and a more reflective form of rumination labelled causal-analytical reasoning were manipulated in the context of the current debate on adaptive and maladaptive components of rumination. It was expected that focus on negative inferences and causal-analytical reasoning would cause significantly stronger increases in negative affect than perceptual details processing, with the strongest increases after focus on negative inferences. Using a between-subjects design, female university students were given instructions to think about a recent stressful event in a particular way: by focusing on the negative inferences, by thinking in a causal-analytical way, or by focusing on contextual facts. A qualitative manipulation check showed that the manipulations succeeded. Sad affect increased in all conditions to a similar degree. Anxious affect increased significantly more after causal-analytic reasoning compared to contextual facts processing. To conclude, not the focus on negative inferences, but the causal-analytical component caused significant increases in anxious affect relative to thinking about the factual aspects of the event. This would imply that dwelling on causes is the particularly harmful component of stress-reactive rumination. The long-term effects of causal-analytical rumination need further investigation.

Chapter 8 describes an experimental study in non-clinical adolescents, which compared the causal effects of rumination, positive reappraisal, mindfulness-based acceptance, and distancing, in response to stressful events on positive and negative affect. We expected that (1) participants would show a greater increase in negative affect after the rumination induction compared to the acceptance, positive reappraisal, and distancing inductions; and that (2) participants would show a stronger increase in positive affect, and a stronger decrease in negative affect, after the positive reappraisal induction compared to the other inductions. Participants $(N=160)$ aged 13-18 were instructed to think about a recent stressful event. Next, they received specific instructions on how to think about that event in each condition. Manipulation checks revealed that the manipulations were successful, except for acceptance. The two most reported events were "a fight" and "death of loved one". Results showed that positive reappraisal (i.e., thinking about the benefits and personal growth) caused a significantly larger increase in positive affect and decrease in negative affect compared to rumination, distancing, and acceptance. Current findings implicate that positive reappraisal seems an adequate coping strategy in the short-term, and therefore could be applied in interventions for youth experiencing difficulties managing negative affect. Future research should focus on 
SUMMARY

long-term effects of these cognitive strategies and on more intensive training of acceptance.

Chapter 9 comprises a general conclusion and critical discussion of the studies described in this dissertation, as well as recommendations for future research. The following conclusions were drawn with regard to the status and future of rumination research in youth. The current dissertation shows that stress-reactive rumination and emotion-focused rumination are statistically distinct types of repetitive thinking. Future prospective studies should investigate their hypothesized specific roles in the onset and development of depression as assessed by clinical interviews. In line with examining different roles, the underlying functions of types of rumination could be explored. This may help determine the possible usefulness of distinguishing types of rumination, before taking on a transdiagnostic approach to rumination. Stress-reactive rumination and emotion-focused rumination significantly contribute to the prediction of depressive symptoms even over a one-year's time in non-clinical youth. Neither stress-reactive rumination nor emotion-focused rumination seem to function as a vulnerability factor within a diathesis-stress account. The model of Alloy and colleagues $(2000 ; 2003)$ may not be applicable to non-clinical youth, and should be tested in high risk youth using a dichotomous outcome measure of depression. Furthermore, the items of the SRRS-C (Stress-Reactive Rumination Scale for Children) need to be reformulated. Stress-reactive rumination may more adequately be assessed by adding items that measure frequency and repetition of negative attributions and inferences to the ACSQ (Adolescent Cognitive Styles Questionnaire), which assesses attributions and inferences. Considering the modest effect sizes regarding the rumination-depression relationship in prospective studies and questions regarding causality, it is time to move forward and use other methodological designs to study the influence of rumination on depression. The causal nature of the rumination-depression relationship should be more closely examined from childhood to adolescence, for example in controlled experimental designs (i.e., manipulation studies) and in diary studies using experience sampling methodology. The constructive and unconstructive qualities of rumination are of special interest. Measuring the effects of training concrete and abstract modes of thinking in response to stressful experiences in children and adolescents would be innovative and may carry implications for prevention and treatment of juvenile depression. Altering thinking style may be more helpful in the long-term than distraction techniques or "stopping" interventions. 



\section{Samenvatting}

Hoofdstuk 1 bevat een algemene inleiding op dit proefschrift met een beschrijving van het theoretisch kader waarbinnen stressreactief en emotiegericht rumineren worden onderzocht. De theoretische invalshoek betreft de Response Styles Theory en de conceptuele uitbreiding van deze theorie door Alloy et al. De veronderstelde verschillende rollen die stressreactief en emotiegericht rumineren spelen in het ontstaan en de instandhouding van depressieklachten worden besproken. Tevens wordt ingegaan op de mogelijke rol van de genoemde vormen van rumineren als moderator van de relatie tussen stressvolle gebeurtenissen en depressieklachten, en tussen een negatieve cognitieve stijl en depressieklachten. Daarnaast wordt achtergrondinformatie gegeven over het onderzoeken van cognitieve kwetsbaarheidfactoren voor depressie vanuit ontwikkelingsperspectief, waarbij rekening wordt gehouden met mogelijke genderverschillen. De algemene inleiding wordt afgesloten met een samenvatting van de voornaamste onderzoeksvragen en onderzoeksmethoden behorende bij de in dit boek gepresenteerde studies. De voornaamste onderzoeksvragen betreffen de mate waarin vormen van rumineren gerelateerd zijn aan depressieklachten. Hierbij wordt rekening gehouden met de mogelijk modererende rollen van leeftijd en gender. Ook wordt nagegaan of rumineren invloed uitoefent op depressieklachten door de effecten van stressvolle gebeurtenissen of een negatieve cognitieve stijl te versterken. Verder richt dit proefschrift zich op de vraag in hoeverre de relatie tussen rumineren en depressie causaal van aard is.

Aangezien stressreactief rumineren nog niet eerder bij jongeren is onderzocht, wordt in Hoofdstuk 2 een psychometrische evaluatie van de versie van de Nederlandstalige Stress-Reactive Rumination Scale voor kinderen en jongeren gepresenteerd. De eerste studie op de baseline data heeft als doel drie vormen van repetitief negatief denken te onderzoeken bij een bevolkingssteekproef van kinderen en adolescenten in de leeftijdscategorie van 10 tot 18 jaar $(N=805)$. Specifieker is de vraag onderzocht in welke mate stressreactief rumineren te onderscheiden is van andere vormen van repetitief denken, zoals emotiegericht rumineren en piekeren, en in welke mate de vormen van repetitief denken gerelateerd zijn aan angst- en depressieklachten. Participanten vulden een batterij aan zelfrapportage vragenlijsten in waaronder maten van stressreactief rumineren, emotiegericht rumineren, piekeren, angst- en depressieklachten. De resultaten laten zien dat stressreactief rumineren, emotiegericht rumineren en piekeren gerelateerd zijn aan elkaar maar van elkaar te onderscheiden zijn als verschillende vormen van repetitief negatief denken. Tussen alle maten van repetitief denken aan de ene kant en angst- en depressieklachten aan de andere kant zijn sterke positieve associaties gevonden, hoewel de effecten van 
emotiegericht rumineren wegvallen wanneer gecontroleerd wordt voor de andere vormen van repetitief denken. Het hoofdstuk sluit af met een bespreking van de resultaten in het licht van eerder onderzoek en er worden suggesties gegeven voor verder onderzoek.

Hoofdstuk 3 omvat een samenvattende studie naar de voornaamste veronderstellingen van The Response Styles Theory bij kinderen en adolescenten wat betreft de relatie tussen responsstijlen en depressieklachten, en genderverschillen in het gebruik van de responsstijlen. Effectmaten (gepoolde correlatiecoëfficiënten) zijn berekend voor de bestaande cross-sectionele en longitudinale studies. De stabiliteit van de verkregen effectmaten is geëvalueerd door middel van een "fail-safe N" analyse. Resultaten laten zien dat stabiele en significante effectmaten zijn gevonden voor de relatie tussen rumineren en depressieklachten op hetzelfde meetpunt en over de tijd. Wanneer wordt gecontroleerd voor het baselineniveau aan depressieklachten, zijn de effectmaten voor rumineren en distractie niet stabiel, wat erop wijst dat de significantie van deze relaties met enige terughoudendheid geïnterpreteerd moeten worden. Tenslotte is een significante en stabiele effectmaat gevonden voor genderverschillen in rumineren bij adolescenten, die erop wijst dat meisjes een sterkere neiging hebben tot rumineren dan jongens. Alles tezamen vormen de bevindingen van deze metaanalyse een gedeeltelijke ondersteuning van de veronderstellingen van de Response Styles Theory. Ze zouden kunnen impliceren dat rumineren een cognitieve kwetsbaarheidfactor is voor depressieklachten bij adolescenten.

Hoofdstuk 4 bestaat uit een prospectieve studie naar de rol van emotiegericht rumineren en distractie in de voorspelling van latere depressieklachten volgens een nieuwe methodologische benadering. De ratiobenadering is onderzocht als een mogelijk meer inzichtelijke en nauwkeuriger toets van de Response Styles Theory. Meer specifiek was de verwachting dat een hoge ratioscore van emotiegericht rumineren gedeeld door distractie positief geassocieerd zou zijn met de residuele verandering in depressieklachten. Lage ratioscores zouden negatief geassocieerd zijn met de residuele verandering in depressieklachten. Proefpersonen $(N=770)$ zijn gevraagd een batterij vragenlijsten in te vullen, waaronder maten van rumineren, distractie, depressie en angst (tijdstip 1), met een vervolgmeting ongeveer 8 tot 10 weken later (tijdstip 2). Resultaten wijzen uit dat de ratioscore van rumineren en distractie significant gerelateerd is aan angst- en depressieklachten over de tijd. Preciezer gezegd: proefpersonen die een sterkere neiging hebben om te rumineren in verhouding tot afleiding zoeken vertonen toenames in depressie- en angstscores over de tijd, terwijl degenen die een sterkere neiging hebben om afleiding te zoeken in verhouding tot rumineren een afname in depressie- en angstscores over de tijd rapporteren. Deze bevindingen wijzen erop dat een ratiobenadering gebruikt kan worden om de relatie tussen responsstijlen en angst- en depressieklachten te 
SAMENVATTING

onderzoeken bij niet-klinische kinderen en adolescenten. Mogelijke implicaties van deze resultaten zijn dat het opgaan in afleidende activiteiten gestimuleerd zou moeten worden en dat ruminatief denken aangepakt moet worden in de behandeling van depressie bij jeugdigen.

In Hoofdstuk 5 wordt een studie op de cross-sectionele data beschreven waarin drie theoretische modellen van cognitieve kwetsbaarheid voor depressie zijn onderzocht bij jongeren. Het concept stressreactief rumineren is geïntroduceerd en getoetst binnen de context van twee van de drie theoretische modellen. De eerste hypothese is dat stressreactief rumineren de relatie tussen een negatieve cognitieve stijl en depressieklachten zal versterken. De tweede hypothese stelt dat stressreactief rumineren de relatie tussen stressvolle gebeurtenissen en depressieklachten versterkt. De derde hypothese is dat een negatieve cognitieve stijl de relatie tussen stressvolle gebeurtenissen en depressieklachten zal versterken. De hypothesen zijn onderzocht vanuit een ontwikkelingsperspectief door de mogelijk modererende rollen van leeftijd en gender mee te nemen. Daarnaast is de specificiteit van een negatieve cognitieve stijl op verschillende gebieden geëxploreerd. Verder is in deze studie onderzocht of mate van puberale ontwikkeling een sensitievere moderator van de modellen is dan leeftijd. Hiertoe vulden jongeren $(N=805$; leeftijdsrange $10-18,59.9 \%$ meisjes) zelfrapportage vragenlijsten in. Stressreactief rumineren blijkt sterk gerelateerd te zijn aan depressieklachten. Een negatieve cognitieve stijl (de neiging om negatieve attributies en gevolgtrekkingen te maken) op de gebieden van prestatie en uiterlijke verschijning is sterker en consistenter gerelateerd aan depressieklachten bij meisjes dan bij jongens. Een negatieve cognitieve stijl op interpersoonlijk gebied is positief gerelateerd aan depressieklachten bij zowel jongens als meisjes, behalve bij vroeg-adolescente meisjes die weinig stressvolle gebeurtenissen rapporteerden. De conclusie is dat de cognitieve kwetsbaarheid-stress interactie mogelijk wordt gemodereerd door de combinatie van leeftijd en gender bij jongeren, wat de inconsistente bevindingen tot dusverre zou kunnen verklaren. De huidige bevindingen benadrukken het belang om rekening te houden met de specificiteit van kwetsbaarheden op verschillende gebieden in het onderzoeken van modellen van depressie bij jongeren.

Hoofdstuk 6 beschrijft de resultaten van een tweejarige multi-wave studie bij kinderen en adolescenten, waarin de integratie van the Response Styles Theory and Hopelessness Theory onderzocht is. Specificiteit van het type rumineren is vastgesteld door zowel stressreactief rumineren als emotiegericht rumineren te onderzoeken. De verwachting was dat rumineren, een negatieve cognitieve stijl, en stressvolle gebeurtenissen zouden co-variëren met depressieklachten, en dat de combinatie van een sterke neiging tot rumineren, een negatieve cognitieve stijl, en een hoog aantal stressvolle gebeurtenissen gerelateerd zou zijn aan het hoogste niveau van depressieklachten. Verder werd verwacht dat de combinatie van een 
sterke neiging tot rumineren, een negatieve cognitieve stijl, en een hoog aantal stressvolle gebeurtenissen zou samenhangen met het hoogste niveau van depressieklachten een jaar later. De modererende rollen van leeftijd en gender zijn geëxploreerd in combinatie met elkaar. Jongeren $(N=800)$ in de leeftijd van 10 tot 18 jaar is gevraagd om gedurende twee jaar eenmaal per jaar vragenlijsten in te vullen. Het co-variatie model laat zien dat rumineren sterker co-varieert met depressieklachten bij jongeren die weinig life events rapporteerden dan bij degenen die veel life events rapporteerden. Een negatieve cognitieve stijl co-varieert sterker met depressieklachten bij meisjes dan bij jongens. De associaties binnen personen zijn dus niet zo sterk als cross-sectionele studies lijken te suggereren. Het prospectieve model laat zien dat rumineren depressieklachten voorspelt over de periode van een jaar. Een negatieve cognitieve stijl voorspelt depressieklachten alleen bij jongeren die weinig gebeurtenissen rapporteerden, wat suggereert dat er twee paden zijn die tot depressie leiden: via een negatieve cognitieve stijl of via het meemaken van veel life events. Co-variaties en voorspellende relaties zijn niet sterker als functie van de leeftijd.

Om de causale aard van de relatie tussen rumineren en depressie te onderzoeken zijn twee studies uitgevoerd bij niet-klinische jongeren. Hoofdstuk 7 omvat een exploratieve experimentele studie bij vrouwelijke studenten $(N=112)$ waarin de causale effecten van drie manieren om negatieve persoonlijke gebeurtenissen te verwerken met elkaar vergeleken zijn op negatief affect. Het gaat om (1) focus op negatieve gevolgtrekkingen, (2) causaal-analytisch redeneren, en (3) focus op perceptuele details. Een focus op negatieve gevolgtrekkingen en een meer reflectieve vorm van rumineren gelabeld causaal-analytisch redeneren zijn gemanipuleerd in de context van het huidige debat aangaande adaptieve en maladaptieve componenten van rumineren. De verwachting was dat de focus op negatieve gevolgtrekkingen en causaal-analytisch redeneren een significant sterkere toename in negatief affect zou veroorzaken dan de focus op perceptuele details, met de sterkste toename na de focus op negatieve gevolgtrekkingen. Er is gebruik gemaakt van een between-subjects design, waarbij studenten zijn geïnstrueerd om te denken aan een recente stressvolle gebeurtenis op een bepaalde manier: door te focussen op de negatieve gevolgtrekkingen, door te denken op een causaalanalytische manier, of door te focussen op contextuele feiten en details. Een kwalitatieve manipulatiecheck laat zien dat de manipulaties succesvol waren. Verdrietig affect neemt toe in alle condities in vergelijkbare mate. Angstig affect neemt significant meer toe na causaal-analytisch redeneren vergeleken met de focus op contextuele details. Geconcludeerd kan worden dat niet de focus op negatieve gevolgtrekkingen, maar de causaal-analytische component een significante toename in angstig affect veroorzaakt in vergelijking met het denken aan de feitelijke aspecten van de gebeurtenis. Dit zou impliceren dat het blijven hangen in de oorzaken in het 
bijzonder de schadelijke component is van stressreactief rumineren. De lange termijn effecten van causaal-analytisch rumineren behoeven meer onderzoek.

In Hoofdstuk 8 wordt een experimentele studie bij niet-klinische adolescenten beschreven waarin de causale effecten van rumineren, positive reappraisal, (een op mindfulness gebaseerde vorm van) acceptatie, en distantiëren op positief en negatief affect zijn onderzocht naar aanleiding van een stressvolle gebeurtenis. De verwachting was dat (1) participanten een grotere toename in negatief affect zouden laten zien na de ruminatie inductie vergeleken met de acceptatie, positive reappraisal, en distantie inducties; en dat (2) participanten een grotere toename in positief affect en een sterkere afname in negatief affect zouden laten zien na de positive reappraisal inductie vergeleken met de andere inducties. Participanten $(N=160)$ in de leeftijd van 13 tot 18 jaar zijn geïnstrueerd om te denken aan een recente stressvolle gebeurtenis. Vervolgens ontvingen zij specifieke instructies over de manier waarop ze moesten denken aan die gebeurtenis in iedere conditie. De manipulatiechecks laten zien dat de manipulaties succesvol zijn behalve die van acceptatie. De twee meest gerapporteerde gebeurtenissen zijn "een ruzie" en "dood van een naaste". De resultaten wijzen uit dat positive reappraisal (d.w.z., denken aan de voordelen van en persoonlijke groei na een stressvolle gebeurtenis) een significant grotere toename in positief affect en afname in negatief affect veroorzaakt vergeleken met rumineren, distantiëren, en acceptatie. De huidige bevindingen impliceren dat positive reappraisal een adequate coping strategie lijkt op de korte termijn, die daarom toegepast zou kunnen worden in interventies voor jongeren die moeilijkheden ervaren in het omgaan met negatief affect. Toekomstig onderzoek moet zich richten op de langetermijneffecten van deze cognitieve strategieën en op het meten van het effect van een intensievere acceptatietraining.

Hoofdstuk 9 bestaat uit een algemene conclusie en kritische discussie van de studies die in deze dissertatie zijn beschreven, alsook aanbevelingen voor toekomstig onderzoek. De volgende conclusies zijn getrokken met betrekking op de status en toekomst van het onderzoek naar rumineren bij jongeren. De huidige dissertatie laat zien dat stressreactief en emotiegericht rumineren statistisch gezien verschillende typen van repetitief denken zijn. Toekomstige prospectieve studies moeten onderzoeken of deze twee typen rumineren specifieke rollen spelen in het ontstaan en instandhouding van depressie zoals vastgesteld aan de hand van klinische interviews. In lijn met het onderzoeken van verschillende rollen kunnen de onderliggende functies van typen rumineren worden onderzocht. Dit kan het mogelijke nut helpen bepalen van het onderscheiden van verschillende typen rumineren, alvorens een transdiagnostisch standpunt in te nemen over rumineren. Zowel stressreactief als emotiegericht rumineren dragen significant bij tot de voorspelling van depressieklachten bij niet-klinische jongeren, zelfs over de periode van een jaar. Noch stressreactief rumineren noch emotiegericht rumineren lijken te 
functioneren als een kwetsbaarheidfactor binnen een diathese-stress model. Het model van Alloy et al. (2000; 2003) lijkt niet van toepassing te zijn bij niet-klinische jongeren, en zou getoetst moeten worden bij kwetsbare jongeren aan de hand van een dichotome uitkomstmaat voor depressie. Daarnaast dienen de items van de SRRS-C (Stress-Reactive Rumination Scale for Children) geherformuleerd te worden. Stressreactief rumineren zou adequater gemeten kunnen worden door items toe te voegen aan de ACSQ (Adolescent Cognitive Styles Questionnaire; die attributies en gevolgtrekkingen meet) die de frequentie en herhaling van negatieve attributies en gevolgtrekkingen meten. Gezien de bescheiden effectmaten met betrekking op de relatie tussen rumineren en depressieklachten in prospectieve studies en de vragen wat betreft de causaliteit van deze relatie, is het tijd om een grotere stap voorwaarts te zetten en de invloed van rumineren op depressie met behulp van andere methodologische designs te onderzoeken. De causale aard van de ruminatie-depressie relatie moet nader worden onderzocht van kindertijd tot adolescentie, bijvoorbeeld in gecontroleerde experimentele designs (bijv. manipulatiestudies) en dagboekstudies waarin gebruik wordt gemaakt van de "experience sampling" methodologie. De constructieve en onconstructieve eigenschappen van rumineren zijn hierbij van bijzondere belang. Het meten van de effecten van trainingen in concrete en abstracte manieren van denken in reactie op stressvolle gebeurtenissen bij kinderen en adolescenten is innovatief en kan belangrijke implicaties hebben voor de preventie en behandeling van depressie bij jongeren. Het veranderen van denkstijl kan op de lange termijn effectiever zijn dan afleidingstechnieken of "stop"-interventies. 


\section{Curriculum Vitae}

\section{Biography}

Lea Rood was born October 12, 1979 in Rotterdam, the Netherlands. After completing secondary school in 1998 (Erasmiaans Gymnasium), she studied psychology at Leiden University. In 2003, she took part of a student exchange programme studying at the University of Lausanne in Switzerland for 6 months, following courses in the field of developmental psychology in French. She obtained her master's diploma in Clinical and Health Psychology in September 2003. Between September 2003 to February 2005 she worked as an assistant teacher in a corrective facility for mentally ill delinquents (Van der Hoevenkliniek in Utrecht), and as an assistant tutor at Leiden University. From August 2004 to February 2006 she was employed as a psychologist at mental health institutions near Rotterdam. From August 2006 to July 2011, she studied the role of rumination in the development of depressive symptoms in youth as a PhD-student at the department of Clinical Psychological Science at Maastricht University. The studies that were conducted during this period are presented in this dissertation.

\section{Publications}

Rood, L., Roelofs, J., \& Bijttebier, P. (accepted pending revision) Negatief denken en psychische klachten bij kinderen en adolescenten. Gedragstherapie.

Rood, L., \& Roelofs, J. (accepted pending revision). Kort Instrumenteel: StressReactive Rumination Scale for Children (SRRS-C). Gedragstherapie.

Rood, L., Roelofs, J., Bögels, S.M., \& Arntz, A. (in press). The beneficial effect of positive reappraisal on mood when thinking about stressful events in adolescents compared to rumination, acceptance, and distancing. Journal of Abnormal Child Psychology.

Rood, L., Roelofs, J., Bögels, S.M., \& Meesters, C. (in press). The moderating role of stress-reactive rumination in the relation between negative cognitive style and symptoms of hopelessness depression. Journal of Youth and Adolescence.

Rood, L., Roelofs, J., Bögels, S.M., \& Alloy, L.B. (2010). Dimensions of negative thinking and the relations with symptoms of depression and anxiety in children and adolescents. Cognitive Therapy and Research, 34(4), 333-342

Rood, L., Roelofs, J., Bögels, S.M., Nolen-Hoeksema, S., \& Schouten, E. (2009). The influence of emotion-focused rumination and distraction on depressive 
symptoms in nonclinical youth: a meta-analytic review. Clinical Psychology Review, 29, 607-616.

Roelofs, J., Braet, C., Rood, L., Timbremont'B., van Vlierberghe, L., Goossens, L., \& van Breukelen, G. (2010). Norms and screening utility of the Dutch version of the Children's Depression Inventory (CDI) in clinical and non-clinical youth. Psychological Assessment, 22, 866-877.

Ruijten, T., Roelofs, J., \& Rood, L. (2011). The mediating role of rumination in the relation between quality of attachment relations and depressive symptoms in non-clinical adolescents. Journal of Child and Family Studies, 20, 452-459.

Roelofs, J., \& Rood, L. (2009). De invloed van rumineren en afleiding zoeken op depressieve klachten bij niet-klinische kinderen en adolescenten: een metaanalyse. GZ-Psychologie, 1, 42-47.

Roelofs, J., Rood, L., Meesters, C., te Dorsthorst, V., Bögels, S., Alloy, L.B., NolenHoeksema, S. (2009). The influence of rumination and distraction on depressed and anxious mood: a prospective examination of the response styles theory in children and adolescents. European Child and Adolescent Psychiatry, 18, 635642.

Moormann, P.P., Bermond, B., Vorst, H., Bloemendaal, A., Teijn, S., \& Rood, L. (2008). New avenues in alexithymia research: the creation of alexithymia types. In Vingerhoets, Nyclicek, \& Denollet, Emotion regulation: conceptual and clinical issues (pp 27-43). New York: Springer.

Moormann, P.P. \& Rood, L. (2004). Een werkmodel voor stressbestendigheid [A working model for stress resilience]. In Moormann, P.P. \& Pijpers, R., Scoren tussen de oren [Scoring between the ears]. Lisse: Harcourt Publishers.

Moormann, P.P., Rood, L., Risseeuw, S. \& Tiggelaar W. (2002). Conversies bij kunstschaatsen: 'Ik heb geen goed gevoel.' [Conversions in ice-skating: 'I don't have a good feeling']. In: P.P. Moormann \& R. Pijpers. Proceedings Congres Sportpsychologie, 7 juni 2002. Leiden: Universiteit Leiden (short paper).

Moormann, P.P. \& Rood, L. (2002). Choreografiestijlen bij kunstschaatsen [Choreography styles in ice-skating] In: P.P. Moormann \& R. Pijpers. Proceedings Congres Sportpsychologie, 7 juni 2002. Leiden: Universiteit Leiden (short paper).

\section{Submitted manuscripts}

Rood, L., Roelofs, J., Bögels, S.M., Schepers, J., \& Arntz, A. The interplay between cognitive vulnerability factors and stress in the prediction of depressive symptoms over time in youth. 
CURRICULUM VITAE

Rood, L., Roelofs, J., Bögels, S.M., \& Arntz, A. Causal-analysis of stressful events, not focus on negative inferences, increases anxious affect compared to focus on contextual facts

\section{Presentations}

Rood, L., Roelofs, J., Bögels, S.M., Schepers, J., \& Arntz, A. (2010). The role of rumination in the development of depressive symptoms over a two-year's time in youth. Oral presentation at expert-meeting on rumination in youth at $\mathrm{KU}$ Leuven 16-17 December

Rood, L., Roelofs, J., Bögels, S.M., \& Arntz, A. (2010). The effect of stress-reactive rumination and other cognitive coping strategies on the onset of a negative mood. Oral presentation at annual congress of the Association for Behavioral and Cognitive Therapy (VGCT) in Veldhoven

Rood, L., Roelofs, J., Bögels, S.M., \& Arntz, A. (2010). The beneficial effect of positive reappraisal on negative mood compared to rumination, acceptance, and distancing in adolescents. Poster presentation at the annual meeting of the Dutch-Flemish Research School of Experimental Psychopathology (EPP) in Utrecht

Rood, L., Roelofs, J., Bögels, S.M., Nolen-Hoeksema, S., \& Schouten, E. (2009). The role of rumination in the onset and maintenance of depressive symptoms in non-clinical children and adolescents. Oral presentation at the annual congress of the European Association for Behavioural and Cognitive Therapies (EABCT) in Dubrovnik, Croatia

Rood, L., Roelofs, J., Bögels, S.M., Schepers, J., \& Arntz, A. (2009). The influence of rumination on the development of depressive symptoms in children and adolescents. Oral presentation at a symposium of the Dutch-Flemish Research School of Experimental Psychopathology (EPP) in Heeze

Rood, L., Roelofs, J., \& Bögels, S.M. (2008). The relationships between stressreactive rumination, negative cognitive style, life events and depressive symptoms in non-clinical children and adolescents. Oral presentation at the annual congress of the European Association for Behavioural and Cognitive Therapies (EABCT) in Helsinki, Finland

Rood, L., Roelofs, J., \& Bögels, S.M. (2008). Dimensions of negative thinking and the relations with symptoms of depression and anxiety in non-clinical children and adolescents. Poster presentation at the annual congress of the European Association for Behavioural and Cognitive Therapies (EABCT) in Helsinki, Finland 
Rood, L., \& Roelofs, J. (2007). On the links between stress-reactive rumination, negative cognitive style and symptoms of depression in non-clinical children and adolescents. Poster presentation at the World Congress of Behavioral and Cognitive Therapies in Barcelona, Spain

Rood, L., Moormann, P.P. (2003). Individuele artistiek-creatieve stijlen in de kunst [Individual artistic-creative styles in art]. Oral presentation at Kreanet-meeting in Eindhoven 


\section{Dankwoord}

Mijn voornaamste dank gaat uit naar:

- de deelnemende scholen, directeuren, zorgcoördinators, leraren, en natuurlijk de kinderen en hun ouders uit Limburg, Zeeland en Brabant.

- de onmisbare onderzoeksassistentie: in het bijzonder Annie Raven en Astrid Dello voor de invoer van honderden vragenlijstboekjes, Sita van Riet die wanneer de tijd het toeliet heeft meegeholpen aan administratie en invoer, Bonnie van Steensel voor hulp bij de werving, Rosanne Janssen voor de internetondersteuning bij het project en voor haar inspanningen ter bevordering van de gezelligheid op de afdeling. Erik Schouten voor het beantwoorden van uiteenlopende statistische vragen en Jan Schepers voor zijn hulp bij het analyseren van de longitudinale data. Joke Rademakers dank ik hartelijk voor de opmaak van het proefschrift.

Verder gaat mijn dank uit naar:

- de vriendelijke secretariaten van CPS: Emmy, Chantal, Jessie en Truus. Lindy Dullens voor haar hulp bij de afhandeling van de administratie rond het proefschrift. Angela Verweij voor haar betrokkenheid bij de afdeling en het welzijn van de promovendi.

- de collega's van CPS, met een aparte vermelding de aio-gang op de $1^{\mathrm{e}}$ verdieping: Sylvia, Esther, Rilana, Ken, Saskia, Andrea, Pim, Jeanine, Lotte L., Fritz, Johanna, Ellin, Yvo, Marjolein (voor haar hulp bij de Rubicon) Sjoertje (voor de mooie tripjes na de congressen in Finland en Kroatië), Tim (voor zijn onverstoorbare optimisme en party-attitude), Lotte B. (voor haar hartelijkheid); de collega's van de sectie Clinical Psychology voor het ondersteunen van elkaars onderzoek, Martien en Petra voor de borrels.

- mijn kamergenoten Hanne, Lieke, en Mark. Mark, dank voor je rust en gezelligheid in de eerste twee jaar. Lieke, dank voor je positieve, nuchtere instelling. Het is fijn om een relativerende en vrolijke kamergenoot te hebben in de afrondingsfase. Hanne, dank voor het delen van lief en leed. Ik heb je gemist toen ik het boekje in mijn eentje thuis moest afschrijven. Heleen dank 
ik voor alle steun, vriendschap en het verkennen van de horecagelegenheden in Maastricht vanaf de dag dat we samen begonnen aan de UM.

- mijn trouwe vriend(inn)en uit Leiden/Rotterdam en omstreken die mij regelmatig hebben opgezocht in Maastricht. Het bijkletsen, shoppen, wandelen, eten \& drinken met jullie heb ik zeer op prijs gesteld.

Mijn grote dank gaat uit naar mijn promotoren Susan Bögels en Arnoud Arntz, en mijn copromotor Jeffrey Roelofs.

- Susan: altijd open en enthousiast. Jij hielp met richting geven aan de uit te voeren studies en het omgaan met tegenslagen. Van jou kwam ik vol energie, hernieuwde hoop en interessante en inspirerende ideeën weer terug.

- Arnoud: scherp, meedenkend, inspirerend, en hamerend op onderbouwing. Bij jou kwam ik met tuitende oren vandaan met nieuwe inzichten. Dank ook voor je hulp in de laatste fase van het proefschrift.

- Jeffrey: voor mij was je in het kort ("concisen!") de allerbeste begeleider die ik me had kunnen wensen. Je bent heel betrokken, makkelijk toegankelijk, en heel prettig om mee samen te werken. Je weet precies hoe je iemand op weg helpt en aan de slag houdt. Ik bewonder je geduld tijdens het wijzen op het belang van structuur.

Als laatste de belangrijkste bedankjes:

- Eva \& Ciré, Jonathan \& Thomas, en mijn liefste nichtjes Fama \& Fayol.

- Lieve Mama: Je wijsheid, liefdevolle steun, en tomeloze daadkracht in alles wat je onderneemt zijn onontbeerlijk geweest de afgelopen jaren.

- Papa: dank ik als een leeuw in het diepst van mijn gedachten. Dat we juist dit niet meer hebben kunnen delen is moeilijk. De stelling: "overgave biedt de schouder aan de machteloosheid" is voor jou. 